\title{
Dynamic non-linear soil behaviour in alpine areas
}

Monograph

Author(s):

Marin, Alexandru

Publication date:

2019-09-30

Permanent link:

https://doi.org/10.3929/ethz-b-000374680

Rights / license:

In Copyright - Non-Commercial Use Permitted

Originally published in:

Veröffentlichungen des Instituts für Geotechnik (IGT) an der ETH Zürich 253 


\section{ETHzürich}

\section{Dynamic non-linear soil behaviour in alpine areas}

Alexandru Marin 
Weitere aktuelle vdf-Publikationen finden Sie in unserem Webshop:

\section{vdf.ch}

, Bauwesen

, Naturwissenschaften, Umwelt und Technik

, Informatik, Wirtschaftsinformatik und Mathematik
, Wirtschaft

, Geistes- und Sozialwissenschaften, Interdisziplinäres, Militärwissenschaft, Politik, Recht

\section{Gerne informieren wir Sie regelmässig per E-Mail über unsere Neuerscheinungen.}

\section{Newsletter abonnieren}

Anmeldung auf vdf.ch 


\section{Dynamic non-linear soil behaviour in alpine areas}

Alexandru Marin

Veröffentlichungen des Instituts für Geotechnik (IGT) der ETH Zürich Band 253, September 2019 
ETH-Dissertation Nr. 23512

(C) 2019, vdf Hochschulverlag AG an der ETH Zürich

ISBN: 978-3-7281-3889-7 (Printversion)

ISBN: 978-3-7281-3890-3 (E-Book)

Doi-Nr.: 10.3218/3890-3

Bibliografische Information der Deutschen Nationalbibliothek Die Deutsche Nationalbibliothek verzeichnet diese Publikation in der Deutschen Nationalbibliografie; detaillierte bibliografische Daten sind im Internet über http://dnb.dnb.de abrufbar. 
"Choose... knowledge rather than choice gold, for wisdom is more precious than rubies, and nothing you desire can compare with her." (Proverbs of Solomon, c. 930 BC) 



\section{Foreword}

Moderate earthquakes are a serious threat in the alpine environment, both for flat lands with soft river deposits, as well as for natural slopes with factors of safety against failure close to one. Earthquakes in the Swiss Alps with magnitude values of around $\mathrm{Mw}=6.5$ are expected to occur every 50-100 years in the canton of Valais. Although the associated seismic hazard is usually relatively small in comparison with much larger events in major earthquake prone areas, the risk levels for the local infrastructure are significant and can be even augmented by landscape effects in alpine areas. Steep valleys filled with alternating fluvial deposits of gravels, silts, and soft soils often at loose to medium densities can amplify and trap incoming waves from an earthquake, causing the event duration and intensity to be increased. The valleys are frequently vegetated and partially saturated, so they exhibit high inclinations that are close to or even greater than the internal angle of friction of the soil. In such situations, when suction and root reinforcement are the main elements contributing to the stability of the slopes, even a small increase of the earthquake duration and intensity might lead to a serious threat to adjacent infrastructure.

Dr. Alexandru Marin addressed the topics related to threats associated with seismic events in the alpine environment, mainly but not exclusively in the canton of Valais in Switzerland. His research included an extensive laboratory analysis of the dynamic response of fluvial silts from the Rhone valley. He focused on the development of soil stiffness and strength, and pore-pressure buildup during dynamic loading, as well as on the preloading effects due to previous seismic events.

He then developed a novel method to analyse the wave propagation in one and two dimensions, using a commercially available program that incorporates both linear and nonlinear soil behaviour, in contrast with conventional approaches that are exclusively either linear or non-linear. The one-dimensional numerical analyses have been applied to study the behaviour of shallow and embedded foundations as well as river protection dams founded on deep sedimentary deposits in the Rhone valley. The two-dimensional approach was necessary to cover the features of wave propagation and trapping in steep valleys.

Further field studies of wave propagation and associated effects in the distinctive alpine geological conditions have been enabled by the installation of a long-term seismic monitoring system in Visp. This includes strong motion sensors to measure the acceleration at several depths, a chain of pore pressure transducers to record the increase of pore pressures during a seismic event, and a string of shape array accelerometers to measure the ground deformation and acceleration simultaneously at shallow depths in the soil.

Finally, extensive numerical and analytical investigations of slope behaviour during earthquakes were carried out to deliver a performance-based design and inspection method for inclined geotechnical structures (i.e. slopes, dams, and embankments). A procedure for the quantification of the seismic performance of such structures was developed, based on the 
outcome of the numerical and analytical investigations using a set of more than 1100 earthquakes selected by the Swiss Seismological Service. An essential part of this performance-based method is the verification of the mechanical compatibility between the quantified seismic performance (i.e. expected co-seismic displacements) and the slope failure mode (i.e. brittle or ductile). In this way, optimised design of new structures can be achieved and appropriate mitigation measures can be developed for existing objects. This method will be incorporated in the Swiss design code for maintenance of existing structures SIA 269/8.

Dr. Marin has made a significant contribution to the understanding of earthquakes in an alpine environment. He completed scientific analyses and incorporated them into implementation on a level that can be used by engineers and geologists in the field. This has had a direct impact on seismic design practice in Switzerland and beyond.

Prof. Dr. Sarah Springman CBE FREng Professor for Geotechnical Engineering Institute for Geotechnical Engineering ETH Zurich
Dr. Jan Laue

Senior Scientist

Institute for Geotechnical

Engineering

ETH Zurich 


\section{Acknowledgements}

The accomplishment of this work was only possible because of the careful guidance of my mentors Prof. Sarah Springman and Prof. Jan Laue. Aside from helping me to acquire a great deal of knowledge in geotechnical engineering, they often set wise examples worth following in my life. Working with them and learning from them was a life-changing experience.

My sincere thanks extend to Prof. Donat Fäh and Prof. George Gazetas, who kindly accepted to be co-supervisors of my research. Their kind advice, counsel, and encouragement came at the best moments, just when I needed them most. They helped me broaden my horizon and see the big picture when I was in danger of losing myself in the details.

Many thanks go to my former and present colleagues, with whom I shared my joys and sorrows throughout the years. I would like to mention here André Arnold, Amin Askarinejad, Ernst Bleiker, Thomas Buchli, Heinz Buschor, Francesca Casini, Fredy Ehrbar, Jean Gautray, Ralf Herzog, Bernd Imre, Andreas Kieper, Gabriela Laios, Daisy Lucas, Pierre Mayor, Linda Seward, Felix Wietlisbach, Yuko Yamamoto, and Sonja Zwahlen. I'm also thankful for the opportunity I had to share the office with two great colleagues, Ferney Morales and Damoun Taeseri. My special appreciation extends to Thomas Weber, who strongly supported me, especially in the final stage of preparations for the doctoral examination. I would also like to thank Prof. Ion Simulescu who never ceased to encourage me along the way.

The financial support received from the Competence Center for Environment and Sustainability of the ETH Domain, the Federal Office for the Environment, the Swiss Federal Railways, and the Federal Roads Office made this research possible and is greatly appreciated.

Last but not least, I'm most grateful for the unconditional support and prayers of my beloved wife, Anca, and my wonderful parents and sister, Cornel, Extera, and Adiela - they helped me persevere and accomplish this work. Together with my closest friends back home, they were the ones who inspired and motivated me all these years. 



\section{Table of Contents}

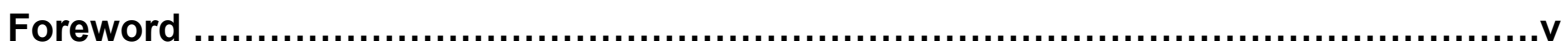

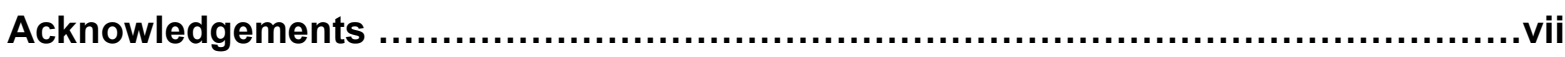

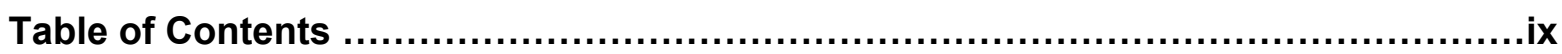

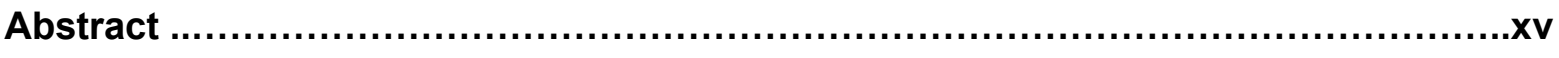

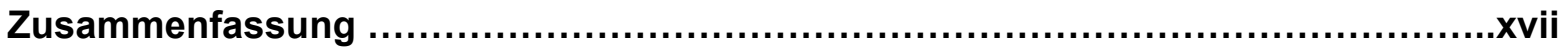

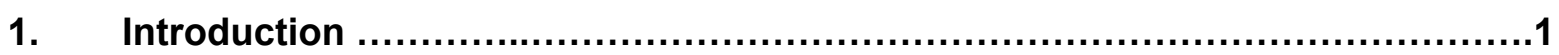

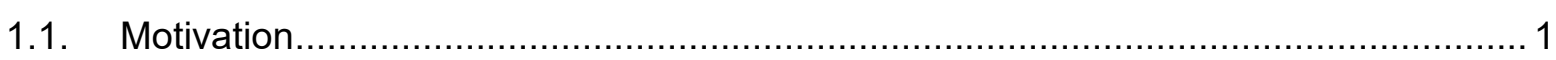

1.2. Main challenges of geotechnical earthquake engineering in alpine areas................ 2

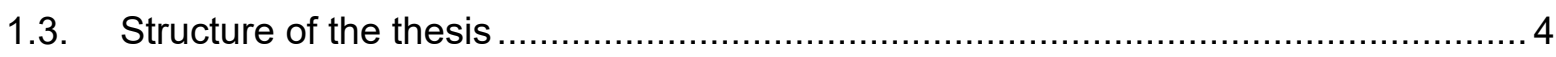

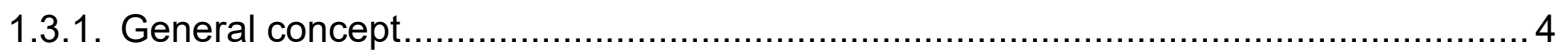

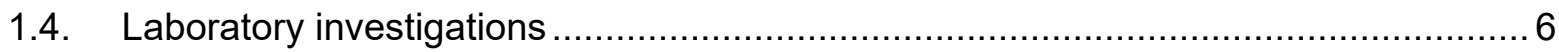

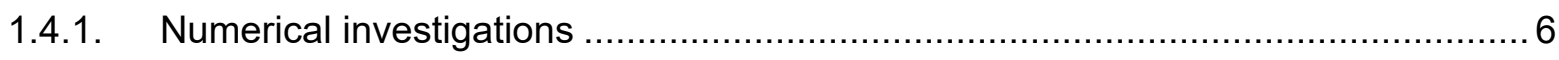

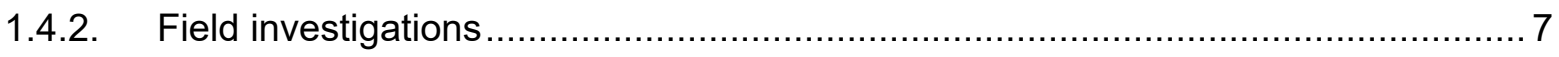

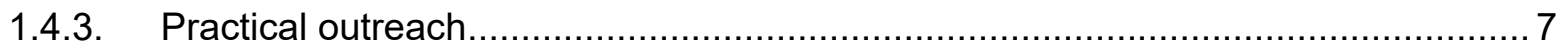

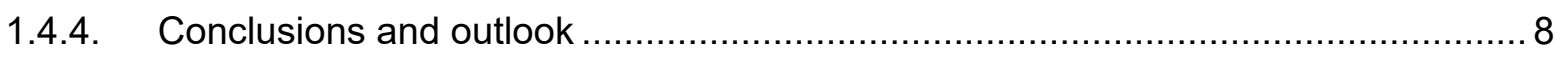

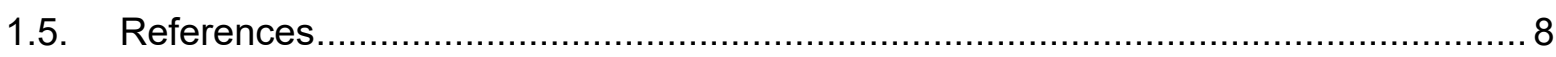

2. Aspects of Dynamic Material Behaviour of Alpine Silty Sand ....................13

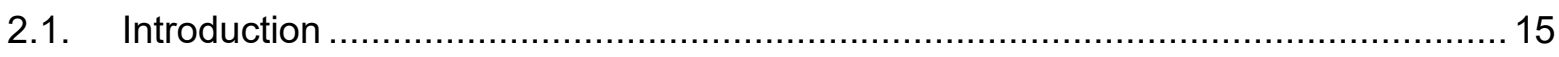

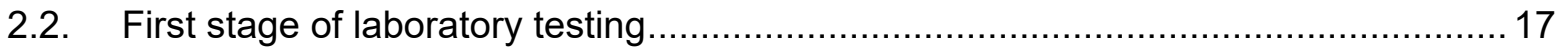

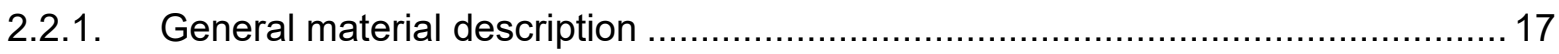

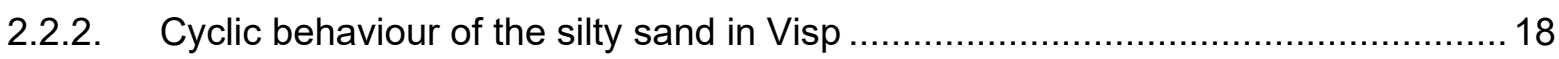

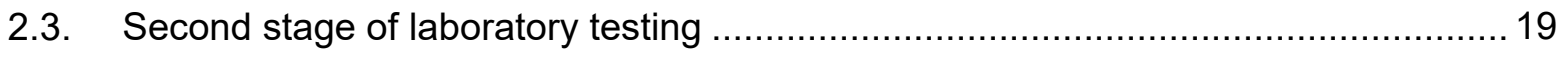

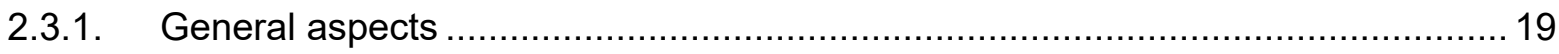

2.3.2. Maximum shear stiffness determination ................................................... 20

2.3.3. Influence of the loading history on the stiffness and strength parameters ........... 23

2.3.4. Influence of the pore pressure increase on the stiffness and

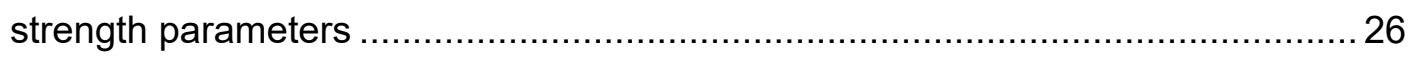

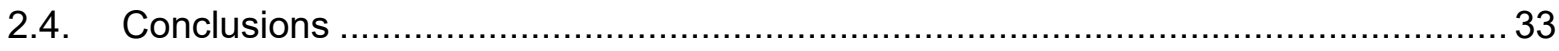




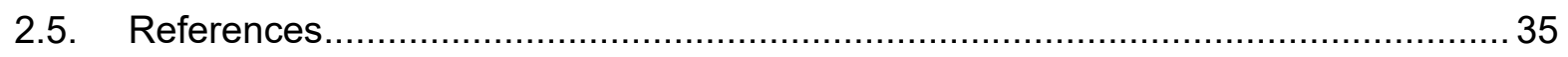

3. One and Two-Dimensional Site Response in the Rhone Valley ..................39

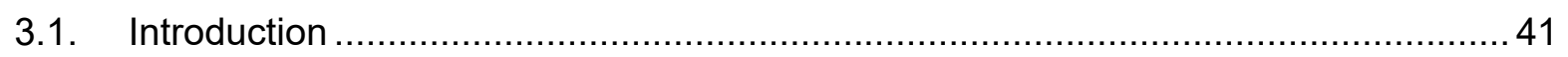

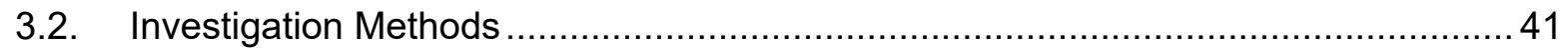

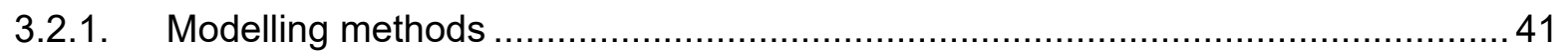

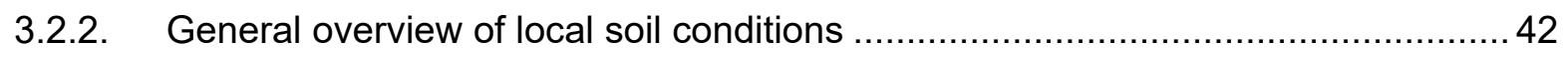

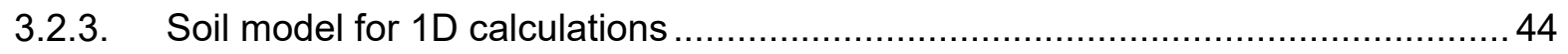

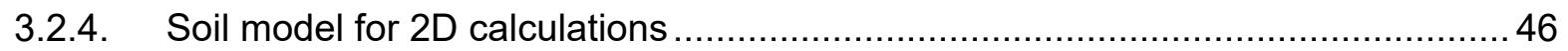

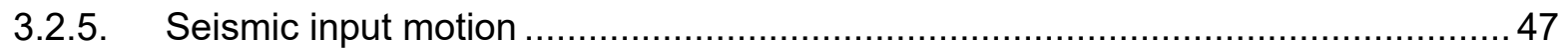

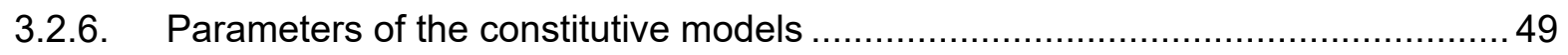

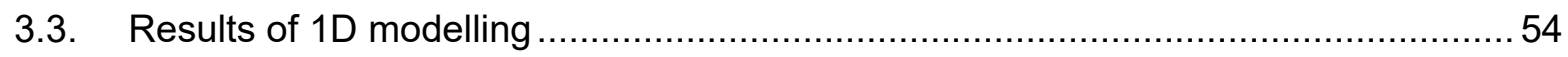

3.3.1. 1D modelling in the frequency domain using equivalent-linear soil properties......54

3.3.2. 1D modelling in the time domain using a linear elastic (LE) constitutive model....58

3.3.3. 1D modelling in the time domain using the linear elastic perfectly plastic Mohr-Coulomb constitutive model (MC) ........................................ 59

3.3.4. 1D modelling in the time domain using the Hardening Soil Small Strain (HSs)

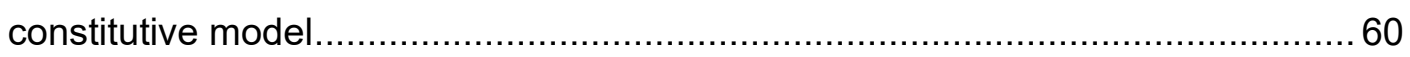

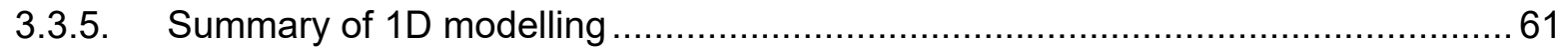

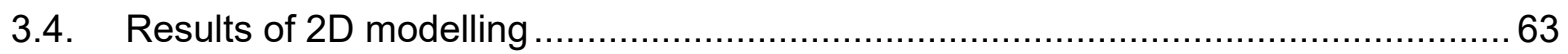

3.4.1. $2 \mathrm{D}$ modelling in the time domain using the linear elastic perfectly plastic Mohr-Coulomb (MC) constitutive model .....

3.4.2. $2 \mathrm{D}$ modelling in the time domain using the Hardening Soil Small Strain (HSs)

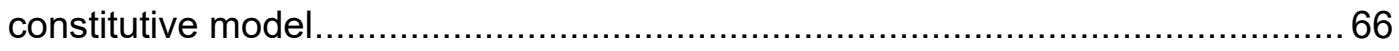

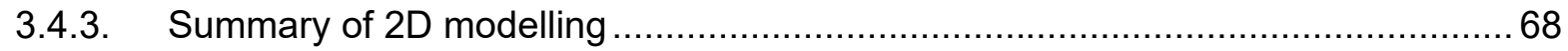

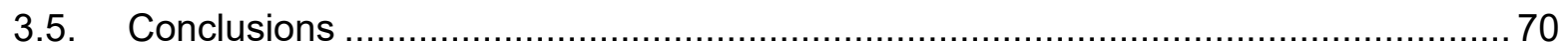

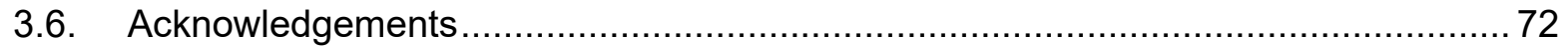

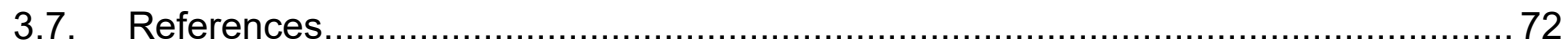

4. Modelling of Soil-Structure Interaction in Alpine Regions .....................77

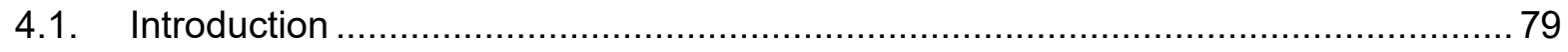

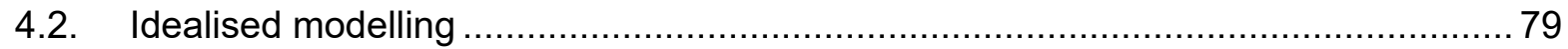

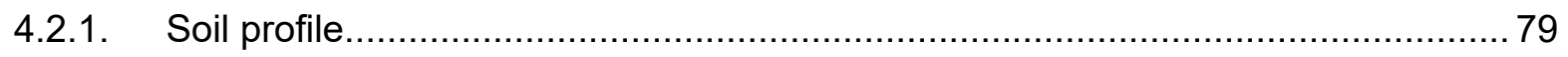

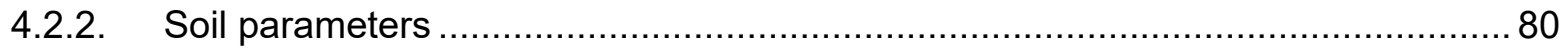




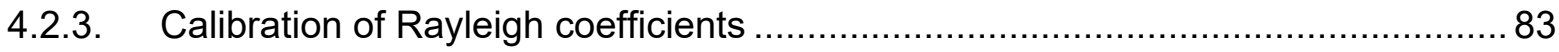

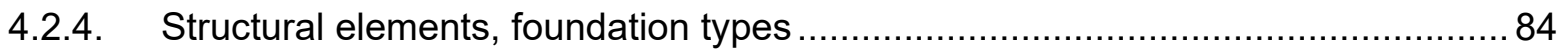

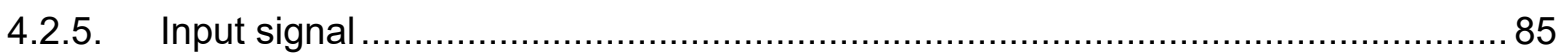

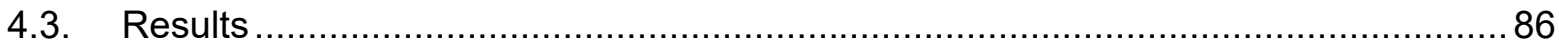

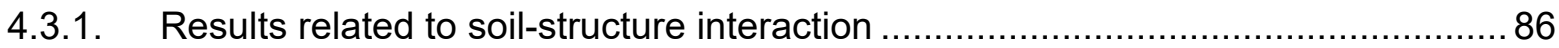

4.3.2. Interaction between basement walls and surrounding soil ................................ 90

4.4. Performance based design. Conclusions and discussion....................................92

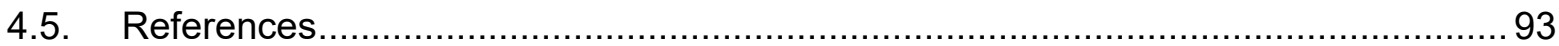

5. Installation and Instrumentation of a Long-Term Seismic Monitoring

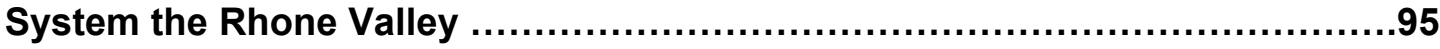

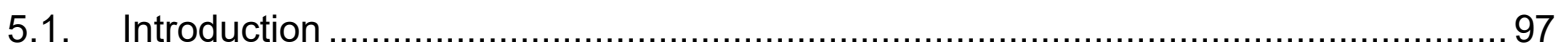

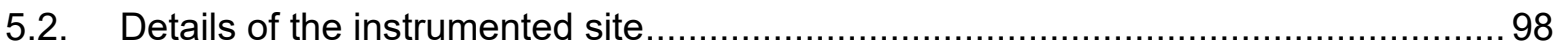

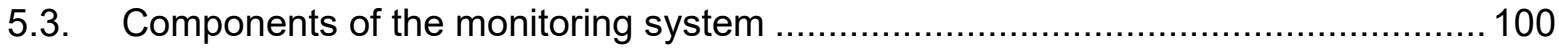

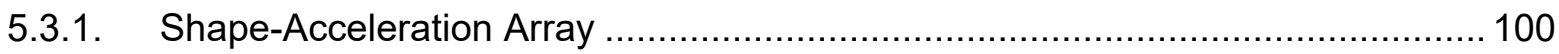

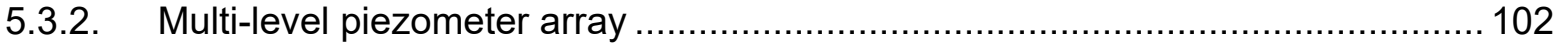

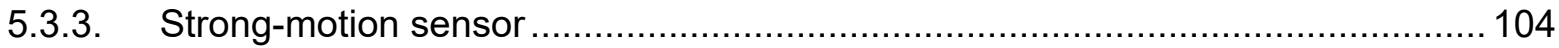

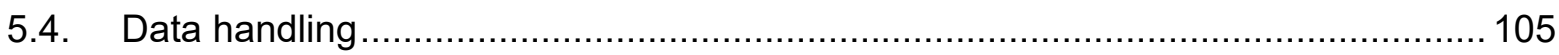

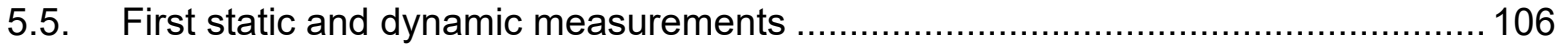

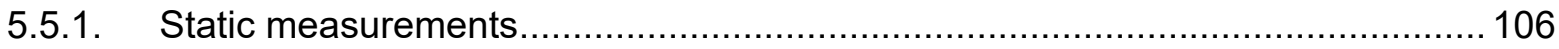

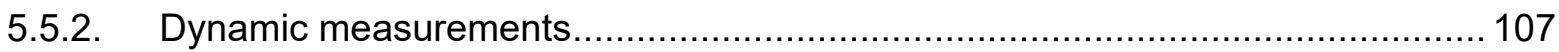

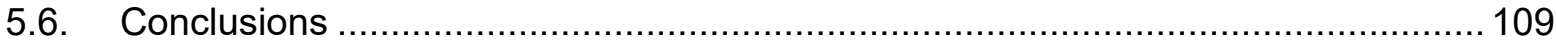

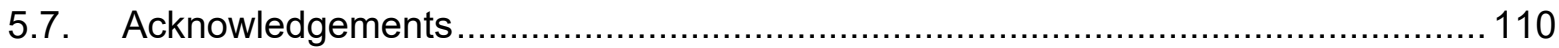

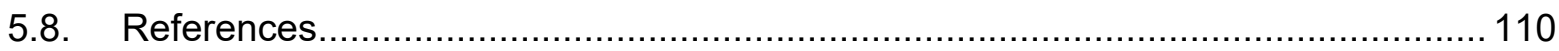

6. Displacement-Based Seismic Analysis of Slopes, Dams, and Embankments ...................................................................113

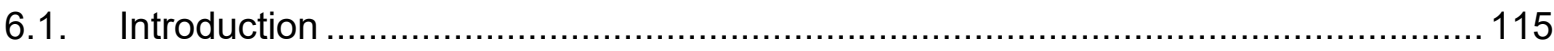

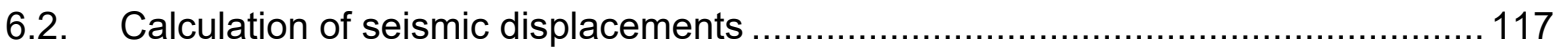

6.3. Development of the displacement estimation relationship ................................... 123

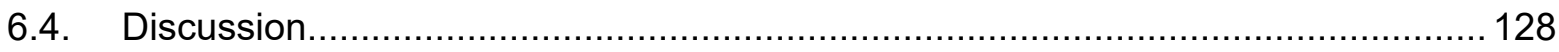

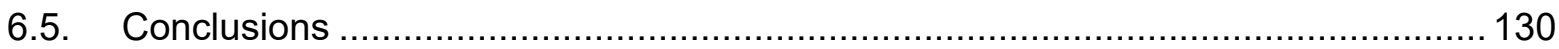

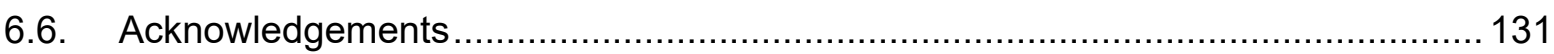

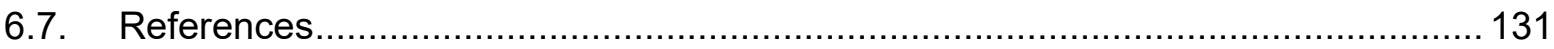




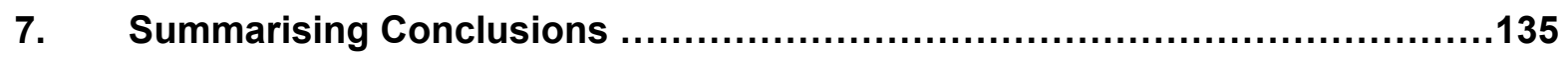

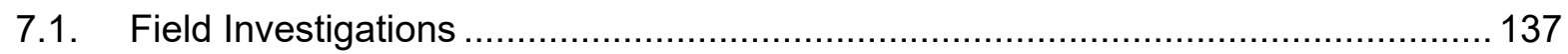

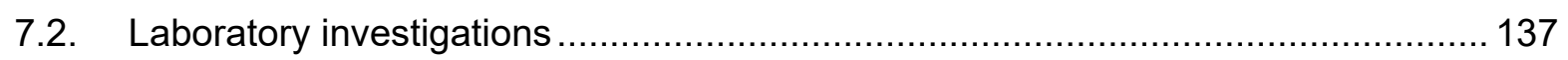

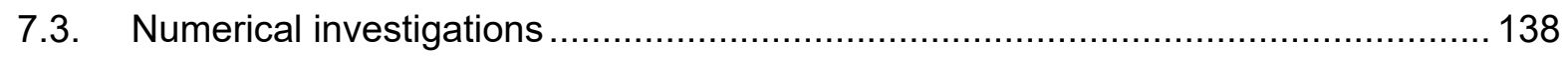

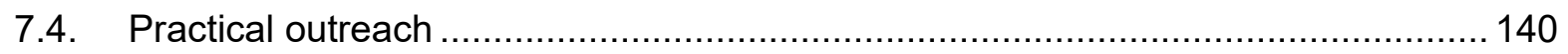

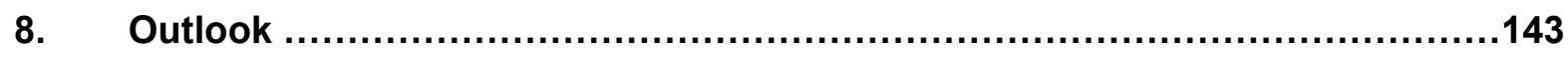

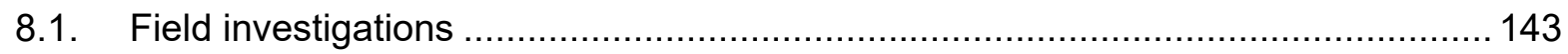

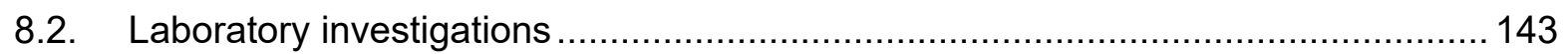

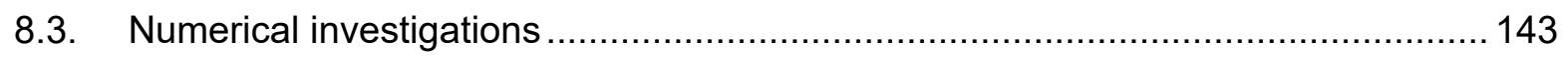

8.4. Displacement-based method for the evaluation of the seismic behaviour of

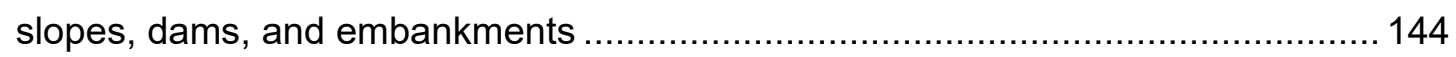

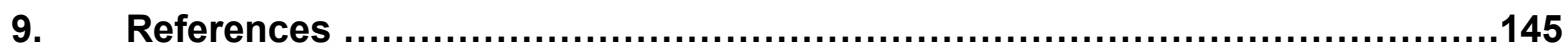

10. Appendix I. Evaluation of the Seismic Behaviour of a Natural Steep Slope ...147

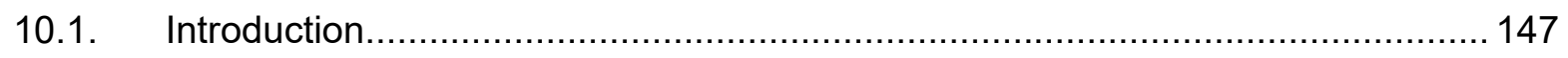

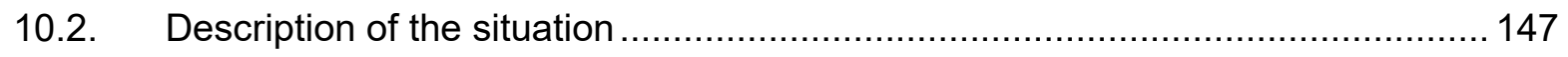

10.3. General assessment of the slope stability under static conditions .................... 148

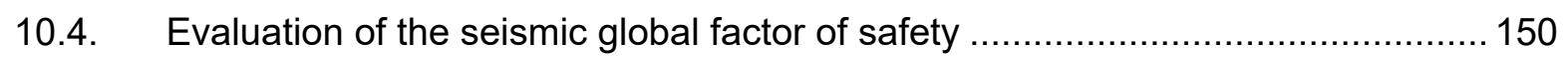

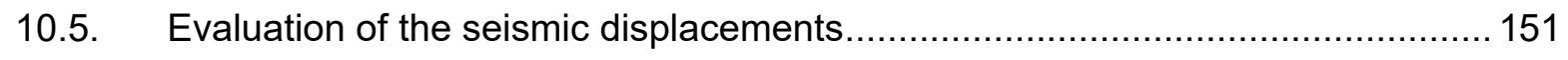

10.6. Detailed numerical analysis of the seismic behaviour of the slope ....................153

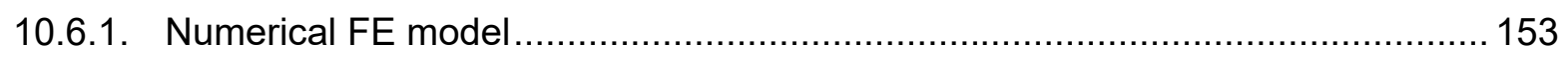

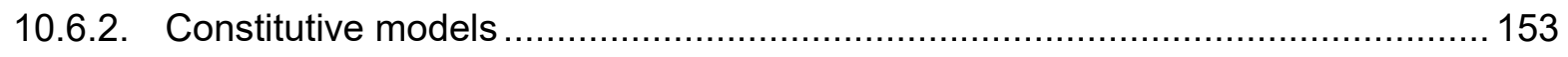

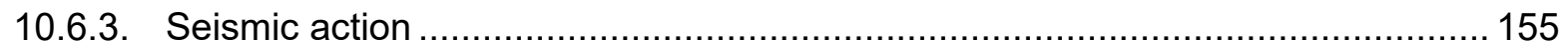

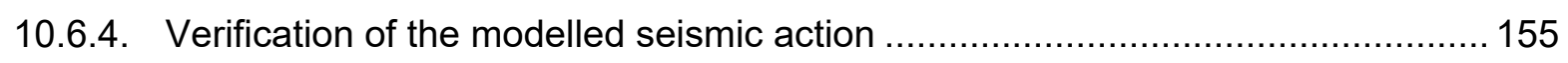

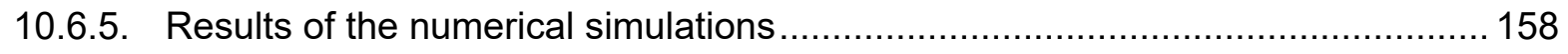

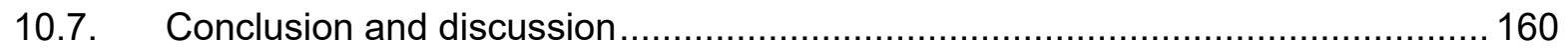

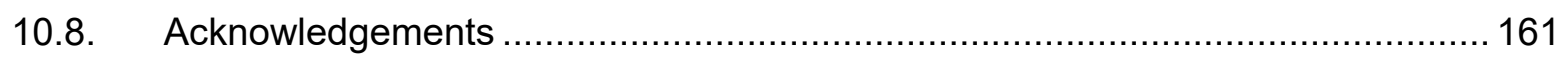

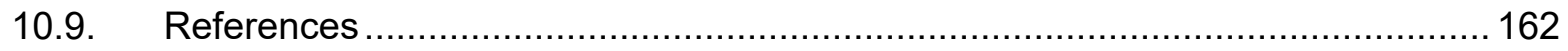

11. Appendix II. Sicherungsmassnahmen der Rhone-Dämme .....................165

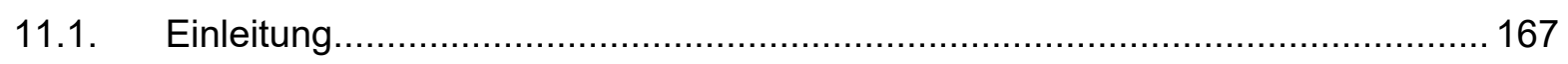

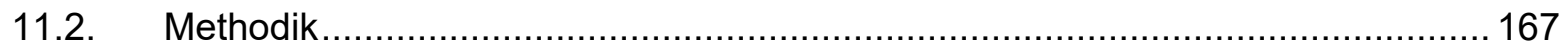

11.2.1. Bestimmung der kritischen Geometrie des Dammprofils ................................ 167 


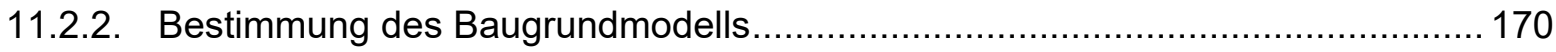

11.2.3. Stoffgesetze, Bodenkennwerte und FE-Netz .............................................. 171

11.2.4. Stoffgesetze und Kennwerte der Dichtwände ............................................. 173

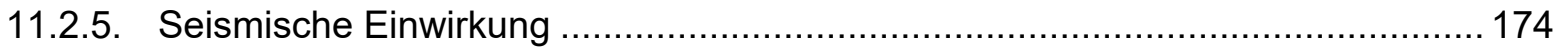

11.3. Resultate der dynamischen Untersuchungen ............................................. 175

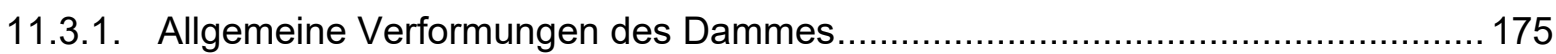

11.3.2. Entwicklung des Verformungsmechanismus............................................. 177

11.3.3. Setzungen infolge der seismischen Anregung .............................................. 178

11.3.4. Seismisches Verhalten der Nachrüstungsmassnahmen ................................. 179

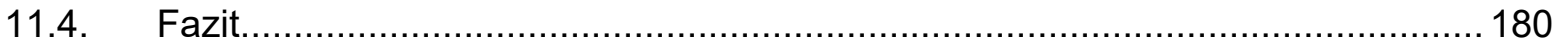

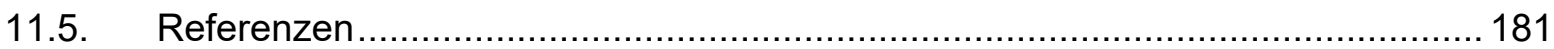





\section{Abstract}

Seismic events in alpine areas have a high impact on society. According to the U.S. Geological Survey, 9'182 casualties were caused by the two major earthquakes on April $24^{\text {th }}$ and May $12^{\text {th }} 2015$ in Nepal, a country with predominantly rough topography. These were major events of $M=7.3-7.8$, but even moderate earthquakes can cause serious damage, landslides and rockfalls in such areas, which are prone to topographical amplification of the ground motion or soil liquefaction.

In this context, mitigating the impact of earthquakes in alpine areas represents an essential task for geotechnical earthquake engineers. The accomplishment of this task is based on the analysis of the dynamic non-linear soil behaviour and its influencing factors using field, laboratory, and numerical investigations. Subsequently, these investigations create the possibility to develop methodologies for the evaluation of the seismic behaviour of inclined geotechnical structures (e.g. slopes, dams, and embankments) for practical applications in design or verification processes. The objective of this work was to make a contribution to geotechnical earthquake engineering and earthquake mitigation in alpine areas subjected to moderate seismicity, such as the Swiss Alps.

A laboratory testing programme was initiated, in the frame of existing field measurements, to create a solid core of parameters related to the static and dynamic response of silty sand, a widely spread soil in the alpine areas. The investigations were performed on soil obtained from the town of Visp VS, located in the Rhone valley, which belongs to the most seismically active region in Switzerland. Static and cyclic triaxial compression tests, and bender element measurements, represented the base of the laboratory testing. Standard (i.e. static axial compression) and advanced stress paths (e.g. sequences of consecutive cyclic loading stages, representing consecutive seismic events) were used to analyse the influence of cyclic loading and stress history on the soil response.

Following the laboratory investigations, a set of numerical analyses were conducted to study wave propagation in alpine areas, local seismic amplification, and soil-structure interaction. In this sense, a benchmark-type of study was performed to facilitate the appropriate choice of seismic amplification analyses, using a specific section of the Rhone valley in Visp. Different types of amplification analyses were presented, emphasising their main advantages and disadvantages. A solution to the usually computationally demanding non-linear ground models for large numerical analyses was suggested in the form of a hybrid model, incorporating a linear elastic and a non-linear section, according to the expected soil behaviour.

The possibility of investigating effects of soil-structure interaction with reduced computational effort and commonly available commercial software was also explored. In this framework an alternative procedure was presented for the determination of Rayleigh coefficients, used to modelling soil damping in numerical analyses. Subsequently, the 
river dams along the Rhone, which require retrofitting measures (i.e. installation of impermeable diaphragm walls or sheet piles), were investigated from the point of view of seismic stability.

Unfortunately, the planned field measurements were delayed by unexpected difficulties related to site identification, acquisition, and receipt of installation permits. However, a novel seismic monitoring system was successfully installed in August 2015 in the area of Visp, incorporating borehole and free-field strong-motion sensors, a Shape-AccelerationArray (SAA), and a set of pore pressure sensors installed at a depth of $15 \mathrm{~m}$. This complex setup allows the wave propagation from the bedrock to the surface and its effects (e.g. 3D deformations and pore pressure variation in the soil layers below the surface) to be monitored in real-time.

Finally, the practical application of the performed investigations in the earthquake mitigation in alpine areas is presented in the form of a displacement-based method of evaluation of the seismic behaviour of inclined geotechnical structures. The approximation of expected seismic displacements was made possible for structures such as dams, embankments, and slopes, located in areas of moderate seismicity. This method is currently being incorporated in the Swiss code SIA 269/8 (2016) and will serve the purpose of maintaining existing geotechnical structures as part of the public safety. 


\section{Zusammenfassung}

Seismische Ereignisse im alpinen Bereich haben wesentliche Auswirkungen auf die gesamte Gesellschaft. Gemäss dem amerikanischen geologischen Institut (USGS) wurden 9'182 Todesopfer durch die zwei starken Erdbeben vom 24. und 12. April 2015 in Nepal - ein Land, das überwiegend durch Gebirgstopografie geprägt ist - verursacht. Diese Beben waren Starkbeben der Magnitude $M=7.3-7.8$. Auch moderate Erdbeben, wie sie in der Schweiz auftreten können, haben das Potenzial, grosse Schäden, Hangrutschungen oder Felsstürze in Gebieten, die durch mögliche Amplifikationen der lokalen Erschütterung oder Bodenverflüssigung gefährdet sind, zu verursachen.

In diesem Zusammenhang ist die Erdbebenvorsorge und die Einschränkung der durch Erdbeben verursachten Auswirkungen im alpinen Bereich eine wesentliche Aufgabe des geotechnischen Erdbebeningenieurwesens. Diese Aufgabe wird durch Feld-, Labor- und numerische Untersuchungen des dynamischen nicht linearen Bodenverhaltens und dessen Einflussfaktoren erfüllt. Im Nachhinein entsteht aus diesen Untersuchungen die Möglichkeit, Methoden für die Abschätzung des seismischen Verhaltens unter alpinen Randbedingungen zu finden und für geneigte Erdbauwerke (z.B. Böschungen, Einschnitte, Dämme) ein Bemessungs- oder Überprüfungsverfahren zu entwickeln, welches für die praktische Anwendung tauglich ist. Das Ziel dieser Arbeit war es, damit einen Beitrag zum geotechnischen Erdbebeningenieurwesen und der Erdbebenvorsorge im alpinen Bereich mittlerer Seismizität (z.B. Schweizer Alpen) zu leisten.

Mit dem Ziel, einen umfassenden Satz von statischen und dynamischen Bodenparametern für den im alpinen Bereich weit verbreiteten siltigen Sand zu schaffen, wurden eine Reihe von Laboruntersuchungen im Zusammenhang mit bestehenden Feldmessungen durchgeführt. Der Boden für die Laboruntersuchungen wurde aus Visp VS - eine Stadt im Rhonetal, die in der höchsten Erdbebenzone in der Schweiz liegt - gewonnen. Statische und zyklische triaxiale Kompressionsversuche und Messungen mit BenderElementen haben die Grundlage der Untersuchungen gebildet. Einfache (d.h. statische axiale Kompression) und komplexe (d.h. aufeinanderfolgende zyklische Belastungsschritte, die zeitlich aufeinanderfolgende Erdbeben darstellen) Spannungspfade wurden verwendet, um den Einfluss der Spannungs- und zyklischen Belastungsgeschichte auf das Bodenverhalten zu untersuchen.

Nach den Laboruntersuchungen wurden eine Reihe von numerischen Untersuchungen, die sich auf die Wellenausbreitung, die lokale seismische Amplifikation und die BodenBauwerk-Wechselwirkung in alpinen Tälern konzentriert haben, durchgeführt. In dieser Hinsicht wurde ein Vorgehen zur seismischen Standortanalyse durch eine BenchmarkStudie an einem spezifischen Schnitt des Rhonetals in Visp aufgezeigt. Unterschiedliche Standortanalysen und deren Vor- und Nachteile wurden für diesen Zweck vorgestellt und durchgeführt. Eine Lösung für die rechenaufwendigen nicht linearen Analysen grosser 
Modelle wurde in der Form eines Hybridmodells mit am erwarteten Bodenverhalten angepassten linear elastischen und nicht linearen Abschnitten hergeleitet.

Im selben Zusammenhang wurde die Möglichkeit, die Auswirkungen der Boden-BauwerkWechselwirkung mit reduziertem Rechenaufwand und allgemein verfügbarer kommerzieller Software zu erfassen, erforscht. In diesem Rahmen wurde auch eine alternative Methode für die Bestimmung der bei der Modellierung der Bodendämpfung verwendeten Rayleigh-Beiwerte entwickelt. In den letzten Berechnungen wurde die seismische Stabilität der Rhonedämme, die Nachrüstungsmassnahmen (d.h. Einbau von Dichtwänden im Dammkörper) bedürfen, analysiert.

Die Felduntersuchungen wurden leider durch unerwartete Schwierigkeiten bei der Identifizierung des optimalen Ortes für die Messstation und der Erhaltung des Landstücks sowie der benötigten Baubewilligungen verzögert. Jedoch wurde August 2015 eine neuartige Messstation in der Nähe von Visp installiert. Unterschiedliche Messgeräte und Geber wurden dabei eingerichtet: Bohrloch- und Freifeldstarkbebenmessgeräte, eine SAA-Inklinometerkette und eine Kette von Porenwasserdruckgeber in regelmässigen Abständen bis in einer Tiefe von 15 Metern. Diese komplexe Einrichtung der Messstation erlaubt die Echtzeitaufnahme der Wellenausbreitung vom Felshorizont bis zur Oberfläche und deren Auswirkungen (z.B. 3D-Verschiebungen, Variation des Porenwasserdrucks in den oberen Bodenschichten) im Rhonetal.

Anschliessend wurde eine verformungsbasierte Methode für die Abschätzung des seismischen Verhaltens geneigter Erdbauwerke wie auch natürlicher Hänge im alpinen Bereich entwickelt. Dadurch wurde die Abschätzung der erwarteten seismischen Verformungen bei Dämmen, Einschnitten und Böschungen unter Bedingungen mittlerer Seismizität ermöglicht. Die Methode wird in die zukünftige Schweizer Norm SIA 269/8 (2016) eingeführt und für die Erhaltung bestehender Erdbauwerke verwendet werden. 


\section{Introduction}

\subsection{Motivation}

Earthquakes represent a serious recurrent threat to the society. According to the US Geological Survey (USGS), in 2015 there were a total of 14'588 earthquakes of magnitude $M>4$ globally. The seismic activity in 2015 was similar to that of previous years, in which an average of 14'500 events were recorded annually. The number of very strong earthquakes of magnitude $M>7.0$ was 19 , close to the average rate since 1900 of around 18 events per year (Koontz, 2016). However, the United Nations Office for Coordination of Humanitarian Affairs reports a seriously increased number of casualties caused by earthquakes, from 664 in 2014 to 9'612 in 2015, adding that the majority of these were caused by the $M>7$ events on April, $25^{\text {th }}$ and May, $12^{\text {th }}$ in Nepal.

The earthquakes have a strong impact, not only in the highly seismically active zones, but also in countries with moderate seismicity such as Switzerland. According to Fäh et al. (2011), in the past seven centuries four events of magnitude $M>5.5$ occured every 100 years in Switzerland and two of them caused severe damage. A graphical representation of the seismicity in the canton Valais (the most active zone in Switzerland) can be seen in Figure 1.1.

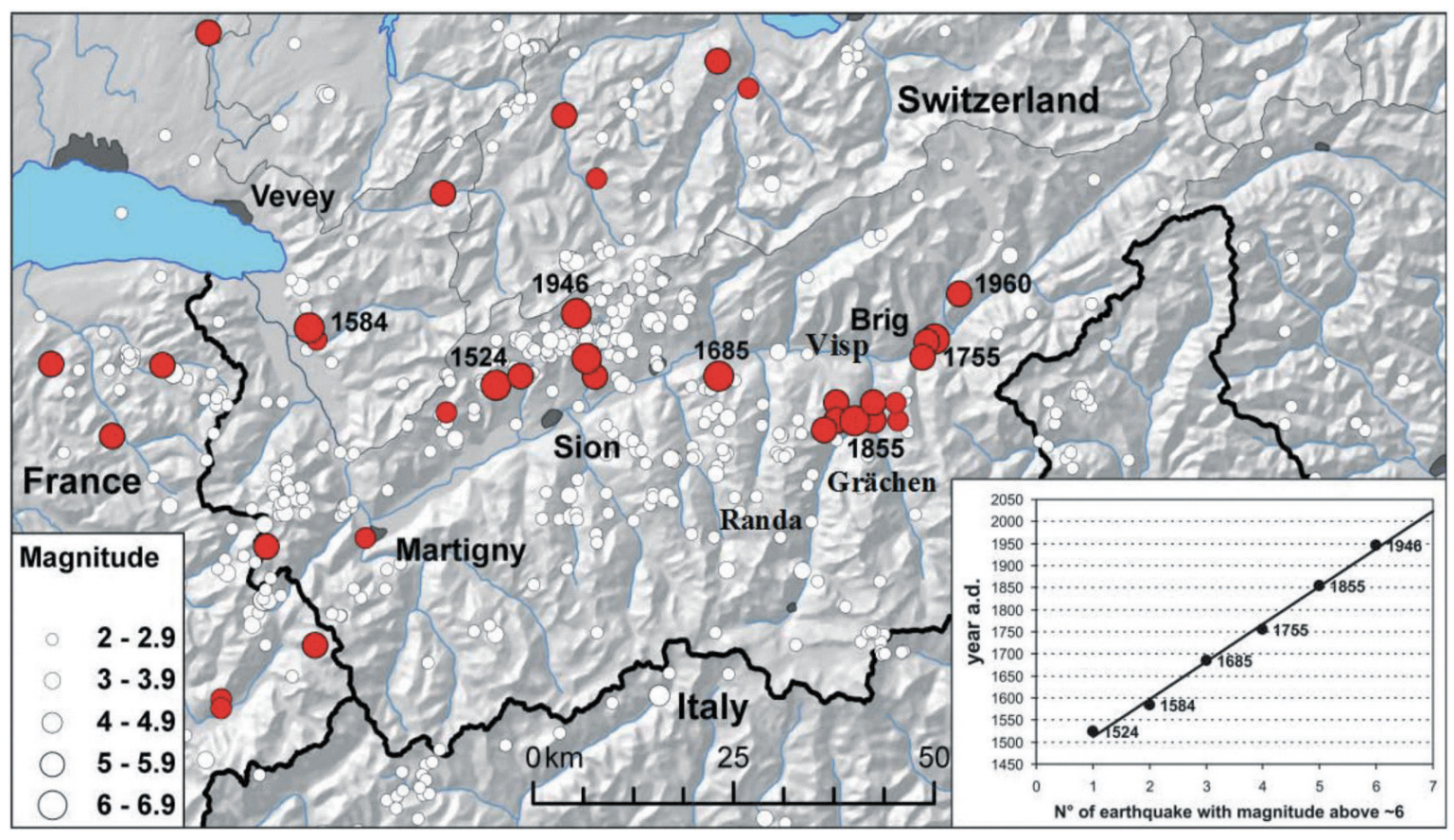

Figure 1.1. Seismicity in the Valais (Fäh et al., 2011).

Earthquake related damage is not caused by the seismic activity alone, but can be exacerbated by a combination of unfavourable factors, as is the case in Valais. These can 
include: rough topography, unstable and steep slopes, deep valleys filled with alluvial deposits, and liquefiable soils. These factors overlap with high population density and an increased degree of industrialisation, which raises the threat of earthquakes to the society.

Under these circumstances, it is the responsibility of earthquake engineers to mitigate the impact of earthquakes by means of more accurate evaluation and prediction of the seismic action, seismic design of geotechnical and civil structures, and proper verification of existing infrastructure. The motivation of this current research is to substantiate this responsibility in the context of alpine areas. As previously mentioned, the combination of moderate seismic hazard and unfavourable factors in the alpine areas leads to significant challenges for seismic design and verification. Issues such as soil liquefaction, lateral spreading, landslides, high local amplification of ground motion, or collapsing infrastructure cannot be excluded and have to be taken into account.

\subsection{Main challenges of geotechnical earthquake engineering in alpine areas}

For weak ground motions during small seismic events, soil behaviour is linear and the stress-strain relations can be represented using Hooke's law. However, during large events, the soil behaviour becomes non-linear with a curvilinear stress-strain dependency (Seed \& Idriss, 1970).

The identification and quantification of dynamic non-linear soil behaviour represents one of the main challenges of geotechnical earthquake engineering. These effects combine to determine the seismic hazard, as defined by seismologists (e.g. Giardini et al., 2004), and influence design and verification methods in structural and geotechnical engineering. Dynamic non-linear soil behaviour is not a trivial matter by far and it is essential to incorporate it together with these methods for both high and moderate seismic hazard areas.

As Beresnev (1996) said, "the significance of non-linear soil behaviour in seismically induced dynamic loading has been a controversial issue among seismologists and geotechnical engineers for decades. The central question of the discussion is whether soil amplification is amplitude dependent." The concept of strain amplitude dependent soil response is well-accepted (Seed \& Idriss, 1970; Finn, 1991; Okur \& Ansal, 2007) in geotechnical earthquake engineering. This gains more momentum in engineering seismology as well, due to expanding networks of strong-motion arrays and increasing quality of data. Evidence of non-linear soil behaviour was obtained by analysing the response of sites subjected to weak and strong motions (Trifunac \& Todorovska, 1996; Field et al., 1997; Wen et al., 2011; Régnier et al., 2013). Moreover, local properties of the subsoil determine the intensity of earthquakes (Bard, 1994) and depending on them, ground motion amplification and pore pressure increase may occur. This can subsequently trigger secondary effects, such as landslides, rock falls, or soil liquefaction. Under these circumstances, laboratory investigations for the determination of local properties of typical soils available in alpine valleys are essential. 
Related to this first challenge, the identification of the main factors influencing the dynamic non-linear soil behaviour is also very important. These may include effective confining pressure, void ratio, overconsolidation ratio (OCR), or plasticity characteristics, which have been proven to influence the dynamic soil properties (Seed \& Idriss, 1970; Zen et al., 1978; Kokushu et al., 1982; Dobry \& Vucetic, 1987; Sun et al., 1988). In addition to these, the stress history of the soil has also an influence on the dynamic behaviour.

Dobry \& Vucetic (1987) showed e.g. that the reduction of the shear modulus after cyclic loading becomes more significant with increasing OCR. According to Hyde \& Ward (1986), a reduction of the undrained strength takes place after cyclic loading. Andersen et al. (1976), Yasuhara \& Andersen (1989), and Yasuhara et al. (2003) also investigated the post-cyclic degradation of material stiffness and strength. Considering this, the influence of such factors needs to be investigated for the local soils under the specific boundary conditions of the alpine environment (e.g. formation of alluvial deposits, stress states in inclined slopes, typical soil types, typical cyclic loading scenarios, etc.)

A further challenge of geotechnical earthquake engineering is the identification and calibration of numerical models for the estimation of seismic ground motion. This implies a sound basis of field measurements to compile a ground model with appropriate boundary conditions, and a set of reliable laboratory investigations to determine the parameters of the constitutive models.

Previous studies (e.g. Roten et al., 2007) exposed how difficult these investigations can be, but they also discussed how useful the results are in the pursuit of mitigating the impact of earthquakes on society. Knowing that topographical conditions and deep sediment layers can change the characteristics of ground motions (e.g. Geli et al., 1988; Gazetas et al., 2002), an accurate estimation of the design seismic hazard can be reached using local seismic response analyses (e.g. Roten et al., 2007; Hashash et al., 2010).

Moreover, the seismic design of infrastructure objects can be improved using numerical studies related to the seismic behaviour of geotechnical structures (e.g. Papalou \& Bielak, 2004; Siyahi \& Arslan, 2008) or to soil-structure interaction (e.g. Psarropoulos et al., 2005; Anastasopoulos et al., 2010). In this context, the challenge identified is to perform similar numerical studies adapted to the alpine environment.

Field measurements connect knowledge about soil behaviour gained in the laboratory, numerical investigations, and evaluation methodologies, by validating all of them. The purposes of field measurements include the determination of wave propagation in complex topographic structures (Roten et al., 2008) and the verification of thresholds for non-linear behaviour ( $\mathrm{Wu}$ et al., 2010). Another use of field measurements is the calibration of complex soil models for more accurate predictions of soil behaviour (Mercado et al., 2011). Finally, field measurements can also be used to develop and validate different seismic evaluation methodologies (Newmark, 1965). In this regard, they are an important element and complete the overall view of the seismic hazard in alpine areas. 
The final challenge in the context of earthquake engineering is the development of standardised evaluation methodologies for the seismic behaviour of inclined geotechnical structures (i.e. dams, slopes, embankments, etc.). It was recognized that e.g. steep natural valleys can induce a great risk to local infrastructure and building stock (Chigira et al., 2010). Standardised seismic evaluation methodologies based on large sets of seismic data simplify the design and verification processes (e.g. Anderson et al., 2008) and mitigate this risk. The need for such methodologies is high, considering that the seismic behaviour of inclined geotechnical structures can have a significant influence on the impact of an earthquake in alpine areas.

Summarizing, four different challenges were identified in relation to geotechnical earthquake engineering in alpine areas:

1. Identification and quantification of dynamic non-linear soil behaviour and its main influencing factors.

2. Identification and calibration of numerical models for seismic analyses.

3. Field investigations adapted to capture the specific seismic effects in alpine areas.

4. The development of standardised evaluation methodologies for the seismic behaviour of inclined geotechnical structures.

The outcome of dealing with these challenges extends beyond the scientific domain and has direct implications in economic and social areas. The impact of earthquakes in the alpine environment can be mitigated by providing a more accurate evaluation and prediction of the seismic action, better seismic design of geotechnical and civil structures, and more reliable verification of existing infrastructure.

\subsection{Structure of the thesis}

\subsubsection{General concept}

The general concept of the thesis resulted from the distribution of the above-mentioned challenges into four main sections:

1. The first section deals with laboratory investigations. This relates to the first challenge, which accounts for the identification and quantification of dynamic nonlinear soil behaviour and its influencing parameters like e.g. previous cyclic loading.

2. The second section contains numerical investigations, and is related to the challenge of identifying and calibrating numerical models.

3. The third section relates to the field investigations in alpine areas, as introduced by the third challenge.

4. In the final section, displacement-based methods for the evaluation of the seismic behaviour of inclined geotechnical structures materialise the practical outreach from the research dimension to the world of practice. 
Each of the sections includes one or more scientific articles addressing specific challenges with direct applications to the alpine environment (Figure 1.2). The normal approach should have started with field investigations followed by laboratory and numerical investigations. This however was not possible due to major difficulties encountered during the preparation stage of the field measurements. On the one hand, the task of finding a site available for seismic instrumentation was very difficult and it involved serious time delays. On the other one, the formal process of authorising the drilling of the boreholes was slower than expected and included supplementary hydrogeological surveying, delaying the project with more than 1.5 years. Under these circumstances the laboratory and numerical investigations were performed before the field measurements to avoid any additional delays.

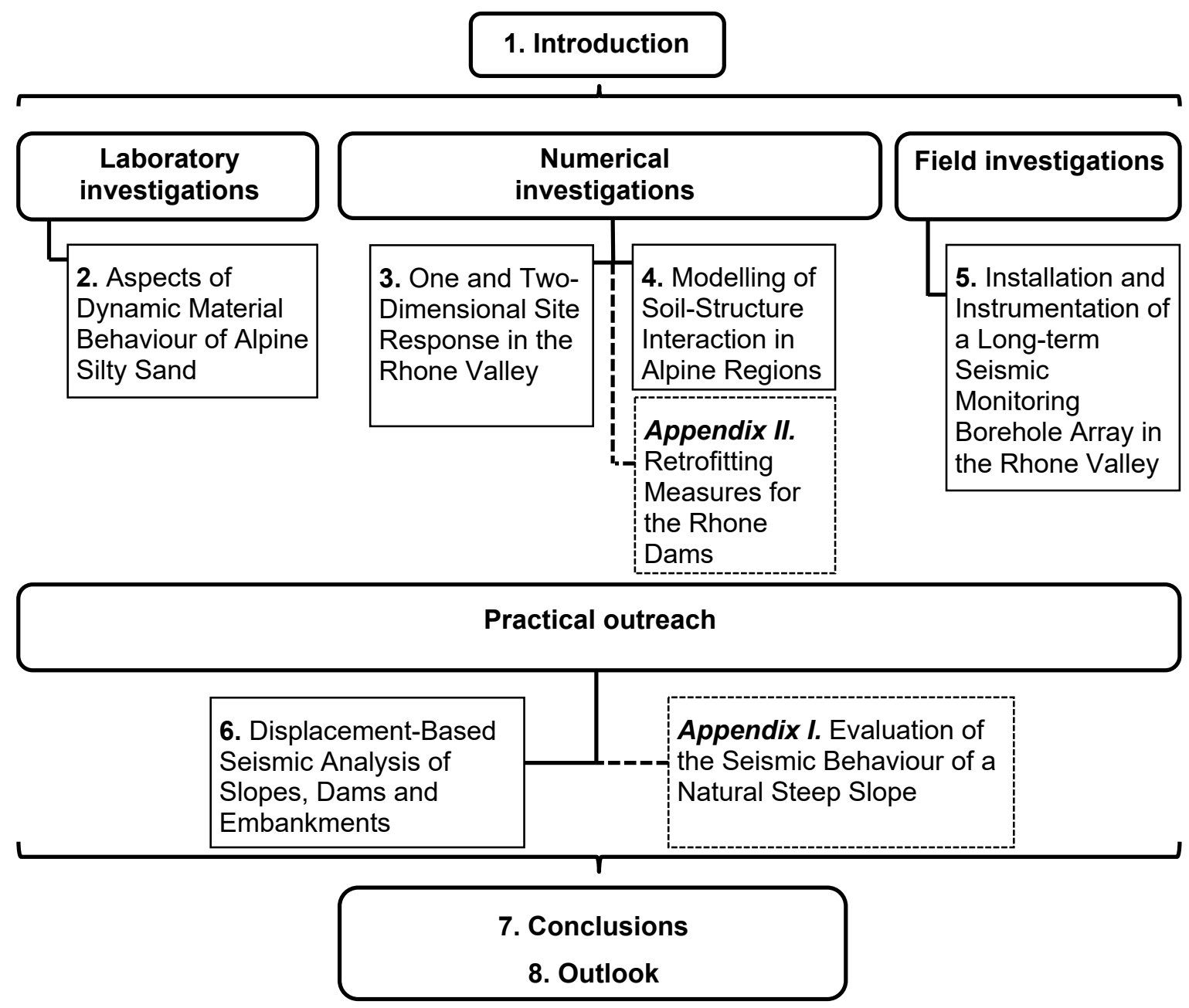

Figure 1.2. General concept and structure of the thesis.

In the following paragraphs a brief summary of the sections succeeding this introductory part is presented to provide a better overview of the research topics by means of short descriptions of the articles included in each section. 


\subsection{Laboratory investigations}

The laboratory investigations section includes one article called "Aspects of Dynamic Material Behaviour of Alpine Silty Sand" by Marin, A., Weber, T.M and Laue, J. This summarises the laboratory investigations performed on alpine silty sand, which is often found in the geological structure of alpine river basins. The investigations start with the soil classification according to USCS and continue with the determination of the maximum shear stiffness by testing the speed of shear wave propagation using bender-elements. Further on, the influence of the loading history on the stiffness and strength parameters was investigated, and in a final step, the development of pore-water pressure during cyclic loading and its influence on the strength parameters was analysed. The results proved that the loading history and the pore pressure development cannot be neglected when investigating the impact of earthquakes in alpine areas. Soil parameters for advanced constitutive models, which can be used in subsequent numerical investigations, are the outcome of the investigations.

The concept of this paper was formulated by the first author who joined together the results from various laboratory investigations, interpreting and merging them in one unitary work. The first stage of investigations, which created the context for more advanced testing, was performed and interpreted by the second co-author. The second stage of investigations related to bender-element measurements, loading history effects, and pore pressure development under advanced stress paths was planned and coordinated by first and the third co-author.

\subsubsection{Numerical investigations}

The numerical investigations section includes three articles, out of which one was published in German and can be found in Appendix II.

The first article has the title "One and Two-Dimensional Site Response in the Rhone Valley" by Marin, A., Habegger, R. and Laue, J. Its topic is related to the influence of topographical conditions and deep sediment layers on the characteristics of local ground motion. The investigations were performed using a common numerical software package (PLAXIS 2D, Brinkgreve et al., 2014) and explored the possibility of non-linear modelling with limited resources. The parameter sets used for the constitutive models were determined based on laboratory and field investigations. Different methods of analysing the site response were compared by investigating their applicability range and appropriateness in different modelling situations, aiming for a more accurate evaluation and prediction of the local seismic action.

The next article, called "Modelling of Soil-Structure Interaction in Alpine Regions" by Marin, A., Laue, J. and Mezger, F. was revised and it contains the first attempts to investigate seismic amplification and soil-structure interaction. These attempts were the first steps made with numerical modelling and they incorporate strong simplifying assumptions related to the local seismic hazard and soil behaviour. Some of the interpretations of the results may be simplistic, but even so, this represented the starting point of the further 
development of the numerical investigations presented in this section. The article contains, however, important information related to the definition of material damping in dynamic analyses using iteratively determined Rayleigh coefficients. Interesting results related to the kinematic soil-structure interaction and to the earth-pressure distribution during cyclic loading are shown to emphasise the possibility of capturing such effects, even under the limitations of the simplifying assumptions.

The last article, which was published in German, can be found in Appendix II and the translation of the title is: "Retrofitting Measures for the Rhone Dams" by Marin, A. This is another practical application of investigations related to local site amplification and seismic behaviour of river dams. The purpose of this article was to perform the verification of existing dam infrastructure, facilitating subsequent measures of earthquake mitigation in this way. The focus was the seismic analysis of retrofitting measures (i.e. insertion of steel sheet-piles and mixed-in-place walls) required to ensure the retention of water without causing erosion of the old flood protection dams along the Rhone in Switzerland. The results showed that the overall behaviour of the dams is not affected by the installation of retrofitting measures and revealed the main differences between the seismic behaviour of sheet-piles and mixed-in-place walls.

\subsubsection{Field investigations}

This section includes one article related to field measurements: "Installation and Instrumentation of a Long-term Seismic Monitoring System in the Rhone Valley" by Marin, A., Laue, J. and Fäh, D. The field work performed to install a long term monitoring station in the most seismically active area in Switzerland (canton Valais) is presented. Three different types of recording instruments were installed in different boreholes in cooperation with the Swiss Seismological Service: strong-motion sensors recording accelerations at different depths and at the surface, a Shape Acceleration Array (SAA) measuring the seismic response of surface layers of alluvial deposits, and a multi-level piezometer array measuring the development of pore pressures at different depths. The first measurements showed that even small earthquakes (e.g. $M=3.1$ ) caused pore pressure increase in the saturated silty materials. The data provided by this monitoring system enables the calibration and validation of numerical investigations of non-linear soil behaviour and liquefaction.

\subsubsection{Practical outreach}

The last section contains one publication which was revised before incorporating it in the thesis. This represents the outcome of the research performed in the design and verification practice. The article is called "Displacement-Based Seismic Analysis of Slopes, Dams, and Embankments" by Marin, A. and Laue, J. As the title suggests, this article presents the possibility to overcome the drawbacks of limit equilibrium calculations in seismic design and verification of slopes, dams, and embankments, using displacementbased concepts. The approach presented is founded on Newmark's method (1965) for the 
estimation of displacements and uses the international experience to define a procedure for the displacement-based seismic analysis in countries with moderate seismic hazard (e.g. Switzerland). The evaluation of the seismic behaviour of inclined geotechnical structures in terms of displacements becomes more accessible using the defined procedure. This very important in the alpine environment, where seismic behaviour of such structures often determines the level of risk associated with an earthquake. The concepts of displacement-based seismic analysis of geotechnical structures presented are currently being implemented in the Swiss design codes and guidelines (SIA 269/8, 2016). However, the discussions related to the final form of these concepts in the codes are still in progress.

In addition to this article, supplementary information related to the displacement-based methodologies is presented in Appendix I under the title "Evaluation of the Seismic Behaviour of a Natural Steep Slope". The main purpose was to provide a verification example for geotechnical engineers dealing with the issue of unstable slopes. Usually, such structures are difficult to approach using standard methods recommended by design codes. The steps required by a sound evaluation of the seismic behaviour are presented together with the assumptions that should be taken into account. Nonetheless, the final form of the verification steps might slightly change, depending on the development of the ongoing discussions related to the displacement-based concepts in the Swiss codes. This also represented the main reason for not incorporating this information in the main body of the thesis.

\subsubsection{Conclusions and outlook}

The final concluding section of the thesis reiterates the scope of the investigations performed and closes the gap opened in the introductory part by showing how the main challenges were approached and resolved. This section is followed by an outlook specifying in which direction future investigations in the field of geotechnical earthquake engineering in alpine environment should advance.

\subsection{References}

Aki, K. (1988) Local site effects on strong ground motion. In: JL van Thun (ed), Earthquake Engineering and Soil Dynamics II - Recent Advances in Ground Motion Evaluation. pp. 103-155.

Anastasopoulos, I., Gazetas, G., Loli, M., Apostolou, M. \& Gerolymos, N. (2010) Soil failure can be used for seismic protection of structures. Bulletin of Earthquake Engineering, 8. pp. 309-326.

Andersen, K.H. (1976) Behaviour of clay subjected to undrained cyclic loading. In: Proceedings of the International Conference on the Behaviour of Offshore Structures, BOSS'76, Trondheim, Norway. Norwegian Institute of Technology, Trondheim. Volume 1. pp. 392-403. 
Anderson, D.G., Geoffrey, R.M., Ignatius, L. \& Wang, J.N. (2008) Seismic Analysis and Design of Retaining Walls, Buried Structures, Slopes, and Embankments. National Cooperative Highway Research Program, NCHRP Report 611. Transportation Research Board, Washington, D.C.

Bard, P.-Y. (1994) Effects of surface geology on ground motion: Recent results and remaining issues. In: Proceedings of the 10th European Conference on Earthquake Engineering, Vienna, Austria. Vol.1. pp. 305-324.

Beresnev, I.A. \& Wen, K.-L. (1996) Nonlinear soil response - A reality? Bulletin of the Seismological Society of America, 86(6). pp. 1964-1978.

Brinkgreve, R.B.J., Engin, E. \& Swolfs, W.M. (2014) PLAXIS 2D Anniversary Edition 2014. Delft University of Technology \& PLAXIS bv. The Netherlands.

Chigira, M., Wu, X., Inokuchi, T. \& Wang, G. (2010) Landslides induced by the 2008 Wenchuan earthquake, Sichuan, China. Geomorphology, 118(3-4). pp. 225-238.

Dobry, R. \& Vucetic, M. (1987) Dynamic properties and seismic response of soft clay deposits. In: Proceedings of the International Symposium on Geotechnical Engineering of Soft Soils, Mexico City. Vol. 2, pp. 51-87.

Fäh, D., Moore, J.R., Burjanek, J., Iosifescu, I., Dalguer, L., Dupray, F., Michel, C., Woessner, J., Villiger, A., Laue, J., Marschall, I., Gischig, V., Loew, S., Marin, A., Gassner, G., Alvarez, S., Balderer, W., Kästli, P., Giardini, D., losifescu, C., Hurni, L., Lestuzzi, P., Karbasi, A., Baumann, C., Geiger, A., Ferrari, A., Laloui, L., Clinton, J. \& Deichmann, N. (2011) Coupled seismogenic geohazards in Alpine regions. Bollettino di Geofisica Teorica ed Applicata 53(4). pp. 485-508.

Field, E.H., Johnson, P.A., Beresnev, I.A. \& Zeng, Y. (1997) Nonlinear ground-motion amplification by sediments during the 1994 Northridge earthquake. Nature, 390. pp. 599602.

Finn, W.D.L. (1991) Geotechnical engineering aspects of microzonation. Proceedings of the Fourth International Conference on Seismic Zonation, Stanford, California. Vol. 1, pp. 199-259.

Gazetas, G., Kallou, P.V. \& Psarropoulos, P.N. (2002) Topography and soil effects in the Ms 5.9 Parnitha (Athens) earthquake: The case of Adámes. Natural Hazards 27. pp. 133169.

Geli, L., Bard, P.-Y. \& Jullien, B. (1988) The effect of topography on earthquake ground motion: a review and new results. Bulletin of the Seismological Society of America, 78(1). pp. 42-63.

Giardini, D., Wiemer, S., Fäh, D. \& Deichmann, N. (2004) Seismic hazard assessment of Switzerland. Swiss Seismological Service (SED), Zürich.

Hashash, Y.M.A., Groholski, D.R. \& Phillips, C. (2010) Recent advances in non-linear site response analysis. In: Proceedings of the 5th International Conference on Recent 
Advances in Geotechnical Earthquake Engineering and Soil Dynamics. San Diego, California.

Hyde, A.F.L., \& Ward, S.J. (1986) The effect of cyclic loading on the undrained shear strength of a silty clay. Marine Geotechnology, 6(3). pp. 299-314.

Kokusho, T., Yoshida, Y. \& Esashi, Y. (1982) Dynamic properties of soft clay for wide strain range. Soils and Foundations 22(4). pp. 1-18.

Koontz, H. (2016) Global earthquake numbers on par for 2015. Online press release on usgs.gov on 1st of February 2016. U.S. Department of the Interior, U.S. Geological Survey Office of Communications and Publishing. Reston VA, USA.

Mercado, V.M., Zeghal, M., \& Abdoun, T. (2011) Advanced Site Monitoring and Characterization of Site Dynamic Properties. Geo-Frontiers 2011, pp. 1774-1784.

Newmark, N.M. (1965) Effects of earthquakes on dams and embankments. Géotechnique, 15 (2). pp. 139-160.

Okur, D.V. \& Ansal, A. (2007) Stiffness degradation of natural fine grained soils during cyclic loading. Soil Dynamics and Earthquake Engineering, 27 (9). pp. 843-854.

Papalou, A. \& Bielak, J. (2004) Nonlinear seismic response of earth dams with canyon interaction. Journal of Geotechnical and Geoenvironmental Engineering, 130(1). pp. 103110.

Psarropoulos, P.N., Klonaris, G. \& Gazetas, G. (2005) Seismic earth pressures on rigid and flexible retaining walls. Soil Dynamics and Earthquake Engineering, 25. pp. 795-809.

Régnier, J., Cadet, H., Bonilla, L. F., Bertrand, E. \& Semblat J.-F. (2013) Assessing Nonlinear Behavior of Soils in Seismic Site Response: Statistical Analysis on KiK-net StrongMotion Data. Bulletin of the Seismological Society of America, 103(3). pp. 1750-1770.

Roten, D., Fäh, D., Bonilla, L.F., Alvarez-Rubio, S., Weber, T.M. \& Laue, J. (2009) Estimation of non-linear site response in a deep Alpine valley. Geophysical Journal International, 178(3). pp. 1597-1613.

Roten, D., Fäh, D., Olsen, K.B. \& Giardini, D. (2008) A comparison of observed and simulated site response in the Rhone valley. Geophysical Journal International, 173. pp. 958-978.

Seed, H.B. \& Idriss, I.M. (1970) Soil Moduli and Damping Factors for Dynamic Response Analysis. Report No: EERC 70-10, University of California, Berkeley, CA.

SIA 269/8 (2016) Existing structures - Earthquakes. Swiss Society of Engineers and Architects. Zurich

Siyahi, B. \& Arslan, H. (2008) Earthquake induced deformation of earth dams. Bulletin of Engineering Geology and the Environment, 67(3). pp. 397-403. 
Sun, J.I., Golesorkhi, R. \& Seed, H.B. (1988) Dynamic moduli and damping ratios for cohesive soils. Report No. ERC-88/15, Earthquake Engineering Research Center. University of California, Berkeley.

Trifunac, M. D. \& Todorovska, M.I. (1996) Nonlinear soil response - 1994 Northridge, California, earthquake, Journal of Geotechnical Engineering, 122. pp. 725-735.

Wen, K.-L., J.-Y. Huang, C.-T. Chen \& Cheng Y.-W. (2011) Nonlinear site response of the 2010 Darfield, New Zealand, earthquake sequence. In: 4th IASPEI/IAEE International Symposium: Effects of Surface Geology on Seismic Motion, Santa Barbara, California.

Wu, C., Peng, Z. \& Ben-Zion, Y. (2010) Refined thresholds for non-linear ground motion and temporal changes of site response associated with medium-size earthquakes. Geophysical Journal International, 182. pp. 1567-1576.

Yasuhara, K. \& Andersen, K. H. (1989) Effect of cyclic loading on recompression of overconsolidated clay. In: Proceedings of the 12th International Conference on Soil Mechanics and Foundation Engineering, Rio de Janeiro. Volume 1, pp. 485-488.

Yasuhara, K., Murakami, S., Song, B.-W., Yokokawa, S. \& Hyde, A.F.L. (2003) Postcyclic Degradation of Strength and Stiffness for Low Plasticity Silt. Journal of Geotechnical and Geoenvironmental Engineering, 129(8). pp. 756-769.

Zen, K., Umehara, Y. \& Hamada K. (1978) Laboratory tests and in-situ seismic test survey on vibratory shear modulus of clayey soils with different plasticities. In: Proceedings of the Fifth Japan Earthquake Engineering Symposium. 



\title{
2. Aspects of Dynamic Material Behaviour of Alpine Silty Sand
}

\author{
Alexandru Marin \\ ETH Zürich, Institute for Geotechnical Engineering \\ Stefano-Franscini-Platz 5, 8093 Zürich, Switzerland \\ E-mail address: amarin@ethz.ch
}

Thomas M. Weber

Studer Engineering $\mathrm{GmbH}$

Thurgauerstrasse 56, 8050 Zürich, Switzerland

E-mail address: weber@studer-engineering.ch

\section{Jan Laue ${ }^{1}$}

ETH Zürich, Institute for Geotechnical Engineering

Stefano-Franscini-Platz 5, 8093 Zürich, Switzerland

E-mail address: jan.laue@ltu.se

\section{Submitted to Canadian Geotechnical Journal}

Status: under review

\footnotetext{
${ }^{1}$ Appointment of Luleå University of Technology since August 2015 Department of Civil, Environmental and Natural Resources Engineering Mining and Geotechnical Engineering SE-971 87 Luleå, Sweden
} 


\begin{abstract}
Alluvial deposits consisting of alternating layers of granular materials, such as silty sands, are very often encountered in alpine areas, but also on or near the ground surface in areas of meandering rivers elsewhere. Modelling a reliable surface response of a seismic action for design purposes implies a complete investigation of the soil behaviour aiming at two goals given by the requirements of the modelling process. On the one hand, the specific features of the soil behaviour have to be identified and a suitable constitutive model to represent them has to be chosen. On the other one, the parameters required by the constitutive model have to be determined and their mechanical compatibility with the modelled results has to be verified. This paper investigates the silty sand from Visp (canton Valais, Switzerland) to determine the ground motion response in the Rhone Valley. Special attention is given to investigations such as shear wave velocity determinations and triaxial tests which represent a good framework for the characterisation of dynamic soil behaviour.
\end{abstract}

Keywords: silty sand, dynamic behaviour, laboratory investigations, earthquake engineering, alpine environment. 


\subsection{Introduction}

The soil behaviour during an earthquake is complex and depends on the magnitude of the seismic waves. The behaviour is elastic for excitations at small strains and becomes highly non-linear as the strains increase. This non-linearity is usually shown by the decreasing shear stiffness and increasing damping ratio of the soil with the increasing shear strains (Figure 2.1).

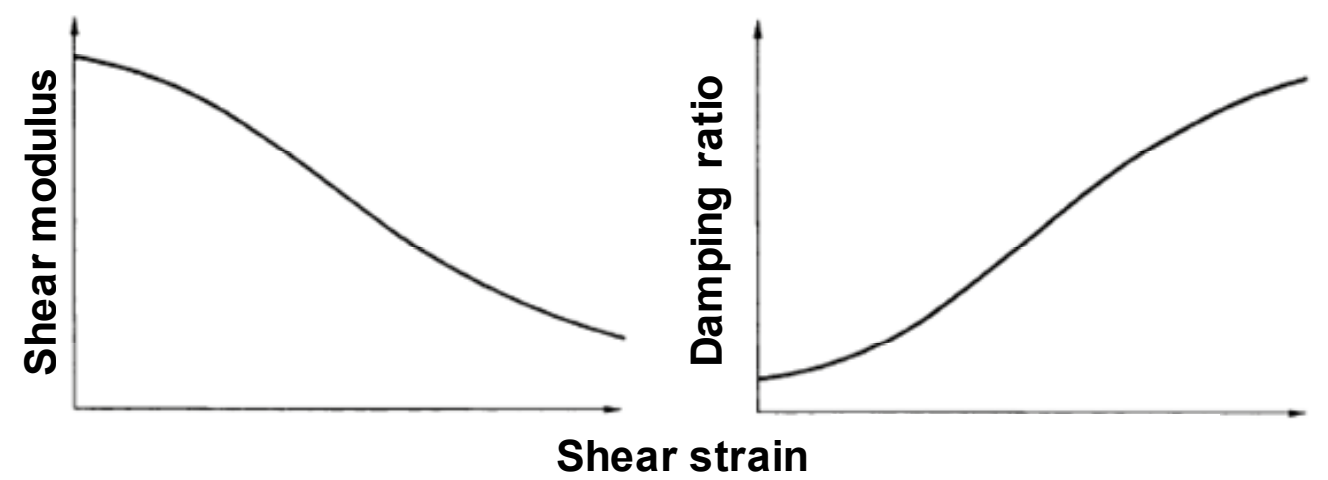

Figure 2.1. Shear modulus reduction curve damping dependence on shear strains (after Studer et al., 2008).

Non-linear soil behaviour can have various effects on the seismic wave propagation, such as: reduced amplification and lower resonance frequencies (Beresnev et al., 1995a; 1995b), extreme amplification of the vertical component (Aoi et al., 2008), or highly frequent horizontal acceleration peaks in saturated dense soil with dilatant behaviour (lai et al., 1995; Archuleta et al., 2000; Kamae et al., 1998). The effects of these mechanisms on seismic amplification usually overlap with complex three dimensional basin effects, which make the exclusive contribution of non-linear behaviour to the seismic action debatable, at least in the case of moderate to strong earthquakes.

Nevertheless, a complete set of laboratory investigations complements available field observations and measurements, and it represents a valuable basis for a sound investigation of such effects. Laboratory investigations are also the basis for numerical simulations aiming to capture non-linear soil behaviour.

This current laboratory investigation begins with the general soil description by means of the grain size distribution and general index parameters. Subsequently, the characterisation of the dynamic behaviour implies the determination of the shear stiffness and its non-linear variation along the relevant range of shear strains. An important element of the characterisation is the analysis of different factors influencing the strength and stiffness parameters of the soil, such as loading history, pore pressure development, etc.

This paper focuses on various laboratory experiments performed to describe the dynamic behaviour of the silty sand from the Visp area in Switzerland thoroughly (Figure 2.2). This 
is an alluvial soil deposited along the Rhone Valley from its source to where it flows in the Lake Geneva. The laboratory investigations were performed in two stages:

- The first stage incorporated extensive laboratory testing carried out within the framework of the research project Earthquake Shaking in Alpine Valleys (SHAKEVAL) (Roten et al. 2005; 2008, Weber et al. 2007) conducted at ETH Zurich by the Institute for Geotechnical Engineering (IGT) and the Swiss Seismological Service (SED). The tests were performed at IGT using silty sand samples obtained from a construction site at the train station in Visp. The main purpose of the project was to identify the seismic response of narrow alpine valleys filled with sediments and to derive the input parameters of a complex constitutive model for the cyclic mobility of soil (lai et al., 1990; lai et al., 1993, Bonilla et al., 2000, Roten et al., 2009).

- The second stage consisted of laboratory investigations performed on a sieved fraction of the silty sand from Visp ( $d<0.5 \mathrm{~mm}$ ) (Geiser, 2013; Scheiwiller, 2013; Fatzer, 2014). The reason for investigating this material fraction is its frequent occurrence in the local alpine geology in the shape of entire layers or localised lenses. The investigations studied influencing parameters of the maximum shear stiffness, effects of the loading history on the soil behaviour, and pore pressure development during cyclic loading.

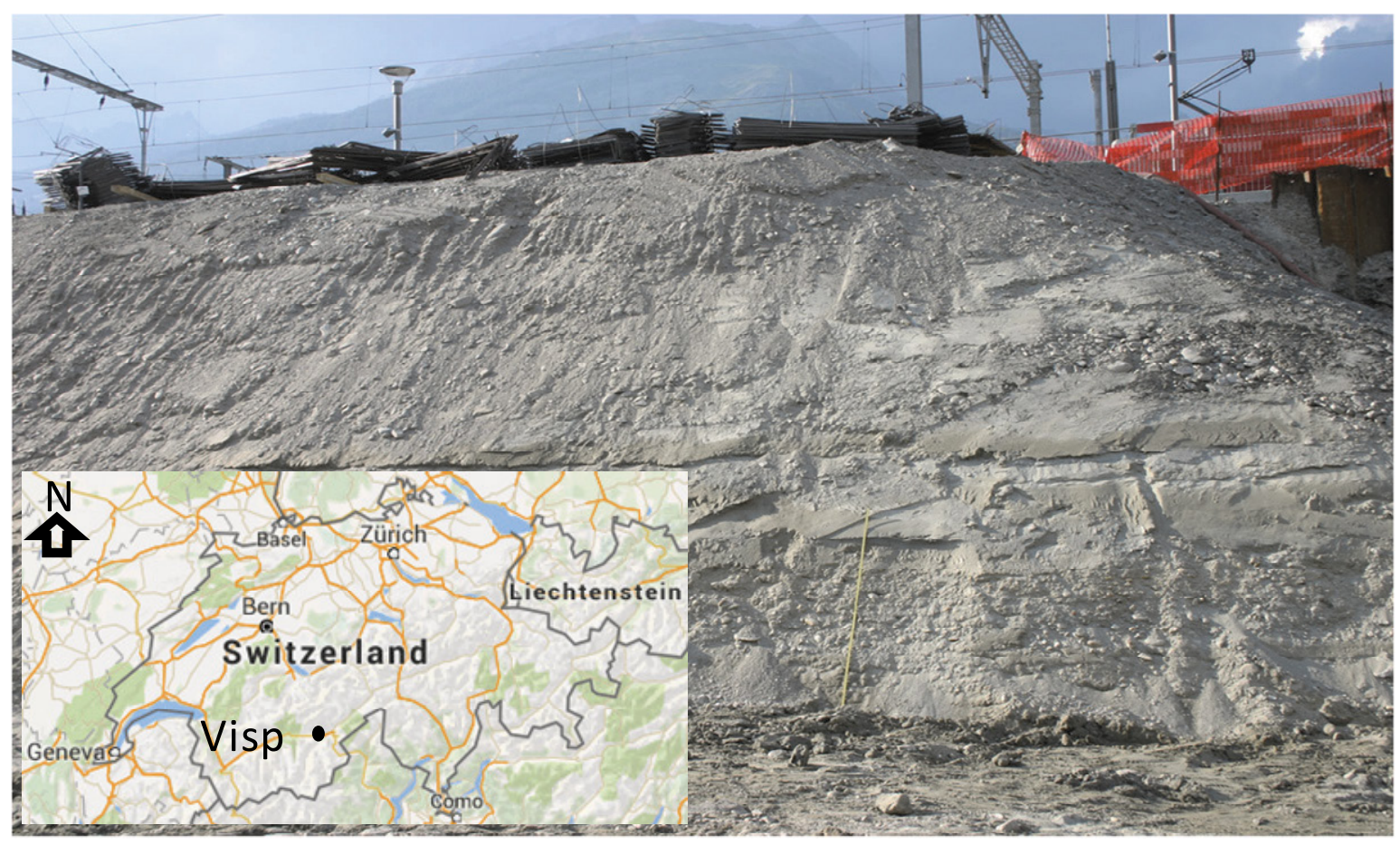

Figure 2.2. Alternating layers of silty sand and gravel layers in the Visp area (after Weber et al., 2007). 


\subsection{First stage of laboratory testing}

\subsubsection{General material description}

The soil obtained from Visp was classified as SP-SM (silty sand) according to USCS, based on the sieve analysis performed by Weber et al. (2007) (Figure 2.3).

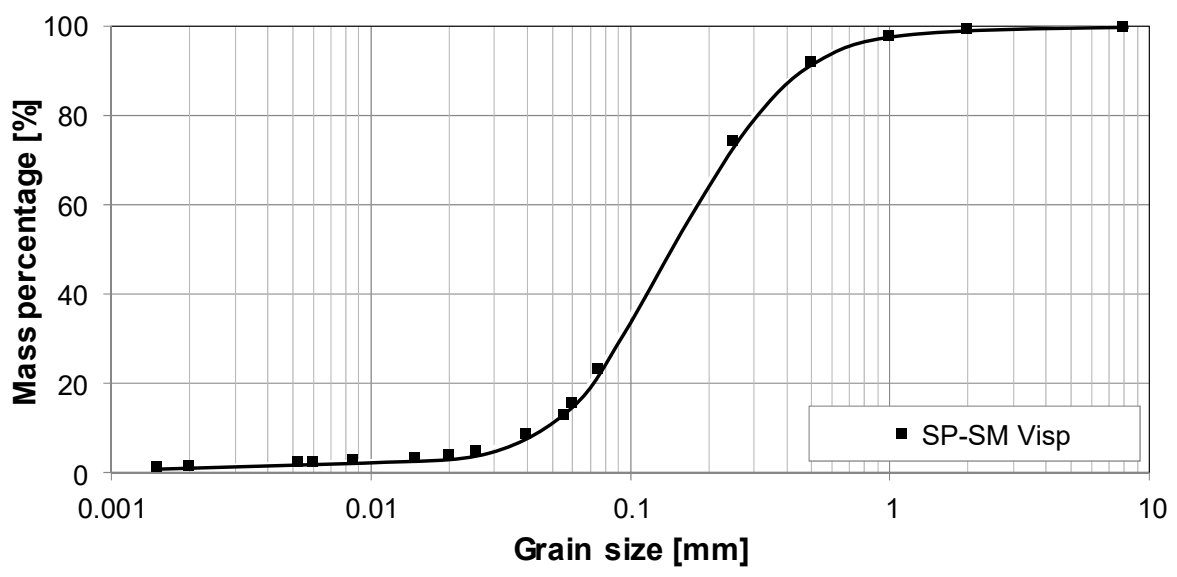

Figure 2.3. Grain size distribution of the SP-SM Visp sand (after Weber et al., 2007).

The minimum density of the SP-SM Visp sand $\rho_{\mathrm{d}, \min }=1.30 \mathrm{~g} / \mathrm{cm}^{3}$ was determined using the standard method A according to the ASTM 4254 (2006), while the maximum density $\rho_{\mathrm{d}, \max }=1.72 \mathrm{~g} / \mathrm{cm}^{3}$ was obtained using the method 1B (ASTM 4253 2006). The specific density of the soil grains, determined using a helium pycnometer, is $\rho_{\mathrm{s}}=2.80 \mathrm{~g} / \mathrm{cm}^{3}$.

Standard axial compression tests were performed on specimens with relative densities between 35-62\%. There was no cohesion between the particles of the investigated soil. The maximum friction angle $\varphi^{\prime}{ }_{\max }=37.4^{\circ}\left(\varepsilon_{\text {axial }} \approx 15-20 \%\right)$ and the value at constant volume $\varphi_{\mathrm{cv}}^{\prime}=35.7^{\circ}\left(\varepsilon_{\text {axial }}=25 \%\right)$ were determined using the gradient values of the critical state lines 1.52 and 1.44, respectively, shown in Figure 2.4 and relationship (2.1).

$$
M=\frac{6 \sin \phi^{\prime}}{3-\sin \phi^{\prime}}
$$

where $\mathrm{M}$ - gradient of the critical state line.

$$
\varphi^{\prime}-\text { soil friction angle. }
$$




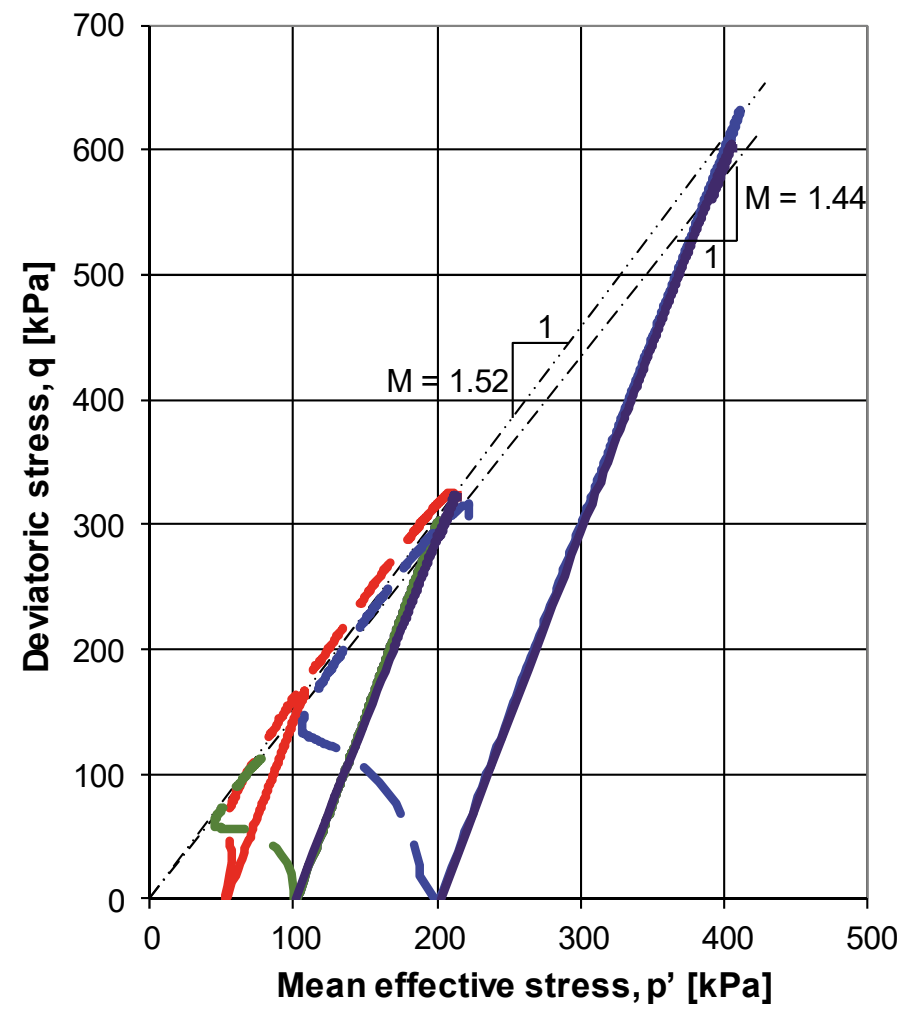

Figure 2.4. Stress paths for drained CD (solid lines) and undrained (CU) triaxial compression tests (after Weber et al., 2007).

\subsubsection{Cyclic behaviour of the silty sand in Visp}

The cyclic behaviour of the SP-SM Visp sand was investigated within the SHAKE-VAL project in terms of pore pressure development. Quasi-static undrained cyclic triaxial test were performed using fully saturated reconstituted samples that were subsequently isotropically consolidated. The samples were cyclically loaded with constant amplitude of deviator stress, until $5 \%$ peak to peak deviatoric strain was reached. The cell pressure was kept constant during testing. Figure 2.5 shows a typical set of results from a cyclic loading test: the stress path of the test in the q-p' diagram (Figure 2.5a) and the pore pressure development during cyclic loading (Figure 2.5b). The tested sample with a relative density $D_{D}=38 \%$, close to that determined from field measurements, was placed under a cell pressure of $100 \mathrm{kPa}$ and subsequently loaded by $\Delta \mathrm{q}= \pm 12.5 \mathrm{kPa}$. A loading function symmetric to $\mathrm{q}=0 \mathrm{kPa}$ was not possible due to limitations of the testing device. The peak to peak deviatoric strain of $5 \%$ was reached after 35 cycles, when, due to the pore pressure increase, the mean effective stress significantly decreased and the sample entered the cyclic mobility state. 

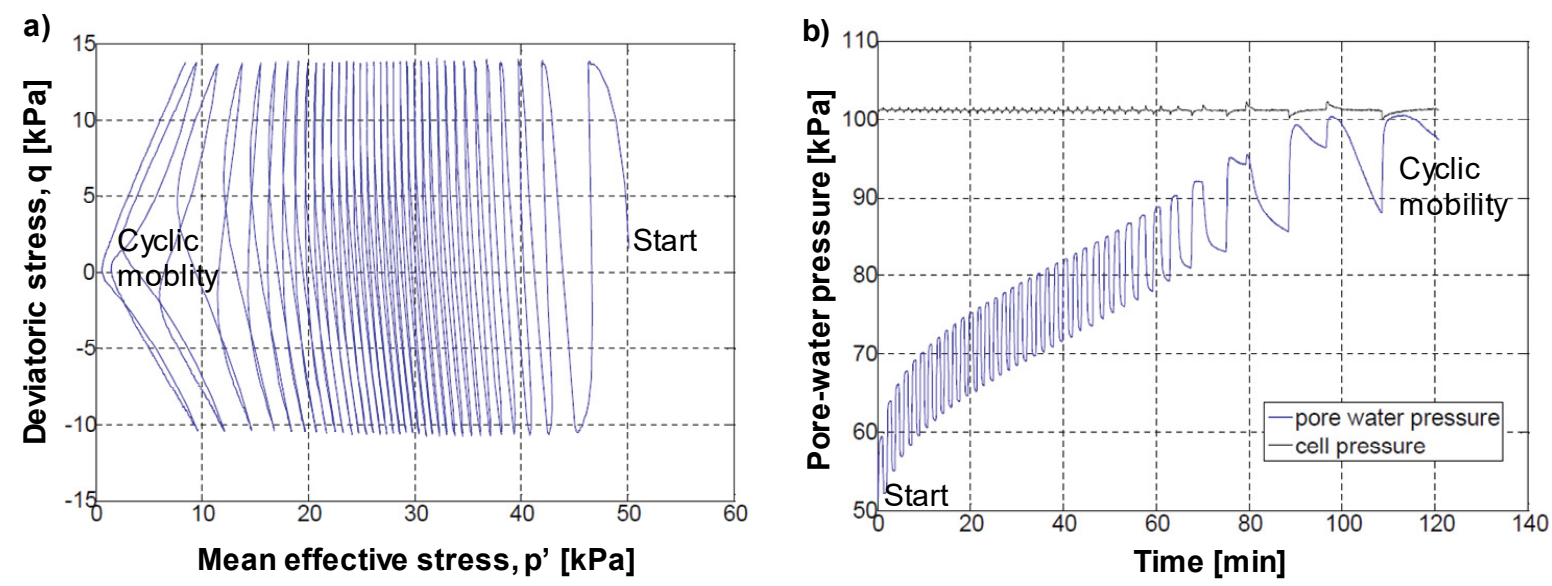

Figure 2.5. Undrained triaxial cyclic test on SP-SM Visp sand: a) stress path and b) pore pressure development (after Weber et al., 2007).

Figure 2.6 contains shear modulus reduction curves and damping values depending on shear strain determined from six triaxial compression and three resonant column tests. These results are very important since they are used as input parameters in linearequivalents analyses of the local seismic amplification.
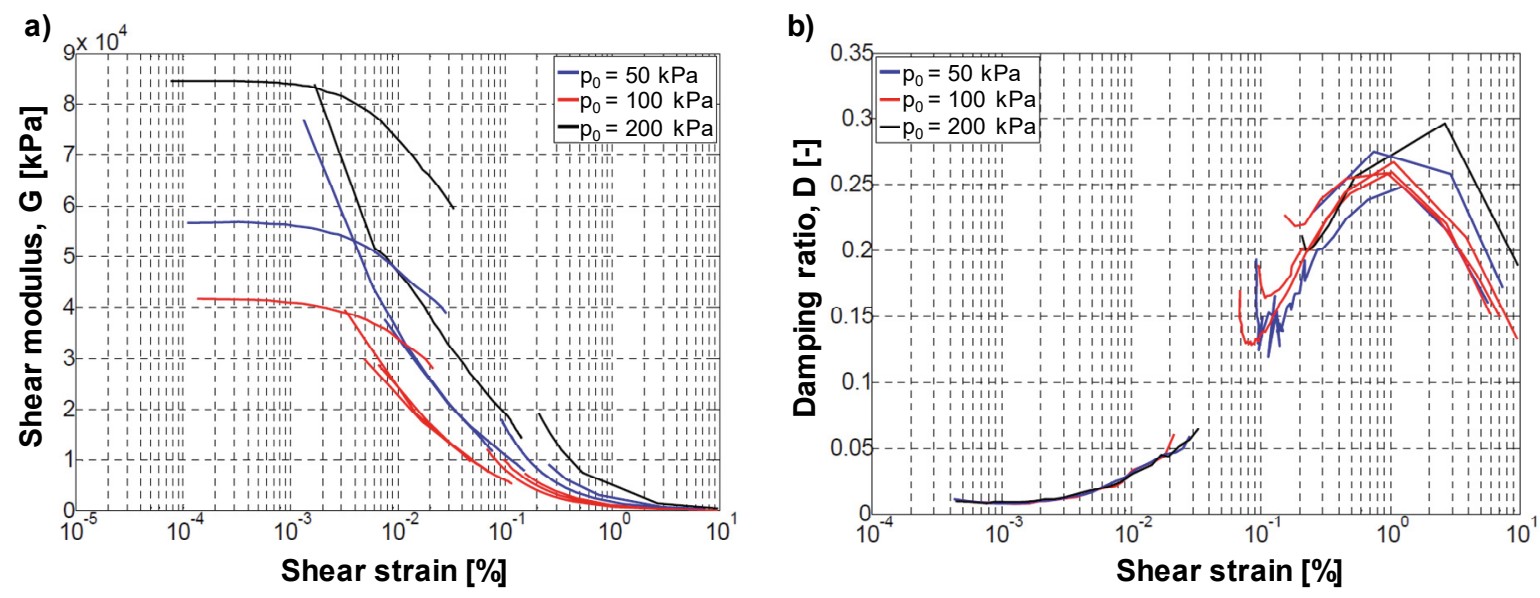

Figure 2.6. Results from triaxial compression and resonant column tests on reconstituted SP-SM Visp sand: a) shear modulus reduction curves and b) damping ratio depending on shear strain (Weber et al., 2007).

\subsection{Second stage of laboratory testing}

\subsubsection{General aspects}

The finer fraction $(\mathrm{d}<0.5 \mathrm{~mm}$ ) of the SP-SM Visp sand was sieved (92\% of the entire mass) and used in the second stage of laboratory testing. The soil was classified as SM, and its grain size distribution is shown in Figure 2.7. The angular and sub-angular shape of the soil particles can be seen in Figure 2.8. 


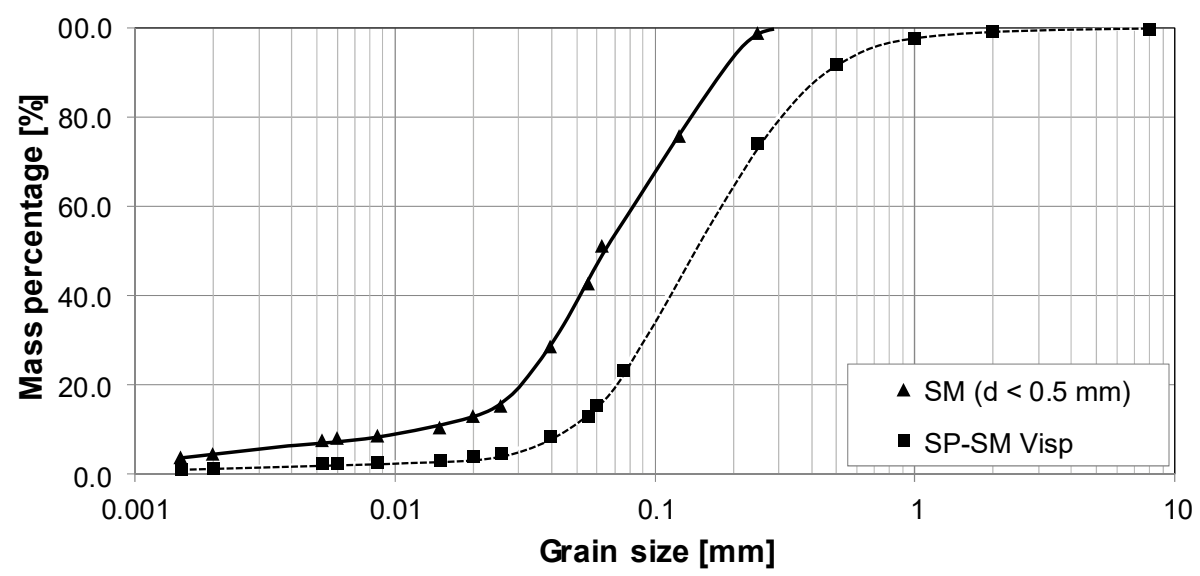

Figure 2.7. Grain size distribution of the SM Visp silty sand $(\mathrm{d}<0.5 \mathrm{~mm})$.

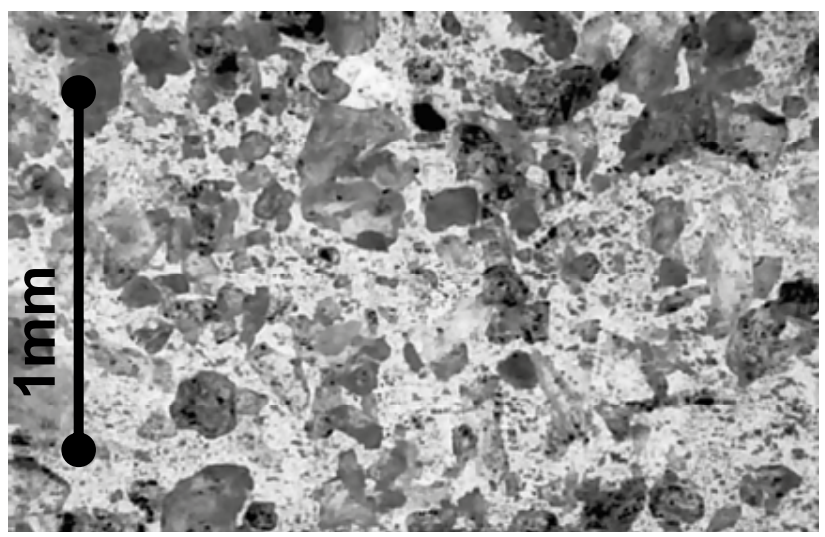

Figure 2.8. Shape of the soil particles for the SM Visp silty sand $(\mathrm{d}<0.5 \mathrm{~mm})$.

\subsubsection{Maximum shear stiffness determination}

The maximum value of the shear modulus $G_{\max }$ represents a key parameter in seismic analyses related to earthquake amplification and soil-structure interaction. The determination of this value, usually associated with small shear strains in the range of $0.001 \%$, is based on resonant column tests or bender element measurements. The first measurements, obtained using bender elements with clay and sand specimens, were performed in the triaxial shear device by Lawrence $(1963 ; 1965)$ and more recent advances were presented by e.g. Viggiani \& Atkinson (1995), Mohsin \& Airey (2003) or Bonal et al. (2012). The concept, however, has remained more or less the same since then. Shear waves are transmitted through a soil specimen subjected to different confining pressures, and the travel time of the waves is determined. The shear wave velocity is calculated by assuming that the height of the soil specimen is also the travel length of the shear waves. The shear wave velocity is then proportional to the shear stiffness of the soil (Timoshenko \& Goodier, 1951):

$$
\mathrm{G}=\mathrm{v}_{\mathrm{s}}^{2} \cdot \rho
$$

where $v_{s}-$ shear wave velocity $[\mathrm{m} / \mathrm{s}]$

$$
\rho-\text { soil density }\left[\mathrm{kg} / \mathrm{m}^{3}\right] \text {. }
$$


Geiser (2013) used a triaxial device with bender elements installed on the base and top plates. He prepared reconstituted specimens using the SM Visp silty sand ( $d<0.5 \mathrm{~mm}$ ), with relative densities between $D_{D}=14-95 \%$. The very loose specimen was obtained by water pluviation and the very dense one by dry compaction. Two kinds of measurements were performed: initially the shear wave velocity was determined for different levels of confining stress, by increasing the pressure in the triaxial cell; subsequently, measurements were performed during shearing of the soil specimen (axial compression) to identify the eventual influence of developing shear bands. The overview of the tests performed can be found in Table 2.1 .

Table 2.1. Overview of the bender element tests performed on SM Visp silty sand $(\mathrm{d}<0.5 \mathrm{~mm})$.

\begin{tabular}{|c|c|c|c|}
\hline Test & Initial relative density $D_{D}$ & Initial conditions & Comments \\
\hline Test 1 & $82 \%$ & $\begin{array}{c}\mathrm{p}_{0}^{\prime}=25.2 \mathrm{kPa} \\
\mathrm{q}_{0}=0 \mathrm{kPa}\end{array}$ & $\begin{array}{l}\text { Isotropically consolidated, } \\
\text { drained increase of the } \\
\text { confining stress }\end{array}$ \\
\hline Test 2 & $14 \%$ & $\begin{array}{c}\mathrm{p}_{0}^{\prime}=33 \mathrm{kPa} \\
\mathrm{q}_{0}=29.4 \mathrm{kPa}\end{array}$ & $\begin{array}{l}\mathrm{K}_{0} \text {-consolidated, undrained } \\
\text { static axial compression }\end{array}$ \\
\hline Test 3 & $95 \%$ & $\begin{array}{l}\mathrm{p}_{0}^{\prime}=35 \mathrm{kPa} ; \\
\mathrm{q}_{0}=21.2 \mathrm{kPa}\end{array}$ & $\begin{array}{c}\mathrm{K}_{0} \text {-consolidated, drained } \\
\text { increase of the confining } \\
\text { stress }\end{array}$ \\
\hline
\end{tabular}

The results of the different tests were compared with the relationship determined by Weber et al. (2007) for the loose to medium dense SP-SM Visp sand.

$$
\mathrm{G}=\mathrm{v}_{\mathrm{s}}{ }^{2} \cdot \rho=280 \cdot\left(\mathrm{p}^{\prime}+100 \mathrm{kPa}\right)
$$

where $v_{s}-$ shear wave velocity $[\mathrm{m} / \mathrm{s}]$

$$
\begin{aligned}
& \mathrm{G} \text { - shear modulus }[\mathrm{kPa}] \\
& \rho-\text { soil density }\left[\mathrm{g} / \mathrm{cm}^{3}\right] \\
& \mathrm{p} \text { '- mean effective stress }[\mathrm{kPa}] .
\end{aligned}
$$

This relationship (2.3) is based on bender element measurements performed after the isotropic consolidation step under initial conditions ( $p^{\prime}=50,100$, and $150 \mathrm{kPa}$ ), before the axial compression of the soil specimens.

Additionally, the curve suggested by Seed \& Idriss (1970) for the stress dependency of the shear modulus was also used to validate the consistency of the data: 
$\mathrm{G}=\mathrm{v}_{\mathrm{s}}{ }^{2} \cdot \boldsymbol{\rho}=220 \cdot \mathrm{K}_{2} \cdot \sqrt{\sigma_{\mathrm{m}}{ }^{\prime}}$

where $\mathrm{K}_{2}$ - coefficient for the influence of the void ratio and strain amplitude

$\sigma_{m}^{\prime}=p^{\prime}-$ mean effective stress $[\mathrm{kPa}]$.

The shear wave velocities vary between $150-550 \mathrm{~m} / \mathrm{s}$ depending on the mean effective stress. The relationship suggested by Seed and Idriss (1970) fits well with the measured values, but tends to provide lower values in the range of high average stresses (Figure 2.9). The values also correlate with the shear wave velocity profiles determined by Burjanek et al. (2011) using ambient noise measurements in the Visp area.

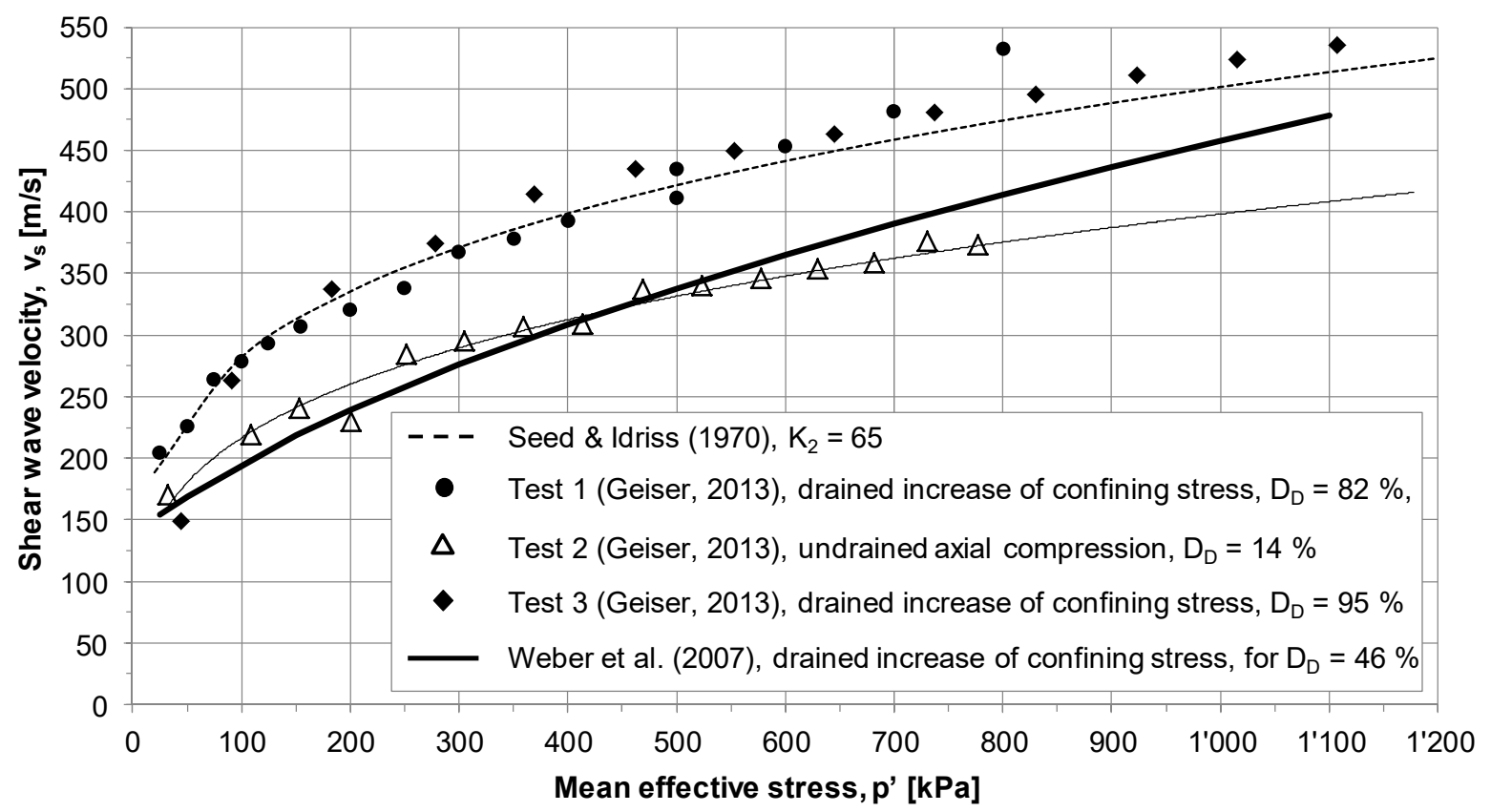

Figure 2.9. Results of the bender element measurements on SM Visp silty sand ( $<<0.5 \mathrm{~mm})$.

The shear wave velocities measured by Geiser (2013) during Test 2 are comparable with the regression curve suggested by Weber et al. (2007) that was developed for loose to medium dense SP-SM Visp sand. For higher mean effective stresses ( $p^{\prime}>600 \mathrm{kPa}$ ) the values measured by Geiser are lower than the regression suggested by Weber. This can be a hint about the influence of shear bands, which started to form towards the end of the axial compression test. However, clear evidence of this effect could not be found, since the relationship suggested by Weber was developed based on measurements at lower mean effective stresses $\left(p^{\prime}=50-200 \mathrm{kPa}\right)$.

Tests 1 and 3 , in which the specimens were subjected to an increase of the confining stress, show very similar results, despite the differences related to consolidation conditions. The soil specimen in Test 1 was isotropically consolidated, while that from Test 3 was consolidated under $\mathrm{K}_{0}$ conditions. Nevertheless, the results of the two tests are in same range, due to the similar relative densities of the specimens, and fit with the relationship provided by Seed \& Idriss (1970) for $\mathrm{K}_{2}=65$. 


\subsubsection{Influence of the loading history on the stiffness and strength parameters}

The effect of the loading history on the stiffness and strength parameters should not be neglected in the process of modelling situations of subsequent events recurring during short time intervals (e.g. an earthquake and its aftershocks). Previous investigations on similar soils subjected to undrained cyclic loading showed a reduction of the post-cyclic shear strength (Hyde \& Ward, 1986) and shear modulus (Dobry \& Vucetic, 1987; Matsui et al., 1980).

A series of laboratory investigations were performed by Scheiwiller (2013) to analyse the effects of a uniform cyclic loading on the post-cyclic strength and stiffness of the soil. A hybrid loading scenario, involving a sequence of static and dynamic loading was used to investigate these effects.

The following loading stages were conducted in each hybrid test (Figure 2.10):

- Consolidation under $\mathrm{K}_{0}$ conditions (Step 1).

- Strain-controlled static axial compression to $\varepsilon_{\text {axial }}=1 \%$ (Step 2).

- Force-controlled cyclic axial loading by applying 40 cycles of constant amplitude $q$ $= \pm 40 \mathrm{kPa}$ (Step 3).

- Strain-controlled static axial compression to $\varepsilon_{\text {axial }}=20 \%$ (Step 4).

This set up provided the appropriate boundary conditions for the identification of the different effects of the cyclic loading on the soil behaviour. The differences between the results of the hybrid and static testing were closely analysed.

The overview of the tests performed using a cyclic triaxial device on dry samples is given in Table 2.2.

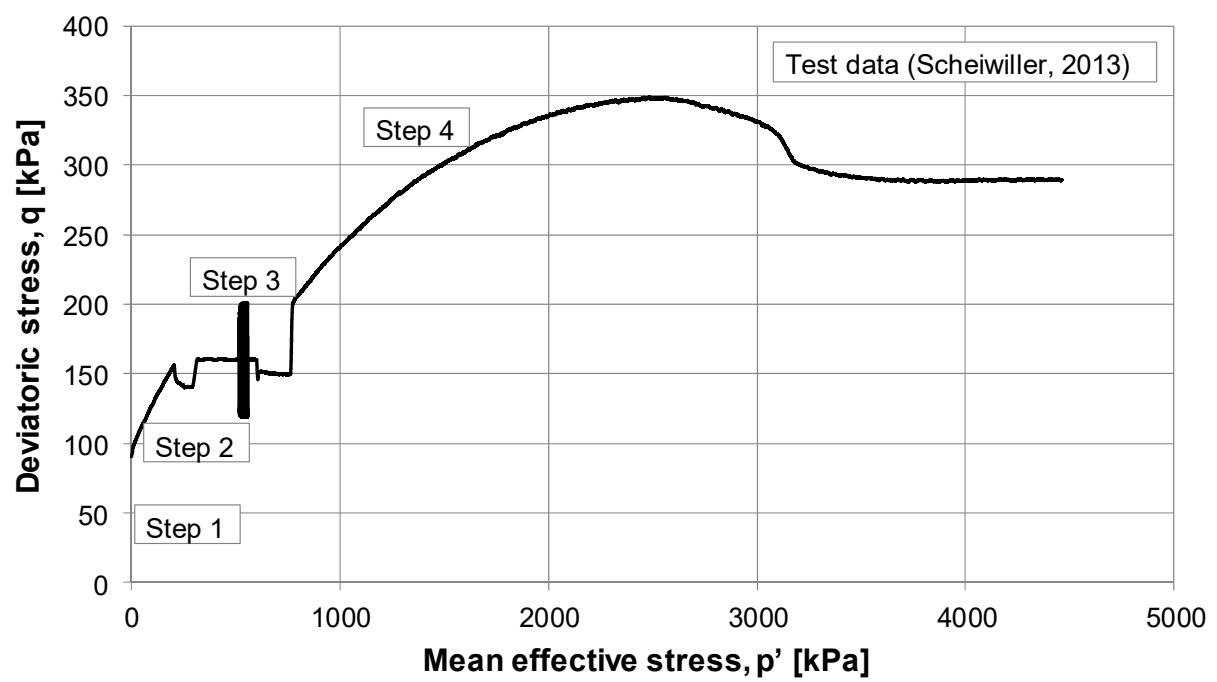

Figure 2.10. Generic stress path in the time domain of the hybrid triaxial test in axial compression on SM Visp silty sand (d $<0.5 \mathrm{~mm})$ (after Scheiwiller, 2013). 
Table 2.2. Overview of the compared tests on SM Visp silty sand (d $<0.5 \mathrm{~mm}$ ).

\begin{tabular}{lccc}
\hline Test & Relative density $\mathbf{D}_{\mathrm{D}}$ & Initial conditions & Comments \\
\hline Test 4 (hybrid) & $79 \%$ & $\mathrm{p}^{\prime}=90.3 \mathrm{kPa}$ & $\begin{array}{c}\mathrm{K}_{0} \text {-consolidated, drained } \\
\text { hybrid triaxial test in axial } \\
\end{array}$ \\
& $\mathrm{q}=82.1 \mathrm{kPa}$ & $\begin{array}{l}\text { compression, intermediate } \\
\text { cyclic loading } \mathrm{q}= \pm 40 \mathrm{kPa}\end{array}$ \\
& & & \\
Test 5 (static) & $81 \%$ & $\mathrm{p}^{\prime}=91.0 \mathrm{kPa}$ & $\begin{array}{l}\text { Ko-consolidated, drained } \\
\text { static axial compression }\end{array}$ \\
\hline
\end{tabular}

A first effect of the cyclic loading on the soil behaviour noted in the literature is the reduction of the maximum deviatoric stress (Yasuhara et al., 2003). The dynamic loading cycles cause crushing of some of the soil particles and lead to a reduction of dilatancy (Bolton, 1986). The reduced dilatancy is then directly related to a reduced value of the maximum friction angle and a reduced maximum deviatoric stress. In other words, the dilatant potential of the soil is reduced by the effects of the cyclic loading, and the postcyclic maximum static strength is therefore lower. In this regard, the strength parameters have to be carefully assessed in situations when a certain sequence of hazards is analysed (i.e. seismic aftershocks).

During Test 5 (static) a maximum value of deviatoric stress of $370 \mathrm{kPa}$ was obtained, while during Test 4 (hybrid) a slightly smaller value of $350 \mathrm{kPa}$ was reached. These values correspond to maximum friction angles of $48.2^{\circ}$ for the static case, and $47.3^{\circ}$ for the hybrid one. A reduction of the deviatoric stress of $5 \%$ corresponds to a reduction of the maximum mobilised friction angle of just $1^{\circ}$. Under these circumstances, it can be assumed that the influence on the maximum strength parameters is marginal. However, the softening of the soil was observed to occur more rapidly due to cyclic loading and the strain range, where dilatancy is available, is smaller.

As a conclusion, for the SM Visp silty sand $(d<0.5 \mathrm{~mm})$, the reduction of the strength parameters caused by previous loading can be neglected when considering subsequent hazards such as an earthquake aftershock. Nevertheless the reduction of the strain range where dilatancy is available has to be taken into account (Figure 2.11). 


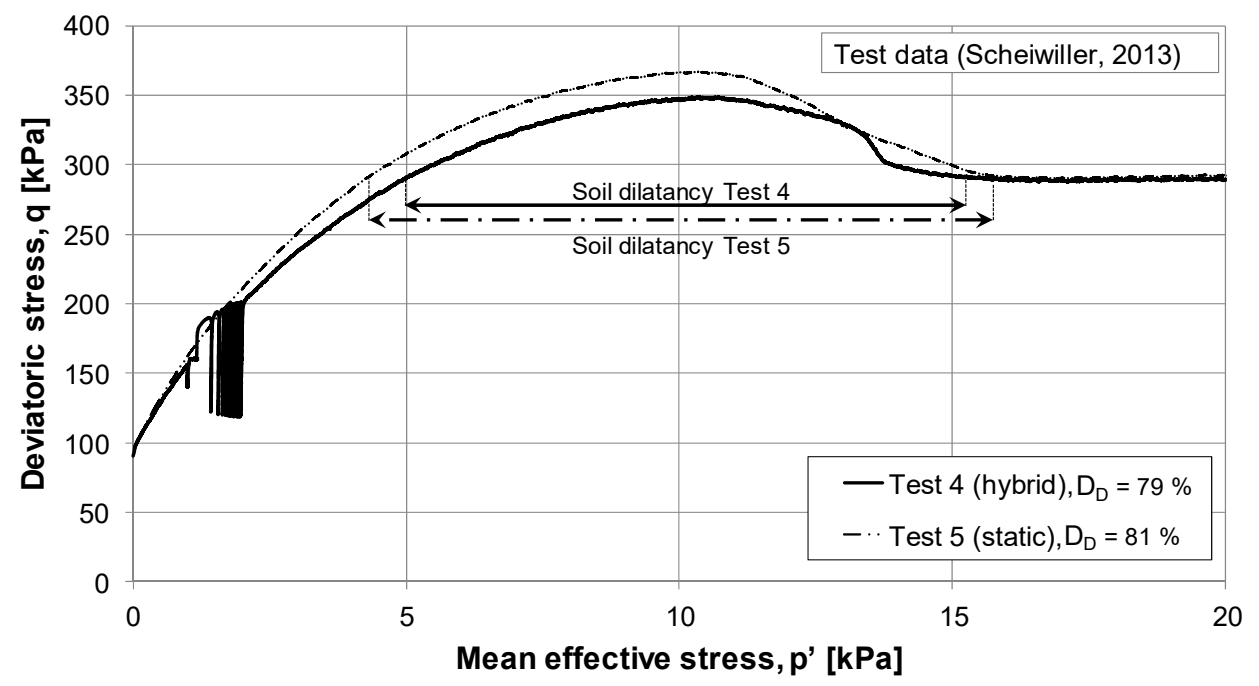

Figure 2.11. Typical results of the static and hybrid drained triaxial tests on SM Visp silty sand $(\mathrm{d}<0.5 \mathrm{~mm})$.

The other effect of cyclic loading investigated was the change of stiffness. Unless a pore pressure increase takes place, the post-cyclic stiffness is expected to be higher through the densification of the soil fabric. The values of the axial stiffness $E$ (Young's Modulus) were measured during the hybrid loading tests before cyclic loading, at the beginning of the first static loading stage (Step 2 - Figure 2.10) and after cyclic loading, at the beginning of the second static loading stage (Step 4 - Figure 2.10).

Typical results are presented in Figures 2.12 and 2.13. The scattered points represent raw measurements from the data-logger, and the curves represent the average regression, together with the upper and lower bounds. The stiffness determinations at small strains were made graphically by calculating the slope of the tangent to the average regression.

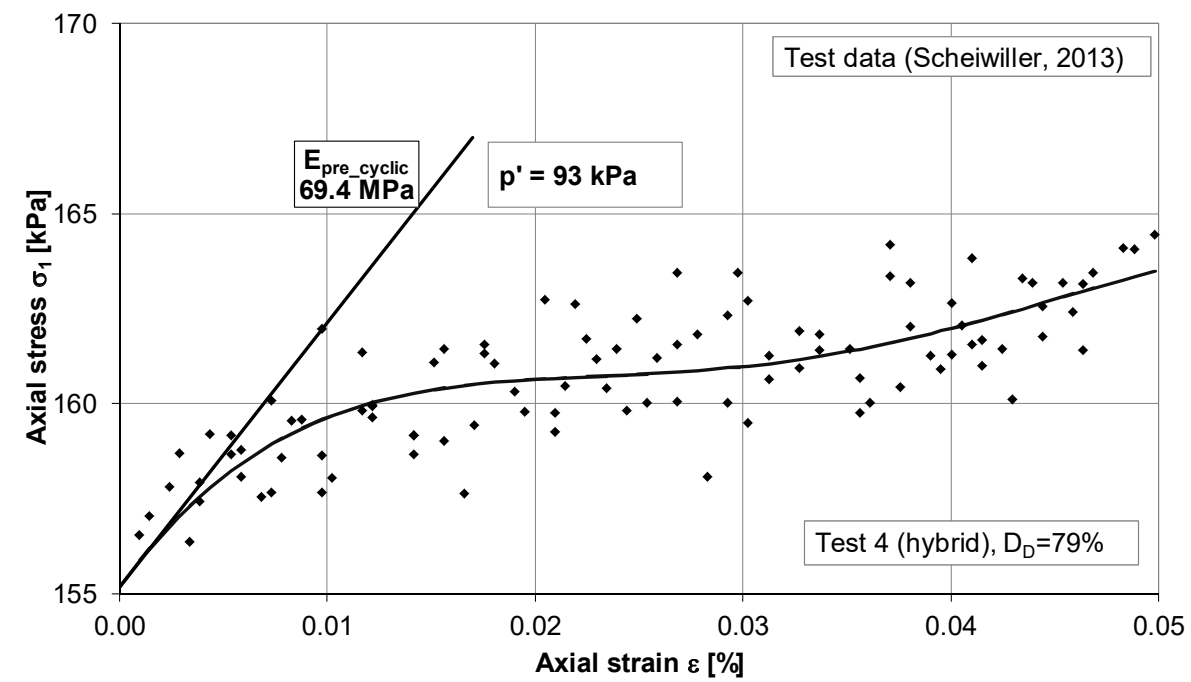

Figure 2.12. Determination of the pre-cyclic axial stiffness (Step 2 in Figure 2.10) on SM Visp silty sand $(\mathrm{d}<0.5 \mathrm{~mm})$. 


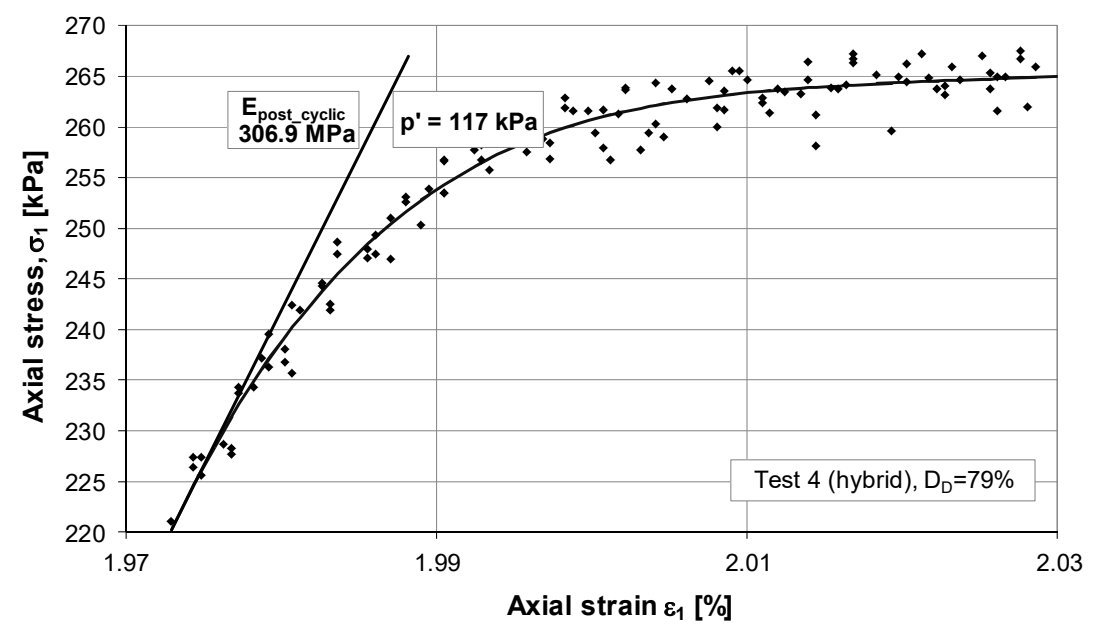

Figure 2.13. Determination of the post-cyclic axial stiffness (Step 4 in Figure 2.10) on SM Visp silty sand $(\mathrm{d}<0.5 \mathrm{~mm})$.

An increase of the E-Modulus by a factor of 4 can be observed by summarizing the results of Test 4 (hybrid) presented in the diagrams above. In terms of shear wave velocities, the pre-cyclic axial stiffness of $E_{\text {pre_cyclic }}=69.4 \mathrm{MPa}$ corresponds to a shear wave velocity of $v_{\text {s_pre_cyclic }}=130 \mathrm{~m} / \mathrm{s}$, whereas the value increases to $v_{\text {s_post_cyclic }}=270 \mathrm{~m} / \mathrm{s}$ after the cyclic loading. The densification of the soil fabric during cyclic loading has a strong influence on the shear wave velocity.

\subsubsection{Influence of the pore pressure increase on the stiffness and strength parameters}

The evolution of pore pressure during and after cyclic loading was investigated as well (Fatzer 2013). Similar studies performed by De Alba et al. (1976), Seed \& Booker (1977) or Egglezos \& Bouckovalas (1998) analysed the development of dynamic pore pressure and suggested analytical relationships for its dependency on the number of loading cycles.

The loading scenarios used by Fatzer (2013) partially overlapped with those assumed by Scheiwiller (2013), and were completed by new approaches. Initially, a set of staticdynamic-static hybrid tests were performed, as described before (see Figure 2.10), with fully saturated samples under undrained conditions (Figure 2.14):

- $\mathrm{K}_{0}$ consolidation

- Strain-controlled axial compression to $\varepsilon_{a x i a l}=1 \%($ Step 1$)$

- Force-controlled cyclic loading by applying two sets of 40 cycles of constant amplitude of $q= \pm 10 \mathrm{kPa}$ and $\mathrm{q}= \pm 20 \mathrm{kPa}$ (Steps 2 and 3)

- Strain-controlled axial compression to $\varepsilon_{\text {axial }}=25 \%$ (Step 4).

An overview of the static-dynamic-static hybrid tests performed can be seen in Table 2.3. 
Table 2.3. Overview of the performed static-dynamic-static hybrid tests on SM Visp silty sand $(\mathrm{d}<0.5 \mathrm{~mm})$.

\begin{tabular}{|c|c|c|c|c|}
\hline Test & $\begin{array}{c}\text { B-Value } \\
{[-]} \\
\end{array}$ & $\begin{array}{l}\text { Relative density } \\
D_{D} \\
\end{array}$ & $\begin{array}{c}\text { Initial } \\
\text { conditions } \\
\end{array}$ & Comments \\
\hline Test 6 & 0.95 & $55 \%$ & $\begin{array}{c}p^{\prime}=107.8 \mathrm{kPa} \\
q=0 \mathrm{kPa}\end{array}$ & $\begin{array}{l}\text { All tests: } \\
\text { - Isotropic consolidation }\end{array}$ \\
\hline Test 7 & 0.98 & $62 \%$ & $\begin{array}{c}p^{\prime}=105.5 \mathrm{kPa} \\
q=0 \mathrm{kPa}\end{array}$ & $\begin{array}{l}\text { - undrained axial compression } \\
\text { to } \varepsilon_{\text {axial }}=1 \%\end{array}$ \\
\hline Test 8 & 0.97 & $69 \%$ & $\begin{array}{c}p^{\prime}=107.1 \mathrm{kPa} \\
q=0 \mathrm{kPa}\end{array}$ & $\begin{array}{l}\text { - undrained cyclic axial } \\
\text { loading: } 40 \text { cycles of } q= \pm \\
10 \mathrm{kPa} \text { and } \mathrm{q}= \pm 20 \mathrm{kPa}\end{array}$ \\
\hline Test 9 & 0.97 & $76 \%$ & $\begin{array}{c}p^{\prime}=107.2 \mathrm{kPa} \\
q=0 \mathrm{kPa}\end{array}$ & $\begin{array}{l}\text { - undrained axial compression } \\
\text { to } \varepsilon_{\text {axial }}=25 \%\end{array}$ \\
\hline
\end{tabular}

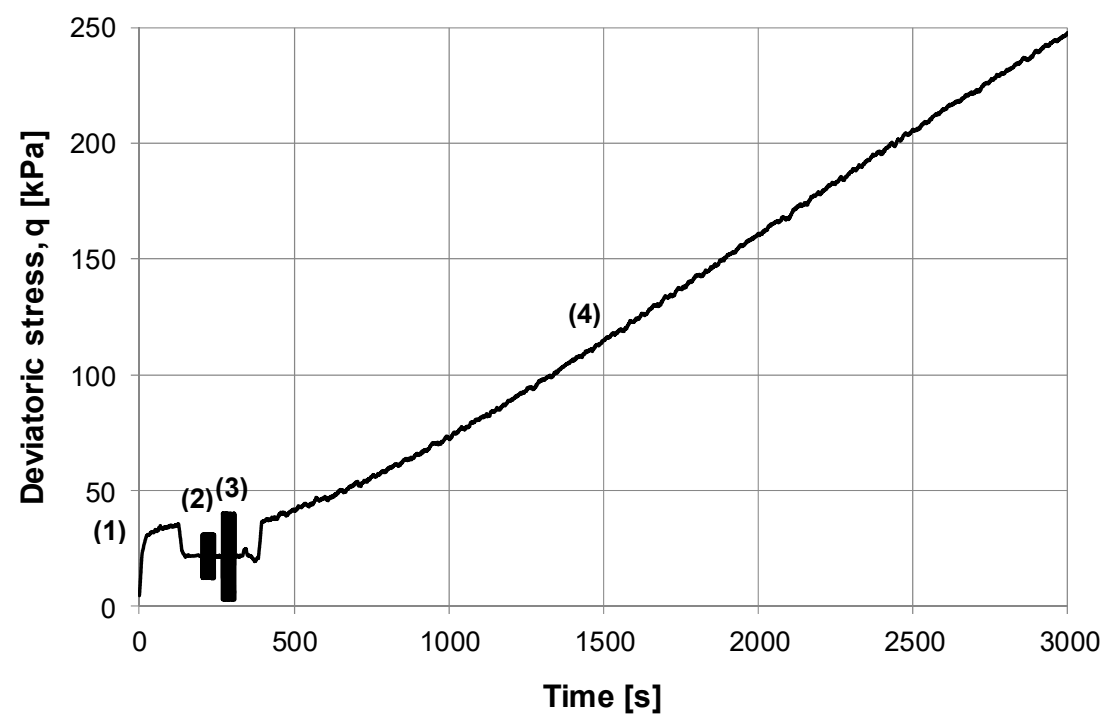

Figure 2.14. Generic stress path in time domain of the hybrid tests on SM Visp silty sand $(\mathrm{d}<0.5 \mathrm{~mm})$. 
The development of excess pore pressure expressed with the ratio $r_{u}=\Delta u / \sigma_{c}$ can be plotted against the axial strain. An increase of the pore pressure to $50 \%$ of the confining pressure was observed during the initial static axial compression. The cyclic loading induced an additional increase to $70 \%$ of the confining pressure, and from this level all samples exhibited a dilatant behaviour during the second static axial compression stage, associated with a drop of the pore pressure. A graphical representation of the test results for the hybrid tests can be seen in Figure 2.15.

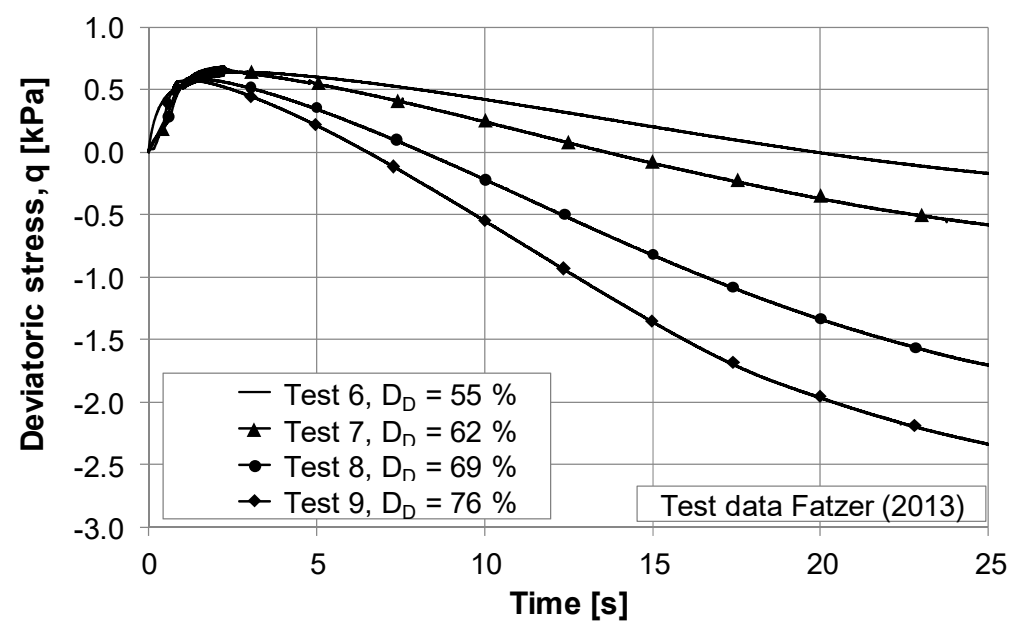

Figure 2.15. Development of pore pressure during the static-dynamic-static hybrid tests on SM Visp silty sand $(\mathrm{d}<0.5 \mathrm{~mm})$.

Subsequently, dynamic tests were performed in which an intermediate release of the pore pressure in the sample was included (Figure 2.16):

- Isotropic consolidation.

- Force-controlled cyclic axial loading by applying two sets of 40 cycles of constant amplitude $(\mathrm{q}= \pm 20 \mathrm{kPa}$ and $\mathrm{q}= \pm 30 \mathrm{kPa}$ ) (Steps 1 and 2).

- Release of $50 \%$ of the accumulated excess pore pressure (Step 3).

- Force-controlled cyclic axial loading by applying sets of 40 cycles of constant amplitude starting with $\mathrm{q}= \pm 30 \mathrm{kPa}$ and increasing it stepwise until failure is reached (Steps 4-8).

An overview of the performed dynamic tests can be seen in Table 2.4. 
Table 2.4. Overview of the performed dynamic tests on SM Visp silty sand (d $<0.5 \mathrm{~mm}$ ).

\begin{tabular}{|c|c|c|c|c|}
\hline Test & $\begin{array}{c}\text { B-Value } \\
{[-]}\end{array}$ & $\begin{array}{c}\text { Relative density } \\
D_{D}\end{array}$ & $\begin{array}{c}\text { Consolidation } \\
\text { Pressure }\end{array}$ & Comments \\
\hline Test 10 & 0.95 & $57 \%$ & $\begin{array}{c}p^{\prime}=98.8 \mathrm{kPa} \\
q=0 \mathrm{kPa}\end{array}$ & $\begin{array}{l}\text { All tests: } \\
\text { - Isotropic consolidation }\end{array}$ \\
\hline Test 11 & 0.95 & $69 \%$ & $\begin{array}{c}p^{\prime}=98.4 \mathrm{kPa} \\
q=0 \mathrm{kPa}\end{array}$ & $\begin{array}{l}\text { - undrained cyclic axial } \\
\text { loading: } 40 \text { cycles of } q= \pm \\
20 \mathrm{kPa} \text { and } \mathrm{q}= \pm 30 \mathrm{kPa}\end{array}$ \\
\hline Test 12 & 0.96 & $57 \%$ & $p^{\prime}=97.5 \mathrm{kPa}$ & $\begin{array}{l}\text { - release of } 50 \% \text { of the pore } \\
\text { pressure }\end{array}$ \\
\hline Test 13 & 0.97 & $68 \%$ & $\begin{array}{c}q=0 \mathrm{kPa} \\
p^{\prime}=95.3 \mathrm{kPa} \\
q=0 \mathrm{kPa}\end{array}$ & $\begin{array}{l}\text { - undrained cyclic axial } \\
\text { loading: } 40 \text { cycles of } \mathrm{q}= \pm \\
30 \mathrm{kPa} ; \pm 40 \mathrm{kPa} \text {; etc. until } \\
\text { failure is reached }\end{array}$ \\
\hline
\end{tabular}
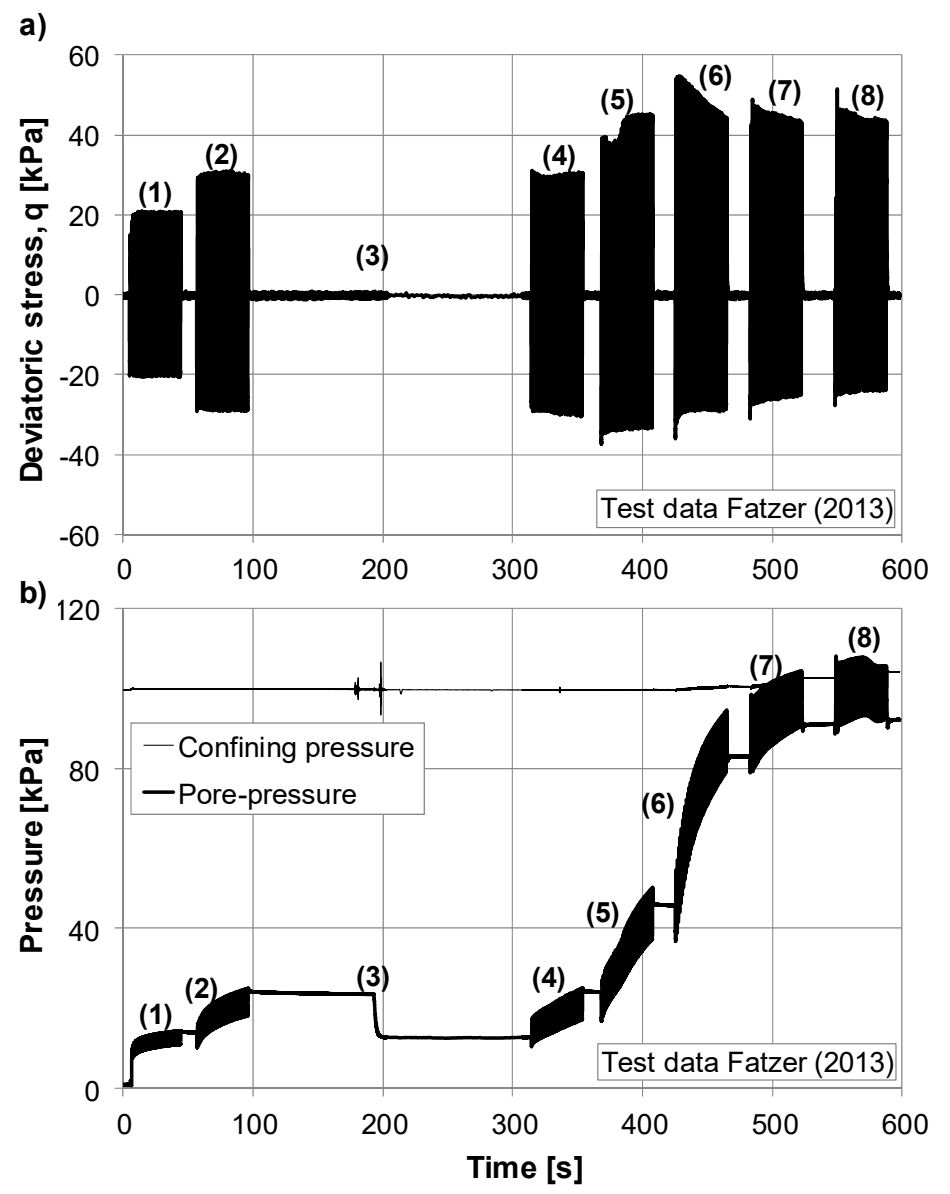

(1) - Cyclic axial loading $q= \pm 20 \mathrm{kPa}$.

(2) - Cyclic axial loading $q= \pm 30 \mathrm{kPa}$

(3) - Release of $50 \%$ of pore-pressure

(4) - Cyclic axial loading $q= \pm 30 \mathrm{kPa}$

(5) - Cyclic axial loading $q= \pm 40 \mathrm{kPa}$

(6) - Cyclic axial loading $q= \pm 50 \mathrm{kPa}$

(7) - Cyclic axial loading $q= \pm 60 \mathrm{kPa}$

(8) - Cyclic axial loading $q= \pm 70 \mathrm{kPa}$

Figure 2.16. Generic stress path in time domain of the dynamic tests with $50 \%$ pore pressure release on SM Visp silty sand $(\mathrm{d}<0.5 \mathrm{~mm})$ : a) time history of deviatoric applied stresses, b) development of pore water pressure. 
The results of the dynamic tests were used to calibrate the relationship for the evaluation of the pore pressure increase for a given number of cycles, proposed by Seed \& Booker (1977) and further developed by Egglezos \& Bouckovalas (1998; 1999):

$\Delta \mathrm{u}(\mathrm{N})=\frac{2}{\pi} \cdot \sigma^{\prime}{ }_{\text {oct }} \cdot \arcsin \left(\mathrm{N}^{\frac{1}{2 \mathrm{~b}_{1}}} \cdot \sin \left(\frac{\pi}{2} \cdot \frac{\Delta \mathrm{u}(1)}{\sigma_{\text {oct }}^{\prime}}\right)\right)$

where $\mathrm{N}$ - number of cycles [-]

$\Delta \mathrm{u}(\mathrm{N})$ - pore pressure increase after $\mathrm{N}$ cycles [kPa]

$\sigma^{\prime}{ }_{\text {oct }}-$ effective consolidation pressure $[\mathrm{kPa}]$

$\mathrm{b}_{1}$ - empirical constant

$\Delta \mathrm{u}(1)$ - pore pressure increase after the first cycle [kPa].

The increase of pore pressure after the first cycle is the key element in the evaluation of pore pressure development during cyclic loading. This depends on consolidation pressure, amplitude of the cyclic shear stress and void ratio, as shown by Egglezos \& Bouckovalas (1998):

$\Delta \mathrm{u}(1)=\mathrm{B} \cdot \mathrm{P}_{\mathrm{a}} \cdot\left(\frac{\sigma_{\text {oct }}^{\prime}}{\mathrm{P}_{\mathrm{a}}}\right)^{\mathrm{b}_{2}} \cdot\left(\frac{\tau_{\text {cyc }}}{\sigma_{\text {oct }}^{\prime}}\right)^{\mathrm{b}_{3}} \cdot \mathrm{e}^{\mathrm{b}_{4}}$

Where $\Delta \mathrm{u}(1)$ - pore pressure increase after the first cycle [kPa]

$\mathrm{B}, \mathrm{b}_{2}, \mathrm{~b}_{3}, \mathrm{~b}_{4}-$ material and test dependent parameters [-]

$\mathrm{P}_{\mathrm{a}}$ - atmospheric pressure $[\mathrm{kPa}]$

$\sigma^{\prime}{ }_{\text {oct }}$ - effective consolidation pressure $[\mathrm{kPa}]$

$\tau_{\mathrm{cyc}}-$ half of the amplitude of the cyclic deviator stress $[\mathrm{kPa}]$

e - void ratio [-].

The parameters $B, b_{2}, b_{3}, b_{4}$ were calibrated for the SM Visp silty sand ( $d<0.5 \mathrm{~mm}$ ) for the specific conditions of the dynamic tests $10-13\left(\sigma^{\prime}\right.$ oct $=95.3-98.8 \mathrm{kPa}, \tau_{\text {cyc }}=9.2 \mathrm{kPa}-$ $24.47 \mathrm{kPa}$ and $\mathrm{D}_{\mathrm{D}}=57 \%-69 \%$ ) and the resulting values are shown in Table 2.5.

Table 2.5. Parameter set for the evaluation of the pore pressure increase after the first loading cycle for the SM Visp silty sand $(\mathrm{d}<0.5 \mathrm{~mm})$.

\begin{tabular}{lc}
\hline Parameter & Calibrated value [-] \\
\hline B & 0.5 \\
$\mathrm{~b}_{2}$ & 0.7 \\
$\mathrm{~b}_{3}$ & 1.6 \\
$\mathrm{~b}_{4}$ & 0.5 \\
\hline
\end{tabular}


The values of the pore pressure increase measured after the first cycle in steps (1), (2), (4), (5) and (6) (see Figure 2.16) of the dynamic triaxial tests and those predicted using relationship (2.6) with the parameters given in Table 2.5 are shown in Figure 2.17. The correlation between measured and the predicted values indicates the possibility of making reliable approximation of the expected pore pressure increase using the parameters calibrated.

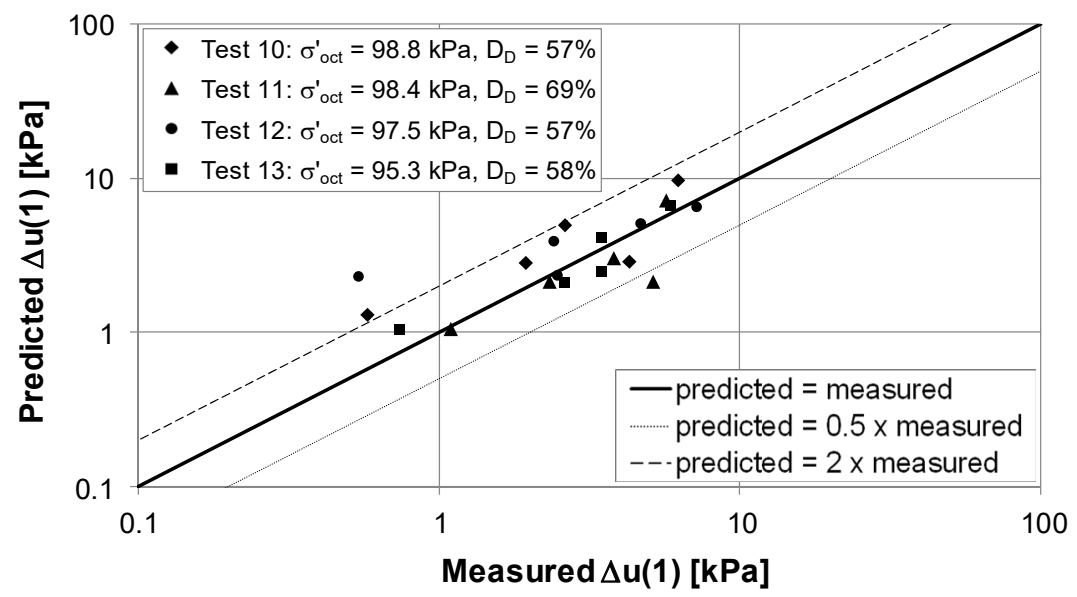

Figure 2.17. Measured and predicted values of the pore pressure increase after the first loading cycle for the SM Visp silty sand $(d<0.5 \mathrm{~mm})$.

The development of the pore pressure increase in the subsequent loading cycles was fitted using the values measured in the dynamic tests. The empirical constant $b_{1}$, which determines the development of the pore pressure with the number of cycles, varies with the amplitude of the cyclic stress $\tau_{\text {cyc. }}$. The results of the calibration show data scattered around the average value $b_{1}=1.39$ (Figure 2.18).

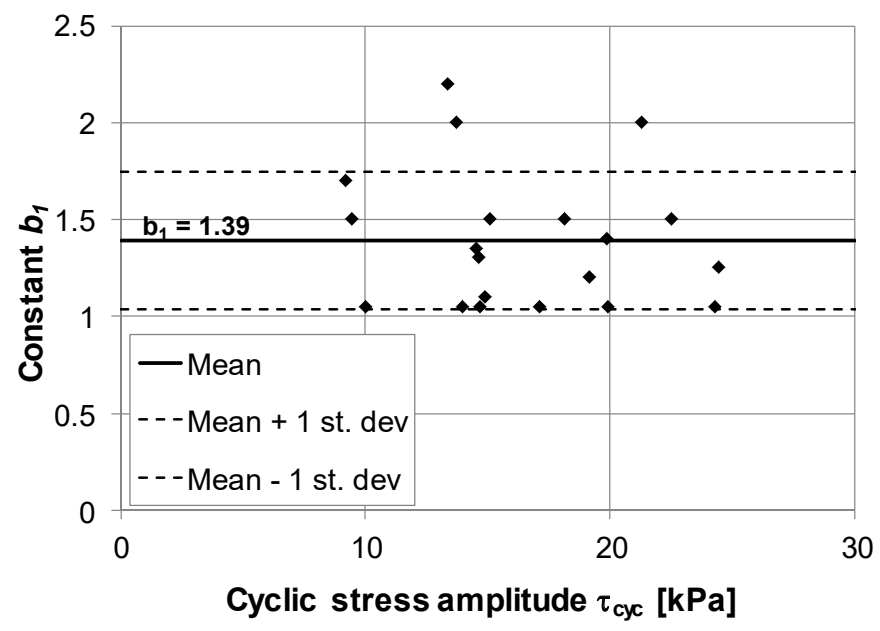

Figure 2.18. Values of the empirical constant $b_{1}$ for $S M$ Visp silty sand $(d<0.5 \mathrm{~mm})$ for different cyclic stress amplitudes. 
The development of pore pressure for the SM Visp silty sand $(\mathrm{d}<0.5 \mathrm{~mm}$ ) with relative densities $D_{D}=50-70 \%$ can be predicted using relationships (2.5) and (2.6) and the calibrated values of the constants $B, b_{1}, b_{2}, b_{2}$, and $b_{3}$. Figures 2.19-2.20 show some typical results comparing the measured and the predicted pore pressure development before (step 2) and after the pore pressure release (step 4) in Test 10, for the given set of constants. Higher values of the pore pressure increase were measured in step (4) indicating the effect of the loading stress history on the subsequent pore pressure development. However, the predicted values, obtained using the same set of parameters for both steps, fitted the measured ones (Figures 2.19-2.20).

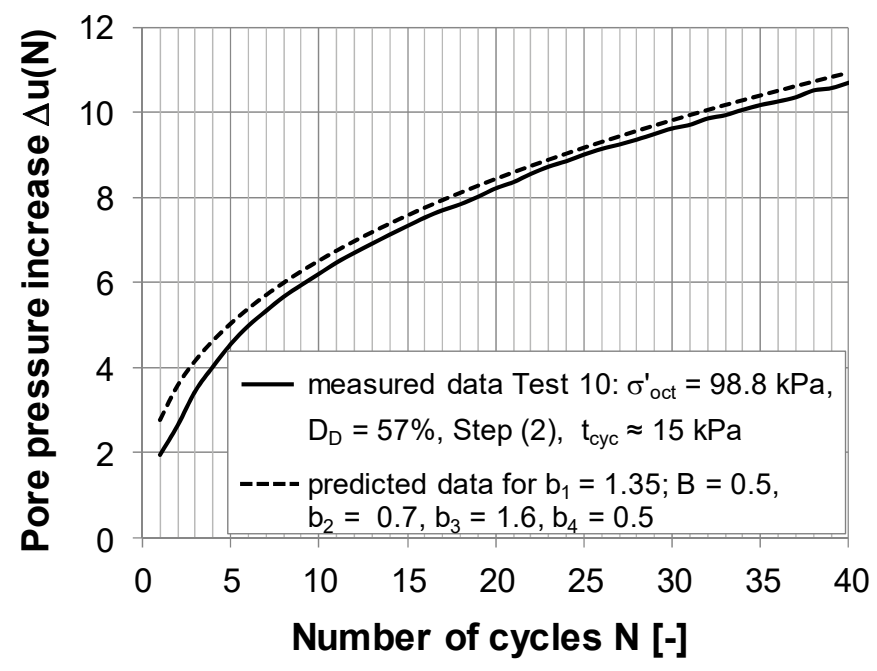

Figure 2.19. Pore pressure increase measured and predicted for SM Visp silty sand (d $<0.5 \mathrm{~mm})$ for Test 10, Step (2).

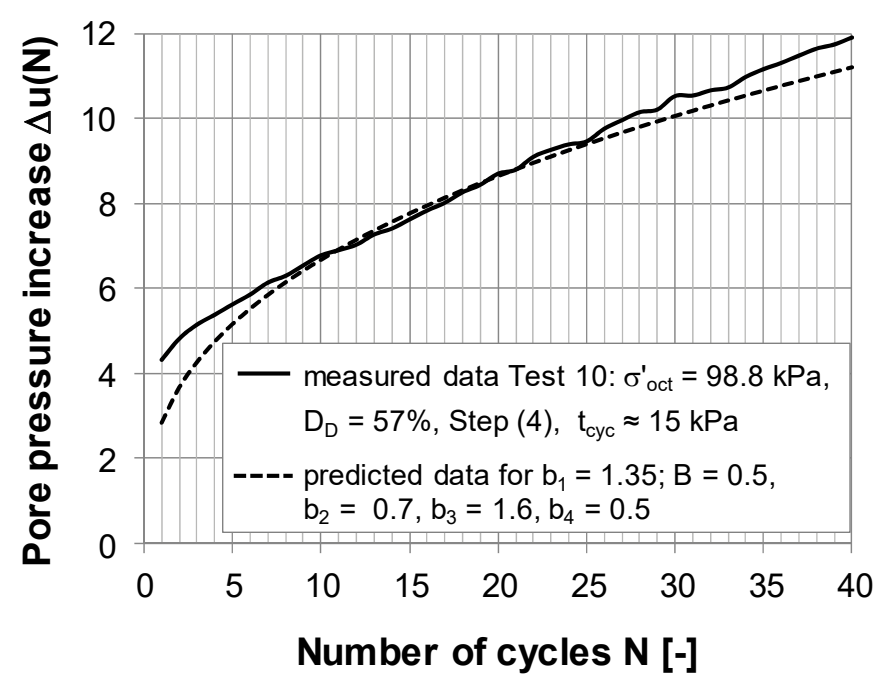

Figure 2.20. Pore pressure increase measured and predicted for SM Visp silty sand (d $<0.5 \mathrm{~mm})$ for Test 10, Step (4). 
The final set of results from the dynamic tests is represented by shear strain-dependency of the shear modulus and damping for the SM Visp silty sand $(\mathrm{d}<0.5 \mathrm{~mm})$. The results were compared those obtained by Weber et al. (2007) for the SM-SP Visp sand (see Figure 2.6), for the same stress level used in the current investigations ( $p=100 \mathrm{kPa})$.

On the one hand, higher values of the shear modulus are available for shear strains $\gamma<$ $0.02 \%$ rendering valid linear-equivalent assumptions of soil behaviour in this strain range (Figure 2.21a). The reduction curve of the shear modulus for $\gamma>0.02 \%$ has a steeper gradient than that presented by Weber et al. (2007), indicating a more brittle behaviour of the soil.

On the other hand, significantly higher damping values were obtained for the SM Visp silty sand (Figure 2.21b). This effect can be explained by the carbonate compounds identified in the soil (13\% of the soil mass) and the greater number of particle contacts. Bounding occurs during cyclic loading at the contact between particles due to the carbonate compounds, and the soil damping increases. Additionally, particle breakage also contributes to the increased damping values. Similar effects were observed by Carraro \& Bortolotto (2015), who compared the influence of the mineralogy on the stiffness degradation and damping of carbonate and silica sands.

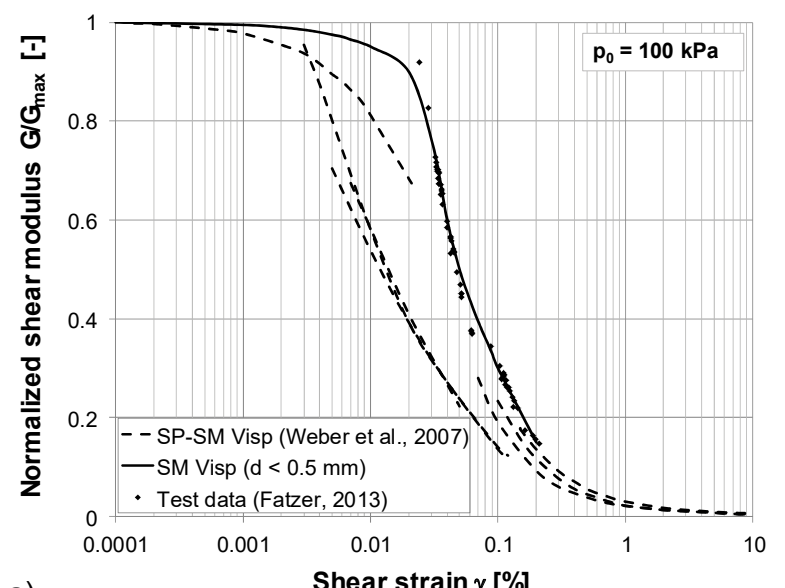

a)

Figure 2.21. Silty sands from Visp: a) shear modulus reduction and b) damping ratio values depending on the shear strain.

\subsection{Conclusions}

The sands and silty sands from Visp were investigated using a wide range of laboratory tests. Simple soil classification, bender element measurements, and triaxial tests with standard and complex stress paths were performed to analyse the soil response under static and cyclic loading conditions. The laboratory investigations revealed important features of the soil response that can be applied for a more realistic approach in subsequent numerical or analytical analyses related to e.g. seismic slope stability or deformation behaviour of geotechnical structures. Moreover, the results obtained can be analysed 
in parallel with observations made with other similar soils, and extrapolated for a more general use.

The bender element measurements of the shear wave velocity were proved to be reliable source for the determination of the small strain stiffness. However, the results showed that the influence of grain size (fine grain fraction vs. entire material fraction) must be incorporated into the assessment of appropriate values for analysis and design. The differences between the measurements emphasise the importance of well-defined and known boundary conditions during bender-element measurements.

The complex triaxial tests with stress paths including static and cyclic loading (i.e. Tests 4 and 5 ) revealed a marginal reduction of the post-cyclic maximum friction angle from $48.2^{\circ}$ to $47.3^{\circ}$. This observation can be practically applied in the analysis of the soil response after a seismic event, when non-altered values of the maximum friction angle can be used. The same tests revealed a faster softening of the soil, caused by the cyclic load applied, and a reduction of the strain range over which the soil exhibited dilatant behaviour. This indicates the possibility of e.g. progressive slope failures caused by eventual earthquake aftershocks. Such events could induce strains in the soil, which would eliminate the positive effect of the dilatancy on the mobilised shear strength and lead to large displacements.

The undrained static-dynamic-static hybrid tests (Tests 6-9) revealed further aspects related to the behaviour of the saturated dense silty sand. After a pore pressure increase due to initial cyclic loading, the specimens exhibited dilatant behaviour during the postcyclic static loading, the volume increased, and the suctions eliminated the effect of positive pore pressures. The stabilising effect of the suctions was observed in the soil even at large strains $\left(\varepsilon_{\text {axial }}=25 \%\right.$ ). Nevertheless, the dilatancy-induced suctions in dense silty sands at large strains are available only if no additional undrained loading and no changes of the water content occur in the soil. This observation is essential for the reliability of displacement-based method (e.g Marin \& Laue 2016), which depends on the appropriate evaluation of the mobilised shear strength of soil and its compatibility with the predicted displacements. More specifically, displacement predictions, taking into account increased shear strength of the soil due to suctions, are reliable for the case of dense silty sands, based on the observations made in the laboratory related to the availability of suctions.

Additional information related to the cyclic behaviour of the silty sands from Visp was obtained by analysing the development of pore pressures and calibrating the prediction relations proposed by Egglezos \& Boucovalas (1998; 1999). However, more extensive investigations are required to verify the validity of the parameters for other initial conditions (i.e. consolidation pressures and relative densities different than those from Tests 10-13). The prediction of the pore pressure increase with the number of loading cycles, using relationships (2.5) and (2.6), is essential when detailed displacement-based analyses of geotechnical structures (e.g. slopes, dams, or embankments) are performed. Most analytical methods for evaluating seismic-induced displacements are based on 
Newmark's method (1965), which assumes the critical acceleration during the seismic event to be constant. In reality, the critical acceleration, which represents a measure of the slope resistance, is strongly dependent on the effective stresses, and, hence, on the pore pressure development during the seismic event. If the pore pressure variation with the loading cycles can be predicted, more accurate methods of displacement evaluation can be used, by taking into account the variation of the critical acceleration during the seismic event (e.g. Biondi et al. 2000).

A final practical outcome of the laboratory investigations are the strain-dependency curves of the shear modulus and damping for the SM Visp silty sand $(d<0.5 \mathrm{~mm})$. An increase of the equivalent elastic strain range was observed, as well as increased damping values in comparison with the results of the investigations performed on the SM-SP Visp sand. These curves can be used as input for e.g. linear-equivalent site response analyses, or in FE investigations with more advanced constitutive models requiring such soil parameters.

\subsection{References}

Aoi, S., Kunugi, T., \& Fujiwara, H. (2008) Trampoline effect in extreme ground motion. Science 322(5902). pp. 727-730.

Archuleta, R., Bonilla, L., \& Lavallee, D. (2000) Nonlinearity in observed and computed accelerograms. In: Proceedings of the 12th World Conference on Earthquake Engineering. Publication No. 1934.

ASTM 4253. (2006) Standard Test Methods for Maximum Index Density and Unit Weight of Soils Using a Vibratory Table.

ASTM 4254. (2006) Standard Test Methods for Minimum Index Density and Unit Weight of Soils and Calculation of Relative Density.

Beresnev, I.A., Wen, K.-L., \& Yeh, Y. T. (1995a) Nonlinear soil amplification: its corroboration in Taiwan. Bulletin of the Seismological Society of America 85(2). pp. 496-515.

Beresnev, I.A., Wen, K.-L., \& Yeh, Y. T. (1995b) Seismological evidence for nonlinear elastic ground behavior during large earthquakes, Soil Dynamics and Earthquake Engineering 14. pp. 103-114.

Biondi, G., Cascone, E., Maugeri M. \& Motta, E. (2000) Seismic response of saturated cohesionsless slopes. Soil Dynamics and Earthquake Engineering 20. pp. 209-215.

Bolton, M.D. (1986) The strength and dilatancy of sands. Géotechnique 36(1). pp. 65-78.

Bonal, J., Donohue, S. \& McNally, C. (2012) Wavelet analysis of bender element signals. Géotechnique 62(3). pp. 243-252. 
Bonilla, L.F., Archuleta, R.J. \& Lavallée, D. (2000) Hysteretic and dilatant behaviour of cohesionless soils and their effects on nonlinear site response: field data observation and modelling. Bulletin of the Seismological Society of America, 95(6). pp. 2373-2395.

Burjanek, J., Gassner-Stamm, G., Poggi, V. \& Fäh, D. (2011) Estimation of local site effects in the Upper Valais (Switzerland). In: 4th IASPEI/IAEE International Symposium: Effects of surface geology on seismic motion. University of California, Santa- Barbara, USA.

Camacho-Tauta, J. F., Alvarez, J. D J. \& Reyes-Ortiz, O. C. (2012) A procedure to calibrate and perform the bender element test. Dyna, 176, year 79, Medellin. pp. 10-18.

Carraro, J.A.H. \& Bortolotto, M.S. (2015) Stiffness degradation and damping of carbonate and silica sands. In: Meyer (ed.), Frontiers in Offshore Geotechnics III. pp. 1179-1183.

De Alba, P., Seed, H. B. \& Chan, C. H. (1976) Sand liquefaction in large-scale simple shear test. Journal of the Geotechnical Engineering Division, ASCE, vol. 102, N. GT9.

Dobry, R. \& Vucetic, M. (1987) Dynamic properties and seismic response of soft clay deposits. In: Proceedings of the International Symposium on Geotechnical Engineering of Soft Soils, Mexico City. Vol. 2, pp. 51-87.

Egglezos, D. N. \& Bouckovalas, G. D. (1998) Analytical relationships for earthquake induced pore pressure in sand, clay and silt. In: 11th European Conference on Earthquake Engineering, Paris. pp. 167. (full article on CD-ROM).

Egglezos, D. N. \& Bouckovalas, G. D. (1999) Permanent strain and pore pressure relations for cyclic loading of sand. In: Seco e Pinto (ed.), Proceedings of the 2nd International Conference on Earthquake Geotechnical Engineering, Lisbon. Balkema, Rotterdam. pp. $131-136$.

Fatzer, P. (2014) Einfluss der Belastungsgeschichte auf das zyklische Verhalten siltigsandiger Flussablagerungen. Master Thesis at the Institute for Geotechnical Engineering, ETH Zurich. (in German)

Geiser, S. (2013) Seismisches Verhalten von Hochwasserschutzbauten. Ertüchtigungsmassnahmen. Master Thesis at the Institute for Geotechnical Engineering, ETH Zurich. (in German).

Hyde, A.F.L., \& Ward, S.J. (1986) The effect of cyclic loading on the undrained shear strength of a silty clay. Marine Geotechnology, 6(3). pp. 299-314.

lai, S., Matsunaga, Y. \& Kameoka, T. (1990) Parameter identification of a cyclic mobility model. Report of The Port and Habour Research Institute, 29(4). pp. 57-83. Nagase, Yokosuka, Japan. 
lai, S., Kameoka, T. \& Matsunaga, Y. (1993) Numerical (class A) predictions of model no 1. Verification of numerical procedures for analysis of soil liquefaction problems. pp. 109127. Balkema, Rotterdam. Netherlands.

lai, S., Morita, T., Kameoka, T., Matsunaga, Y. \& Abiko, K. (1995) Response of a dense sand deposit during 1993 Kushiro-Oki earthquake, Soils and Foundations 35. pp. 115131.

Kamae, K., Irikura, K. \& Pitarka, A. (1998) A technique for simulating strong ground motion using hybrid Green's function. Bulletin of the Seismological Society of America 88(2). pp. 357-367.

Lawrence, F.V. (1963) Propagation of ultrasonic waves through sand. Research Report R63-8, Massachusetts Institute of Technology, Cambridge, MA.

Lawrence, F.V. (1965) Ultrasonic shear wave velocity in sand and clay. Research Report R65-05, Soil Publication No. 175, Massachusetts Institute of Technology, Cambridge, MA.

Marin, A \& Laue, J. (2016) Displacement-based seismic analysis of slopes, dams and embankments. Journal of Earthquake and Tsunami 10(1). DOI: 10.1142/ S1793431116500056.

Matsui, T., Ohara, H. \& Ito, T. (1980) Cyclic shear stress history and shear characteristics of clay. Journal of Geotechnical and Geoenvironmental Engineering 106(10). pp. 11011120.

Mohsin, A. \& Airey, D. (2003) Automating Gmax Measurement in Triaxial Tests. In: Di Benedetto H, Doanh T, Geoffroy H, Sauzeat C (eds.), Proceedings of the $3^{\text {rd }}$ International Symposium on Deformation Characteristics of Geomaterials, Lyon, Vol. 1. pp. 73-80. Balkema, Lisse.

Newmark, N.M. (1965) Effects of earthquakes on dams and embankments. Géotechnique, 15 (2). pp. 139-160.

Roten, D., Fäh, D. \& Giardini, D. (2005) Earthquake Shaking in Alpine Valleys. In: Proceedings of the 6th Ph.D. Students' and Advisors' Meeting, Cardada, Locarno.

Roten, D., Fäh, D., Olsen, K.B. \& Giardini, D. (2008) A comparison of observed and simulated site response in the Rhône valley. Geophysical Journal International 173. pp. 958-978.

Roten, D., Fäh, D., Bonilla, L.F., Alvarez-Rubio, S., Weber, T.M. \& Laue, J. (2009) Estimation of non-linear site response in a deep Alpine valley. Geophysical Journal International, 178(3). pp. 1597-1613. 
Scheiwiller, A. (2013) Seismisches Verhalten von Hochwasserschutzbauten. Dauerhaftigkeit. Master Thesis at the Institute for Geotechnical Engineering, ETH Zurich. (in German).

Seed, H.B. \& Booker, J.R. (1977) Stabilization of potential liquefiable sand deposit using gravel drains. Journal of the Geotechnical Engineering Division, ASCE 103(N GT7).

Seed, H.B. \& Idriss, I.M. (1970) Soil Moduli and Damping Factors for Dynamic Response Analysis. Report No: EERC 70-10, University of California, Berkeley, CA.

Timoshenko, S. \& Goodier, J.N. (1951) Theory of elasticity. McGraw-Hill Book Company. New York. USA.

Viggiani, G. \& Atkinson, J.H. (1995) Interpretation of bender element tests. Géotechnique 45(1). pp.149-154.

Weber, T. M., Laue, J. \& Springman, S. M. (2007) Geotechnical laboratory tests for identification of soil parameters for the cyclic mobility model of sandy soil from Visp (VS). Project report - „SHAKE - VAL 2“, IGT Report No. 4698, ETH Zürich.

Yasuhara, K., Murakami, S., Song, B.-W., Yokokawa, S. \& Hyde, A.F.L. (2003) Postcyclic Degradation of Strength and Stiffness for Low Plasticity Silt. Journal of Geotechnical and Geoenvironmental Engineering, 129(8). pp. 756-769. 


\title{
3. One and Two-Dimensional Site Response in the Rhone Valley
}

\author{
Alexandru Marin \\ ETH Zürich, Institute for Geotechnical Engineering \\ Stefano-Franscini-Platz 5, 8093 Zürich, Switzerland \\ E-mail address: amarin@ethz.ch
}

\section{Rebekka Habegger ${ }^{1}$}

ETH Zürich, Institute for Geotechnical Engineering

Stefano-Franscini-Platz 5, 8093 Zürich, Switzerland

Email: rebekka.habegger@baslerhofmann.ch

Jan Laue ${ }^{2}$

ETH Zürich, Institute for Geotechnical Engineering

Stefano-Franscini-Platz 5, 8093 Zürich, Switzerland

E-mail address: jan.laue@ltu.se

\section{Submitted to Bulletin of Earthquake Engineering}

Status: under review

\footnotetext{
1 Basler \& Hofmann AG, Bachweg 1, 8133 Esslingen, Switzerland

2 Appointment of Luleå University of Technology since August 2015 Department of Civil, Environmental and Natural Resources Engineering Mining and Geotechnical Engineering SE-971 87 Luleå, Sweden
} 


\begin{abstract}
Seismic site characterisation plays a significant role in the risk analysis and design processes providing an approximation of the local ground motion (free-field motion) used as input in subsequent analyses. This paper focuses on the different methods of site characterisation, starting from the traditional one-dimensional (1D) linear analysis in the frequency domain to the more complex two-dimensional (2D) non-linear finite element simulations in the time domain. The purpose of these investigations is to create the basis for an appropriate choice of the numerical method for seismic analyses of earthquake response. For this purpose, the main advantages and disadvantages of each method were identified using factors such as the possibility of capturing complex non-linear phenomena (e.g. basin effects), the availability of the modelling software, or the computational effort.
\end{abstract}

Keywords: seismic site characterisation, non-linear behaviour, basin effects, numerical modelling, benchmark study. 


\subsection{Introduction}

Stiffness contrasts between different subsurface layers, as well as different topographic shapes (e.g. slopes, cliffs, ridges, sedimentary basins, etc.), determine the level of amplification of seismic waves and have an influence on the natural frequencies of the ground. For instance, Zeevaert (1964), Borcherdt (1970), Aki (1988), Yamanaka et al. (1989) and Atakan et al. (2004) showed how the seismic ground motion is strongly influenced by site conditions such as local geology. Moreover, Bouchon (1973), Geli et al. (1988), Pedersen et al. (1994) and Ashford et al. (1997) emphasised the influence of topographic conditions on the seismic motion. The combination of local geology and particular topographic conditions, and their influence on the local earthquake motion was investigated by e.g. Bard and Bouchon (1985), Celebi, M. (1987), Jongmans and Campillo (1993), Gazetas et al. (2002), and Faccioli and Vanini (2003).

Deep sediment-filled valleys represent a typical combination of particular topographic conditions and extreme local geology. This is the case for the Rhone Valley in Switzerland, which is characterised by sedimentary soft deposits, with thicknesses up to $300 \mathrm{~m}$ and above. This situation is often encountered in alpine areas and is usually associated with a high risk level in the case of a moderate to strong earthquake, due to the increased density of the building stock and infrastructure in those areas. An appropriate seismic site characterisation, including the evaluation of basin effects, represents the key element of the seismic design. This was also the main subject of investigation for Roten (2007), who studied site effects for an area in the Rhone Valley.

Based on a standardised soil model from the same area in Switzerland, this paper covers a wide spectrum of analysis methods from the classic 1D calculations in the frequency domain (Seed and Idriss, 1970) to 2D modelling in the time domain, outlining the main particularities of each method. After presenting the investigation methods, the different results are discussed and compared, and a conclusion is formulated about the appropriateness, effectiveness, and justification of the methods.

\subsection{Investigation Methods}

\subsubsection{Modelling methods}

The challenge of seismic site characterisation can be approached using various modelling methods, depending on the assumptions related to the seismic wave propagation and soil behaviour. This paper focuses on the following methods:

- 1D modelling in the frequency domain, using equivalent-linear soil properties

- 1D modelling in the time domain, using a linear elastic constitutive model

- 1D modelling in the time domain, using the linear elastic perfectly plastic MohrCoulomb constitutive model 
- 1D modelling in the time domain, using the Hardening Soil Small Strain non-linear constitutive model

- 2D modelling in the time domain, using the linear elastic perfectly plastic MohrCoulomb constitutive model

- 2D calculations in the time domain, using the Hardening Soil Small Strain nonlinear constitutive model

The frequency domain modelling was performed using the software package EERA (Equivalent-linear Earthquake site Response Analyses, Bardet et al., 2000), while the time domain analyses were performed using PLAXIS 2D (Brinkgreve et al., 2014). The 1D modelling in the time domain was also performed using PLAXIS 2D, but with special boundary conditions to avoid any unwanted 2D effects.

Excess pore pressure generation and soil liquefaction are possible during a moderate to strong earthquake, considering the local silty-sandy soil conditions and high water levels. However, the numerical modelling of such soil response implies advanced constitutive models, which often require numerous input parameters that have to be calibrated in the local geological and seismic context. Soil liquefaction is generally approached by other methods (e.g. Idriss and Boulanger, 2008) in current engineering practice, and the decision was made not to include such numerical investigations in the set of analyses presented in this paper.

\subsubsection{General overview of local soil conditions}

The investigated site is located in Switzerland in the canton of Valais (Figure 3.1), which belongs to the highest seismic hazard zone $\mathrm{Z3b}$, with a design value of the horizontal acceleration in the soil class $A$ (hard rock, $v_{s}>800 \mathrm{~m} / \mathrm{s}$ ) of $a_{g d}=0.16 \mathrm{~g}$, for a return period of 475 years (SIA 261, 2014).

The river Rhone crosses the canton from East (Rhone glacier) to West (Lake Geneva) and its basin is a typical example of deep sediment-filled valleys. The city of Visp, located in the eastern part of the canton, was chosen to be the focus of investigations, as it is the epicentre of the most well documented historical earthquake in the region (Fritsche et al., 2006). The large amount of information on the geology of the valley in Visp, available from different previous investigations, such as ambient-noise array measurements, and shear wave velocity measurements (Roten, 2007; Burjanek et al., 2011), facilitated the development of the soil model for the current analysis. 


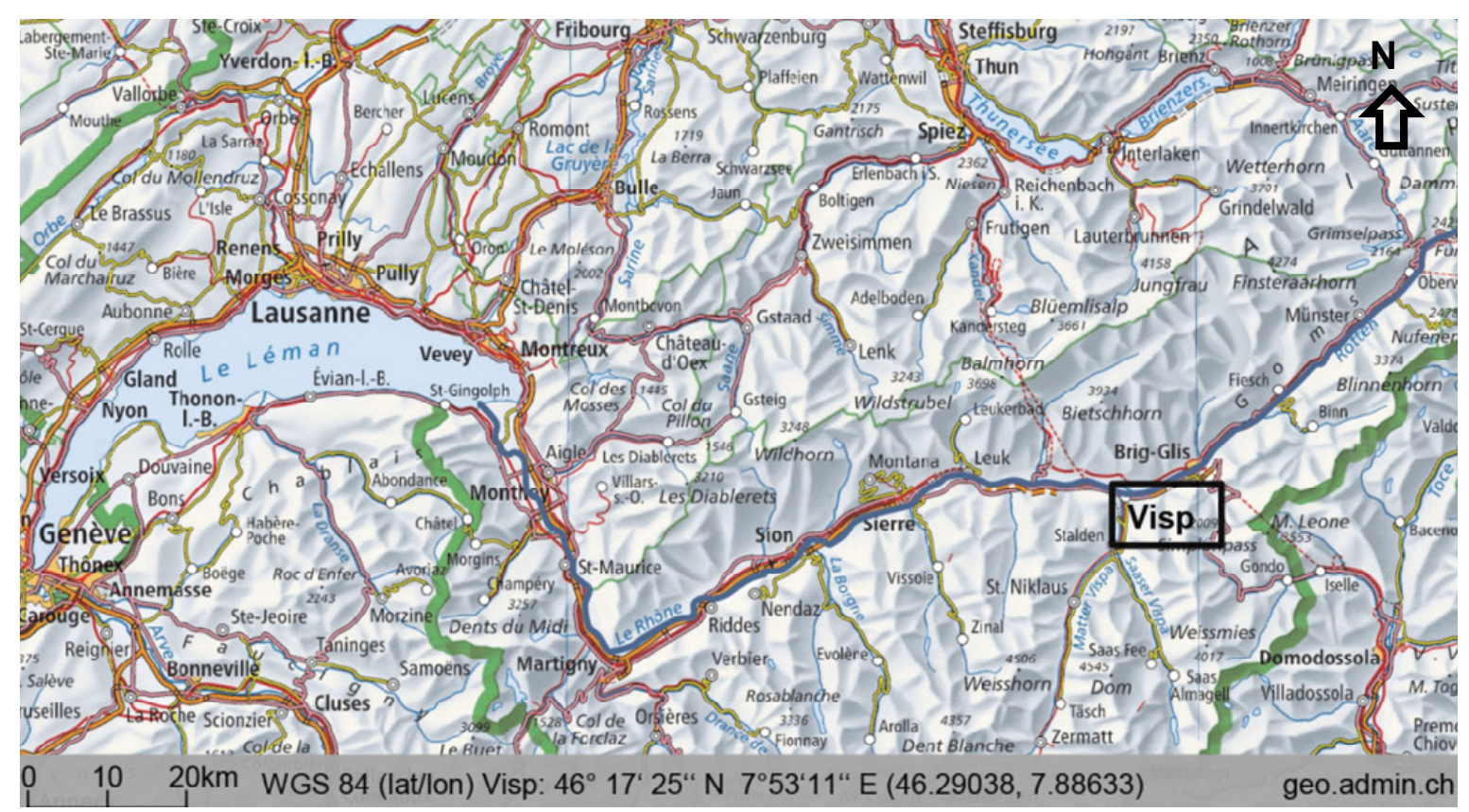

Figure 3.1. Location of Visp in the Rhone valley in Switzerland.

Multiple investigations along the valley (Frischknecht and Wagner, 2004; Pfiffner et al., 1997; Roten, 2007; Steimen et al., 2003; Wagner et al., 2000) have revealed its geological structure. Layers of fluviatile gravels alternate with deltaic sediments (sands and silts) in the first $50 \mathrm{~m}$ of depth. Wagner et al. (2000) grouped the deposited materials in generalised sub-units with various thicknesses, which are present in most locations along the entire valley:

- Surface deltaic sediments of sandy silts, consisting of layers of 5-10 m depth.

- Surface river gravels (Rhone gravel) representing the water-bearing geologic formations, located at 5-10 $\mathrm{m}$ below the surface.

- Deep deltaic sediments consisting of fine sands and silts, located at 10-25 m below the surface.

- Deep river gravels mixed with sand layers, located at 25-30 m below the surface.

The specific geological structure of the valley used for the analyses in this paper is based on the site characterisation performed by Wagner et al. (2000) and the bedrock depth estimations made by Burjanek et al. (2011) (Figure 3.2 and 3.3). 


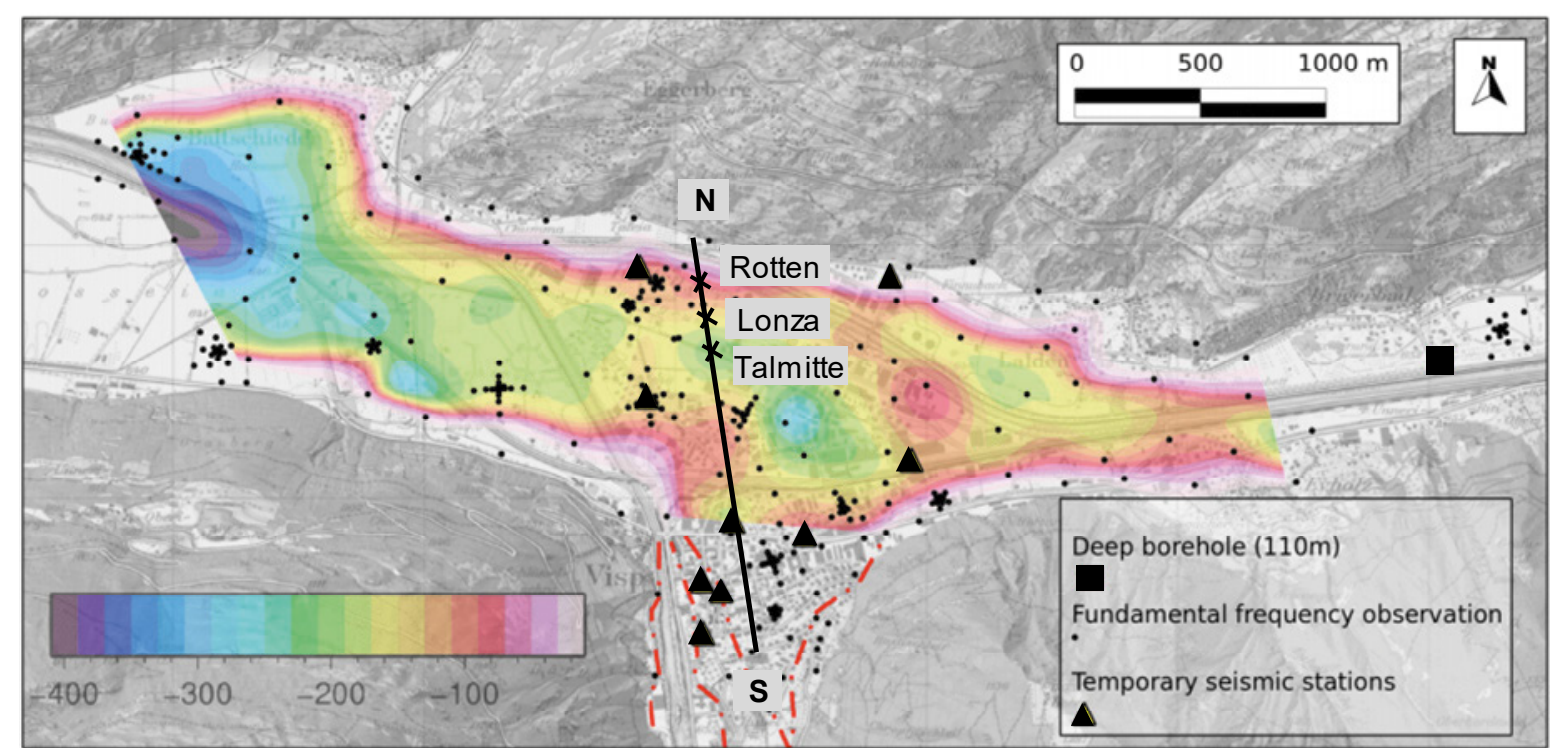

Figure 3.2. Estimated bedrock depth and location of the valley cross-section investigated in this study (after Burjanek et al., 2011).

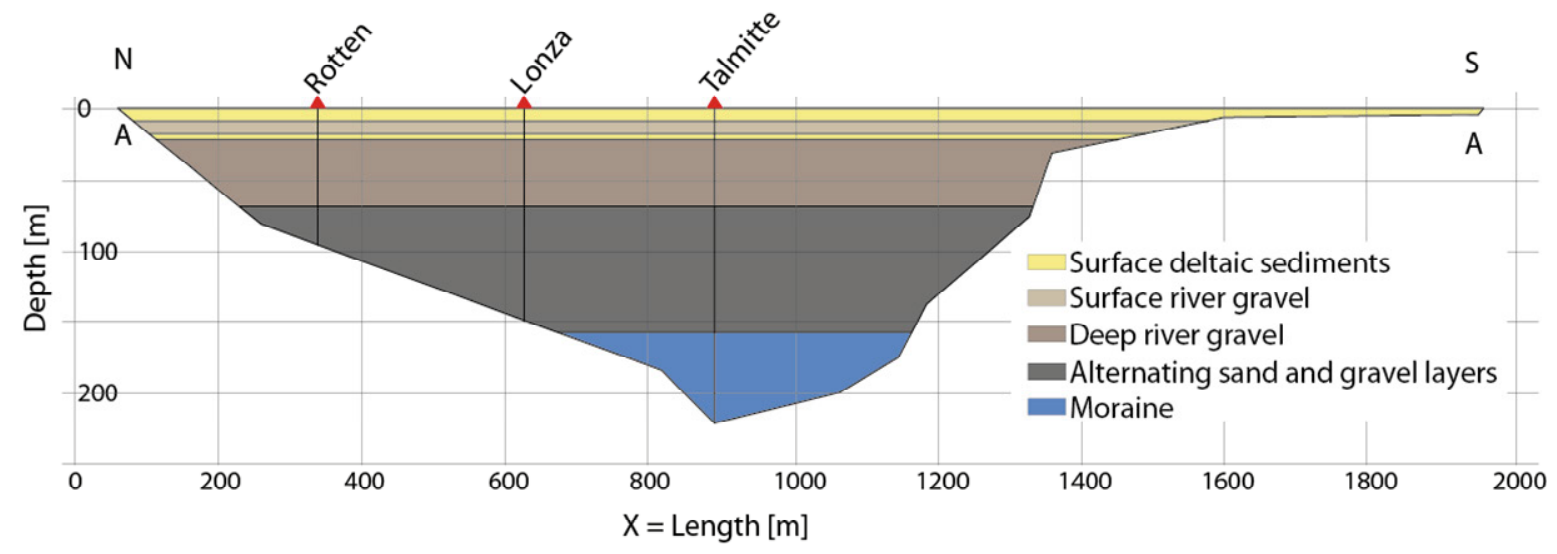

Figure 3.3. Geological profile and valley cross-section (A-A) in Visp.

\subsubsection{Soil model for $1 \mathrm{D}$ calculations}

The soil model and the shear wave velocity profile for the 1D calculations is based on various investigations performed in the area of Visp, such as combined inversion of the Rayleigh waves dispersion and 2D resonance frequencies (Roten, 2007) or array measurements of the ambient noise and $\mathrm{H} / \mathrm{V}$ ratio determinations (Nakamura method) (Burjanek et al., 2011, Résonance et al., 2005). Using this information, the shear wave velocity profile was determined at the location "Talmitte" (Figure 3.4), which contains all the generalised sub-units of soil, as identified by Wagner et al. (2000). The upper $\left(v_{\text {s.max }}\right)$ and lower $\left(v_{s . m i n}\right)$ bounds of the shear wave velocity profile were introduced to account for the uncertainty of the model, also shown by Résonance et al. (2005) who observed strong variations of the shear wave velocities. The upper and lower bounds were determined by assuming a factor $1 / \sqrt{ } 2$ and $\sqrt{ } 2$, which corresponds to $1 / 2$ and 2 for the variation of shear modulus. 

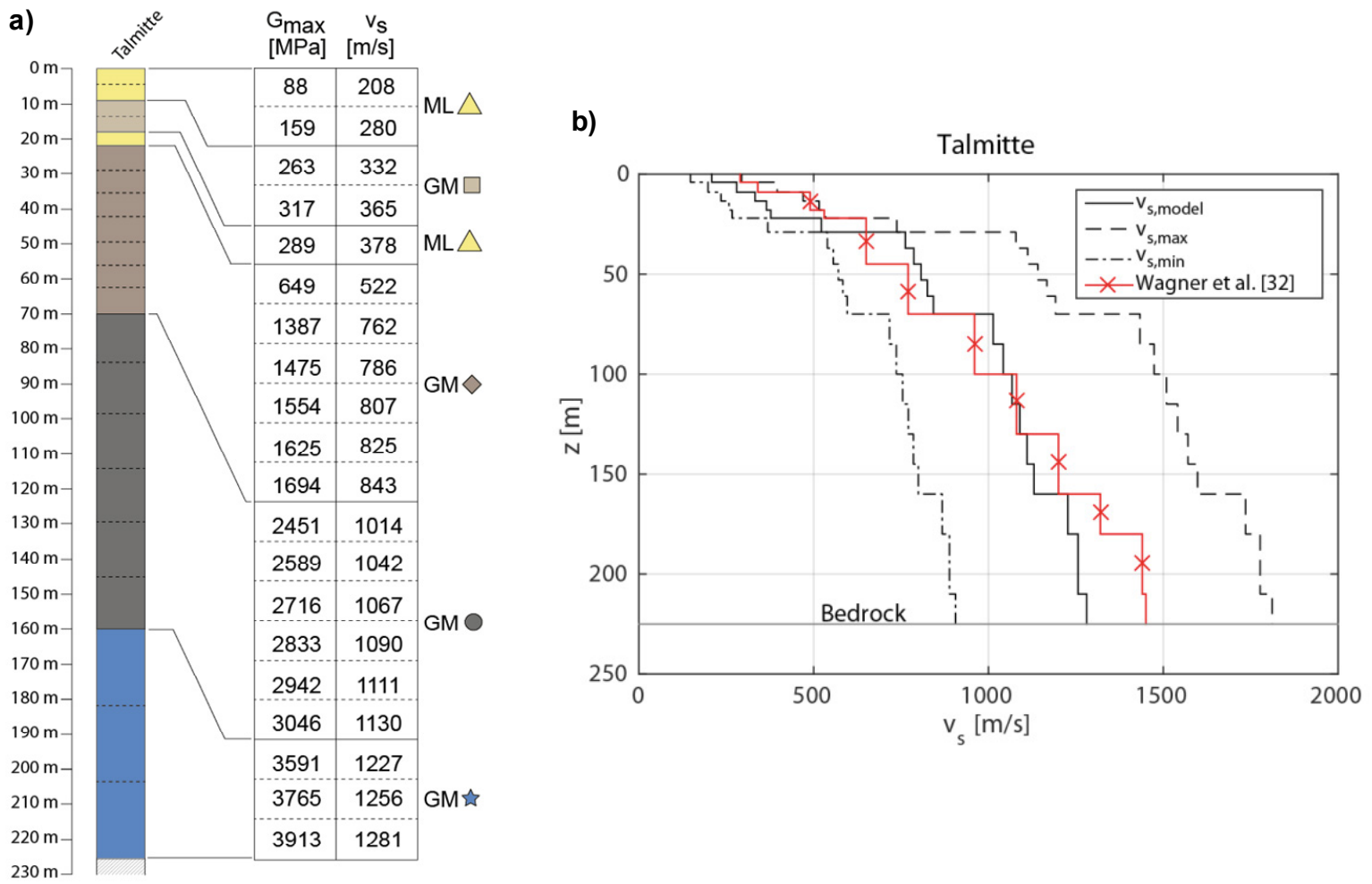

Figure 3.4. Soil profile for the location "Talmitte" with: a) stiffness parameters and b) shear wave velocity profile.

The profiles for two other locations in the valley ("Lonza" and "Rotten"), shown in Figure 3.5 , were determined based on the variation of the geological layers presented by Wagner et al. (2000) and the information available from Résonance et al. (2005) and Marin et al. (2012).
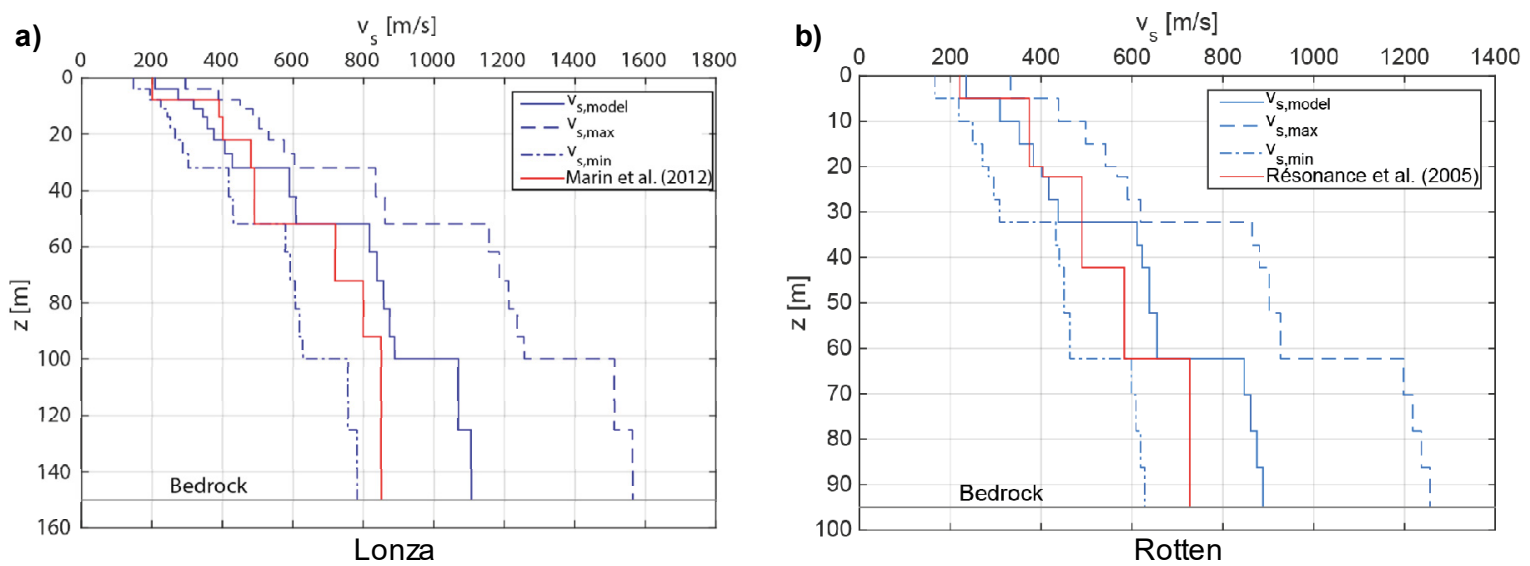

Figure 3.5. Shear wave velocity profiles at locations a) “Lonza" and b) "Rotten".

Additional profiles were generated for the locations "Lonza" and "Rotten" by extrapolating the profile "Talmitte" to these locations. The depth of the bedrock was determined in each case according to the valley cross-section shown in Figure 3.2, namely $95 \mathrm{~m}$ for the location "Rotten" and $150 \mathrm{~m}$ for "Lonza". On the one hand, this simplification has a strong influence on the seismic response at the investigated locations, which will be different 
from the real one, but on the other hand, it simplifies the comparison of the results at the different locations. A better identification of the effects related to the profile depth is made possible based on the common geological profile assumed for the different locations.

All 1D calculations in the time domain were performed using PLAXIS 2D. The soil layers were kept horizontal and parallel, as previously described, and the boundaries of the model were placed far enough from each other to avoid any boundary influences. The width of the model was increased iteratively, and the optimal value was obtained when the further increase of the width did not cause any changes in the response spectrum at the surface, in the centre of the model. Special free-field boundary conditions were used for the vertical boundaries of the soil model. These simulate the continuation of waves into the far field, by reducing reflections at the boundaries (Brinkgreve et al., 2012). The bottom horizontal boundary of the model is rigid for both the frequency and time domain analyses, to account for the presence of the stiff bedrock.

The resulting soil profile for the analysis of one-dimensional propagation of seismic waves is presented in Figure 3.6 for the location "Talmitte". The profiles were cropped according to their depth for the other locations.

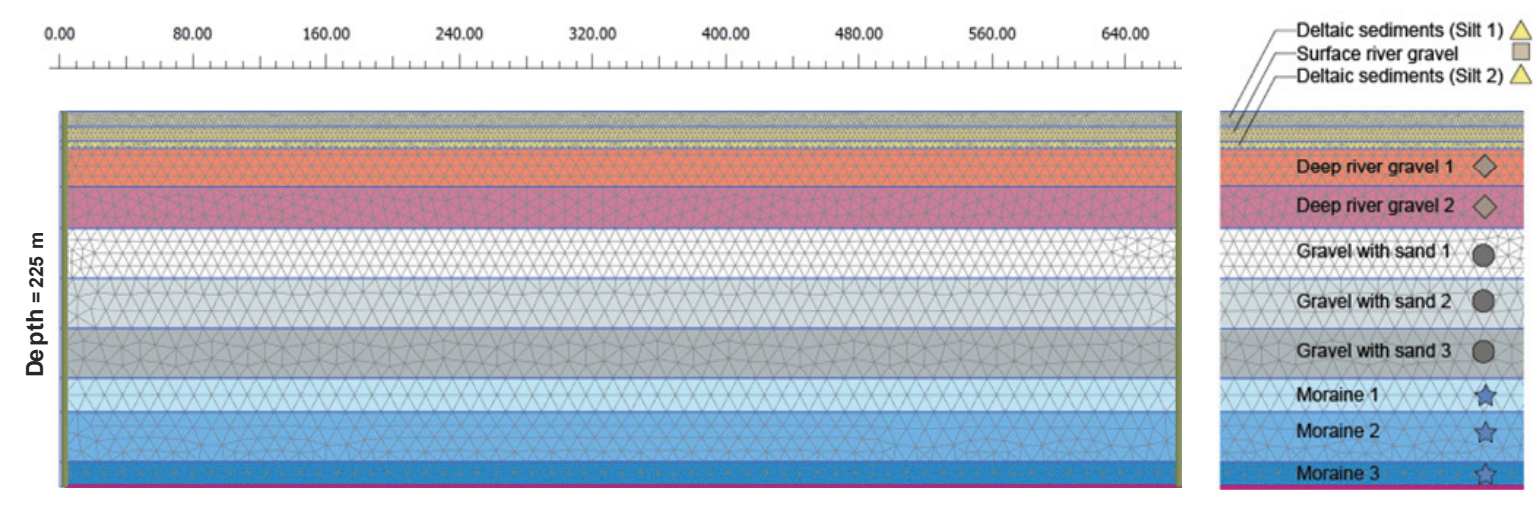

Figure 3.6. Representative soil profile for the Visp valley for 1D calculations in the time domain (average element size $3.88 \mathrm{~m}$ ).

\subsubsection{Soil model for $2 \mathrm{D}$ calculations}

The results presented by Wagner et al. (2000), and shown in Figure 3.2, provided an insight into the variation of the geological profiles at the different locations in the valley. A drilling campaign performed in the area of Visp (Marin et al., 2016) showed geological variations, even for boreholes located close to each other. The efforts to define a perfect ground model, containing all variations of the local geology, are disproportional and exceed the framework of creating the basis for an appropriate selection of the numerical method for seismic investigations in alpine areas. However, the existence of a clear similarity between the geological profiles at the locations investigated was shown by Wagner et al. (2000), who identified the four main geological sub-units present in most cases: surface deltaic sediments, surface river gravels, deep deltaic sediments, and deep river gravels. Based on this, a strong simplifying assumption was made for the $2 \mathrm{D}$ soil model, which was derived using the soil profile at the location "Talmitte". This soil profile 
contains all the main geological sub-units and can be considered as representative for the entire valley.

Figure 3.7 shows the 2D soil model, based on the extrapolation of the geological profile "Talmitte" while maintaining horizontal layering. The assumption of horizontal layering does not fully represent reality, and it introduces additional uncertainties in the results of the investigation, but this additional simplification facilitates the analysis of the effects related to the topography of the valley. The cross-section (A-A) from Figure 3.3 was simplified by cropping it along the coordinate $X=1,400 \mathrm{~m}$ to reduce the model width and to avoid any inconsistencies in the generated mesh caused by the thin layer of loose deltaic sediments, present on the right hand side of the section. The alternation of the granular soil layers is the same as for the 1D calculations (see Figure 3.6).

Standard fixities were associated with the boundaries of the 2D model. An optimal solution had to be found related to the compliance of the element size with the accuracy conditions given by Kuhlemeyer and Lysmer (1973), due to the large size of the model $(1364 \times 259 \mathrm{~m})$.

The FE mesh was obtained after several iterative steps using 15-noded triangular elements and has an average element size of $4.22 \mathrm{~m}$, and a resulting average node-to-node distance of $1.05 \mathrm{~m}$.

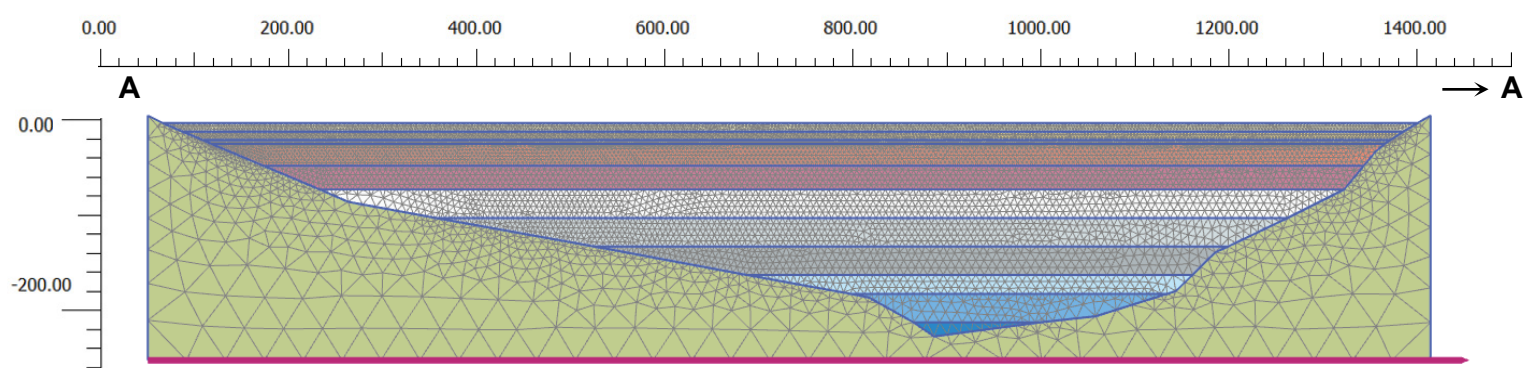

Figure 3.7. Soil model for the 2D calculations in the time domain (average mesh size 4.22m) approximated along section (A-A) shown in Figure 3.3.

\subsubsection{Seismic input motion}

The seismic input motion consists of three earthquake signals from the European Strong Motion Database (Ambraseys et al., 2002): Spitak - Armenia, $1988\left(M_{w}=6.7, R_{\text {epi }}=36\right.$ $\mathrm{km}$, recorded on soft soil), Iceland $2008\left(\mathrm{M}_{\mathrm{w}}=6.2, \mathrm{R}_{\mathrm{epi}}=8 \mathrm{~km}\right.$, recorded on rock) and L'Aquila - Italy, $2009\left(\mathrm{M}_{\mathrm{w}}=6.3, \mathrm{R}_{\mathrm{epi}}=4.3 \mathrm{~km}\right.$, recorded on rock). The choice of such a reduced number of seismic signals was based on the conditions for non-linear seismic analyses introduced by EC8 (2004), which require that a minimum number of three suitable accelerograms should be used in such investigations. This limited number of seismic motions can be adequate to evaluate the differences between the results of the analyses, but it must be increased for a more detailed microzonation study. 
The signals are compliant with the seismic hazard described by Giardini et al. (2004), because the new seismic hazard for Switzerland (SED, 2015) was not available when this study was carried out.

A response spectrum for hard rock sites with $v_{s}>1500 \mathrm{~m} / \mathrm{s}$ ("Hard-rock" in Figure 3.8) was derived according to the procedure described by Lateltin et al. (2004). The uniform hazard spectral values for a return period of 500 years, presented by Giardini et al. (2004) for the Sion area in the Rhone valley (45 km from Visp) were used for this purpose (UHS500 in Figure 3.8). The shape of the "Hard-rock" response spectrum is similar to that of soil class A defined by SIA 261 (2014). This is a conservative assumption, especially in the range of long periods, considering that soil class $A$ includes weathered rock conditions with shear wave velocities $v_{s}>800 \mathrm{~m} / \mathrm{s}$. The spectral value corresponding to the maximum amplification (spectral plateau) for "Hard-rock" is $0.172 \mathrm{~g}$ and was obtained as the average between the UHS500 values at T $=0.1$ and $0.2 \mathrm{~s}$. The spectral value for very low periods is $P G A=0.068 \mathrm{~g}$, considering a factor of 2.5 between the spectral plateau and PGA. The signal Spitak 1988, which was recorded on soft soil, has an increased energy content in the long period range, exceeding the "Hard-rock" spectrum for $T=0.6-1.3 \mathrm{~s}$ and was used to introduce additional conservatism in the input of the analyses. The frequency content of the signal L'Aquila 2009 was modulated by matching its response spectrum to "Hard-rock" (Figure 3.8).

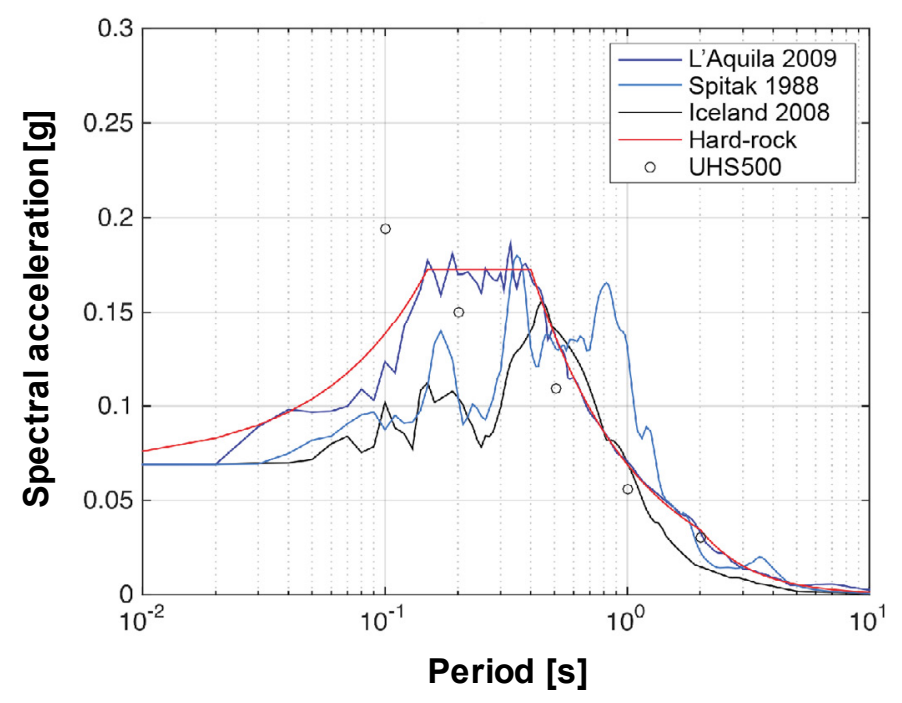

Figure 3.8. Comparison between response spectra of the input signals and Hard-rock (response spectrum derived for sites with $v_{s}>1500 \mathrm{~m} / \mathrm{s}$ ).

All three earthquake signals (Spitak 1988, Iceland 2008, and L'Aquila 2009) were scaled to $P G A=0.068 \mathrm{~g}$. The resulting time histories of the input ground motions can be seen in Figure 3.9. 

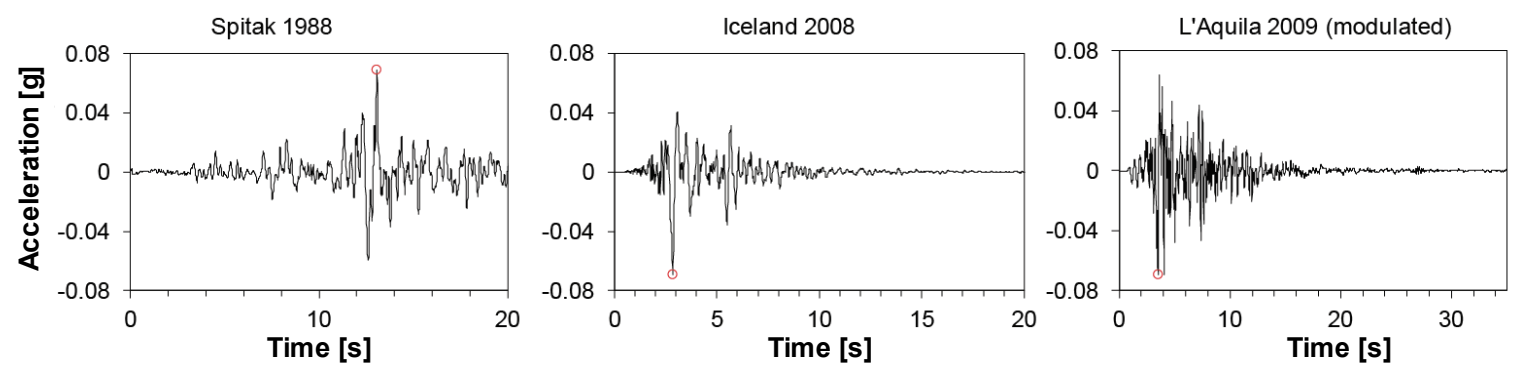

Figure 3.9. Scaled seismic input signals $(P G A=0.068 \mathrm{~g})$.

Alternatively, the deaggregation of the sesimic hazard (Giardini et al., 2004) can be used to determine magnitude-distance scenarios compatible with the local seismicity. Subsequently, input signals can be selected according to the scenarios from the hazard deaggregation and used as input motions for the numerical analyses.

The input motion for the calculations in the frequency domain using EERA was introduced at the bottom of the model as an INSIDE motion (Bardet et al., 2000) to avoid any modification of the selected earthquake signals. The seismic input motion was introduced at the bottom of the FE model, for the other calculations which were performed in PLAXIS 2D, without any additional modifications.

\subsubsection{Parameters of the constitutive models}

\section{Linear-equivalent "constitutive model"}

The linear-equivalent calculations provide results that will be accurate enough in situations when the input seismic signal induces only elastic strains in the soil, since linearequivalent assumptions of soil behaviour are not valid beyond the elastic strain range. However, these calculations represent the most common practice in the geotechnical response analyses and were proved to work well for most cases (Kramer \& Paulsen, 2004). Nevertheless, non-linear models should be used when large strains are mobilised in the ground (i.e. soft soils subjected to strong ground motion).

The linear-equivalent parameters were derived based on the shear modulus and damping curves for sands presented by Seed and Idriss (1970). The lower bound $G / G_{\max }$ curve was used to estimate the stiffness reduction for the soft deltaic sediments, and the upper bound for the moraine material. Values were interpolated between the upper and lower bounds for the other soil layers. These curves are still in extensive use (e.g. Studer et al., 2008), although they are rather old and crude in comparison with the results presented by Darendeli (2001) that also take into account the variability and uncertainty of the data. Thus, the curves after Seed and Idriss (1970) were used as input for the linear-equivalent model to create a relationship with the current practice, before mode advanced models are adopted. The summary of linear-equivalent parameters derived for the soil model chosen can be seen in Figure 3.10. 
a)

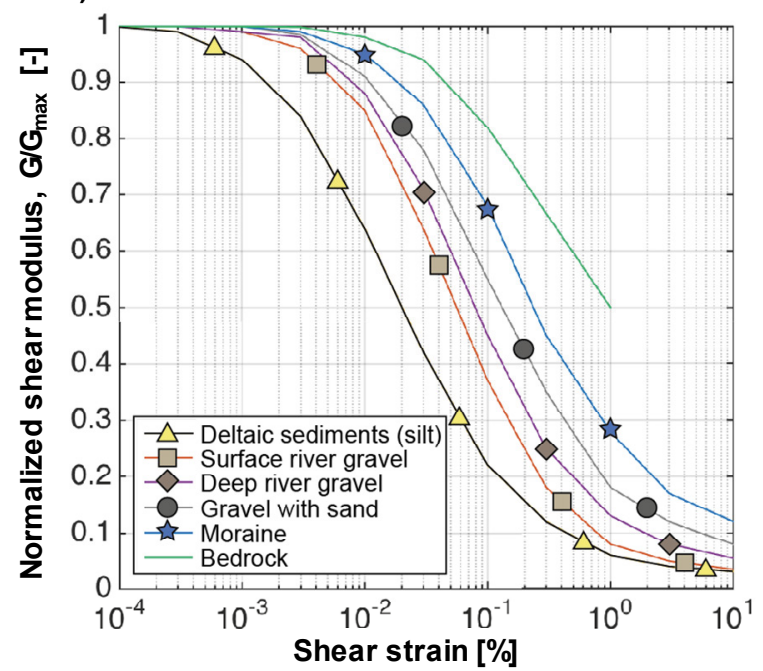

b)

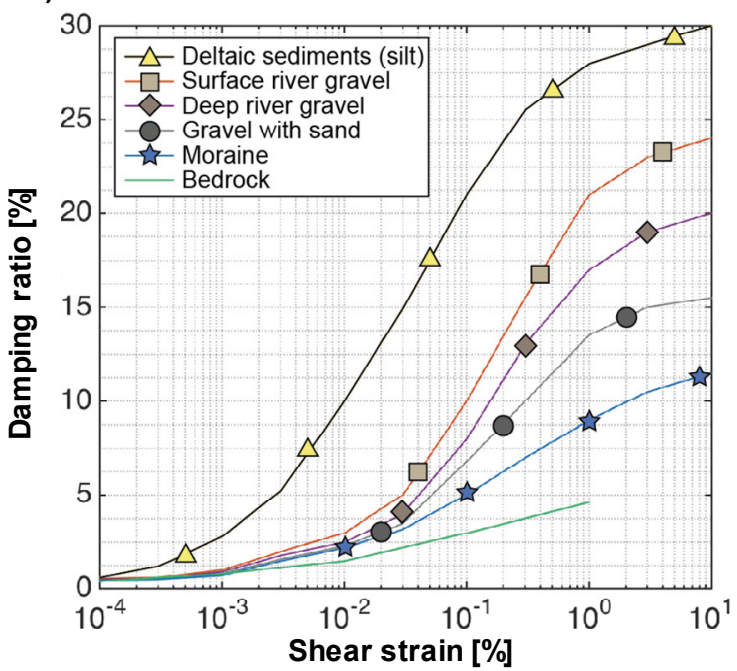

Figure 3.10. Equivalent linear parameters for the different soil layers: a) shear modulus reduction and b) damping ratio values with shear strains.

\section{Linear elastic (LE) constitutive model}

The linear elastic (LE) model simulates the soil behaviour without taking into account any plastic deformations, assuming that strains are directly proportional to the relevant stresses. Material damping, required for a realistic modelling of the soil behaviour, can be introduced using the Rayleigh parameters (Rayleigh and Lindsay, 1945).

The determination of soil parameters for this model was based on 1D calculations in the frequency domain. The shear modulus $G$ for each layer was calculated using the previously introduced maximum value $G_{\max }$ (see Figure 3.4) and the stiffness degradation ratio $G / G_{\max }$ reached at the convergence of the calculations in the frequency domain. Subsequently, the Young's modulus $E$ was easily determined from the value of the shear modulus $\mathrm{G}$, using equation (3.2):

$$
\mathrm{E}=2 \mathrm{G}\left(1+\boldsymbol{v}^{\prime}\right)
$$

where E-Young's modulus

$\mathrm{G}$ - shear modulus

$v^{\prime}$ - Poisson's ratio assumed to be $v^{\prime}=0.3$ all materials.

Similarly, the damping values at convergence were taken from the calculations in the frequency domain and used in the determination of the Rayleigh parameters for the time domain calculations. In this way, the linear elastic and the linear-equivalent models are essentially identical.

The different set of parameters for the LE constitutive model determined for each earthquake, based on the results from the $1 \mathrm{D}$ calculations in the frequency domain. are summarised in Table 3.1. 
Table 3.1. Material parameters for the LE constitutive model.

\begin{tabular}{|c|c|c|c|c|c|}
\hline & Soil & $\gamma\left[\mathrm{kN} / \mathrm{m}^{3}\right]$ & $\mathbf{G} / \mathbf{G}_{\max }[-]$ & $\mathrm{E}$ [MPa] & D [\%] \\
\hline \multirow{11}{*}{ 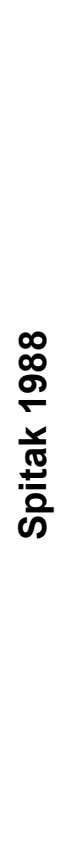 } & Silt 1 & 19.9 & 0.45 & 134.4 & 14.6 \\
\hline & Surface river gravel & 23.4 & 0.19 & 507.3 & 4.7 \\
\hline & Silt 2 & 19.9 & 0.19 & 144.3 & 22.3 \\
\hline & Deep river gravel 1 & 23.4 & 0.85 & 2627.0 & 2.8 \\
\hline & Deep river gravel 2 & 23.4 & 0.84 & 3532.8 & 2.9 \\
\hline & Gravel with sand 1 & 23.4 & 0.91 & 5935.2 & 2.3 \\
\hline & Gravel with sand 2 & 23.4 & 0.89 & 6441.8 & 2.5 \\
\hline & Gravel with sand 3 & 23.4 & 0.88 & 6889.4 & 2.6 \\
\hline & Moraine 1 & 23.4 & 0.95 & 8841.0 & 2.2 \\
\hline & Moraine 2 & 23.4 & 0.95 & 9266.1 & 2.2 \\
\hline & Moraine 3 & 23.4 & 0.95 & 9644.7 & 2.2 \\
\hline \multirow{10}{*}{ 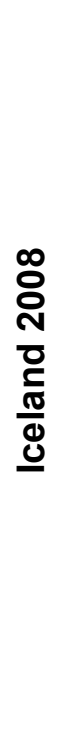 } & Surface river gravel & 23.4 & 0.76 & 576.2 & 3.8 \\
\hline & Silt 2 & 19.9 & 0.34 & 255.1 & 17.4 \\
\hline & Deep river gravel 1 & 23.4 & 0.92 & 2813.8 & 2.2 \\
\hline & Deep river gravel 2 & 23.4 & 0.92 & 3880.6 & 2.2 \\
\hline & Gravel with sand 1 & 23.4 & 0.95 & 6232.4 & 1.9 \\
\hline & Gravel with sand 2 & 23.4 & 0.94 & 6812.7 & 2.0 \\
\hline & Gravel with sand 3 & 23.4 & 0.94 & 7334.6 & 2.0 \\
\hline & Moraine 1 & 23.4 & 0.97 & 9081.8 & 1.8 \\
\hline & Moraine 2 & 23.4 & 0.97 & 9515.2 & 1.8 \\
\hline & Moraine 3 & 23.4 & 0.97 & 9888.4 & 1.8 \\
\hline
\end{tabular}




\begin{tabular}{|c|c|c|c|c|c|}
\hline & Soil & $\gamma\left[\mathrm{kN} / \mathrm{m}^{3}\right]$ & $\mathbf{G} / \mathbf{G}_{\max }[-]$ & $\mathrm{E}$ [MPa] & D [\%] \\
\hline \multirow{11}{*}{ 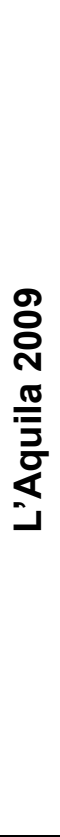 } & Silt 1 & 19.9 & 0.57 & 174.0 & 11.6 \\
\hline & Surface river gravel & 23.4 & 0.76 & 573.1 & 3.8 \\
\hline & Silt 2 & 19.9 & 0.33 & 249.0 & 17.6 \\
\hline & Deep river gravel 1 & 23.4 & 0.91 & 2784.6 & 2.3 \\
\hline & Deep river gravel 2 & 23.4 & 0.91 & 3841.7 & 2.3 \\
\hline & Gravel with sand 1 & 23.4 & 0.95 & 6201.3 & 1.9 \\
\hline & Gravel with sand 2 & 23.4 & 0.94 & 6767.8 & 2.0 \\
\hline & Gravel with sand 3 & 23.4 & 0.93 & 7265.2 & 2.1 \\
\hline & Moraine 1 & 23.4 & 0.97 & 9032.0 & 1.9 \\
\hline & Moraine 2 & 23.4 & 0.97 & 9471.2 & 1.9 \\
\hline & Moraine 3 & 23.4 & 0.97 & 9851.3 & 1.9 \\
\hline
\end{tabular}

\section{Linear elastic perfectly plastic Mohr-Coulomb (MC) constitutive model}

Mohr-Coulomb (MC) is a linear elastic perfectly plastic constitutive model, which can represent irreversible plastic strains (Brinkgreve et al., 2014). However, these are developing at constant yield stress and no material hardening or softening can be modelled. It is known that this model is not realistic for dynamic analyses, as it over-estimates damping and under-estimates the propagation of highly frequent waves for seismic signals inducing plastic strains. However, the decision of using it in the analysis was made based on its extensive use in current practice, as in the case of linear-equivalent parameters based on the curves from Seed and Idriss (1970). Additionally to the strength parameters $\varphi^{\prime}$ and $C^{\prime}$, which were estimated according to VSS SN670010 (1999), the stiffness parameters for the MC constitutive model were determined based on the shear wave velocity profile in Figure 3.4b. A summary of these parameters including the lower $\left(E_{\min }\right)$ and upper $\left(E_{\max }\right)$ bounds of the stiffness profile is available in Table 3.2. 
Table 3.2. Material parameters for the linear elastic perfectly plastic MC constitutive model.

\begin{tabular}{|c|c|c|c|c|c|c|}
\hline & $\begin{array}{c}\gamma \\
{\left[\mathrm{kN} / \mathrm{m}^{3}\right]}\end{array}$ & $\begin{array}{l}\varphi^{\prime} \\
{\left[^{\circ}\right]}\end{array}$ & $\begin{array}{c}\mathrm{c}^{\prime} \\
{[\mathrm{kPa}]}\end{array}$ & $\begin{array}{c}E_{\min } \\
{[\mathrm{MPa}]}\end{array}$ & $\begin{array}{l}\mathbf{E}_{\text {model }} \\
\text { [MPa] }\end{array}$ & $\begin{array}{c}E_{\max } \\
{[\mathrm{MPa}]}\end{array}$ \\
\hline Silt 1 & 19.9 & 33.9 & 6.5 & 160.3 & 320.6 & 641.3 \\
\hline Surface river gravel & 23.4 & 35 & 0 & 377.4 & 754.8 & 1509.6 \\
\hline Silt 2 & 19.9 & 33.9 & 0 & 375.8 & 751.6 & 1503.3 \\
\hline Deep river gravel 1 & 23.4 & 35 & 0 & 1521.6 & 3043.2 & 6086.4 \\
\hline Deep river gravel 2 & 23.4 & 35 & 0 & 2111.3 & 4222.4 & 8444.9 \\
\hline Gravel with sand 1 & 23.4 & 35 & 0 & 3276.2 & 6552.4 & 13104.8 \\
\hline Gravel with sand 2 & 23.4 & 35 & 0 & 3606.6 & 7213.1 & 14426.3 \\
\hline Gravel with sand 3 & 23.4 & 35 & 0 & 3892.5 & 7785.0 & 15570.0 \\
\hline Moraine 1 & 23.4 & 35 & 0 & 4668.6 & 9337.2 & 18674.4 \\
\hline Moraine 2 & 23.4 & 35 & 0 & 4895.1 & 9790.2 & 19580.5 \\
\hline Moraine 3 & 23.4 & 35 & 0 & 5086.8 & 10173.6 & 20347.1 \\
\hline
\end{tabular}

Hardening Soil Small Strain (HSs) constitutive model

The Hardening Soil Small Strain (HSs), as described by Brinkgreve et al. (2014), can model the soil behaviour using higher stiffness values $\left(\mathrm{G}_{0}\right)$ at small strains, and stiffness parameters which are stress- and strain-dependent at large strains. HSs presents clear advantages over the models presented previously and is suitable for seismic response analyses. Figure 3.11a shows the stress-strain relationship for a triaxial compression test with definition of the relevant stiffness parameters and the total yield contour for the HSs model is shown in the principal stress space in Figure 3.11b.

a)

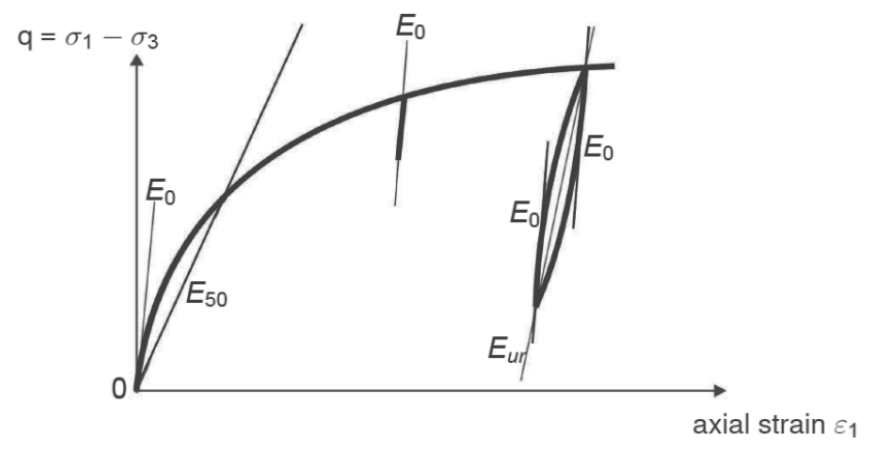

b)

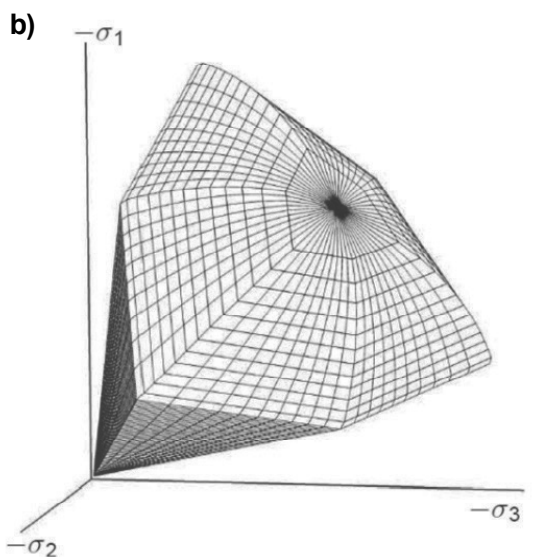

Figure 3.11. HSs constitutive model: a) Stress-strain relationship modelled for a triaxial test and b) total yield surface (Brinkgreve et al., 2012). 
The strength parameters are the same as in the case of the MC model, and the stiffness parameters were determined using results from laboratory investigations and the relationships suggested by Alpan (1970) and Brinkgreve et al. (2014). An additional damping of $3 \%$ was introduced using Rayleigh coefficients, for a more accurate representation of the soil response in the range of small strains, where no hysteretic damping is mobilised. This constitutive model was applied only for the soil directly below the surface, expected to experience highly plastic deformations. A summary of the parameters can be found in Table 3.3.

Table 3.3. Material parameters for the HSs constitutive model.

\begin{tabular}{lcccccccc}
\hline & $\begin{array}{c}\gamma \\
{\left[\mathbf{k N} / \mathbf{m}^{3}\right]}\end{array}$ & $\begin{array}{c}\varphi^{\prime} \\
{\left[{ }^{\circ}\right]}\end{array}$ & $\begin{array}{c}\mathbf{c}^{\prime} \\
{[\mathbf{k P a}]}\end{array}$ & $\begin{array}{c}\mathbf{E}_{50}{ }^{\text {ref }} \\
{[\mathrm{MPa}]}\end{array}$ & $\begin{array}{c}\mathbf{E}_{\text {oed }}{ }^{\text {ref }} \\
{[\mathrm{MPa}]}\end{array}$ & $\begin{array}{c}\mathbf{E}_{\text {ur }}{ }^{\text {ref }} \\
{[\mathrm{MPa}]}\end{array}$ & $\begin{array}{c}\gamma_{0.7} \\
{[-]}\end{array}$ & $\begin{array}{c}\mathbf{G}_{0}{ }^{\text {ref }} \\
{[\mathrm{MPa}]}\end{array}$ \\
\hline Silt 1 & 19.9 & 33.9 & 6.5 & 19.3 & 19.3 & 58.0 & $4.5 \cdot 10^{-5}$ & 120.7 \\
Surface river gravel & 23.4 & 35 & 0 & 77.2 & 77.2 & 231.7 & $15 \cdot 10^{-5}$ & 289.7 \\
Silt 2 & 19.9 & 33.9 & 0 & 46.3 & 46.3 & 138.8 & $4.5 \cdot 10^{-5}$ & 289.1 \\
Deep river gravel 1 & 23.4 & 35 & 0 & 303.0 & 303.0 & 909.1 & $20 \cdot 10^{-5}$ & 1136.4 \\
\hline
\end{tabular}

\subsection{Results of 1D modelling}

The "Rhonetal" microzonation study performed by Résonance et al. (2005) and the elastic response spectrum for soil class $C\left(v_{s, 30}=300-500 \mathrm{~m} / \mathrm{s}\right.$ according to SIA 261,2014$)$ were used as a basis for comparison in the interpretation of the results. The "Rhonetal" spectrum was determined from computer simulations performed by Résonance et al. (2005), using a 2D linear-equivalent code based on the method of Aki and Larner (1970). Therefore, this spectrum incorporates the influence of local topography and facilitates a more accurate evaluation of the seismic response than the design spectra for soil class $\mathrm{C}$. According to the Swiss code SIA 261 (2014), such microzonation spectra are recommended over of the design spectra available in the code.

\subsubsection{D modelling in the frequency domain using equivalent-linear soil properties}

In a first step, the response spectrum at the surface of the model in the location "Talmitte" was investigated. The response spectra for all three earthquakes show peak spectral values between $\mathrm{T}=0.8-0.9 \mathrm{~s}$ (Figure $3.12 \mathrm{a}$ ), which correspond to the natural period of the soil profile that was evaluated analytically at the relevant location:

$\mathrm{T}_{\mathrm{n}}=\frac{1}{\mathrm{f}_{\mathrm{n}}}=\frac{4 \cdot \mathrm{H}}{\mathrm{v}_{\mathrm{s}}}=0.91 \mathrm{~s}$

where $T_{n}-$ first natural period of the soil profile [s] 


$$
\begin{aligned}
& f_{n}-\text { first natural frequency of the soil profile }[\mathrm{Hz}] \\
& \mathrm{V}_{s}-\text { average shear wave velocity of the soil profile }[\mathrm{m} / \mathrm{s}] \\
& \mathrm{H}-\text { height of the soil profile }[\mathrm{m}] .
\end{aligned}
$$

The averaged surface response lies above the reference spectra and it shows the same peak (Figure 3.12b).
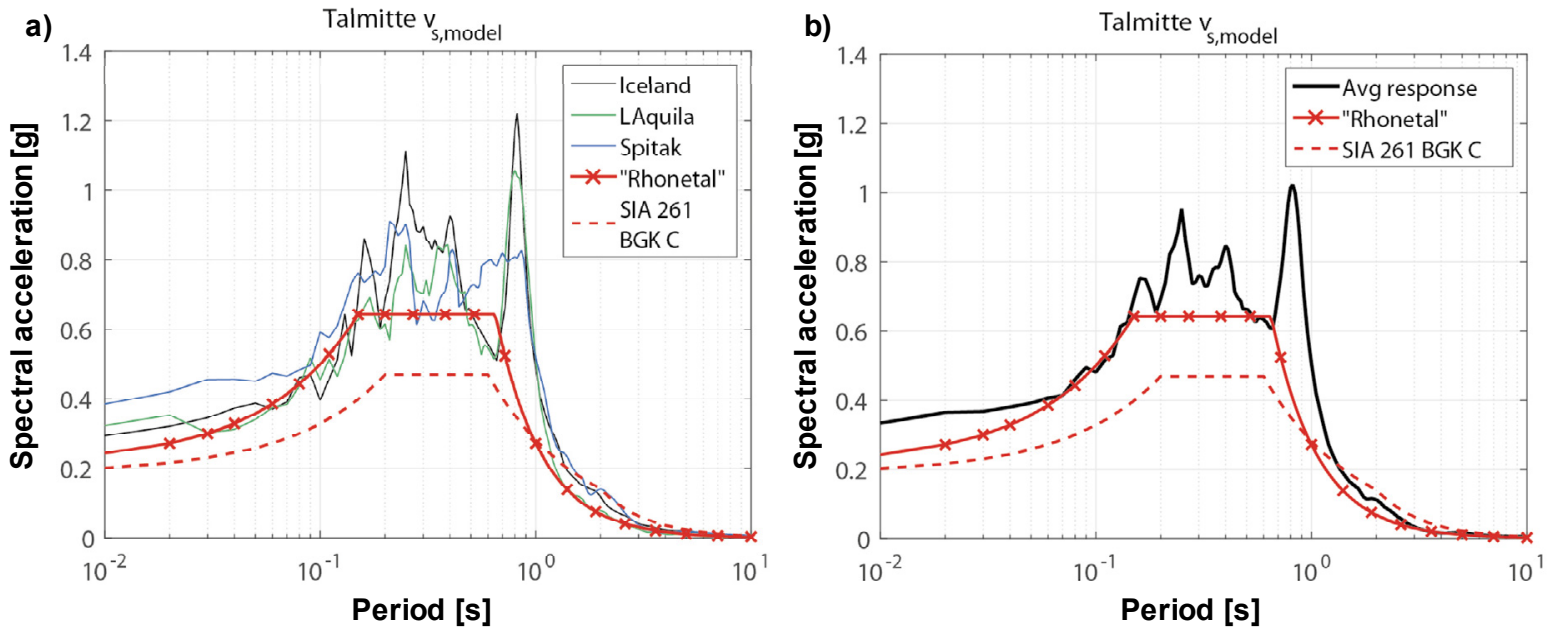

Figure 3.12. 1D EERA surface response spectra at location "Talmitte": a) individual signals and b) averaged response.

The influence of the depth of the soil profile is the only topography-related factor, which can influence the 1D calculations. In this sense, the same analysis was repeated at the other two locations, "Lonza" and "Rotten". A short summary of the dynamic properties of the soil profiles at the selected locations can be seen in Table 3.4. The natural frequencies $f_{n}$ of the profiles were determined using equation (3.3).

Table 3.4. Dynamic properties of the soil profiles at the selected locations in the Visp valley crosssection (Figure 3.2 and 3.3).

\begin{tabular}{lcccc}
\hline Location & $\mathbf{H}[\mathbf{m}]$ & $\mathbf{v}_{\mathbf{s}}[\mathbf{m} / \mathbf{s}]$ & $\mathbf{T}_{\mathbf{n}}[\mathbf{s}]$ & $\mathbf{f}_{\mathbf{n}}[\mathrm{Hz}]$ \\
\hline Talmitte & 225 & 985.8 & 0.91 & 1.10 \\
Lonza & 150 & 860.4 & 0.7 & 1.43 \\
Rotten & 95 & 728.3 & 0.52 & 1.92 \\
\hline
\end{tabular}

The results, displayed in the form of response spectra at the surface, are shown in Figure 3.13. The identification of resonance peaks at the natural periods of the soil profiles is again possible, particularly at the location "Rotten". At this location, the calculated surface response shows spectral values up to $1.4 \mathrm{~g}$ and two major peaks at $\mathrm{T}=0.24 \mathrm{~s}$ and $\mathrm{T}=0.5 \mathrm{~s}$. 

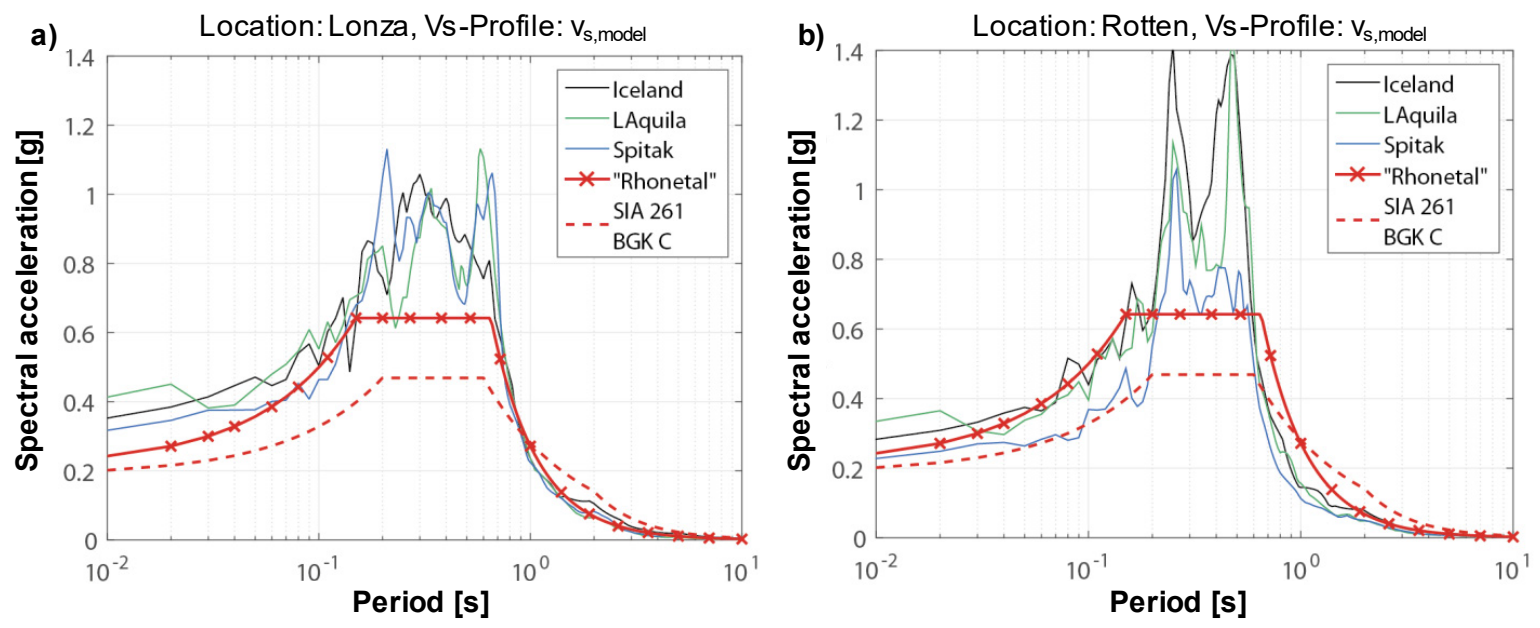

Figure 3.13. 1D EERA surface response spectra at the locations a) "Lonza" and b) "Rotten".

Compared to the location "Talmitte", the peak values for "Rotten" are higher, although this soil profile is the shallowest one $(\mathrm{H}=95 \mathrm{~m})$. The highest peaks of the seismic response at the location "Rotten" are generated by the earthquakes Iceland and L'Aquila. A short evaluation of the energy content of the three earthquakes using the Fourier transformation shows that these two input signals have high energy contents at frequencies around $2 \mathrm{~Hz}$ (Figure 3.14), which are very close to the first natural frequency of the soil profile $f_{n}=1.92$ $\mathrm{Hz}$ (see Table 3.4). These results show that the deepest profile does not always imply the highest surface response. In this case, the shallowest of the three different profiles ("Rotten") exhibits the highest spectral acceleration peaks.
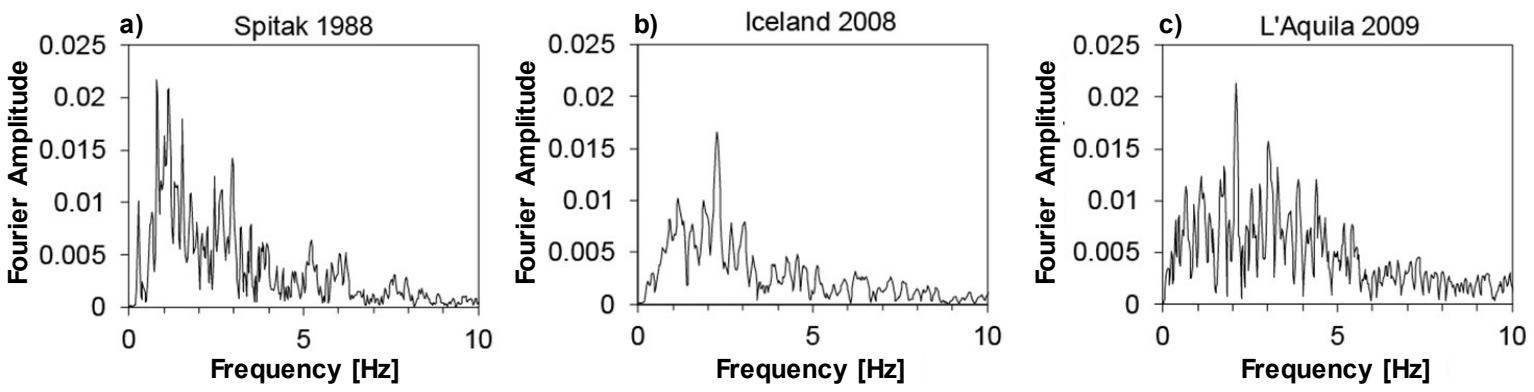

Figure 3.14. Fourier spectra of the three input motions a) Spitak, b) Iceland, and c) L'Aquila.

Shear wave velocities are another factor affecting the surface response in the case of 1D equivalent-linear analyses. A sensitivity analysis was performed for the soil profile "Talmitte", assuming the upper and lower bound profiles of shear wave velocities presented in Figure 3.4b.

The reduced shear wave velocity profile $v_{s, \min }$ causes lower values of the spectral accelerations, compared to the normal case. The average response spectrum is, in this case, in the same range or even below the reference spectra from the microzonation study. A shift of the average response spectrum towards the right, in the range of larger periods, occurs due to the reduced values of the shear wave velocities. The value of the maximum ground acceleration corresponds to the reference values (Figure 3.15). 

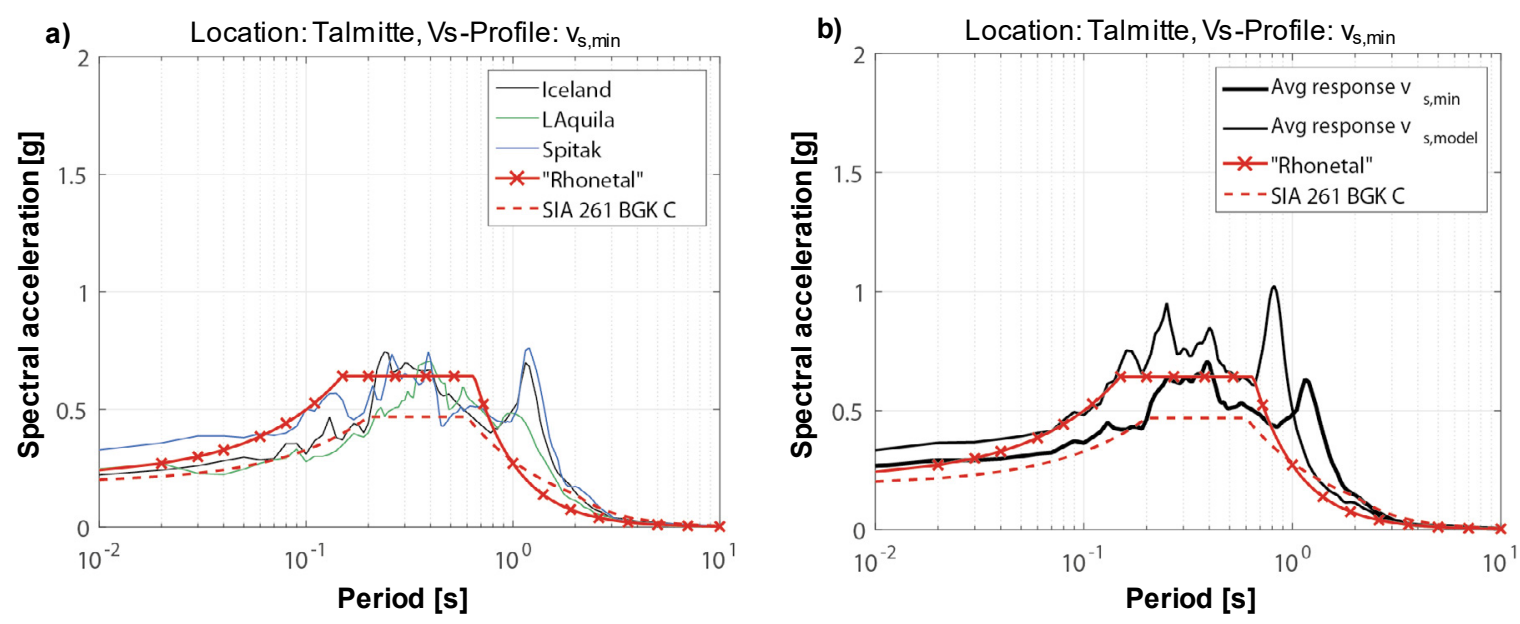

Figure 3.15. 1D EERA surface response spectra at the location "Talmitte" for the lower bound of the shear wave velocity profile: a) individual signals; b) averaged response.

An opposite effect can be observed in the results of the simulations based on the increased values of the shear wave velocities $v_{s, \max }$. The peaks of the average response reach $1.5 \mathrm{~g}$, while in the initial case $\left(\mathrm{v}_{\mathrm{s} \text {,model }}\right)$ they were at $1 \mathrm{~g}$. A shift of the spectrum towards the left can be observed as well, indicating that the soil column has an increased average stiffness. In this case, the reference spectra are below the average spectrum up to a period of $\mathrm{T}=0.7 \mathrm{~s}$ (Figure 3.16).
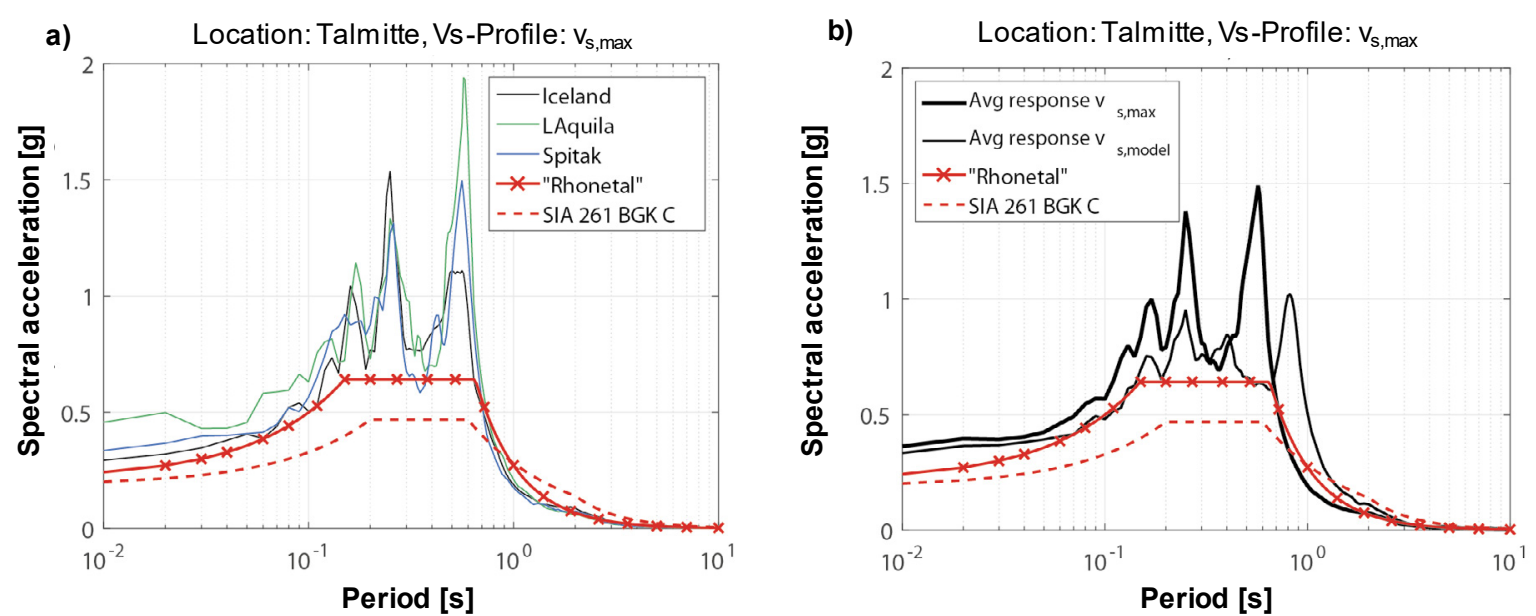

Figure 3.16. 1D EERA surface response spectra at the location "Talmitte" for the upper bound of the shear wave velocity profile: a) individual signals; b) averaged response. 


\subsubsection{D modelling in the time domain using a linear elastic (LE) constitutive model}

The results of the 1D numerical calculations under linear elastic assumptions in the time domain at the location "Talmitte" were obtained by incremental integration of the equations of motion. The stiffness parameters were considered in the initial step constant and strain-independent to facilitate the comparison with the results in the frequency domain.

The response spectra of the horizontal accelerations obtained at the surface for the three earthquakes were compared with the reference spectra, i.e. microzonation spectrum "Rhonetal" (Wagner et al., 2000) and the code spectrum for Zone 3b BGK C (SIA 261, 2014). No vertical accelerations or displacements were modelled at the surface of the model, as expected under 1D LE conditions with shear waves originating at the base and horizontal soil layers. The value of the PGA is overestimated in this case, as well as the spectral accelerations in the plateau range, starting from $T=0.2 \mathrm{~s}$, with some exceptions between $T=0.5-0.7 \mathrm{~s}$. The tendency of the average spectrum obtained is to shift towards the right, indicating a behaviour of the soil during the seismic event softer than given by the reference spectra. The clear peak between $T=0.8-0.9 \mathrm{~s}$ represents an indication of resonance at the first natural period of the soil-profile $T_{n}=0.91 \mathrm{~s}$ (Figure 3.17).
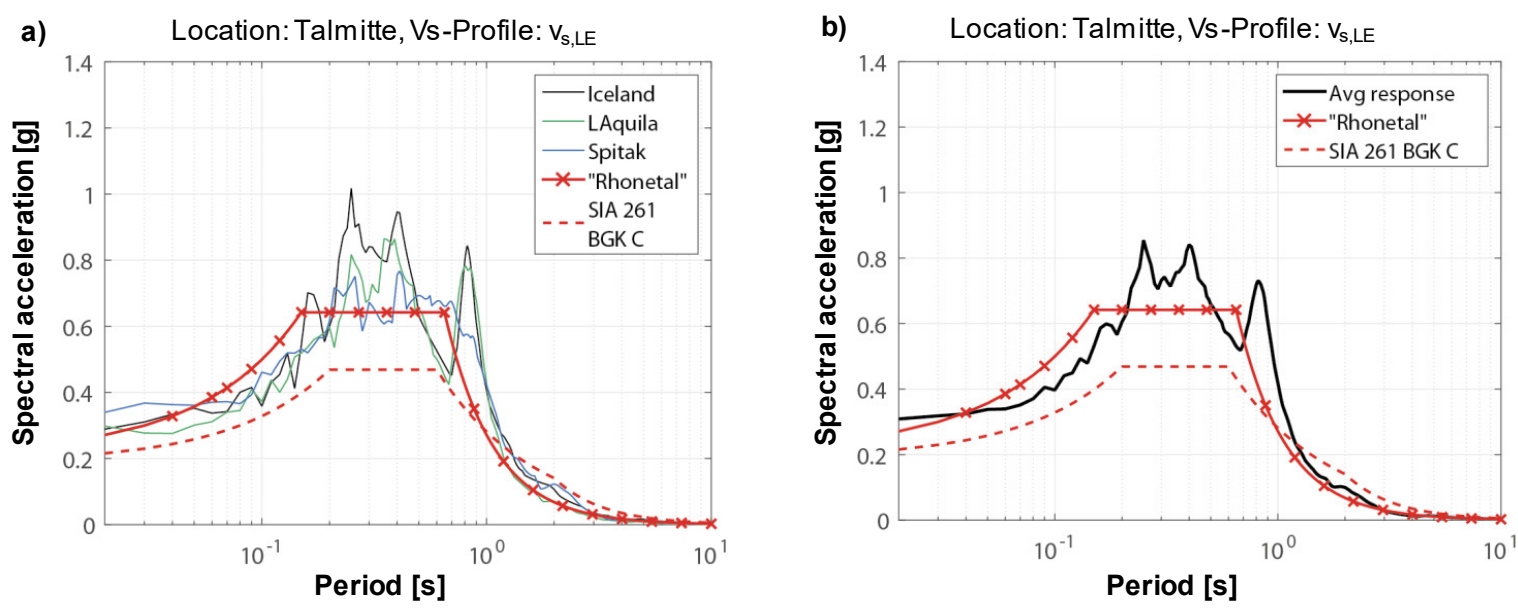

Figure 3.17. 1D LE surface response spectra at the location "Talmitte": a) individual signals; b) averaged response.

The comparison of the average response spectra at the location "Talmitte" from the 1D analyses in the frequency (EERA), and in the time domain using the LE constitutive model (1D LE), is shown in Figure 3.18. The results of the two independent numerical approaches are very similar and the spectral shapes are nearly parallel, as expected. The spectral values from the time domain analysis (1D LE) show an increased damping for $\mathrm{T}<$ 0.3 and $T>0.5$, when compared with the frequency-domain results. This behaviour is closely related to the mathematical formulation of the Rayleigh damping, as shown by Brinkgreve et al. (2014), and to the high damping values in the silty material (see Table 3.1). 


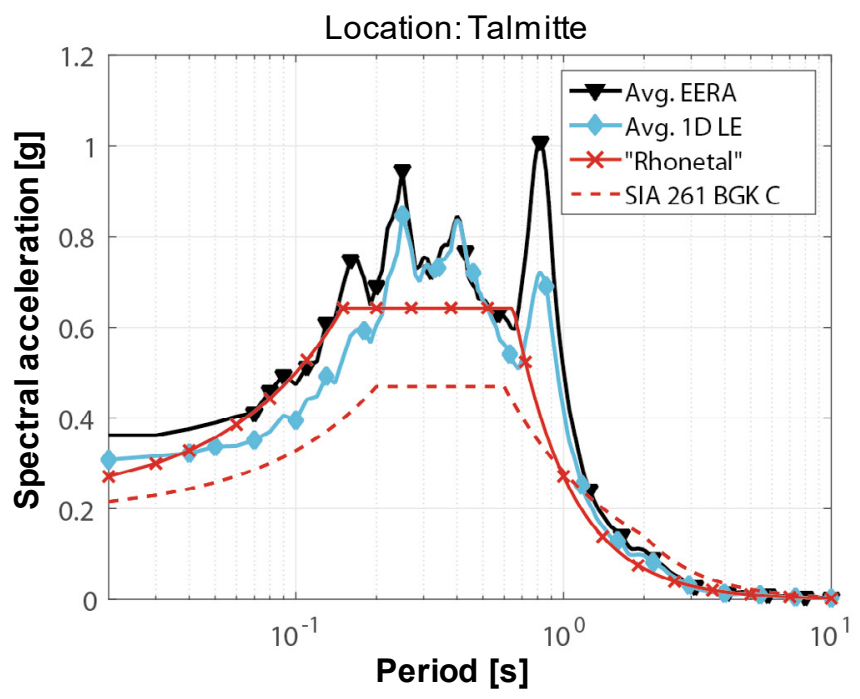

Figure 3.18. Average response spectra in the frequency domain (EERA) and in the time domain (1D LE).

\subsubsection{D modelling in the time domain using the linear elastic perfectly plastic Mohr- Coulomb constitutive model (MC)}

A step further in the 1D calculations was made by introducing in the analyses the linear elastic perfectly plastic constitutive model with a Mohr-Coulomb failure criterion. The results obtained under the assumption of linear elastic perfectly plastic soil behaviour at the location "Talmitte" can be seen in Figure 3.19 in the form of acceleration response spectra at the surface of the soil model. As in the case of LE calculations, no vertical accelerations or seismic settlements were modelled by the MC constitutive model. The spectral values are in the range of the Rhonetal microzonation spectrum, excepting the period range $\mathrm{T}=0.2-0.4 \mathrm{~s}$, where the peaks reach $1.3 \mathrm{~g}$. A further resonance peak indicating the first natural frequency of the soil profile can be observed at $T_{n}=0.8 \mathrm{~s}$.
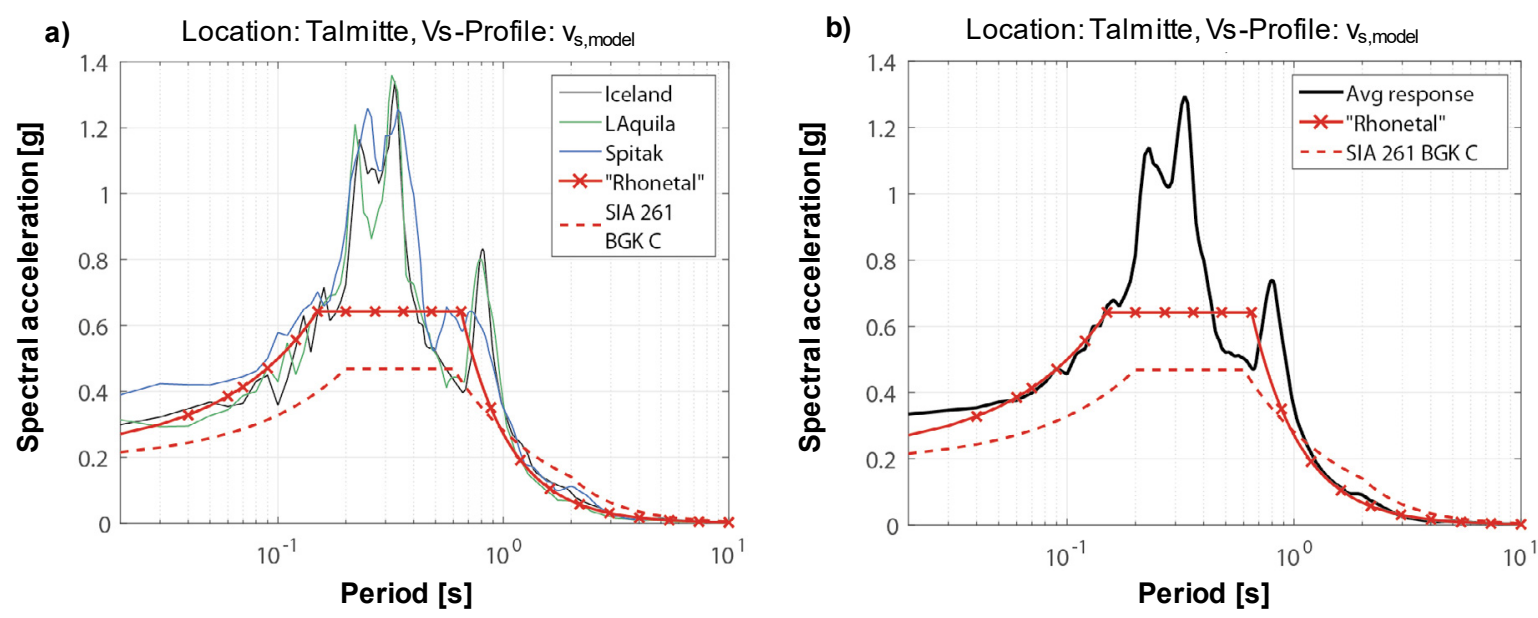

Figure 3.19. 1D MC surface response spectra at the location "Talmitte": a) individual signals; b) averaged response. 


\subsubsection{D modelling in the time domain using the Hardening Soil Small Strain (HSs) constitutive model}

The final set of calculations performed under 1D conditions represent the transition to more complex investigations introducing the HSs constitutive model in the numerical analyses for the top $45 \mathrm{~m}$ of the soil profile "Talmitte". Plastic deformations, material hardening, and hysteretic cyclic behaviour can be modelled at the cost of a more extended set of parameters and longer calculation times. The results show that the calculated response spectra are closer to the reference spectra and the average response fits the Rhonetal microzonation better than in all previous cases (Figure 3.20).
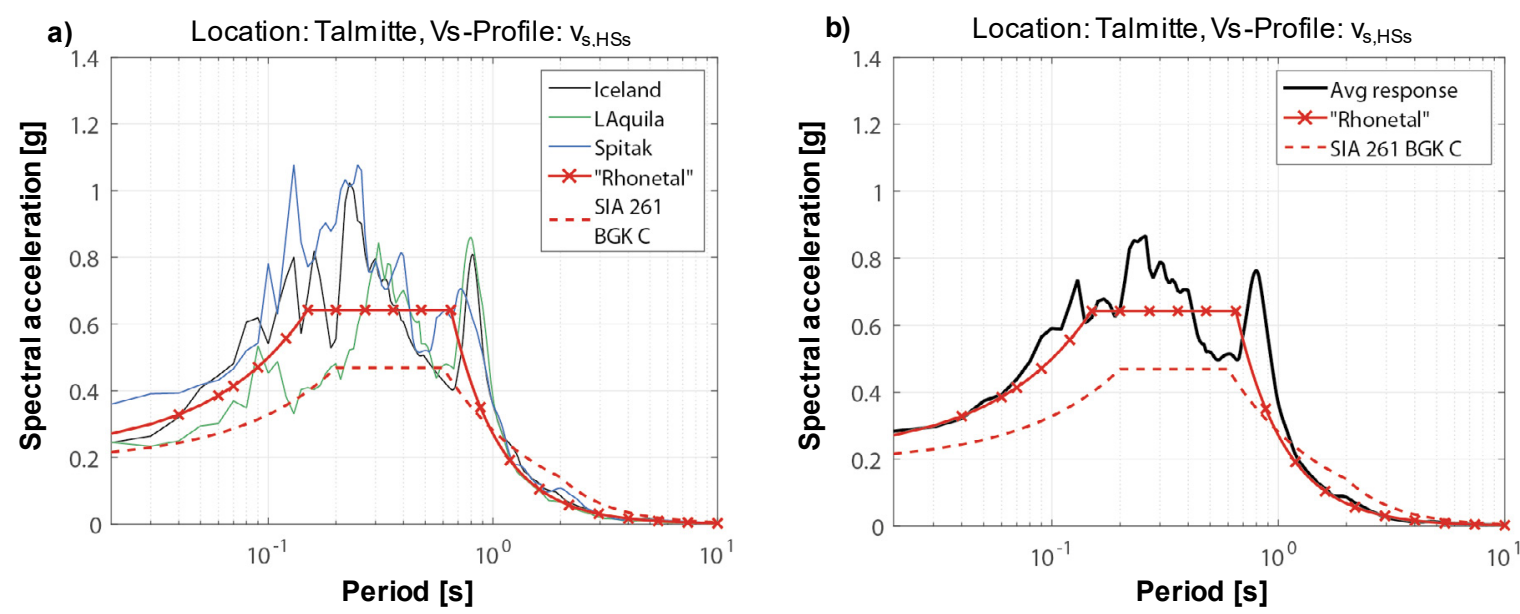

Figure 3.20. 1D HSs surface response spectra at the location "Talmitte": a) individual signals; b) averaged response.

Additional to the horizontal accelerations, the 1D HSs model was able to capture the vertical displacements (seismic settlements) of the soil profile and corresponding accelerations. The stiffness of the soil layers modelled with HSs decreased during the seismic shaking, due to the strains induced in the soil, leading to vertical displacements at the surface of the ground model. Figure 3.21 shows the evolution of the vertical displacements with time and the corresponding vertical spectral accelerations, modelled at the location "Talmitte" with the three earthquake signals. The vertical displacements are very similar for the signals Iceland and L'Aquila, with a residual value of $0.57 \mathrm{~cm}$, and they develop in a different way for the Spitak signal, reaching a residual value of $0.8 \mathrm{~cm}$ in this case. The corresponding vertical spectral accelerations follow the same trend and the highest values of $0.28 \mathrm{~g}$ at $\mathrm{T} \approx 0.2 \mathrm{~s}$ are modelled for the Spitak signal. 

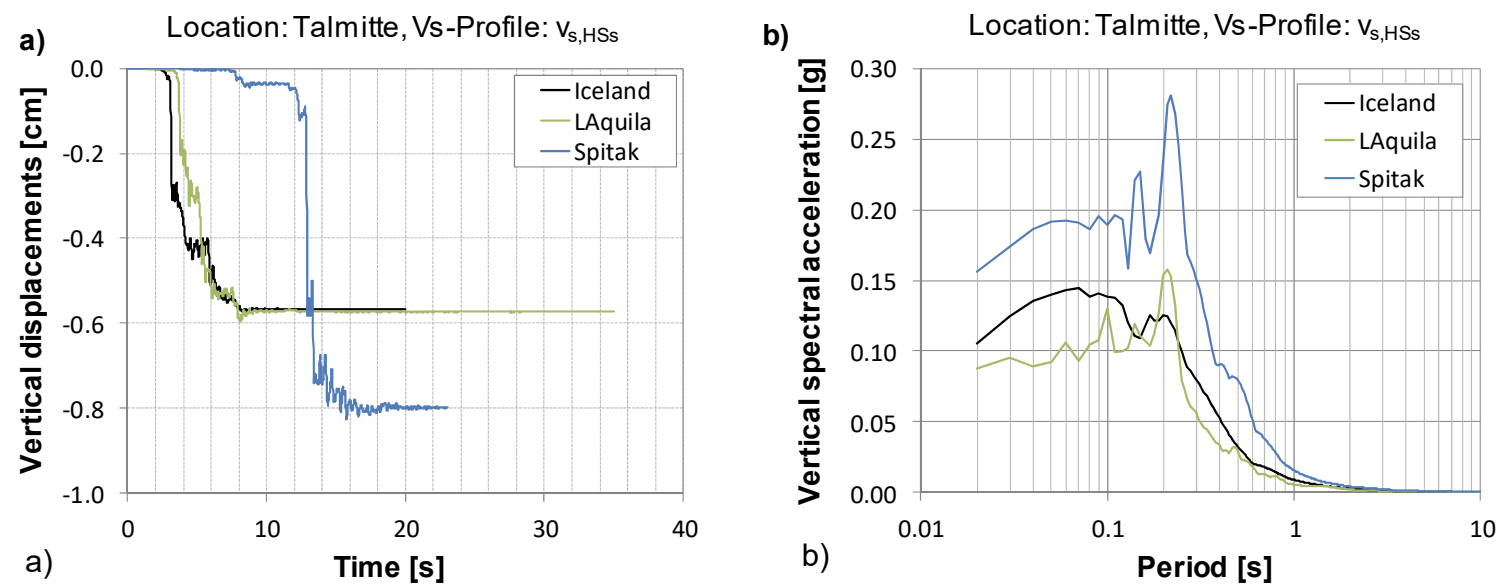

Figure 3.21. 1D HSs modelling results: a) development of vertical displacements at location "Talmitte", and b) vertical acceleration spectra.

\subsubsection{Summary of 1D modelling}

Figure 3.22a shows the comparison of the results obtained from all 1D calculations for the soil profile "Talmitte". The 1D HSs and 1D LE analyses provided results similar to the microzonation spectrum "Rhonetal". Moreover, the results obtained from the 1D HSs analysis can capture the seismic settlements developing in the soil, due to stiffness reduction caused by seismic strains.

The results from EERA and $1 D M C$ are in a similar range with the output of the 1D LE analysis, with certain exceptions. The results obtained from EERA in the frequency domain show an increased soil response at $T=0.8-0.9 \mathrm{~s}$, close to the natural period of the soil profile. This shows the sensitivity of such analyses to resonance effects in the range of the natural period. The results obtained from 1D MC showed spectral values at the natural period of the soil profile similar to the other analyses. However, this model overestimated the spectral response at $T=0.2-0.3 \mathrm{~s}$, due to its limitations outside the elastic range.

Figure 3.22b shows depth profiles of the maximum acceleration (PGA) for the Iceland signal at the location "Talmitte". The shapes of the profiles are very similar and they all show an abrupt increase of the PGA values in the top $22 \mathrm{~m}$ of the soil profile. This corresponds to the top-most layers of river gravel and silty material. The PGA values at the surface around $0.25 \mathrm{~g}$ are also very close to each other, with the exception of the HSs results, which marginally exceed $\mathrm{PGA} \approx 0.2 \mathrm{~g}$. 

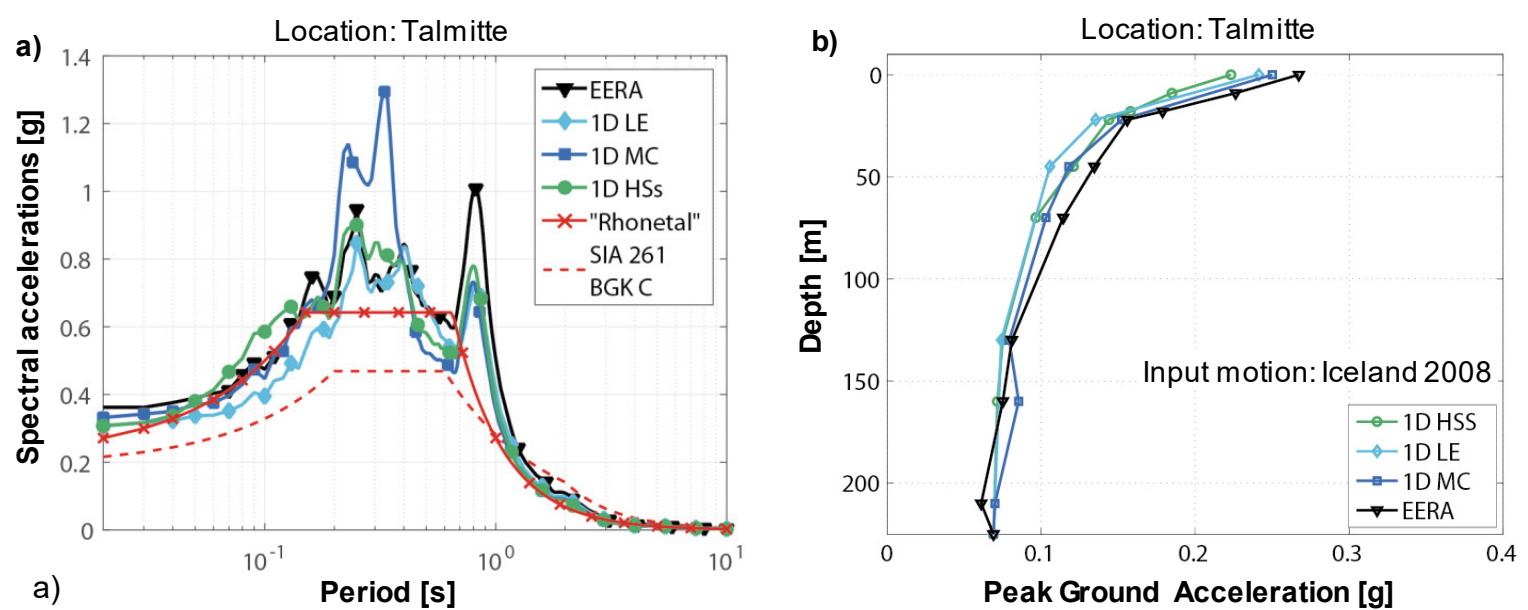

Figure 3.22. a) Summary of the average response spectra for the 1D linear calculations; b) Depth profile of PGA for the earthquake Iceland 2008.

The summary of the calculations under the 1D conditions showed that the most appropriate method for 1D seismic investigations is in the time domain, with a hybrid ground model: HSs for the soil below the surface (45 $\mathrm{m}$ in this analysis) and MC for the deep soil layers. The results of this analysis are the closest to the microzonation spectrum, considered as reference in the current investigations. The most significant difference is the softer soil behaviour indicated by response peaks modelled at the natural period of the soil profile that are outside the plateau area of the reference spectrum "Rhonetal". This analysis was also the only one able to provide information related to the seismic settlements of the soil profile.

Possible alternatives are the frequency domain investigations under linear-equivalent assumptions (EERA) and the time domain ones using linear elastic assumptions (1D LE). They require a simple set of material parameters, and the results provided are relatively accurate. As the comparison in Figure 3.22a showed, the results obtained with e.g. the LE model are very similar to HSs, in terms of horizontal spectral accelerations. They represent, therefore, an alternative solution, especially for weak seismic events that do not induce significant plastic strains in the soil.

The use of the constitutive model Mohr-Coulomb in dynamic calculations does not represent a good solution. This model is unable to represent the soil behaviour under cyclic loading due to the rather simplistic way of modelling plastic strains. The constant stiffness parameters that are independent of the seismic strain, as well as the damping modelled using the purely mathematical Rayleigh formulation, do not recommend this soil model for seismic analyses.

The 1D analyses represent an accurate enough and fast solution for the evaluation of the seismic response in alpine valleys, when $2 \mathrm{D}$ investigations are not possible. They are able to model site effects induced by the alternation of the geological layers or by the combination between energy content of the earthquake and natural frequency of the soil 
profile. However, the 1D results indicated a softer soil behaviour by providing resonance peaks of the spectral accelerations outside the plateau range of the reference response spectrum "Rhonetal", determined under 2D conditions. The most important disadvantage is the inability of the $1 \mathrm{D}$ analyses to capture basin effects, or to provide accurate information related to seismic displacements.

\subsection{Results of $2 \mathrm{D}$ modelling}

\subsubsection{D modelling in the time domain using the linear elastic perfectly plastic Mohr-Coulomb (MC) constitutive model}

In the next stage, the shape of the entire alpine valley was included in the numerical investigations and the basin effects influencing the free field motion were analysed. The soil was modelled in a first step using $M C$, and the bedrock using a linear elastic constitutive model.

The reference location for the comparison with previous results from 1D modelling was "Talmitte". Additional influencing factors related to the sequence of soil layers were eliminated from the comparison, considering that the 2D ground model was generated by extrapolating horizontal soil layers from the location "Talmitte" to the entire valley.

The average spectrum obtained in Figure $3.23 \mathrm{~b}$ is above the reference spectra for all periods $T<0.8 \mathrm{~s}$ and reaches maximal values of $1.5 \mathrm{~g}$. The spectrum obtained using $2 \mathrm{D}$ $\mathrm{MC}$ is shifted towards the left (lower periods) and the natural period can be identified at $T$ $=0.6 \mathrm{~s}$, indicating that the modelled soil behaviour is stiffer than in the case of the 1D MC. As observed from the 1D results, the MC model provided higher spectral values than the linear-equivalent model (EERA) or the linear elastic one (LE). The 2D MC results follow the same trend, considering that the "Rhonetal" reference spectrum was obtained under 2D conditions with linear-equivalent assumptions for the soil behaviour (Résonance et al., 2005). These differences emphasise once more the limitation of the MC constitutive model in the case of seismic loading. Due to the presence of the inclined stiff rock flanks, non-vertical incident waves reach the surface of the ground model, and surface waves are generated. This is a major difference from the 1D analysis, which showed no vertical motion at the surface of the soil profile. The effect of the additional surface waves generated can be quantified by the spectral values that are higher in the $2 \mathrm{D} M C$ than in the 1D MC case. 

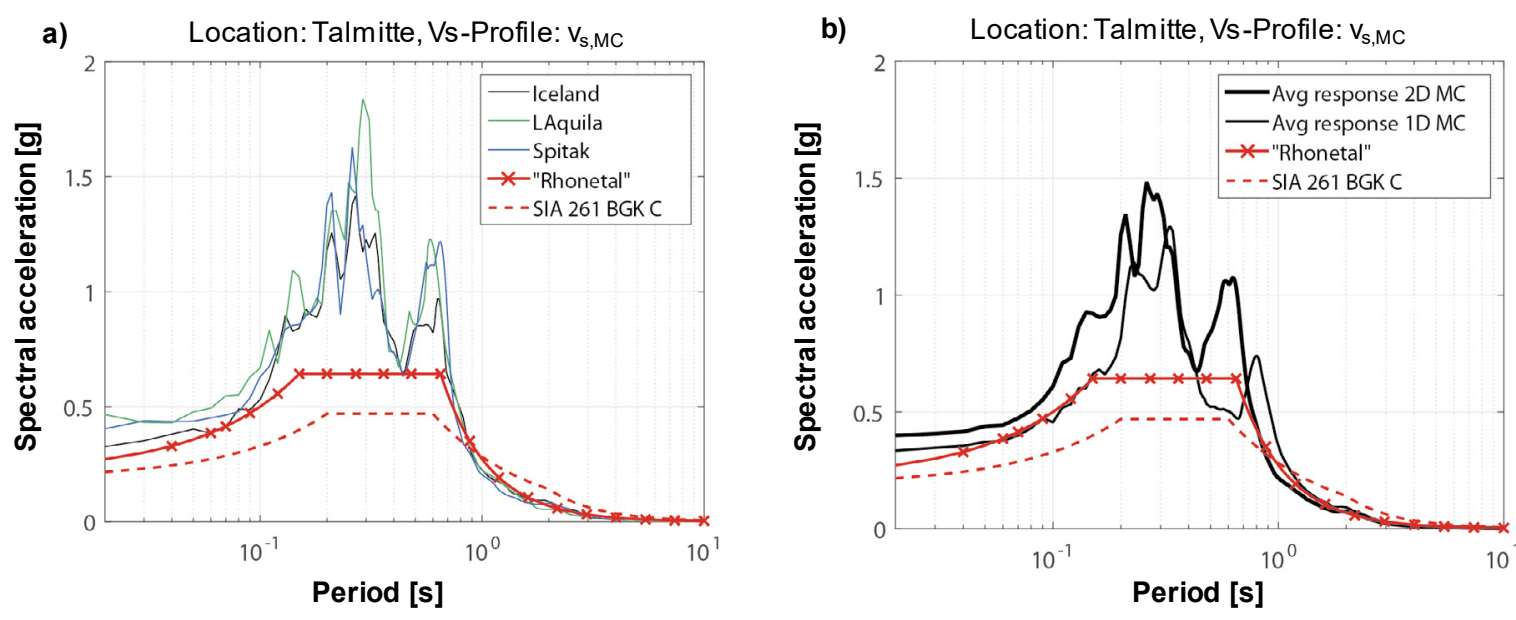

Figure 3.23. 2D MC surface response spectra at location "Talmitte": a) individual signals; b) averaged response.

The amplification function was defined as the ratio between the Fourier spectra at the surface and at bedrock level. This function shows the amplification factors for each frequency of the Fourier spectrum of an earthquake and can be used to identify the natural frequency of the soil profile. Figure 3.24 depicts the amplification functions for all three earthquakes at the different locations across the valley. The resonance peaks are independent of the location, and the corresponding natural frequency is around $1.55 \mathrm{~Hz}$, corresponding to $T=0.6 \mathrm{~s}$, for all cases. This result is in accordance with the results presented by Bard and Bouchon (1985), which showed that the natural frequency of a sediment basin is constant and does not depend on the location in the valley.
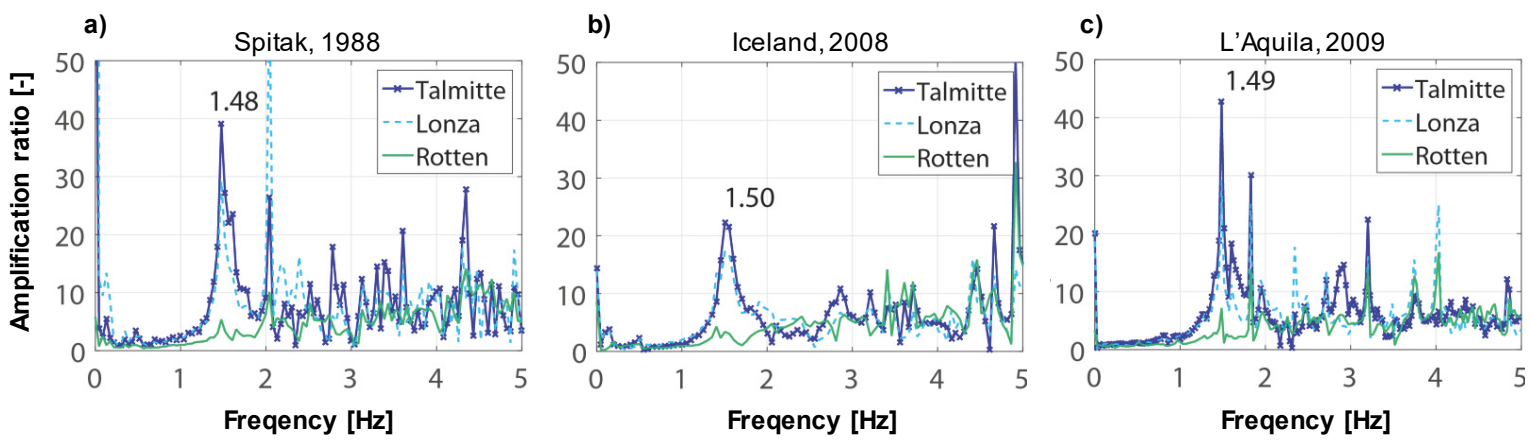

Figure 3.24. Amplification functions for the three earthquakes at the different locations across the valley (2D MC).

The development of vertical displacements and accelerations at the location "Talmitte" is shown in Figure 3.25. The generated displacements are predominantly elastic and have low amplitudes, reaching maximum values of $0.15-0.2 \mathrm{~cm}$. The L'Aquila seismic signal induced reduced plastic displacements with residual values below $0.05 \mathrm{~cm}$. The vertical accelerations modelled reach peak spectral values between $0.15 \mathrm{~g}$ and $0.40 \mathrm{~g}$ at a vertical resonance period of $\mathrm{T}=0.2-0.3 \mathrm{~s}$, similar to the one observed under 1D conditions (see Figure $3.21 \mathrm{~b}$ ). These results, and those presented in Figure 3.23, indicate the effect of the surface waves generated in 2D topographical conditions. 

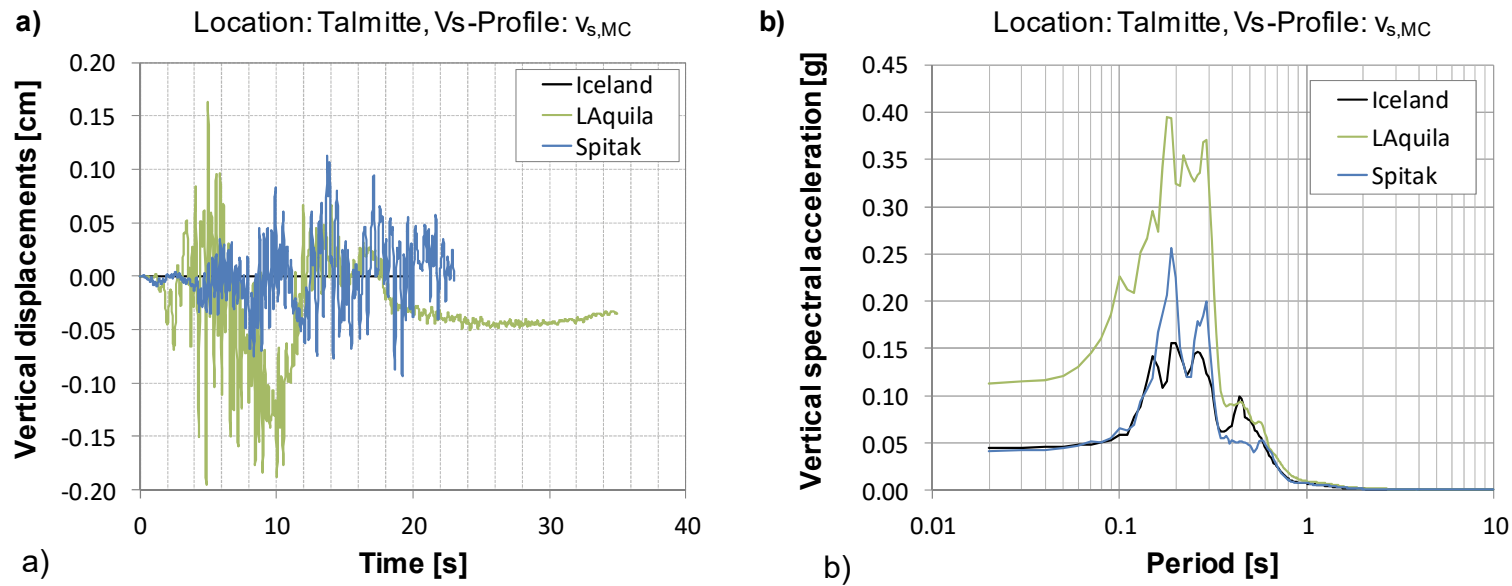

Figure 3.25. 2D MC modelling results: a) development of vertical displacements at location "Talmitte", and b) vertical acceleration spectra.
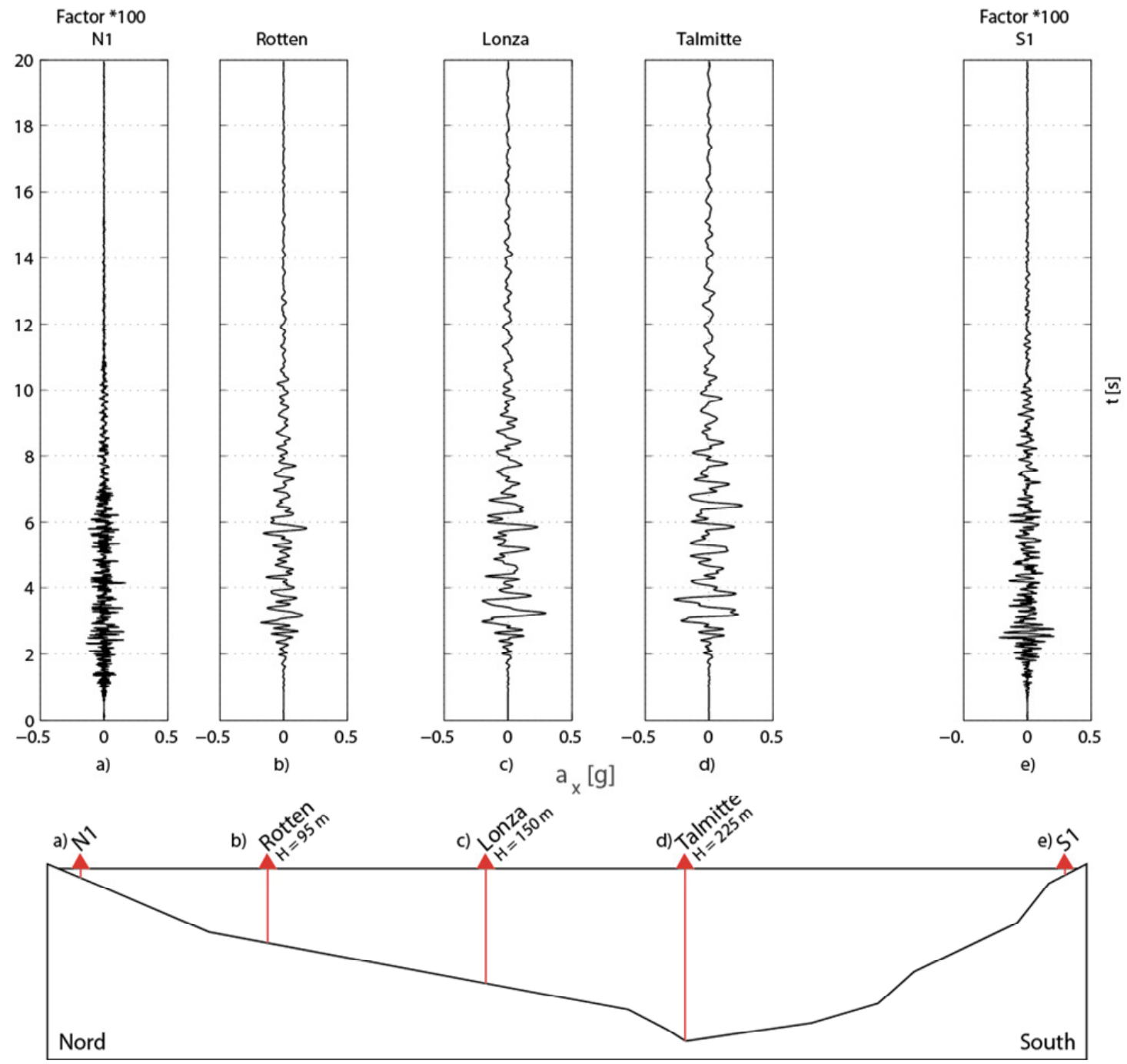

Figure 3.26. 2D MC modelled free-field motions for input signal Iceland 2008 at different locations across the valley. 
The reflection of the body waves within the valley has a strong influence on the free field motion, which depends on the location at the ground surface. As a result, both the amplitude and the duration of the free-field motion decrease from the centre of the valley towards the flanks. This, however, overlaps with the influence of the depth of the soil profile at each location and a clear separation between the two effects is difficult to be made. The influence of the reflected waves is also a contribution to the differences between the $1 \mathrm{D}$ and $2 \mathrm{D}$ response spectra presented in Figure $3.23 \mathrm{~b}$, besides the effect of non-vertical incident waves, which has been mentioned already. The time histories of accelerations across the valley showing these effects are displayed in Figure 3.26.

\subsubsection{D modelling in the time domain using the Hardening Soil Small Strain (HSs) constitutive model}

The last calculations in this study were performed under 2D conditions using the HSs constitutive model. The information gained from 1D calculations (Figure 3.22b) showed a rapid increase of the PGA in the first $22 \mathrm{~m}$ of the soil profile. This was identified as the depth above which non-linear soil behaviour can occur. As a result, a hybrid soil model was compiled using HSs for the first $22 \mathrm{~m}$ of granular soil and MC for the rest of the granular deposit. The rock was modelled, similarly to the previous calculations, as a linear elastic medium.

The individual response spectra at the location "Talmitte" for the three earthquakes and the average response can be seen in Figure 3.27. The average response spectrum in this case is above the spectra obtained under 1D conditions and exceeds the reference spectra. The peak values reach around $1.2 \mathrm{~g}$ and the spectral shape is similar to that obtained in 1D conditions.
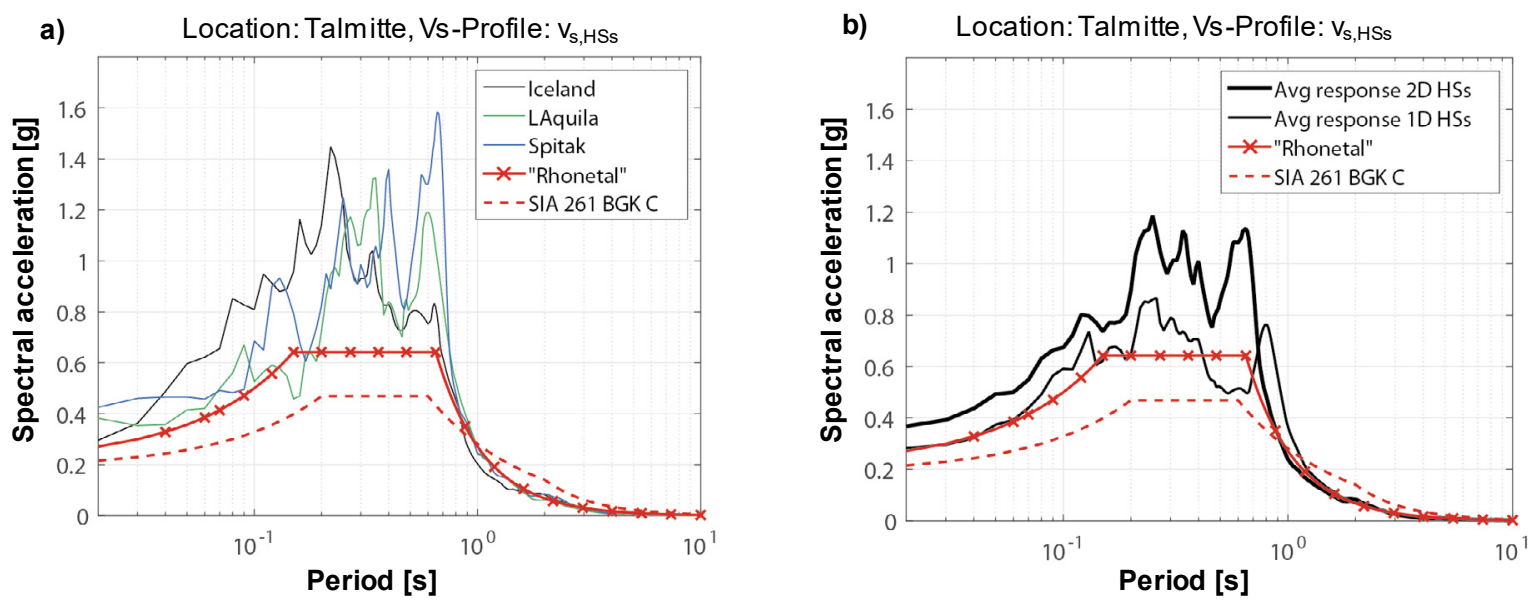

Figure 3.27. 2D Hss surface response spectra at location "Talmitte": a) individual signals; b) averaged response.

The amplification functions were calculated for all earthquakes and all locations across the valley. The first natural frequency of the soil profile can again be identified at $\mathrm{f}=1.50 \mathrm{~Hz}$, which doesn't depend on location, input motion, or soil model. This value corresponds with the spectral peaks between $T=0.6-0.7 \mathrm{~s}$ observed in Figure $3.27 \mathrm{~b}$ for $2 \mathrm{D}$ HSs. 
However, the value of the amplification ratio at the first natural frequency is dependent on the location: ratios of 3-5 can be observed for "Rotten", as opposed to "Lonza" and "Talmitte", where values of up to 42 are reached (Figure 3.28).
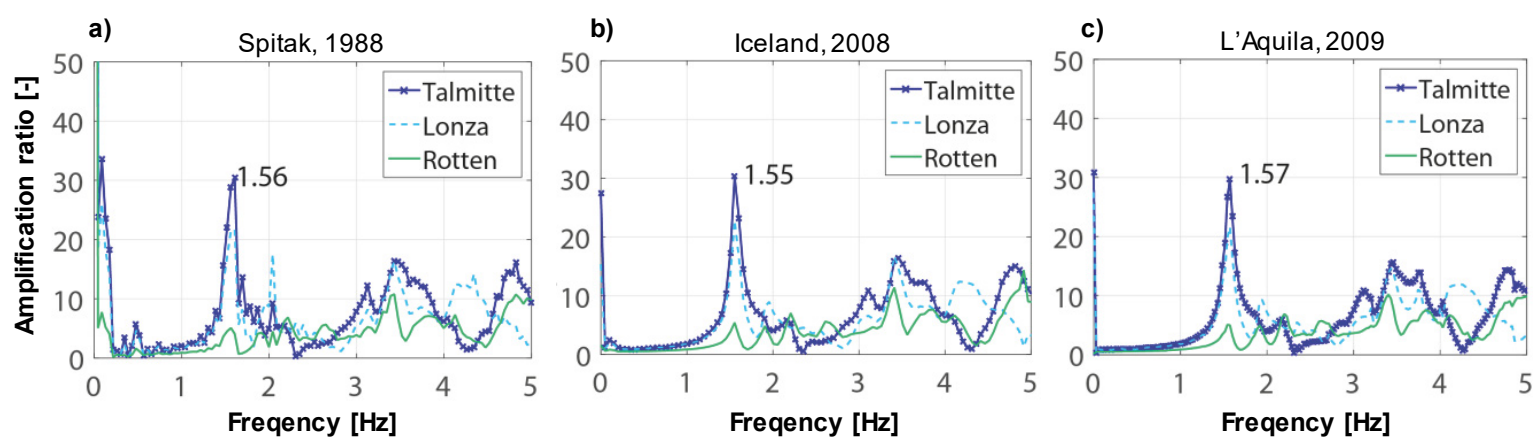

Figure 3.28. Amplification functions for the three earthquakes at the different locations across the valley (2D HSs).

Figure 3.29 a displays the vertical displacements and accelerations modelled at the location "Talmitte" for the three different earthquakes used in the analysis. The hybrid model is able to represent settlements due to the stiffness reduction caused by the seismic-induced strains, similar to the 1D case. The vertical displacements are permanent and reach values between $0.7-1.0 \mathrm{~cm}$ at the end of the seismic loading, as opposed to the $2 \mathrm{D}$ $\mathrm{MC}$ results, which showed elastic displacements with very low amplitudes (i.e. $0.2 \mathrm{~cm}$ ). The 1D HSs results indicated a development of the vertical displacements similar to the $2 \mathrm{D}$ case, with lower residual values, i.e. $0.6-0.8 \mathrm{~cm}$.

The spectral values of the vertical accelerations in Figure 3.29b show the same predominant period $\mathrm{T}=0.2-0.3 \mathrm{~s}$, as in the 1D HSs (Figure 3.21) and 2D MC (Figure 3.25) cases. The vertical spectral accelerations at low periods $(T=0.02 \mathrm{~s})$ are similar to the 1D HSs and larger than in the $2 \mathrm{D} \mathrm{MC}$ case, i.e. $0.15-0.2 \mathrm{~g}$ compared to $0.05-0.01 \mathrm{~g}$. These results indicate that the 1D and 2D HSs models are able to represent the seismic response of the soil in a realistic way. The 1D HSs has the disadvantage of disregarding effects related to the topography, such as non-vertical incident waves at the ground surface and body wave reflections in the valley.
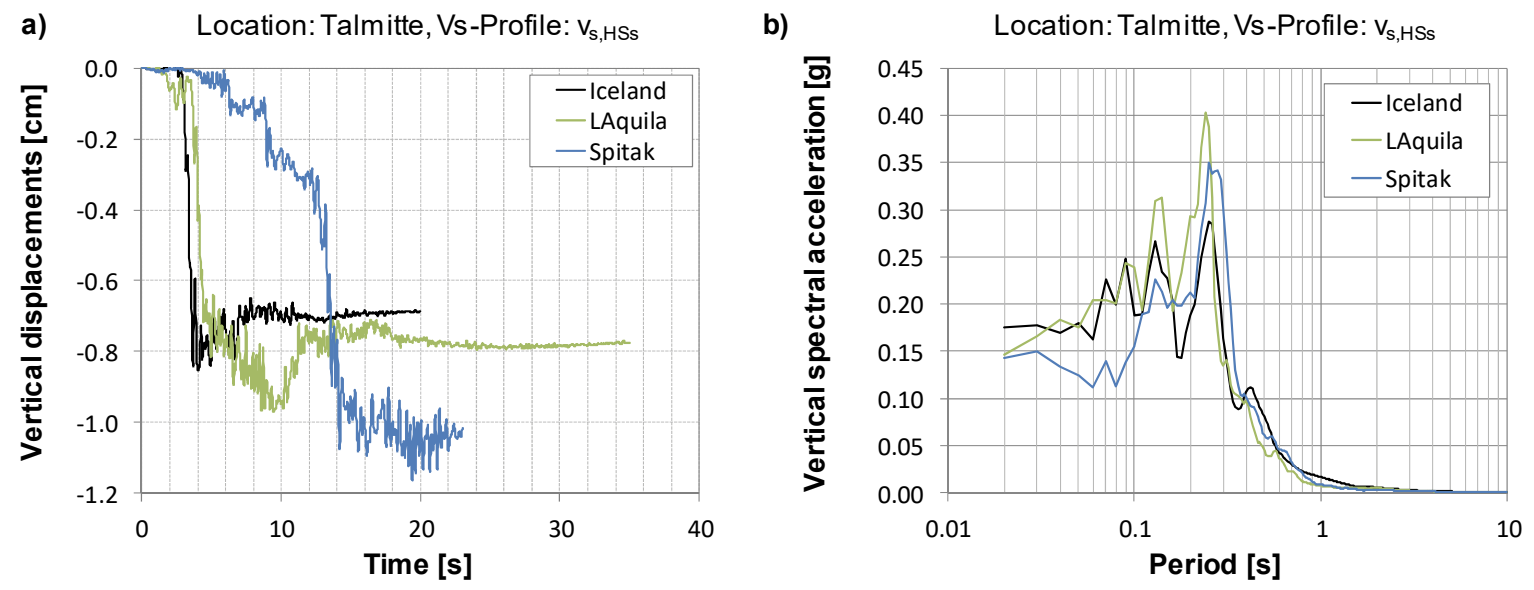

Figure 3.29 2D HSs modelling results: a) development of vertical displacements at location "Talmitte", and b) vertical acceleration spectra. 
The free field motion modelled at different locations across the valley is shown in Figure 3.30.
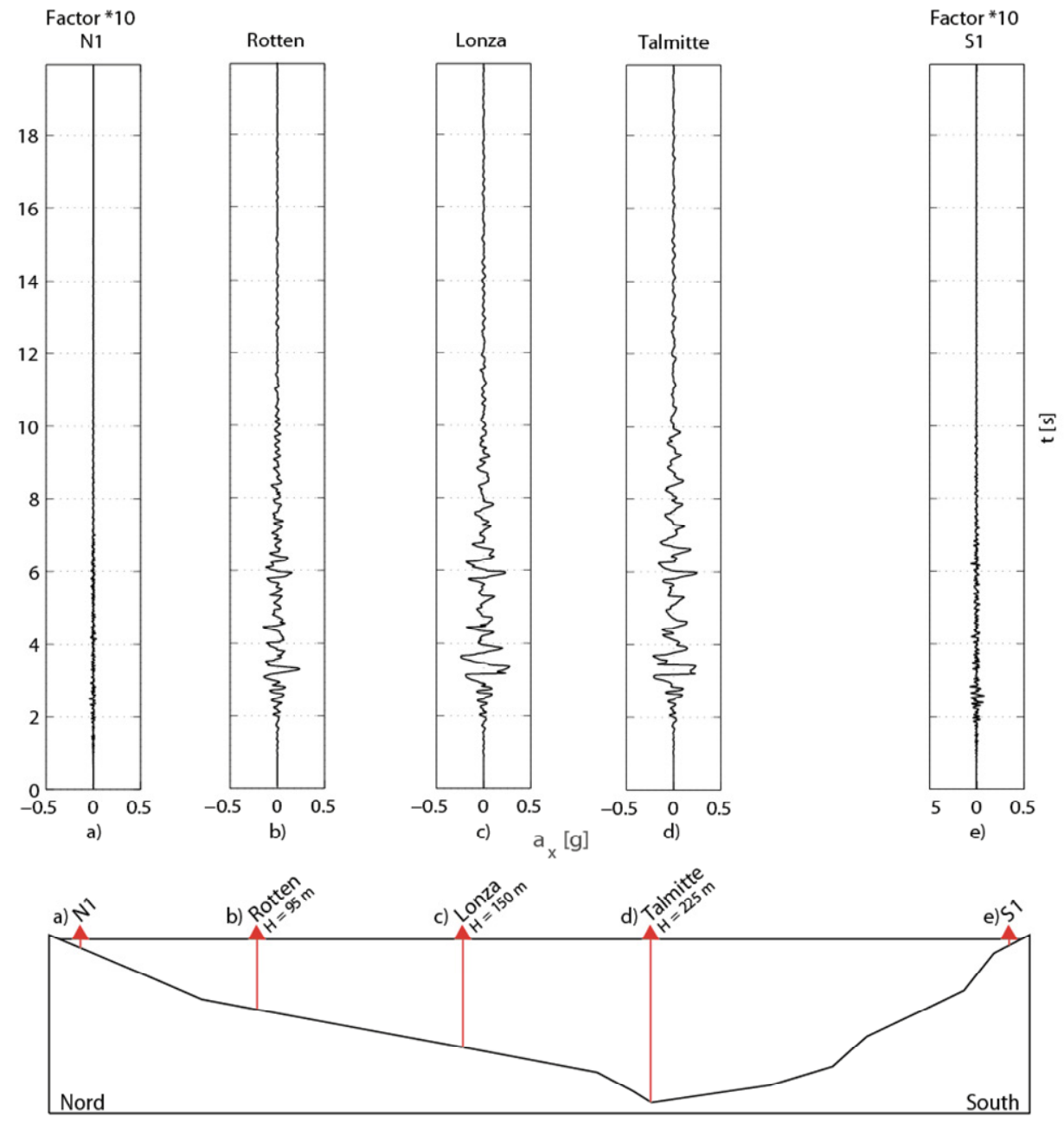

Figure 3.30. 2D HSs modelled free-field motions for input signal Iceland 2008 at different locations across the valley.

Similar effects (e.g. body waves reflection within the valley and non-vertical incident waves at the ground surface) as in the 2D MC case (Figure 3.26) can be observed, causing the amplitude and the duration of the motion to decrease from the centre towards the flanks of the valley. The PGA values are slightly lower than in the 2D MC case and follow the same trend indicated by the response spectra.

\subsubsection{Summary of $2 \mathrm{D}$ modelling}

The results showed that the topographic conditions cannot be neglected in the evaluation of the soil response during seismic events, emphasising the effect of the topography in the form of increased spectral values of the horizontal and vertical accelerations (Figure 3.31). The modelled seismic settlements were not significantly different, with an average residual value $0.8 \mathrm{~cm}$ in the $2 \mathrm{D}$ case, and $0.6 \mathrm{~cm}$ in the $1 \mathrm{D}$ one (see Figure 3.25 and 3.29 ). 
a) Location:Talmitte, Vs-Profile: $\mathrm{v}_{\mathrm{s}, \mathrm{HSs}}$

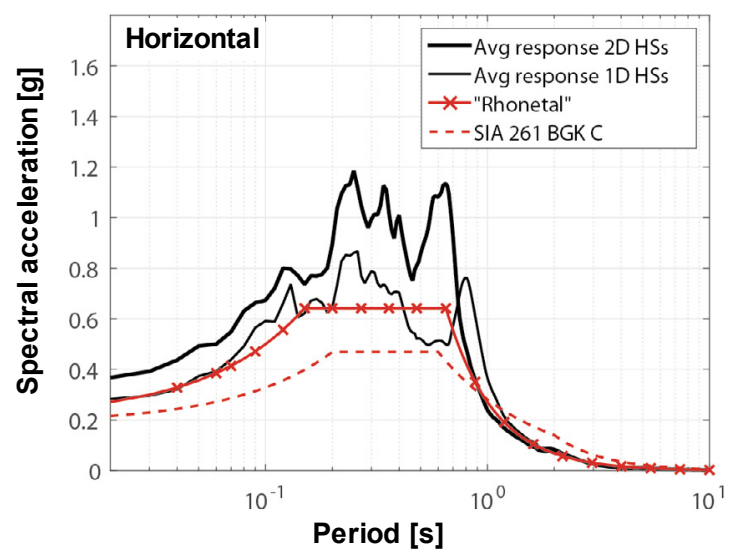

b) Location:Talmitte, Vs-Profile: $v_{s, H S s}$

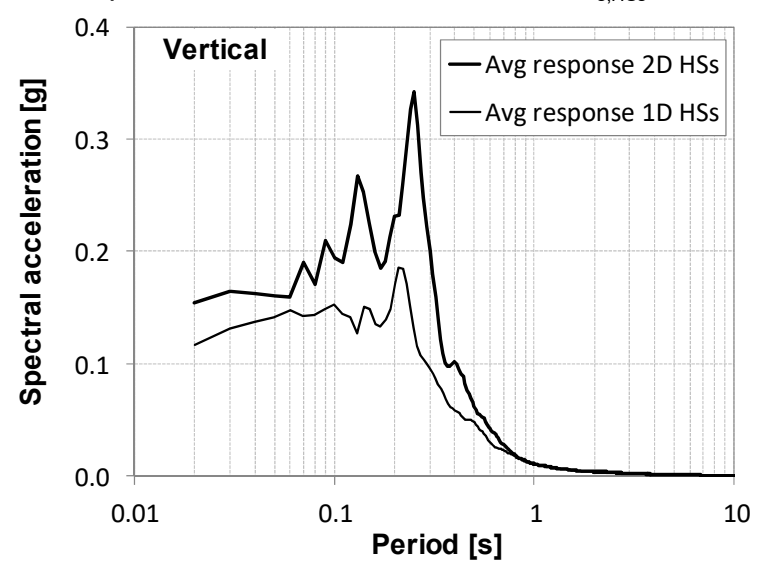

Figure 3.31. Comparison of the average response spectra of vertical (a) and horizontal (b) accelerations at location "Talmitte" for 1D and 2D HSs.

The comparison between the average response spectra at the location "Talmitte" for the two different constitutive models, 2D MC and 2D HSs, is shown in Figure 3.32. Besides the inability of $\mathrm{MC}$ to represent the seismic settlements of the soil, the spectral values obtained with this model are also higher than those obtained with HSs, overestimating in an unjustified manner the soil response. The values obtained using HSs are more reliable because this model is able to represent the soil response to cyclic loading in a realistic way, as shown by e.g. Liang et al. (2015) in the results of their numerical and experimental investigations of rooted slopes subjected to seismic loading in the geotechnical centrifuge.

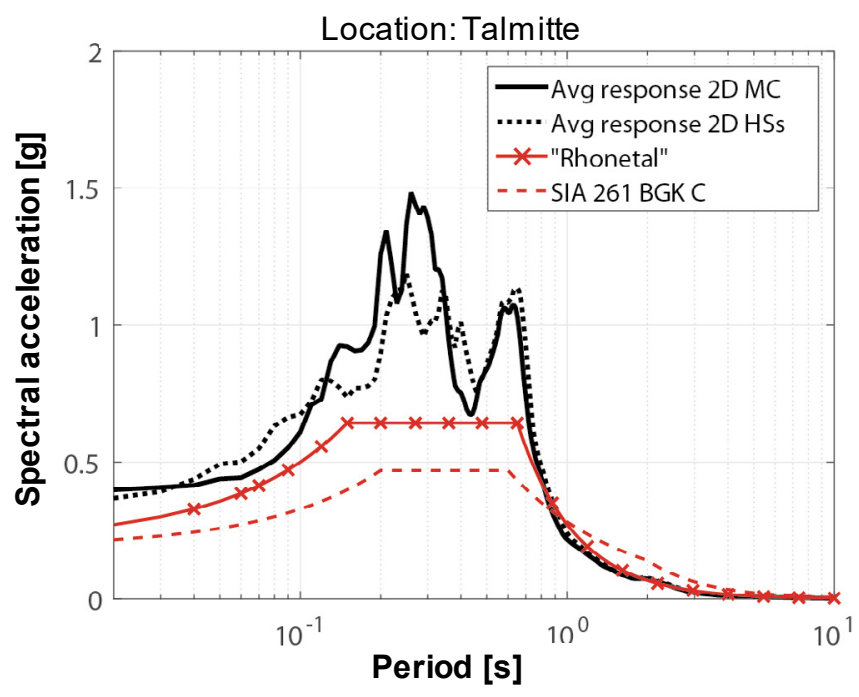

Figure 3.32. Comparison of the results from the $2 \mathrm{D}$ analyses using MC and HSs.

The shapes of the deformed soil model after the seismic event, showing the residual displacement of the soil mass, indicate variable surface settlements, irrespective of the horizontal soil layers of uniform thickness (Figures 3.33-3.34). The MC model shows an overall rotation of the entire soil mass, including the bedrock, from left to right and a wave- 
like surface of the ground. The soil model with HSs for the first $22 \mathrm{~m}$ of granular soil shows a more stable shape, but with an irregular surface. The maximum residual total displacements are $18.2 \mathrm{~mm}$ for HSs, which accounts for soil softening and $0.6 \mathrm{~mm}$ in the case of MC.

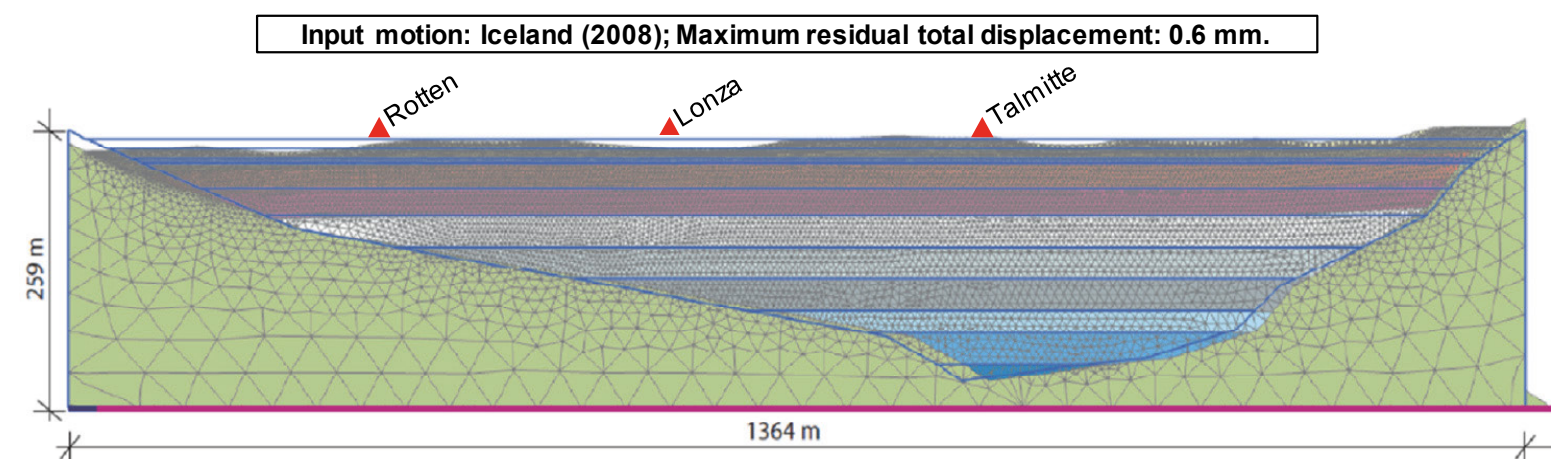

Figure 3.33. Post-seismic deformed shape of the soil model (2D MC).

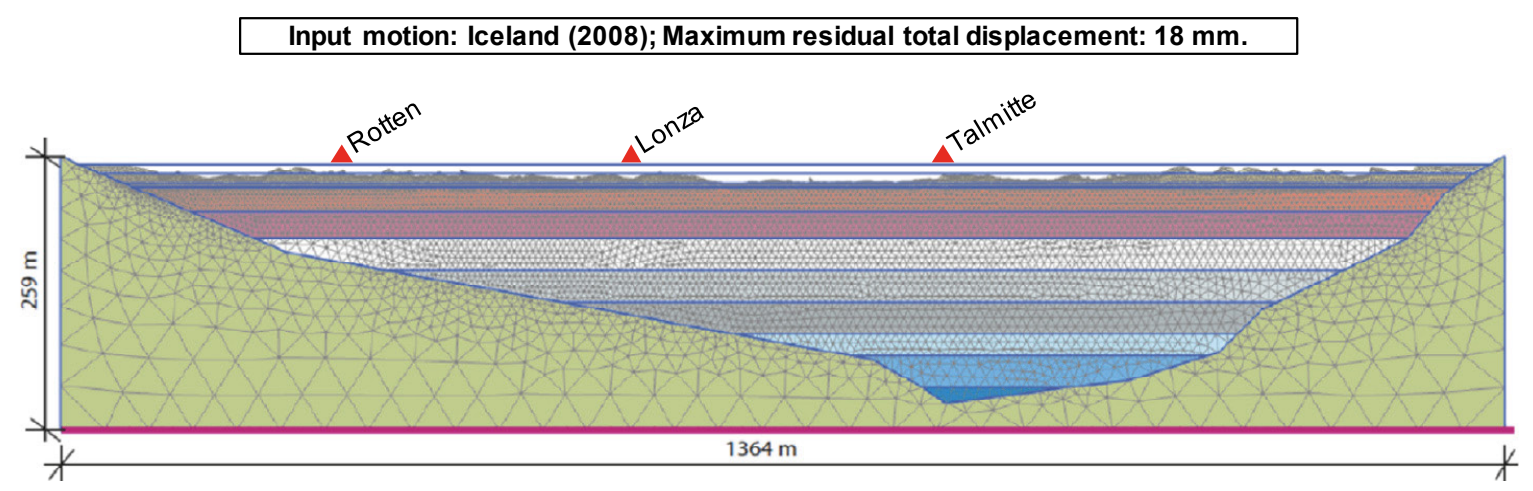

Figure 3.34. Post-seismic deformed shape of the soil model (2D HSs).

\subsection{Conclusions}

An entire set of seismic investigations was performed in the context of a benchmark type of study, aiming to emphasize the appropriateness of different modelling methods for the evaluation of the seismic site response. The investigations started with very simple 1D calculations performed in the frequency domain, then continued with analyses in the time domain using linear elastic, linear elastic perfectly plastic, and finally non-linear constitutive models. In the last stage, 2D conditions were introduced and numerical investigations were performed using linear elastic perfectly plastic and hybrid non-linear constitutive models.

The calculations performed showed that the best solution for the evaluation of the seismic response in alpine valleys is a $2 \mathrm{D}$ analysis with a hybrid ground model, involving both linear and non-linear constitutive models (e.g. HSs and MC). This solution is also compatible with observations of non-linear soil behaviour in limited depth ranges, where 
the confining stresses are low, the aging effects are mostly absent, and the seismic action is usually high.

The results obtained using HSs for the soil layers below the surface, expected to experience non-linear soil behaviour, and $\mathrm{MC}$ for the rest of the deposits, predicted the soil response in a realistic manner. Basin effects, such as surface waves generated by nonvertical wave propagation, or reflections within the valley, were captured by the $2 \mathrm{D}$ models and caused increased values of the ground accelerations. Additionally, the non-linear constitutive model (i.e. HSs) was able to represent the soil settlements due to the stiffness reduction caused by the strains induced in the soil by the seismic motion. In this way, the inaccuracy of the linear models (e.g. MC) applied to the entire soil profile, and the high computational efforts involved for a fully non-linear approach using only e.g. HSs, could be avoided with the proposed hybrid model, at least partially.

The main disadvantages of using non-linear models (e.g. HSs) are the modelling and computational efforts. However, the determination of additional model parameters, or the issue of calculation times, cannot be avoided completely when it comes to high requirements for the seismic investigations. For example, one calculation with a seismic signal of $20 \mathrm{~s}$, and a time step of $0.01 \mathrm{~s}$ applied to the 1'364 x $259 \mathrm{~m}$ model, including 19'693 15noded triangular elements with an average size of $4.2 \mathrm{~m}$, required about 100 hours wallclock time on a regular PC. This might be a long calculation time but it still cannot be compared with the financial and computational efforts needed for fully non-linear simulations of similar ground models, which usually involve super-computers with clusters of hundreds of processors. As shown by Roten (2007) in his study, one calculation using the code developed by Olsen (1994) required eight hours wallclock time with 20 CPUs of the supercomputer cluster at San Diego State University.

In conclusion, the 2D and even 3D investigations are essential for the evaluations of seismic soil response in alpine valleys. These investigations should always take the potential non-linear soil behaviour into account and consider it using appropriate solutions, i.e. hybrid models incorporating both linear and non-linear constitutive models. The existing microzonation studies in the Rhone valley and adjacent areas should be updated including non-linear constitutive models, taking into account that linear-equivalent or linear elastic assumptions are not sufficient for the prediction of seismic displacements (i.e. seismic settlements). Similar solutions should be adopted for future numerical investigations in other similar areas with rough topography and potential non-linear soil behaviour.

The use of 1D site response analyses can be a possible alternative, when more advanced $2 \mathrm{D}$ investigations are not possible, but the use of hybrid models, is recommended in this case as well. The results obtained in this way are more realistic than those obtained using classical linear-equivalent methods, especially for situations where strong ground motion is expected. However, the inability of such analyses to model the effects related to the local topography should not be underestimated under any circumstances. 


\subsection{Acknowledgements}

The numerical investigations presented in this paper are complementary to the interdisciplinary project COGEAR (Coupled Seismogenic Geohazards in Alpine Regions) funded by the Competence Center for Environment and Sustainability (CCES), Zurich. The IT hardware and support required for the numerous numerical analyses performed were kindly made available by the Institute for Geotechnical Engineering (IGT) at ETH Zurich.

\subsection{References}

Aki, K. (1988) Local site effects on strong ground motion. In: JL van Thun (ed), Earthquake Engineering and Soil Dynamics II - Recent Advances in Ground Motion Evaluation. pp. 103-155.

Alpan, I. (1970) The geotechnical properties of soils. Earth-Science Reviews 6. pp. 5-49.

Ambraseys, N., Smit, P., Sigbjornsson, R., Suhadolc, P. \& Margaris, B. (2002) InternetSite for European Strong-Motion Data, European Commission, Research-Directorate General, Environment and Climate Programme. Accessed 30 January 2015.

Ashford, S.A. \& Sitar N. (1997) Analysis of topographic amplification of inclined shear waves in a steep coastal bluff. Bulletin of the Seismological Society of America 87(3). pp. 692-700.

Atakan, K., Ciudad Real, M. \& Torres, R. (2004) Local site effects on microtremors, weak and strong ground motion in San Salvador. In: Bommer, JJ, Rose WI, Lopez, DL, Carr, MJ, Major, JJ (eds) Natural Hazards in El Salvador. Geological Society of America SPE 375. pp. 321-328.

Bard, P.-Y. \& Bouchon, M. (1985) The two-dimensional resonance of sediment-filled valleys. Bulletin of the Seismological Society of America 75(2). pp. 519-541.

Bardet, J.P., Ichii, K. \& Lin, C.H. (2000) EERA. A computer program for equivalent-linear earthquake site response analyses of layered soil deposits. University of Southern California. Department of Civil Engineering.

Borcherdt, R.D. (1970) Effects of the local geology on ground motion near San Francisco Bay. Bulletin of the Seismological Society of America 60(1). pp. 29-61.

Bouchon, M. (1973) Effect of topography on surface motion. Bulletin of the Seismological Society of America 63(2). pp. 615-632.

Brinkgreve, R.B.J., Engin, E. \& Swolfs, W.M. (2014) PLAXIS 2D Anniversary Edition 2014. Delft University of Technology \& PLAXIS bv. The Netherlands. 
Burjanek, J., Gassner-Stamm, G., Poggi, V. \& Fäh, D. (2011) Estimation of local site effects in the Upper Valais (Switzerland). In: 4th IASPEI/IAEE International Symposium: Effects of surface geology on seismic motion. University of California, Santa-Barbara, USA.

Celebi, M. (1987) Topographic and geological amplification determined from strongmotion and aftershock records of the 3 March 1985 Chile earthquake. Bulletin of the Seismological Society of America 77(4). pp. 1147-1167.

Darendeli, M. B. (2001) Development of a new family of normalized modulus reduction and material damping curves. Dissertation of University of Texas at Austin. USA.

EC 8 (2004) EN 1998-1 Design of structures for earthquake resistance - Part 1: General rules, seismic actions and rules for buildings. European Comittee for Standardization.

Faccioli, E. \& Vanini, M. (2003) Complex seismic site effects in sediment-filled valleys and implications on design spectra. Progress in Structural Engineering and Materials 5. pp. 223-238.

Frischknecht, C. \& Wagner, J.-J. (2004) Seismic soil effect in an embanked deep alpine valley: a numerical investigation of two-dimensional resonance. Bulletin of the Seismological Society of America 94(1). pp. 171-186.

Fritsche, S., Fäh, D., Gisler, M. \& Giardini, D. (2006) Reconstructing the damage field of the 1855 earthquake in Switzerland: historical investigations on a well-documented event. Geophysical Journal International, 166. pp. 719-731.

Gazetas, G., Kallou, P.V. \& Psarropoulos, P.N. (2002) Topography and soil effects in the Ms 5.9 Parnitha (Athens) earthquake: The case of Adámes. Natural Hazards 27. pp. 133169.

Geli, L., Bard, P.-Y. \& Jullien, B. (1988) The effect of topography on earthquake ground motion: a review and new results. Bulletin of the Seismological Society of America 78(1). pp. 42-63.

Giardini, D., Wiemer, S., Fäh, D. \& Deichmann, N. (2004) Seismic hazard assessment of Switzerland. Swiss Seismological Service (SED), Zürich.

Idriss, I.M. \& Boulanger, R.W. (2008) Soil Liquefaction During Earthquakes. Earthquake Engineering Research Institute MNO-12, Oakland California.

Jongmans, D. \& Campillo, M. (1993) The response of the Ubaye Valley (France) for incident SH and SV waves: comparison between measurements and modelling. Bulletin of the Seismological Society of America 83(3). pp. 907-924.

Kramer, S.L. \& Paulsen, S.B. (2004) Practical Use of Geotechnical Site Response Models. In: Proceedings of the International Workshop on Uncertainties in Nonlinear Soil 
Properties and their Impact on Modeling Dynamic Soil Response. PEER Center Headquarters, Richmond, CA.

Kuhlemeyer, R.L. \& Lysmer, J. (1973) Finite Element Method Accuracy for Wave Propagation Problems. Journal of Soil Mechanics and Foundations Division ASCE 99. pp. $421-427$.

Lateltin, O., Duvernay, B., Fäh, D., Giardini, D., Haemming, C., Lacave, C., Tissières, P., Widmer, F. (2004) Verfahren zur Erstellung und Verwendung von Mikrozonierungsstudien in der Schweiz. Richtlinien des BWG. Bundesamt für Wasser und Geologie BWG, Bern.

Liang, T., Knappett, J.A. \& Duckett, N. (2015) Modelling the seismic performance of rooted slopes from individual root-soil interaction to global slope behaviour. Géotechnique 65(12). pp. 995-1009.

Marin, A., Laue, J. \& Mezger, F. (2012) Modelling of soil-structure interaction in Alpine regions. In: Maugeri \& Soccodato (eds) Second International Conference on Performance-Based Design in Earthquake Geotechnical Engineering, Taormina (Italy). Patron editore, Bologna. pp. 1426-1439.

Marin, A., Laue, J. \& Fäh, D. (2016) Installation and instrumentation of a long-term seismic monitoring system in the Rhone Valley. Soil Dynamics and Earthquake Engineering. Under review.

Olsen, K.B. (1994) Simulation of three-dimensional wave propagation in the Salt Lake Basin. Dissertation, University of Utah, Salt Lake City.

Pedersen, H., Le Brun, B., Hatzfeld, D., Campillo, M. \& Bard, P.-Y. (1994) Ground motion amplitude across ridges. Bulletin of the Seismological Society of America 84(6). pp. 17861800.

Pfiffner, O.A., Heitzmann, P., Lehner, P., Frei, W., Pugin, A. \& Felber, M. (1997) Incision and backfilling of Alpine valleys: Pliocene, Pleistocene and Holocene processes. In: Deep Structure of the Swiss Alps - Results of NRP 20. Birkhäuser, Basel. pp. 265-276.

Rayleigh, J.W.S. \& Lindsay, R.B. (1945) The Theory of Sound. Dover Publications, New York.

Résonance S.A., Rovina-Partner A.G. \& Tissières S.A. (2005) Spektrale seismische Mikrozonierung der Region Brig-Visp. Technischer Bericht No. 220.4. Kanton Wallis. Dienststelle für Raumplanung.

Résonance S.A. (2010) Reévaluation du danger de liquéfaction du sol sur le site de Lonza à Viège. Rapport no. RT 226.26. Carrouge, Suisse.

Roten, D. (2007) Site effects in the Rhone valley analysed by ambient noise, weak motion records and numerical simulations. Dissertation No. 17471. ETH Zurich. 
Schnabel, P.B., Lysmer, J. \& Seed, H.B. (1972) SHAKE: A Computer Program for Earthquake Response Analysis of Horizontally Layered Sites. Report No. UCB/EERC72/12. Earthquake Engineering Research Center, University of California, Berkeley.

SED (2015) European Facility for Earthquake Hazard and Risk. Schweizerisches Erdbeben Dienst. Online Data Resource: www.efehr.org. Accessed on 25th of November 2015.

Seed, H.B. \& Idriss, I.M. (1970) Soil Moduli and Damping Factors for Dynamic Response Analysis. Report No: EERC 70-10, University of California, Berkeley, CA.

SIA 261 (2014) Actions on Structures. Swiss Society of Engineers and Architects. Zurich.

Steimen, S., Fäh, D., Kind, F., Schmid, C. \& Giardini, D. (2003) Identifying 2D resonance in microtremor wave fields. Bulletin of the Seismological Society of America. 93(2). pp 583-599.

Studer, J., Laue, J. \& Koller, M. (2008) Bodendynamik. Grundlagen, Kennziffern, Probleme und Lösungsansätze. Springer. (in German).

VSS, SN 670010 (1999) Bodenkennziffern. Vereinigung Schweizerischer Strassenfachleute. Zürich (in German).

Wagner, J.-J., Frischknecht, C., Rosset, P., Sartori, M., Schindler, C., Beer, C., MayerRosa, D., Rüttener, E. \& Smit, P. (2000) Contribution au zonage sismique dans la vallée du Rhône entre Sion et Brigue. Rapport géologique no. 25. Office federal des eaux et de la géologie, Service hydrologique et géologique national. Berne, Suisse (in French).

Yamanaka, H., Seo, K. \& Samano, T. (1989) Effects of sedimentary layers on surfacewave propagation. Bulletin of the Seismological Society of America: 79(3). pp. 631-644.

Zeevaert, L. (1964) Strong ground motions recorded during earthquakes of May the 11th and 19th, 1962 in Mexico City. Bulletin of the Seismological Society of America, 54(1). pp. 209-231. 



\title{
4. Modelling of Soil-Structure Interaction in Alpine Regions
}

\author{
Alexandru Marin \\ ETH Zürich, Institute for Geotechnical Engineering \\ Stefano-Franscini-Platz 5, 8093 Zürich, Switzerland \\ E-mail address: amarin@ethz.ch
}

\section{Jan Laue}

ETH Zürich, Institute for Geotechnical Engineering

Stefano-Franscini-Platz 5, 8093 Zürich, Switzerland

E-mail address: jlaue@ethz.ch

\section{Florence Mezger}

ETH Zürich, Institute for Geotechnical Engineering

Stefano-Franscini-Platz 5, 8093 Zürich, Switzerland

E-mail address: florence.mezger@igt.baug.ethz.ch

Submitted for the Proceedings of the Second International Conference on Performance-Based Design in Earthquake Geotechnical Engineering, May 28-30, 2012, Taormina Italy

Status: published

This chapter represents a revised version of the original article. 


\begin{abstract}
The understanding and quantification of soil structure interaction becomes increasingly important in new projects, as well as in the risk assessment of existing buildings. The local site effects, in conjunction with special performance requirements imposed by different types of structures (e.g. industrial buildings), are challenging and an appropriate evaluation of the soil-structure interaction is therefore often neglected. The possibility of using widely available FE software to consider soil structure interaction is being explored in this contribution. The case studied is an industrial building, with different types of foundations, located in a glacial alpine valley with extensive deposits of alluvial soil, characterized by moderate seismicity. Verification procedures and calibration of input parameters are presented with the purpose of facilitating the future use of the employed software in other similar situations.
\end{abstract}

Keywords: time domain analysis, frequency domain analysis, soil structure interaction, alpine valleys. 


\subsection{Introduction}

Changes in risk perception, as well as increasing requirements arising from the corresponding changes in codes for engineering purposes, result in a need in practice for a clear, simple and efficient way to deal with field situations incorporating soil structure interaction. These have to be provided with the limitations of numerical modelling using available FE programs and respecting the boundary conditions of modelling procedures, different ways of analysis and computation capabilities.

The task of modelling the soil, the foundation, and the soil-structure interaction for a generalised industrial building located in a glacial alpine valley with alluvial deposits is presented for the area of Visp (Switzerland). Visp is characterised by a moderate seismicity (PGA $=1.6 \mathrm{~m} / \mathrm{s}^{2}$ according to SIA 261, 2003) and experienced an estimated momentmagnitude $\left(\mathrm{M}_{\mathrm{w}}\right)$ of 6.2 event on July 25, 1855 (Fritsche, 2008).

The research is directly connected to COGEAR (Coupled seismogenic Geohazards in Alpine Regions), a multidisciplinary project within ETH Zurich, funded by the Competence Centre for Environment and Sustainability (CCES). The main object of study of COGEAR is the seismic-induced hazard chain. One of the main interest areas is represented by the physics of non-linear processes, which have been reported by eye witnesses about 150 years ago (Fritsche, 2008), in relation to topography and soil disposition.

\subsection{Idealised modelling}

The FE modelling was performed using PLAXIS 2D (Brinkgreve et al., 2012) under the assumption of plane-strains. A multitude of parameters and assumptions are required, and it is very important to understand their influence on the reliability of results.

\subsubsection{Soil profile}

The ground model (Figure 4.1) was obtained as the result of compiling already data on the subsoil in the area of interest, such as borehole profiles (COGEAR Platform, 2010) and soil investigation reports (Résonance, 2010; Weber et al., 2007). Additionally, a final simplification and verification of the model was performed using shear wave velocity profiles from ambient noise array measurements (Burjanek, 2011).

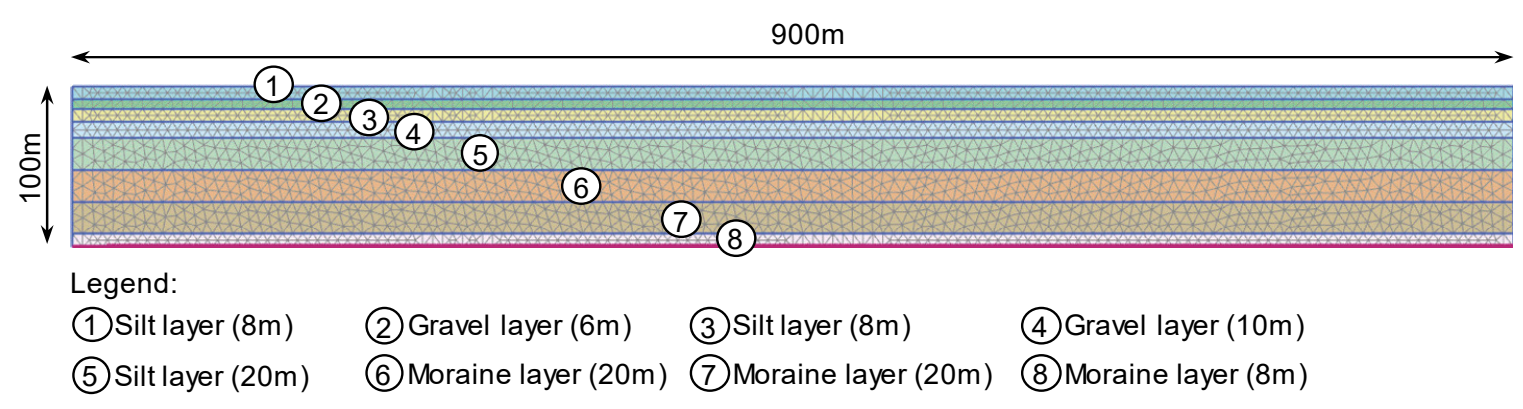

Figure 4.1. Ground model used in the numerical investigations. 
The FE mesh was generated using 15-noded triangular elements with an average size of $4.22 \mathrm{~m}$ and an average distance between nodes of $4.17 \mathrm{~m} / 4=1.05 \mathrm{~m}$. This value is below the maximum node-to-node distance of $2.94 \mathrm{~m}$ obtained using the conditions presented by Kuhlemeyer and Lysmer (1973) for $95 \%$ accuracy of the FE calculations.

A sensitivity analysis investigating the influence of the lateral boundary conditions on the free field motion in the centre of the ground model was performed to obtain the optimal model width, which minimises the unwanted effect of the reflected waves. PLAXIS offers the possibility to define absorbent boundaries by means of relaxation coefficients. The variation of the relaxation coefficients used to define the absorbent boundaries in PLAXIS was observed to influence the response spectrum of the free field motion in the centre of the ground model. The optimal width of the model was therefore obtained as the width at which a doubling of these coefficients had an influence of less than $5 \%$ on the response spectrum of the free field motion. After several iterations, the optimal value of the model width was determined to be $900 \mathrm{~m}$ (Figure 4.2) for an assumed constant depth of the soft deposits of $100 \mathrm{~m}$. This depth has been chosen as relevant for the site of the industrial area (compare Roten et al., 2009).

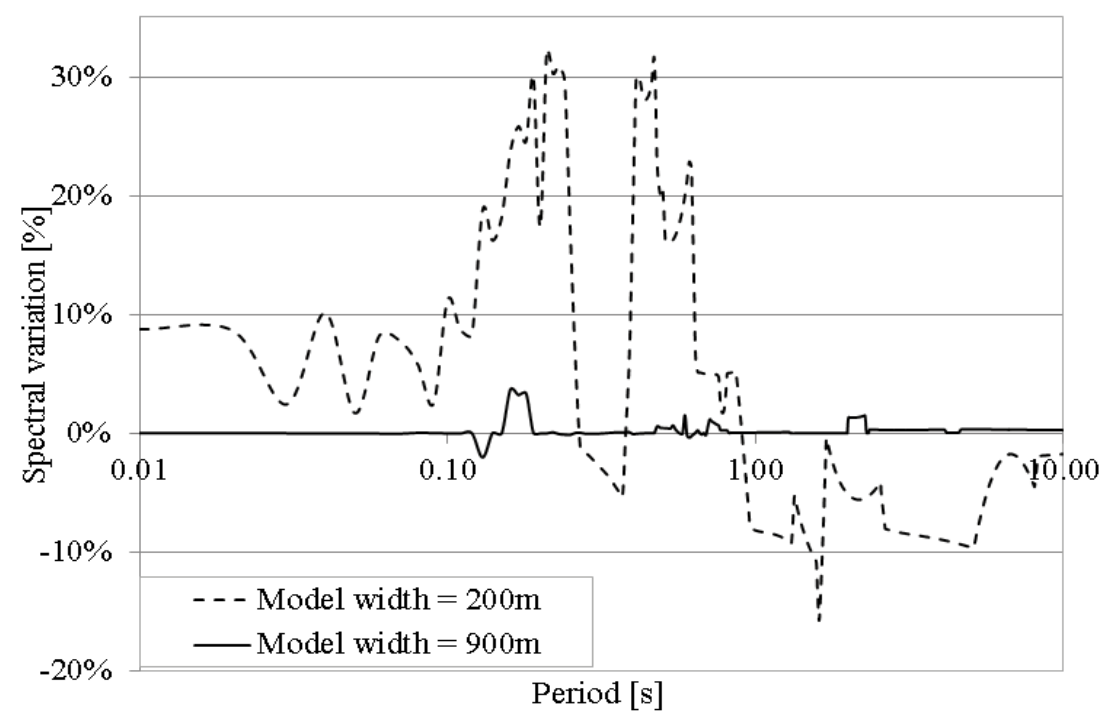

Figure 4.2. Spectral variation with the increase of the relaxation coefficients for a constant model width.

\subsubsection{Soil parameters}

The linear elastic perfectly plastic Mohr-Coulomb constitutive model was used to simplify the calculations. The set of corresponding soil parameters is given in Table 4.1, based on Weber et al. (2007): 
Table 4.1. Parameters for the soil layers in the analysed ground model.

\begin{tabular}{cccccccccc}
\hline Layer & Soil type & $\begin{array}{c}\mathbf{V}_{\mathbf{s}} \\
{[\mathrm{m} / \mathbf{s}]}\end{array}$ & $\begin{array}{c}\mathbf{v}^{\prime} \\
{[-]}\end{array}$ & $\begin{array}{c}\mathbf{G} \\
{[\mathrm{MPa}]}\end{array}$ & $\begin{array}{c}\mathbf{E}^{\prime} \\
{[\mathrm{MPa}]}\end{array}$ & $\begin{array}{c}\mathbf{E}_{\text {oed }} \\
{[\mathrm{MPa}]}\end{array}$ & $\begin{array}{c}\mathbf{V}_{\mathbf{p}} \\
{[\mathrm{m} / \mathbf{s}]}\end{array}$ & $\begin{array}{c}\boldsymbol{\phi}^{\prime} \\
{\left[{ }^{\circ}\right]}\end{array}$ & $\begin{array}{c}\mathbf{c}_{\text {ref }}^{\prime} \\
{[\mathbf{k P a}]}\end{array}$ \\
\hline 1 & Silt & 200 & 0.3 & 81.63 & 212.2 & 285.7 & 374.2 & 33.9 & 1 \\
2 & Gravel & 390 & 0.3 & 357 & 928.1 & 1249 & 729.6 & 35 & 1 \\
3 & Silt & 400 & 0.3 & 326.5 & 849.0 & 1143 & 748.3 & 33.9 & 1 \\
4 & Gravel & 480 & 0.3 & 540.7 & 1406 & 1893 & 898.0 & 35 & 1 \\
5 & Silt & 490 & 0.3 & 490 & 1274 & 1715 & 916.7 & 33.9 & 1 \\
6 & Moraine & 720 & 0.3 & 1217 & 3163 & 4258 & 1347 & 35 & 1 \\
7 & Moraine & 800 & 0.3 & 1502 & 3905 & 5257 & 1497 & 35 & 1 \\
8 & Moraine & 850 & 0.3 & 1696 & 4409 & 5935 & 1590 & 35 & 1 \\
\hline
\end{tabular}

Interfaces were used between structural elements and soil clusters to account for the soilstructure interaction. However, no strength reduction was assumed at the contact between soil and structural elements, and the PLAXIS 2D parameter called "Strength of the Interface" has been defined as rigid.

One of the most important aspects of the soil parameters in the dynamic analysis is the material damping, which is introduced by the Rayleigh coefficients $\alpha_{R}$ and $\beta_{R}$ in PLAXIS. According to Park and Hashash (2004), these coefficients may be determined using the following system of equations:

$\left[\begin{array}{l}\xi_{m} \\ \xi_{n}\end{array}\right]=\frac{1}{4 \pi} \cdot\left[\begin{array}{ll}\frac{1}{f_{m}} & f_{m} \\ \frac{1}{f_{n}} & f_{n}\end{array}\right] \cdot\left\{\begin{array}{l}\alpha_{R} \\ \beta_{R}\end{array}\right\}$

where $f_{m}$ and $f_{n}$ are two significant natural frequencies, while $\xi_{m}$ and $\xi_{n}$ are the corresponding damping ratios. The most suitable pair of Rayleigh coefficients was obtained by calibrating the proposed PLAXIS model using a frequency domain analysis in the elastic range (EERA - Bardet et al. 2000).

The elastic range was identified as the range where the damping values calculated in the soil profile are under $5 \%$. Significant plastic deformations occur above this threshold and the behaviour of the soil becomes non-linear. Figures 4.3 and 4.4 show the four different earthquake signals (two earthquakes recorded by two different seismic stations: Aquila 2009, $M_{w}=6.3$ and Iceland 2008, $M_{w}=6.2$ ) that can occur in Switzerland used in the calibration procedure. The signals were scaled down for the calibration of the Rayleigh parameters, so that all the resulting values in the damping profile from EERA remained under $5 \%$. 

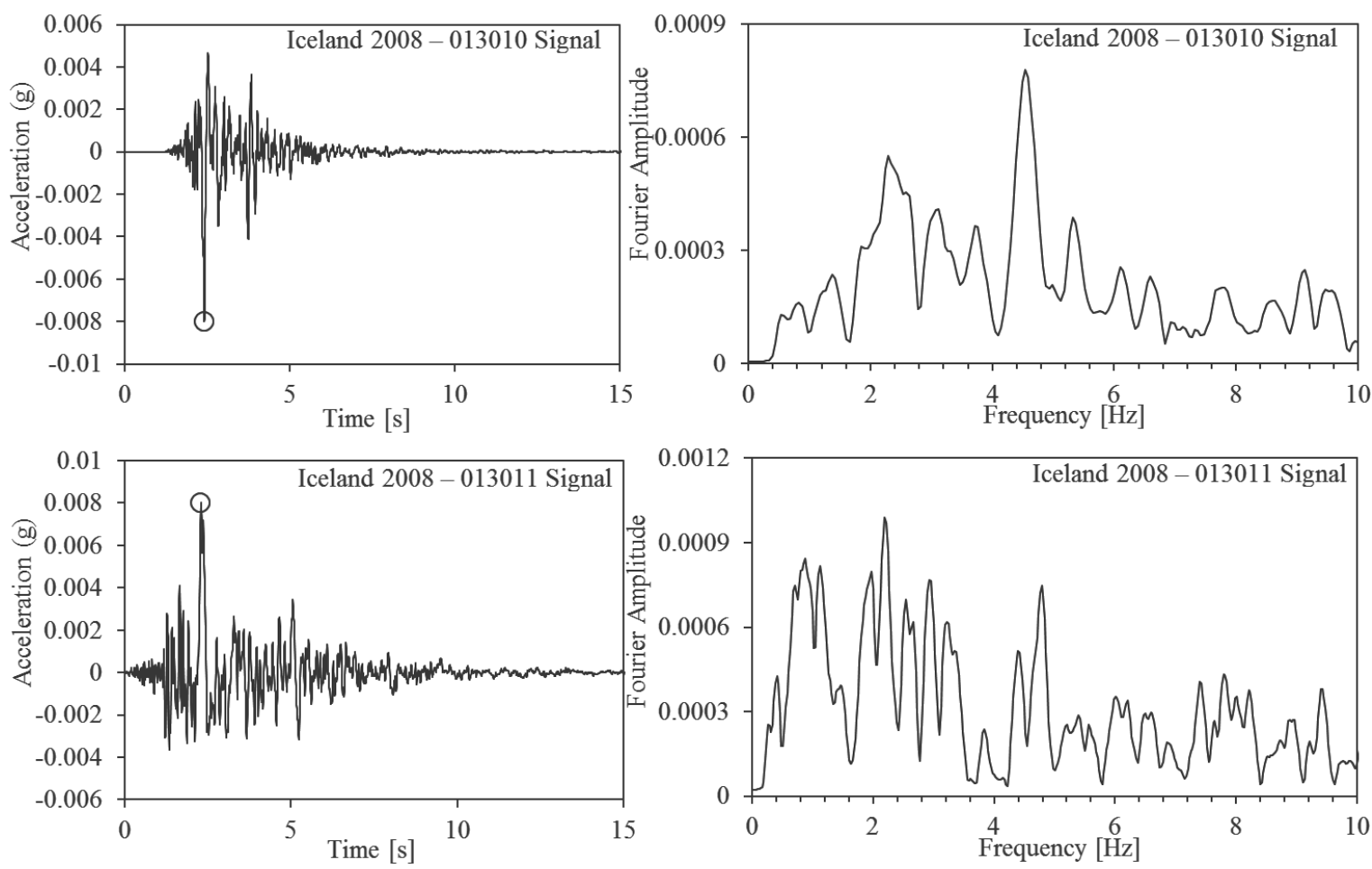

Figure 4.3. Iceland earthquake signals (two different stations).
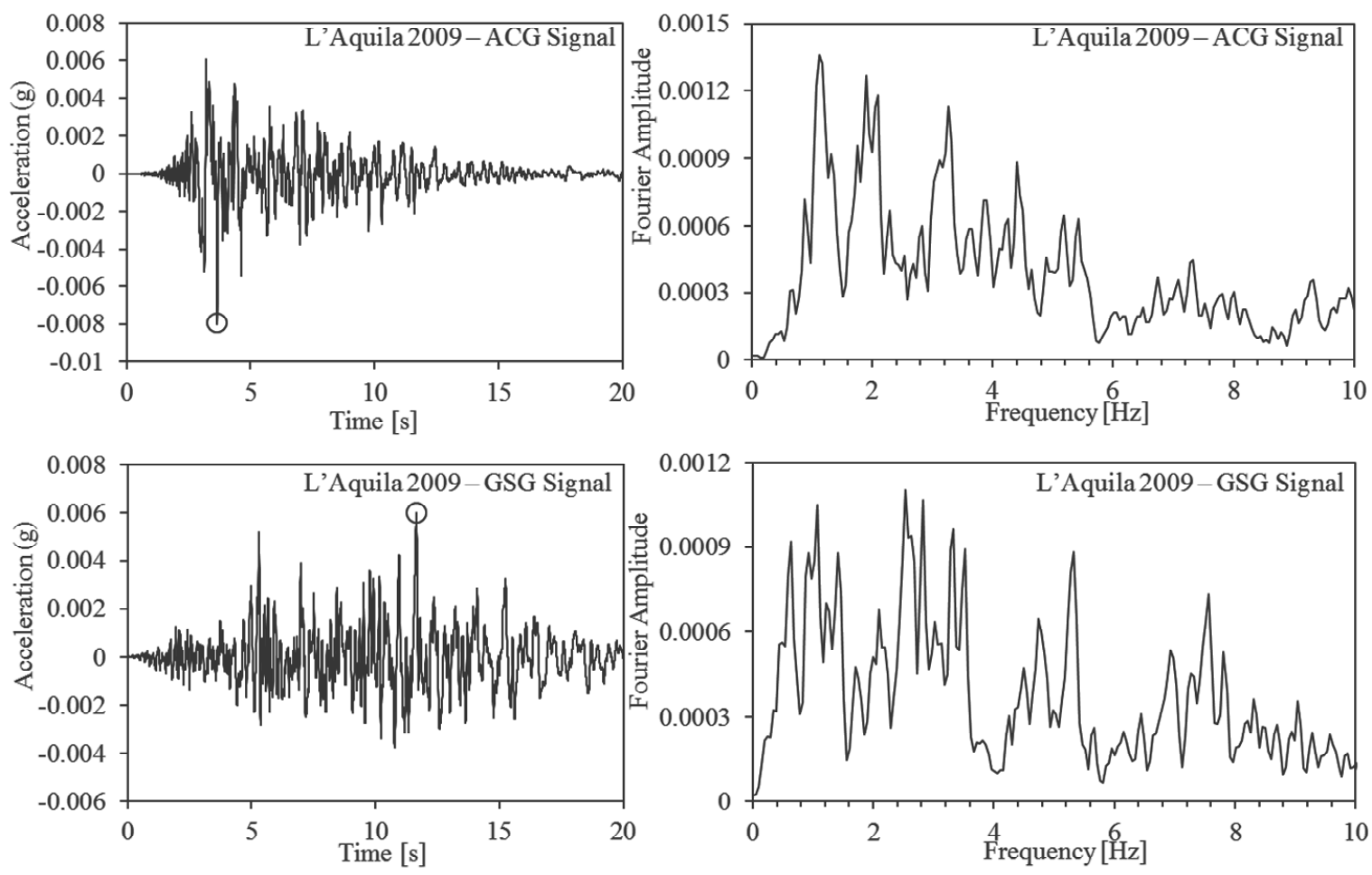

Figure 4.4. L'Aquila earthquake signals (two different stations). 


\subsubsection{Calibration of Rayleigh coefficients}

The calibration procedure consisted of a trial-and-error method for picking the right frequencies, which lead to the convergence of the results from the time (PLAXIS) and frequency domain (EERA). Park and Hashash (2004), Visone and de Magistri (2010) presented different methods to choose the appropriate frequencies, which would deliver convergence. However, the best convergence of the results was obtained using the current iterative calibration for combinations between the second and another superior frequency (third, fourth, etc.). The damping ratios required in the equations system (4.1) were obtained for each soil layer from the EERA analysis

The results obtained with EERA and PLAXIS, for the input signals presented above, are shown in Figures 4.5-4.8, by indicating the chosen natural frequencies.
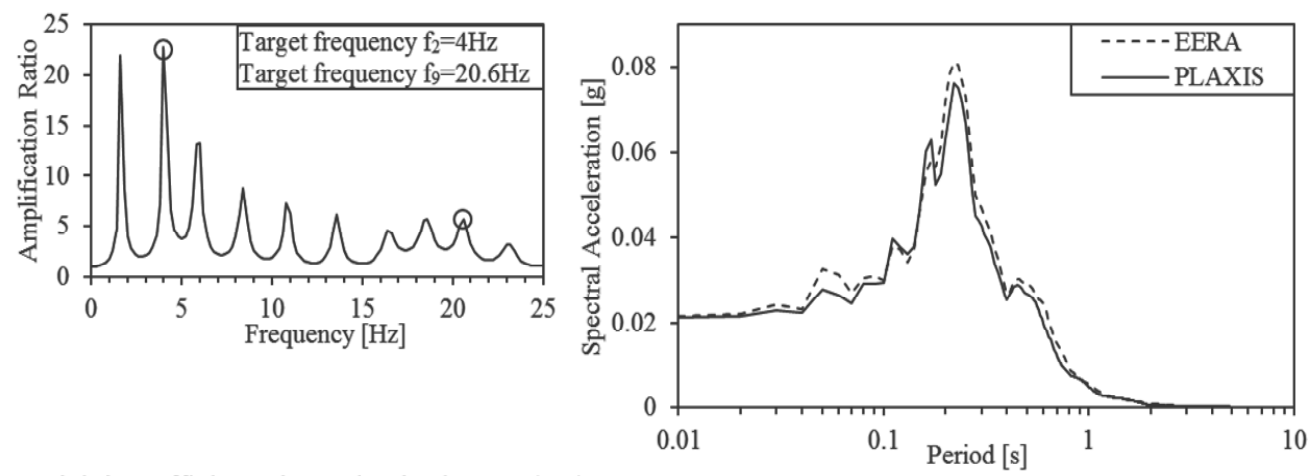

Rayleigh coefficients determined using eq. (4.1):

\begin{tabular}{|c|c|c|c|c|c|c|c|c|}
\hline Layer & 1 (Silt) & 2 (Gravel) & 3 (Silt) & 4 (Gravel) & 5 (Silt) & 6 (Moraine) & 7 (Moraine) & 8 (Moraine) \\
\hline$\alpha_{R}[-]$ & 1.447 & 0.272 & 1.084 & 0.272 & 0.910 & 0.226 & 0.227 & 0.215 \\
\hline$\beta_{R}[-]$ & 0.000445 & 0.000084 & 0.000333 & 0.000084 & 0.000280 & 0.000070 & 0.000070 & 0.000066 \\
\hline
\end{tabular}

Figure 4.5. Calibration results for Iceland 2008 - 013010 Signal.
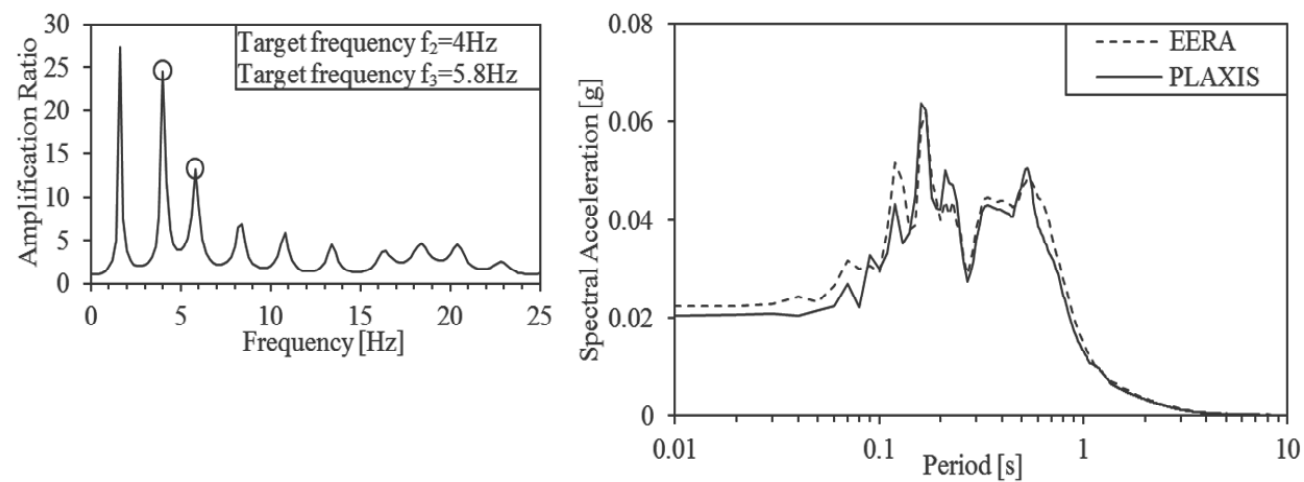

Rayleigh coefficients determined using eq. (4.1):

\begin{tabular}{|c|c|c|c|c|c|c|c|c|}
\hline Layer & 1 (Silt) & 2 (Gravel) & 3 (Silt) & 4 (Gravel) & 5 (Silt) & 6 (Moraine) & 7 (Moraine) & 8 (Moraine) \\
\hline$\alpha_{R}[-]$ & 1.071 & 0.206 & 0.945 & 0.229 & 1.049 & 0.203 & 0.194 & 0.182 \\
\hline$\beta_{R}[-]$ & 0.001171 & 0.000226 & 0.001033 & 0.000250 & 0.001146 & 0.000221 & 0.000212 & 0.000199 \\
\hline
\end{tabular}

Figure 4.6. Calibration results for Iceland 2008 - 013011 Signal. 

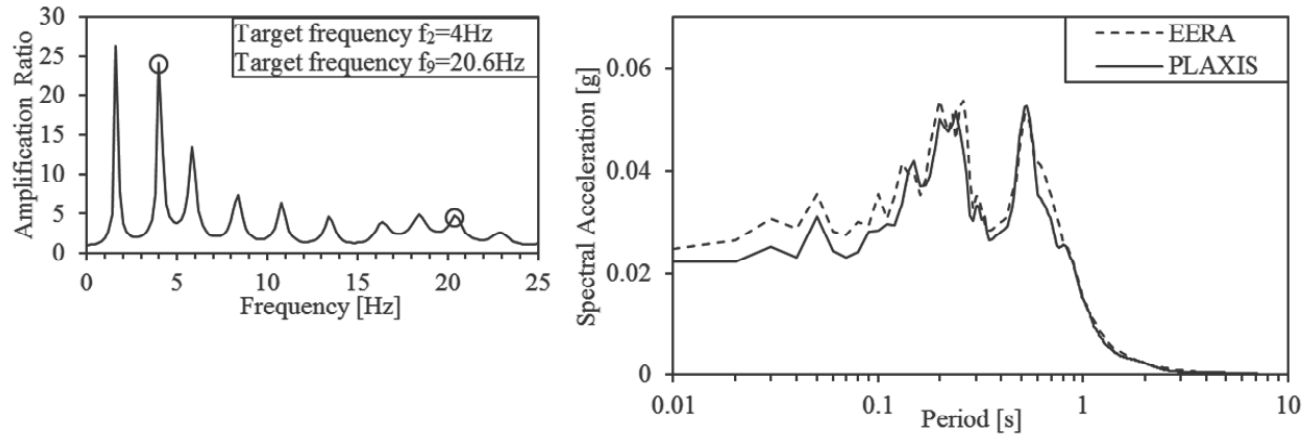

Rayleigh coefficients determined using eq. (4.1):

\begin{tabular}{|c|c|c|c|c|c|c|c|c|}
\hline Layer & 1 (Silt) & 2 (Gravel) & 3 (Silt) & 4 (Gravel) & 5 (Silt) & 6 (Moraine) & 7 (Moraine) & 8 (Moraine) \\
\hline$\alpha_{R}[-]$ & 1.489 & 0.277 & 1.209 & 0.317 & 1.404 & 0.264 & 0.249 & 0.241 \\
\hline$\beta_{R}[-]$ & 0.000458 & 0.000085 & 0.000372 & 0.000098 & 0.000432 & 0.000081 & 0.000077 & 0.000074 \\
\hline
\end{tabular}

Figure 4.7. Calibration Results for L'Aquila 2009 - ACG Signal.
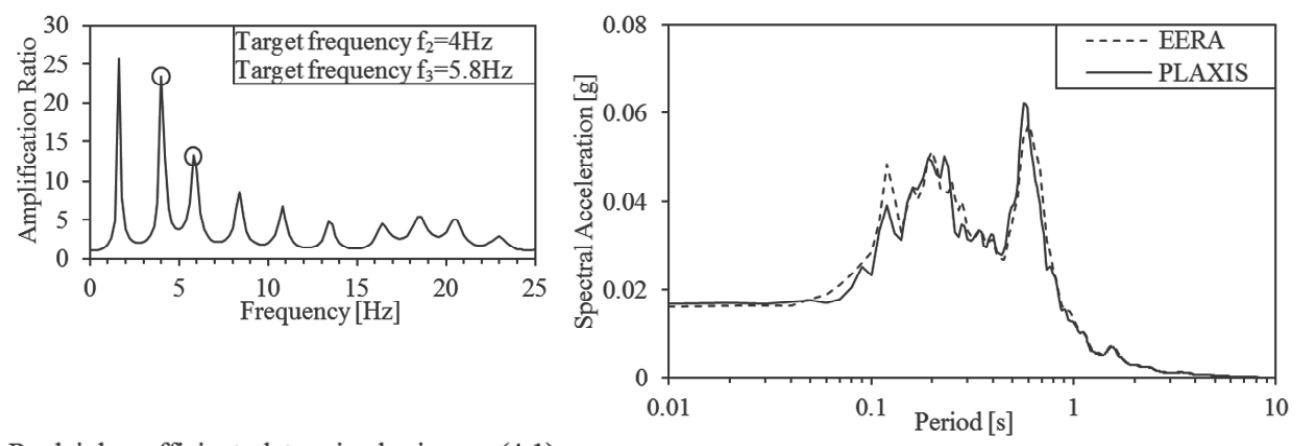

Rayleigh coefficients determined using eq. (4.1):

\begin{tabular}{|c|c|c|c|c|c|c|c|c|}
\hline Layer & 1 (Silt) & 2 (Gravel) & 3 (Silt) & 4 (Gravel) & 5 (Silt) & 6 (Moraine) & 7 (Moraine) & 8 (Moraine) \\
\hline$\alpha_{R}[-]$ & 0.872 & 0.193 & 0.846 & 0.218 & 0.935 & 0.188 & 0.177 & 0.168 \\
\hline$\beta_{R}[-]$ & 0.000953 & 0.000211 & 0.000925 & 0.000238 & 0.001022 & 0.000206 & 0.000193 & 0.000184 \\
\hline
\end{tabular}

Figure 4.8. Calibration Results for L'Aquila 2009 - GSG Signal.

\subsubsection{Structural elements, foundation types}

The structural elements were modelled using plate elements, according to Mindlin's plate theory (Bathe, 1982). The superstructure was replaced using the simplifying assumption of an equivalent distributed load (including the self-weight and the live loads on the structure), limiting the analysis to considerations related to the kinematic response. The analysis includes three types of foundations: a shallow foundation, a deep basement and a pile foundation.

Interfaces were introduced at the contact between structural elements (i.e. foundation mat, piles, walls) and soil clusters (Figure 4.9) to allow for differential displacements between soil and structures (i.e. sliding and gapping). The interfaces have identical material properties with the surrounding soil.

The piles in Figure 4.9b were considered to be fixed at the top (at slab level) and the spatial interaction between soil and pile rows was modelled under plane-strains conditions by using equivalent sheet pile walls with reduced smeared stiffness, as suggested by Randolph (1981) and Naylor (1982). The dimension of the foundation in the direction 
perpendicular to the 2D problem modelled by PLAXIS was assumed to be $30 \mathrm{~m}$ (assumption of a rectangular layout of the foundation). The seven circular piles ( $D=75 \mathrm{~cm}$ ) were assimilated with a sheet pile wall of equivalent width $d=60 \mathrm{~cm}$, characterized by a smeared Young Modulus of E = 4.04 GPa.
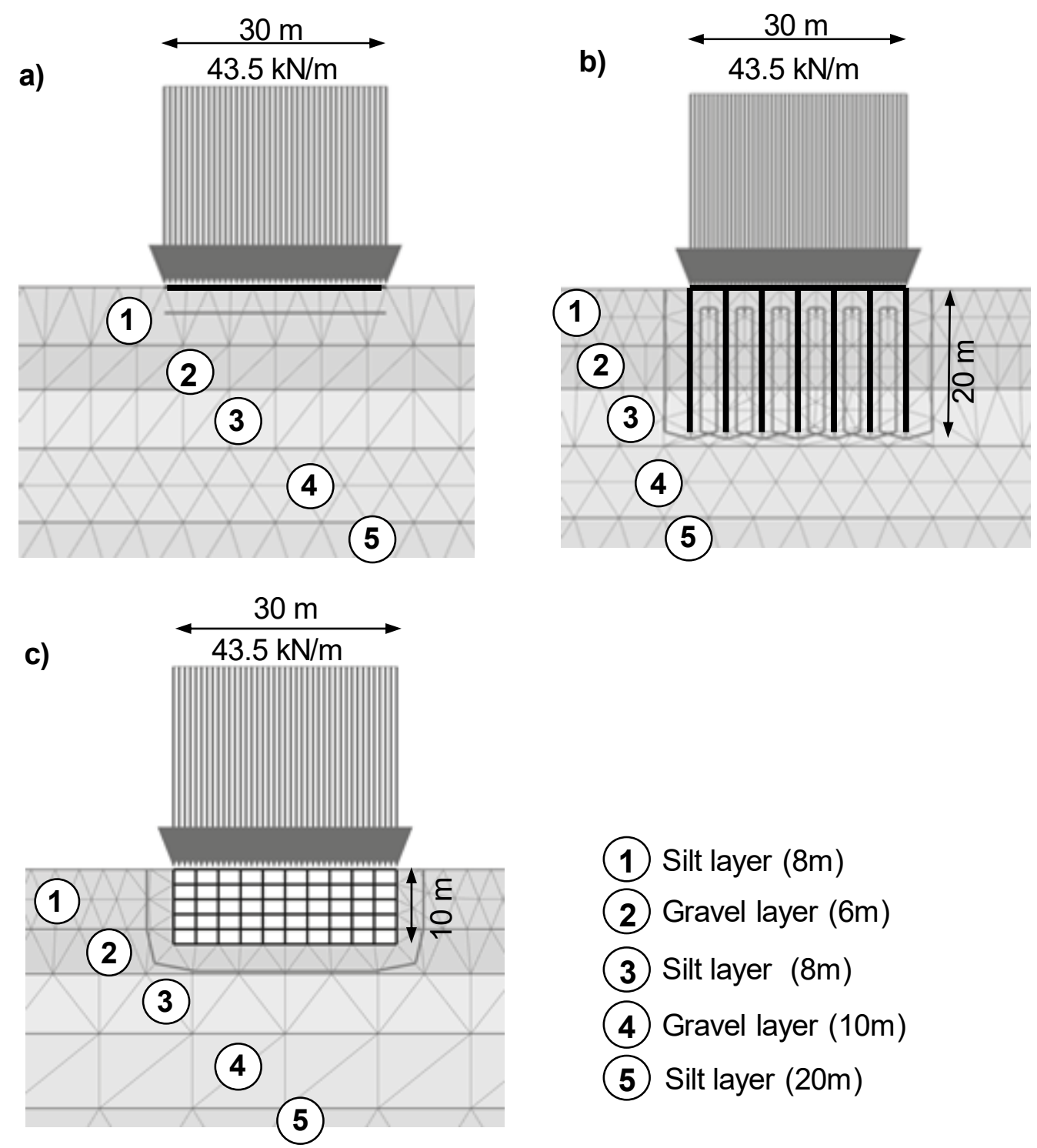
(1) Silt layer $(8 \mathrm{~m})$
(2) Gravel layer $(6 m)$
(3) Silt layer $(8 \mathrm{~m})$
(4) Gravel layer $(10 \mathrm{~m})$
(5) Silt layer $(20 \mathrm{~m})$

Figure 4.9. Foundation layouts and soil profile below the surface: a) shallow foundation; b) pile foundation; c) deep basement.

\subsubsection{Input signal}

The most common earthquake mechanisms in the area of Wallis are either strike-slip, or normal fault (Deichmann \& Ballarin-Dolfin, 2003) at a shallow depth. All computations were performed using the 2008 Iceland (013010 Signal) earthquake $\left(M_{w}=6.3\right)$, which was characterized by a normal fault mechanism and an epicentral depth of $10 \mathrm{~km}$ (USGS, 2008). 
One method to obtain an input signal appropriate for the bottom of the FE model from PLAXIS is to back-calculate an inside motion signal (which is more suitable for the nonrigid bottom layer of the FE model) from the given outcrop signal. This can be obtained easily in EERA, by applying the input original signal to the model as an outcrop motion, and calculating the inside motion corresponding to the lower most layer. This motion (Figure 4.10) was used as input in the further analyses performed with PLAXIS.

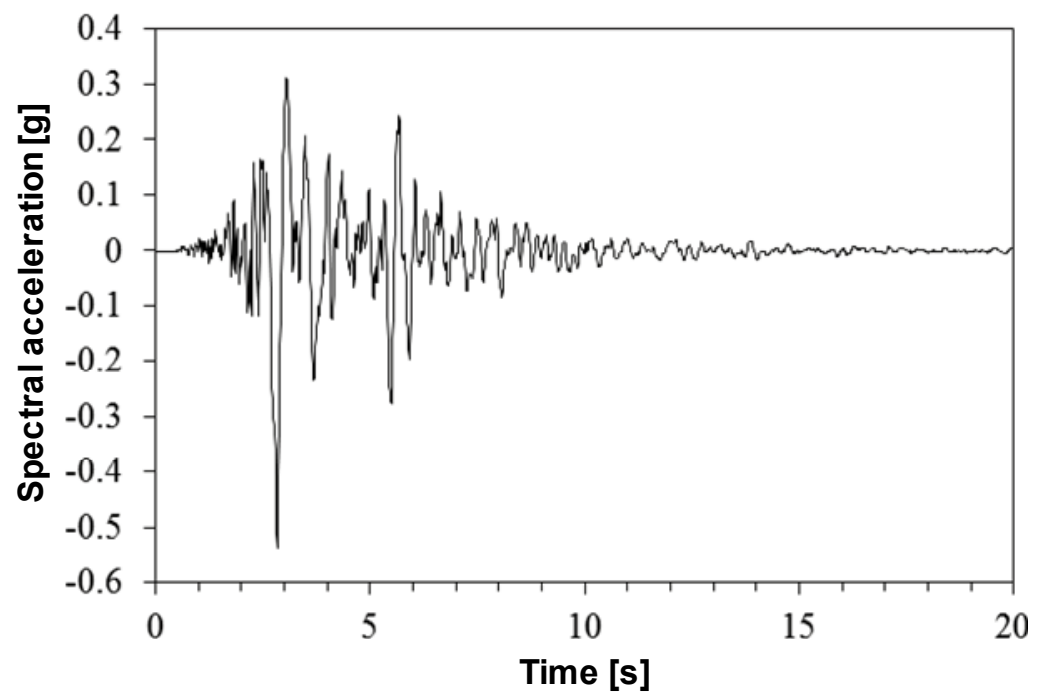

Figure 4.10. Input Motion (Iceland $2008-013010$, inside motion).

\subsection{Results}

\subsubsection{Results related to soil-structure interaction}

The first parameter to be analysed is the foundation input motion (FIM) in terms of response spectra of the horizontal accelerations. The FIM for the shallow foundation shows almost identical values with the free field motion (Figure 4.11a). For periods $\mathrm{T}<$ $0.09 \mathrm{~s}$, the effect of base slab averaging can be observed in the reduction of the spectral values. The stiff foundation slab acts like a low-pass filter averaging the acceleration components in the low period (high frequency) range. The $20 \mathrm{~m}$ long slender piles $(D=0.75$ $\mathrm{m}$ ) are flexible enough to deform with the soil mass and the FIM is very similar to the freefield motion (Figure 4.11b). Several values exceeding the free field motion can be observed, indicating the kinematic effect caused by the stiffness contrast between the foundation system and the surrounding soil. The lowest spectral values were calculated for the deep basement as combined effect of the kinematic soil-structure interaction: on the one hand, the effect of the embedment at $10 \mathrm{~m}$ below the surface, and, on the other one, the base slab averaging at the contact between basement and the soil below (Figure 4.11c). 

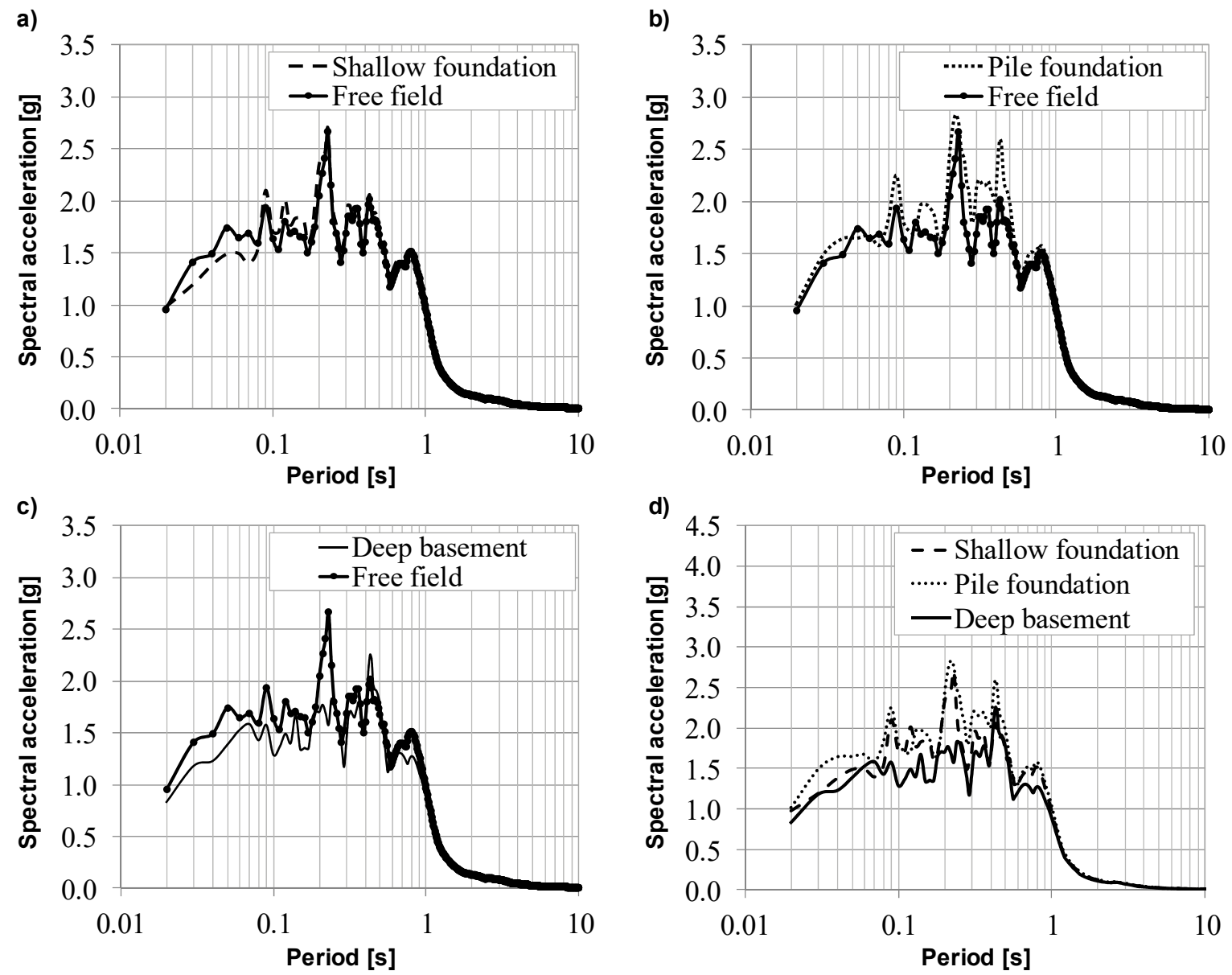

Figure 4.11. Output response spectra of the foundation input motion (Iceland $2008-013010$ ).

Figure 4.12 shows the comparison between the FIM and the free field motion in terms of horizontal displacements. The FIM is very similar for all foundation types, with residual values of the horizontal displacements between 7 and $8 \mathrm{~cm}$, which are slightly higher than the free field motion (Figure 4.12 a-c). Figure 4.12d shows the difference between the three different FIMs and the free field horizontal displacements. The deformations at the interface between the shallow foundation and the soil are constrained due to the high stiffness of the slab, and slippage occurs, leading to a permanent difference of $0.6 \mathrm{~cm}$. Similar values were calculated in the case of the deep basement, where the waves propagating vertically through the soft soil cause a translation motion of the stiff deep basement. These kinematic effects of the soil-structure interaction can be observed also in the clear phase difference revealed by the oscillating differences calculated for the deep basement in Figure 4.12d. The pile foundation, which showed the highest spectral values of the FIM, also experienced the largest difference from the free field motion, with a residual value of $1.6 \mathrm{~cm}$. 

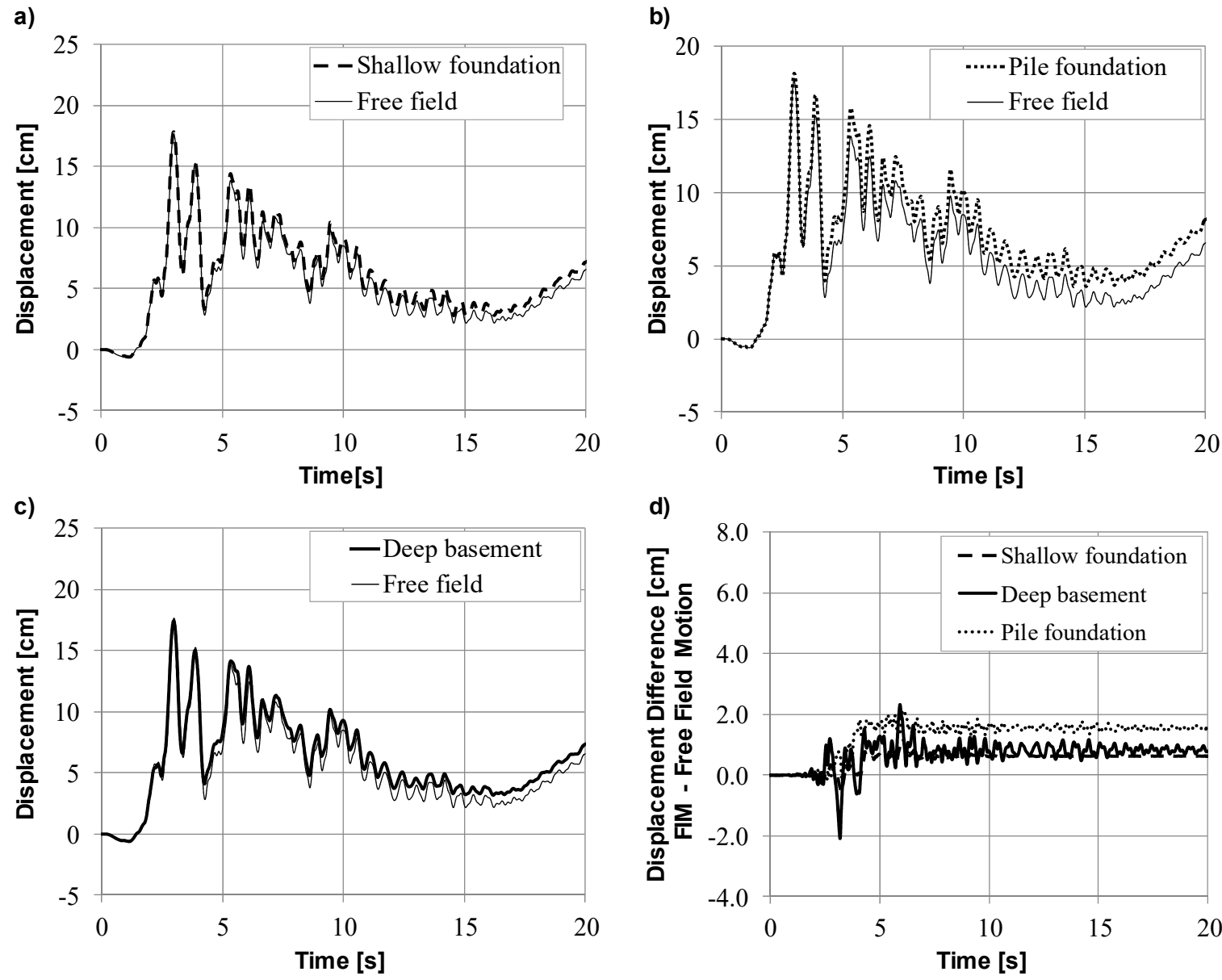

Figure 4.12. Horizontal displacements for the three investigated situations: a) shallow foundation; b) pile foundation; c) deep basement; d) summary of all results (Iceland 2008 - 013010).

Due to the limitations of the modelling conditions, vertical displacements occurred in the soil mass at the lateral boundaries, inducing surface (Rayleigh) waves in the ground model. The foundations interacted kinematically with these waves and tilted. Figure 4.13 shows the distribution of residual vertical displacements of the ground model and of the shallow foundation at the end of the seismic signal $(t=20 \mathrm{~s})$. 


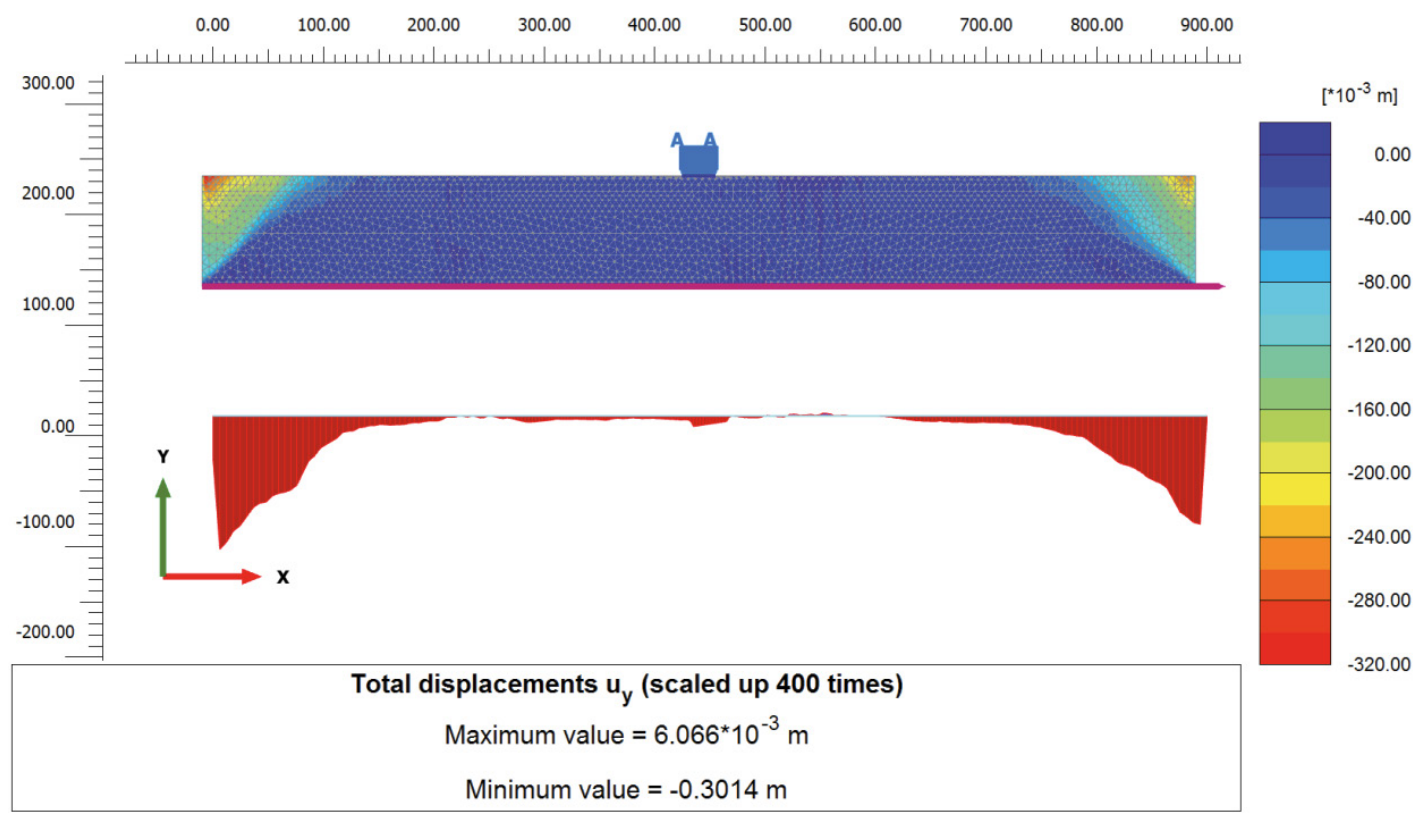

Figure 4.13. Distribution of vertical displacements on the surface of the ground model for the shallow foundation at the end of the seismic signal Iceland $2008-013010$.

The induced surface waves had the strongest impact on the shallow foundation located on the surface of the ground model. The residual tilt calculated at the end of the seismic motion had an absolute value $0.037 \%$. The deep basement tilted less than the shallow foundation and a residual value of $0.016 \%$ was calculated. In this case, however, a clear distinction between the influence of surface waves and the kinematic effect of the embedment of the stiff basement in the soft soil cannot be made. The $20 \mathrm{~m}$ long piles counteracted the effect of the surface waves in terms of vertical displacement and the residual tilt of the pile foundation was close to zero (Figure 4.14).

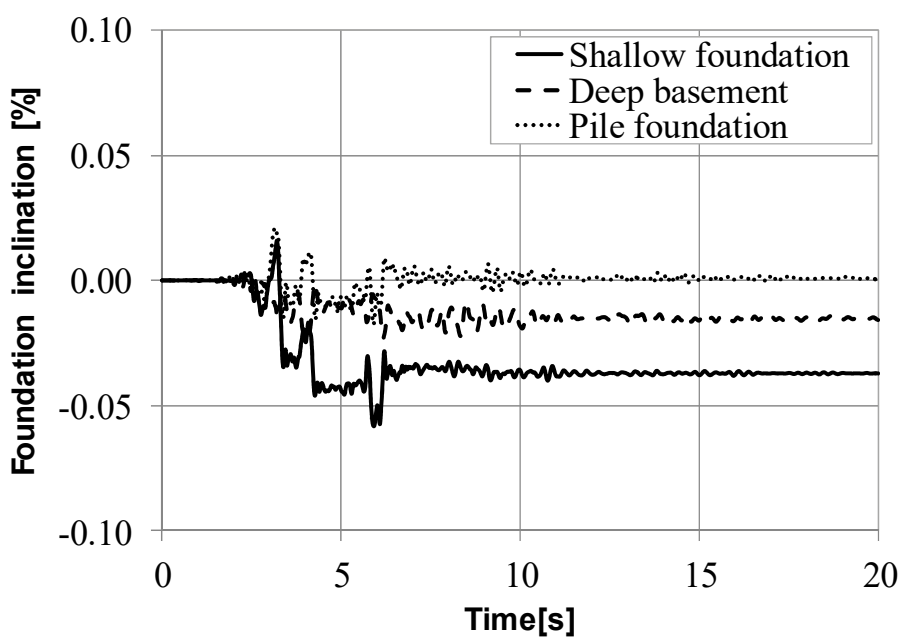

Figure 4.14. Average tilting of the foundations (Iceland 2008 - 013010). 


\subsubsection{Interaction between basement walls and surrounding soil}

The soil structure interaction was modelled using the interface elements with the same strength parameters as the surrounding soil. Sliding and gapping are modelled using elastic-perfectly plastic springs, as defined by van Langen (1991) and implemented by Brinkgreve et al. (2012). Gapping occurs when the tensile strength of the interface is reached during loading in one direction. When the load is reversed, contact stresses are modelled to develop immediately, considering that the surrounding material is granular and no additional displacement is required to close the gap. The stiffness of the interface is automatically determined by the FE software to avoid any inconsistencies of the local stiffness matrix.

Figure 4.15 shows the lateral displacements of two pairs of points on the wall and in the adjacent soil clusters: points $A$ and $B$ at the top, and $C$ and $D$ at the bottom (Figure 4.15d). The horizontal displacements of the two pair of points are almost identical, with some small differences at the top part (points $A$ and $B$ ). The plot of the relative displacements between these two points reveals the gapping mechanism modelled by the interface elements, with five major gapping events (Figure 4.15c).

a)

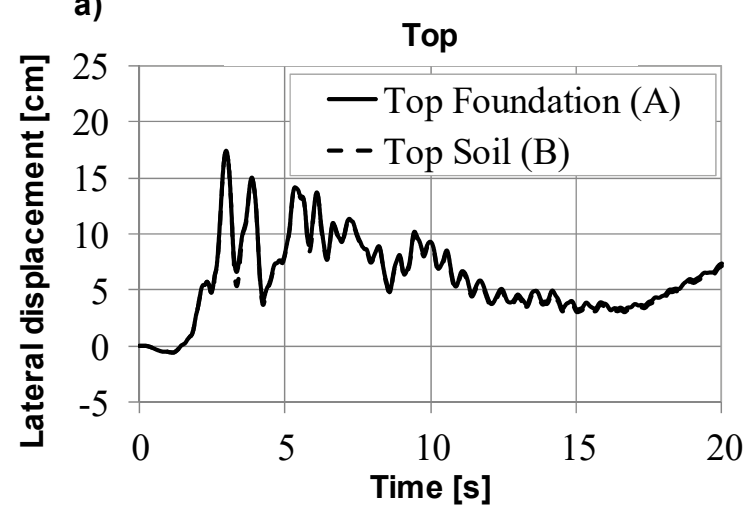

c)

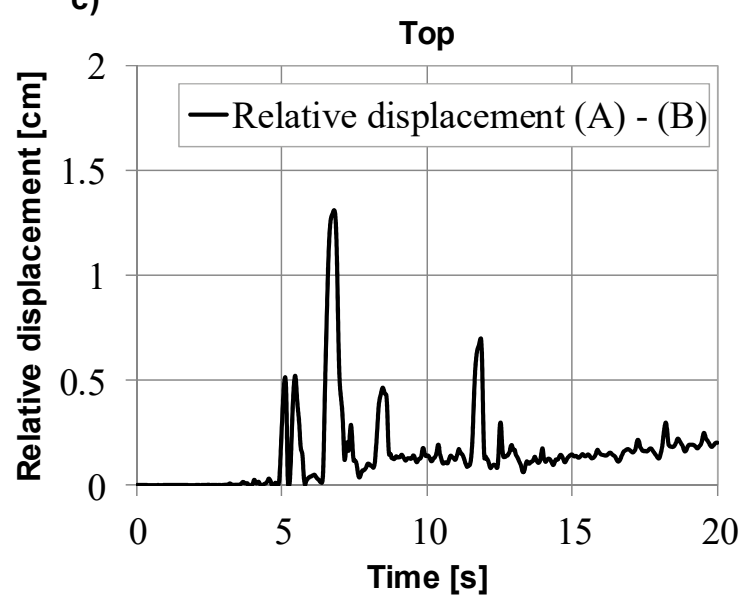

b)

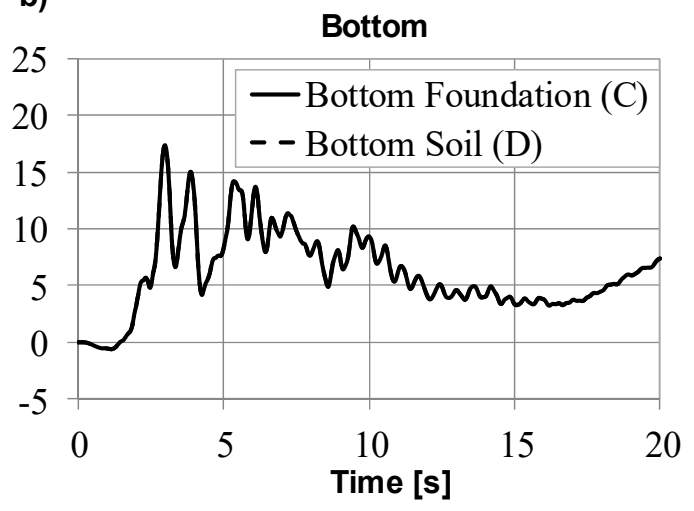

d)

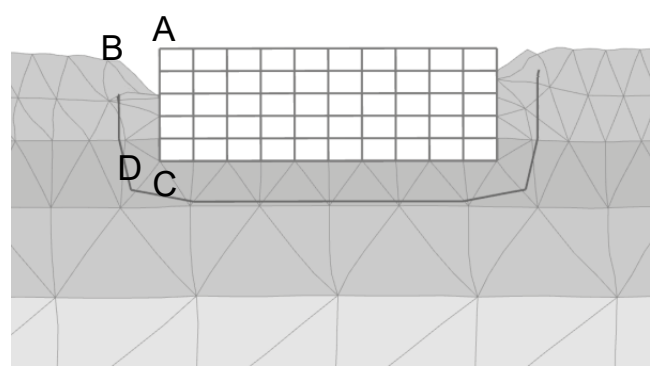

Figure 4.15. Soil-wall interaction: a) top lateral displacement; b) bottom lateral displacement; c) top relative displacement; d) representation of the soil-wall interface (not to scale) - (Iceland 2008 013010). 
The variation of the lateral earth-pressure on the basement wall can be seen in Figure 4.16. The discretisation of the FE mesh around the walls of the deep basement includes five elements and 21 nodes for the entire wall height of $10 \mathrm{~m}$ (see Figure 4.9c). This resulted in a node-to-node distance of approx. $0.5 \mathrm{~m}$, which ensured the accuracy of the results obtained for this section.

At the beginning of the seismic motion, an active pressure distribution is modelled. Subsequently, the pressure starts to concentrate on central part of the wall, between 2 and $5 \mathrm{~m}$ of depth, showing lower values in the top and bottom parts of the wall. The overestimated values of the earth-pressure modelled at the bottom of the wall (10m of depth) are caused by the inflexible corner points of the interface elements, which are unable to model accurate values of the stresses. The increased stresses between 2 and $5 \mathrm{~m}$ of depth at $\mathrm{t}=3 \mathrm{~s}$ and $10 \mathrm{~s}$ correspond to the displacement peaks in the positive direction shown in Figure 4.15a, while the lower ones, modelled at $\mathrm{t}=5 \mathrm{~s}$ and $7 \mathrm{~s}$, correspond to the gapping events visible in Figure 4.15c.

This modelled behaviour fits with previously observed data in the literature (Chari \& Meyerhof, 1983; Tsang et al., 2002). Similar variations of the earth pressure were experienced with integral bridge abutments subjected to cyclic loading ( $\mathrm{Ng}$ et al., 1998), when the granular soil filled the space behind the abutments, created as the interface repeatedly opened and closed during cyclic loading. Due to this accumulation, the soil densified, the local stiffness increased in the denser area, and horizontal stresses concentrated and built up at mid-height of the abutment.
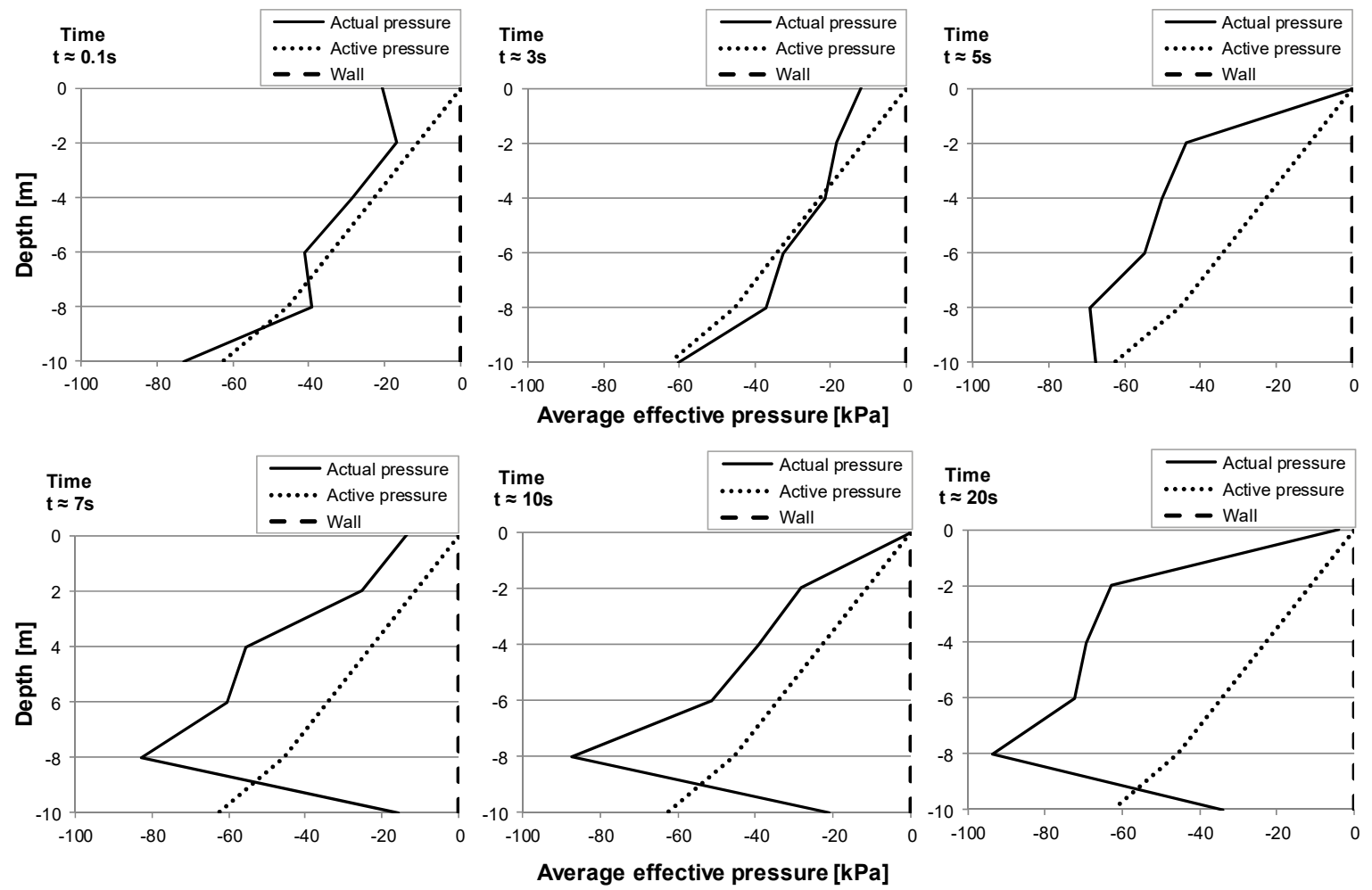

Figure 4.16. Variation of earth pressure on the wall of the foundation basement (Iceland 2008- 013010). 


\subsection{Performance based design. Conclusions and discussion}

The kinematic interaction between the fluvial sediments in an alpine valley and the foundation of an industrial building was analysed. The static soil parameters for the 2D model were obtained from existing data, while the dynamic ones were calibrated using a frequency domain analysis in the elastic range. The results of the analysis matched already observed behaviour and confirmed the possibility of using widely available software (PLAXIS) to provide a reasonable approach to the performance-based design, even when using strongly simplifying assumptions. Typical effects of the soil structure interaction were observed, such as base slab averaging and embedment effects (Kramer \& Stewart, 2004). In this way, the results served the purpose of confirming and presenting a possible approach to performance-based design, including soil-structure interaction. A consistent qualitative and quantitative investigation can be performed by taking the inertial effects of the structure into account.

The motivation behind this reiteration was introduced in the context of performance-based design tendencies observed especially in the Swiss Norms. According to SIA 260 (2003), paragraph 2.2 (Figure 4.17), the design of a structure involves a service criteria agreement, which has to be defined in a dialogue between the client and the designers of the project.

\begin{tabular}{|ll|}
\hline 2.2 & Service criteria agreement \\
2.2 .1 & The service criteria agreement shall be formulated on the basis of a dialogue between the owner and the \\
& design engineers. \\
2.2 .2 & The service criteria agreement comprises: \\
& - general aims for the use of the construction works \\
& - ambient conditions and third party requirements \\
& - operational and maintenance requirements \\
& - special requirements of the owner \\
& - objectives of protection and special risks \\
2.2 .3 & The objectives and the degree of protection shall be determined on the basis of a risk evaluation.
\end{tabular}

Figure 4.17. SIA 260 Basis of structural design (Paragraph 2.2).

Thus, there are two sides of the project, which are compared and matched in advance: the required performance, which is given by the service criteria requested by the client (owner), and the predicted performance, provided by the designer. Considering the required boundary conditions, the performance of the provided solution can only be evaluated using simplified calculations or numerical simulations. The alternative of reliable calculations and design charts involves, in the case of seismic design, an extensive database of past seismic events. This is a sensitive matter in areas of moderate seismicity, such as Switzerland, where significant events are rare. The second alternative, represented by numerical simulations, provided the motivation of performing the FE analysis presented above, which showed a simple and efficient method to approach performancebased design including soil-structure interaction effects. 


\subsection{References}

Antes, H., Jessberger, H.L., Schmid, G., Chow, N., Forchap, E., Grundhoff, T., Laue, J., Le, R. \& Siemer, T. (1996) Dynamic and cyclic soil-structure interaction. In: Krätzig et al. (eds.) Dynamics of Civil Engineering Structures, pp. 451-532. A. A. Balkema, Rotterdam.

Bardet, J.P., Ichii, K. \& Lin, C.H. (2000) EERA. A computer program for equivalent-linear earthquake site response analyses of layered soil deposits. University of Southern California. Department of Civil Engineering.

Bathe, K.J. (1982) Finite element procedures in engineering analysis. Prentice-Hall, Englewood Cliffs.

Brinkgreve, R.B.J., Engin, E. \& Swolfs, W.M. (2014) PLAXIS 2D Anniversary Edition 2014. Delft University of Technology \& PLAXIS bv. The Netherlands.

Burjanek, J. (2011) Development of 3D Velocity Model for Visp area. Presentation at the Third Annual Meeting of COGEAR, January 2011. Visp.

Chari, T.R. \& Meyerhof, G.G. (1983) Ultimate capacity of rigid single piles under inclined loads in sand. Canadian Geotechnical Journal, 20. pp. 849-854.

COGEAR Platform. (2010) https://geodata.ethz.ch/cogear/ (accessed on $20^{\text {th }}$ of January 2012).

Deichmann, N. \& Ballarin-Dolfin, D. (2003) Seismotektonische Karte der Schweiz. Schweizerisches Erdbeben Dienst.

Fritsche, S. (2008) Large historical earthquakes in Switzerland. Multidisciplinary studies on damage fields and site-effects. Dissertation No. 17710. ETH Zurich.

Kramer, S.L. \& Stewart, J.P (2004) Geotechnical aspects of seismic hazards. In: Y. Bozorgnia \& V. V. Bertero (eds), Earthquake Engineering From Engineering Seismology to Performance-Based Engineering. CRC press LLC.

Kuhlemeyer, R.L. \& Lysmer, J. (1973) Finite Element Method Accuracy for Wave Propagation Problems. Journal of Soil Mechanics and Foundations Division ASCE 99. pp. 421-427.

Naylor, D.J. (1982) Finite element study of embankment loading on piles. Report for the Department of Transport (HECB). New Jersey.

Ng, C., Springman, S.M. \& Norrish, A. (1998) Soil-structure interaction of spread-base integral bridge abutments. Soils and Foundations, 38(1). pp. 145-162.

Park, D \& Hashash, Y.M.A. (2004) Soil damping formulation in nonlinear time domain site response analysis. Journal of Earthquake Engineering, 8(2). pp 249-274. 
Randolph, M.F. (1981) Pilot study of lateral loading of piles due to soil movement caused by embankment loading. Report for Department of Transport (HECB).

Résonance S.A. (2010) Reévaluation du danger de liquéfaction du sol sur le site de Lonza à Viège. Rapport no. RT 226.26. Carrouge, Suisse.

Roten, D., Fäh, D., Bonilla, L.F., Alvarez-Rubio, S., Weber, T.M. \& Laue, J. (2009) Estimation of non-linear site response in a deep Alpine valley. Geophysical Journal International, 178(3). pp. 1597-1613.

SIA 261 (2003) Actions on structures. Swiss Society of Engineers and Architects. Zurich

SIA 260 (2003) Basis of structural design. Swiss Society of Engineers and Architects. Zurich.

Tsang, N.C.M., England, G.L. \& Dunstan, T. (2002) Soil-Structure interaction of integral bridge with full height abutments. 15th ASCE Engineering Mechanics Conference. Columbia University, New York.

US Geological Survey. (2008) Iceland region earthquake 2008. ShakeMap Archive ID: sqba2008.

Van Langen, H. (1991) Numerical analysis of soil-structure interaction. Disseration TR 1905. TU Delft.

Visone, C. \& de Magistris, F.S. (2010) Comparative study on frequency and time domain analyses for seismic site response. Electronical Journal of Geotechnical Engineering, vol. 15.

Weber, T. M., Laue, J. \& Springman, S. M. (2007) Geotechnical laboratory tests for identification of soil parameters for the cyclic mobility model of sandy soil from Visp (VS). Project report - „SHAKE - VAL 2“, IGT Report No. 4698, ETH Zürich. 


\title{
5. Installation and Instrumentation of a Long-Term Seismic Monitoring System in the Rhone Valley
}

\author{
Alexandru Marin \\ ETH Zürich, Institute for Geotechnical Engineering \\ Stefano-Franscini-Platz 5, 8093 Zürich, Switzerland \\ E-mail address: amarin@ethz.ch
}

Jan Laue ${ }^{1}$

ETH Zürich, Institute for Geotechnical Engineering

Stefano-Franscini-Platz 5, 8093 Zürich, Switzerland

E-mail address: jan.laue@ltu.se

Donat Fäh

ETH Zürich, Swiss Seismological Service

Sonneggstrasse 5, 8092 Zürich, Switzerland

E-mail address: donat.faeh@sed.ethz.ch

Submitted to Soil Dynamics and Earthquake Engineering

Status: under review

\footnotetext{
${ }^{1}$ Appointment of Luleå University of Technology since August 2015 Department of Civil, Environmental and Natural Resources Engineering Mining and Geotechnical Engineering SE-971 87 Luleå, Sweden
} 


\begin{abstract}
The installation and instrumentation of a novel long-term seismic monitoring system, in the most active seismic zone in Switzerland, is presented in this paper. The novelty of the system is represented by the constellation of sensors installed together at the same seismic site. The system includes a Shape-Acceleration-Array (SAA), a multi-level piezometer array, and triaxial downhole and surface strong-motion sensors. The deformation, acceleration and pore pressure profiles can be recorded during an earthquake with a high degree of accuracy using this system. The site response in an alpine valley with a complex bedrock shape can be measured and analysed, the influence of non-linear soil behaviour under moderate seismicity can be detected, and in case of a strong event, the process of liquefaction can be monitored. The obtained data will be used to calibrate numerical simulations of the wave field and seismic behaviour of civil and geotechnical structures located in alpine valleys.
\end{abstract}

Keywords: seismic monitoring, site response, borehole, SAA, multi-level piezometer, non-linear behaviour, soil liquefaction 


\subsection{Introduction}

The risk associated with the seismic hazard in alpine valleys increases with the development of lifeline, civil, and industrial structures in areas with historical evidence of strong ground-motion and liquefaction during past earthquakes (Fritsche et al., 2006). In this case, the understanding of wave propagation, non-linear soil behaviour, and associated effects is essential. For this purpose, numerical models (e.g. Roten et al., 2008, 2009; Marin et al., 2016) have to be developed to simulate the seismic amplification and its effects, and monitoring systems have to be installed to validate the models developed and to enhance the capacity to forecast possible earthquake impacts.

The Rhone Valley in Switzerland is a typical example of an alpine valley filled with sediments expected to show strong ground-motion amplification, non-linear soil behaviour and associated effects in the case of an earthquake. Areas like this, prone to highly nonlinear soil behaviour or soil liquefaction, are already developed and cannot be avoided in the planning process, due to the increasing density of buildings in the limited space provided by the valleys. As a consequence, safety measures have to be considered based on a clear understanding of the anticipated soil response during an earthquake. The interdisciplinary project COGEAR (Coupled seismogenic geohazards in alpine regions) approached this challenge by investigating the hazard chain related to earthquakes in the Alpine environment in Switzerland (Fäh et al., 2011, http://www.cces.ethz.ch/ projects/hazri/COGEAR).

Module $3 a$ of this project studied the wave propagation in complex surface structures in the alpine environment. On the one hand, numerical modelling of wave propagation and associated phenomena was performed to evaluate the effects of the seismic loading in terms of ground displacements, induced stresses and strains, and non-linear behaviour of soil. On the other hand, local long term strong-motion networks and geotechnical monitoring systems were installed to provide data to calibrate numerical simulations.

The long-term seismic monitoring system presented here combines both strong-motion sensors and geotechnical monitoring systems. It was installed in the Rhone Valley in the town of Visp with a planned operation time of about 20 years. The set-up aims to collect relevant data related to the local amplification of seismic waves from the bedrock to the surface of the alluvial deposits, together with information about non-linear soil behaviour and development of pore pressure. The strong-motion sensors were installed in boreholes and at the surface to capture the local amplification of the seismic motion. The ShapeAcceleration Array (SAA) (Danisch et al., 2004) capturing deformations, and the multilevel-piezometer array recording pore pressure changes associated to the non-linear soil behaviour, were installed in boreholes in the top $12 \mathrm{~m}$ of the alluvial deposits. The system is integrated in the real-time strong motion network operated by the Swiss Seismological Service (Clinton et al., 2011), with additional strong motion stations in Visp and the surrounding region (Michel et al., 2014). 
This seismic monitoring system is the first of its type in Switzerland and one of the few worldwide. Preliminary tests (Zeghal et al., 2004) showed that the SAA represents an effective tool to analyse and assess the local dynamic response of a geological structure. Abdoun et al. (2008) performed full-scale laboratory tests in a laminar container and compared the data obtained using the SAA with parallel measurements made with tradetional instruments, such as accelerometers and displacement sensors. The good agreement between the measurements showed that the SAA is able to measure in-situ accelerations and displacements simultaneously and accurately. An SAA-based seismic monitoring system was installed in the Wildlife Refuge area in southern California (Mercado et al., 2011) with the purpose to identify the soil parameters at low and high strains, but also to record any occurring earthquakes and to provide data for further model identification and verification. Mercado et al. (2011) reported data recorded by the monitoring system, which included pore pressure time-histories parallel with the SAA measurements, during the Baja California earthquake from April 4, 2010.

The monitoring system installed in Visp will provide data and advance this field of earthquake engineering for areas with moderate seismicity such as Switzerland. Locally, the installation of these combined instruments represents a novelty and can be considered as a pilot project, used to prove the feasibility of such monitoring systems and to calibrate models from observations of small earthquakes $(M<4)$ that occur frequently in that area.

\subsection{Details of the instrumented site}

The site of the monitoring system is located in the most seismically active region in Switzerland in the canton of Valais, in the Rhone Valley, next to the town of Visp. This location is representative for the situation of deep alpine valleys filled with granular sediments, which are prone to two-dimensional effects and are associated with non-linear soil behaviour. The bedrock is $160-180 \mathrm{~m}$ deep in the area of the instrumented site and it can reach a maximum depth of 260-300 $\mathrm{m}$ depending on the location in the valley (Burjanek et al., 2011) (Figure 5.1).

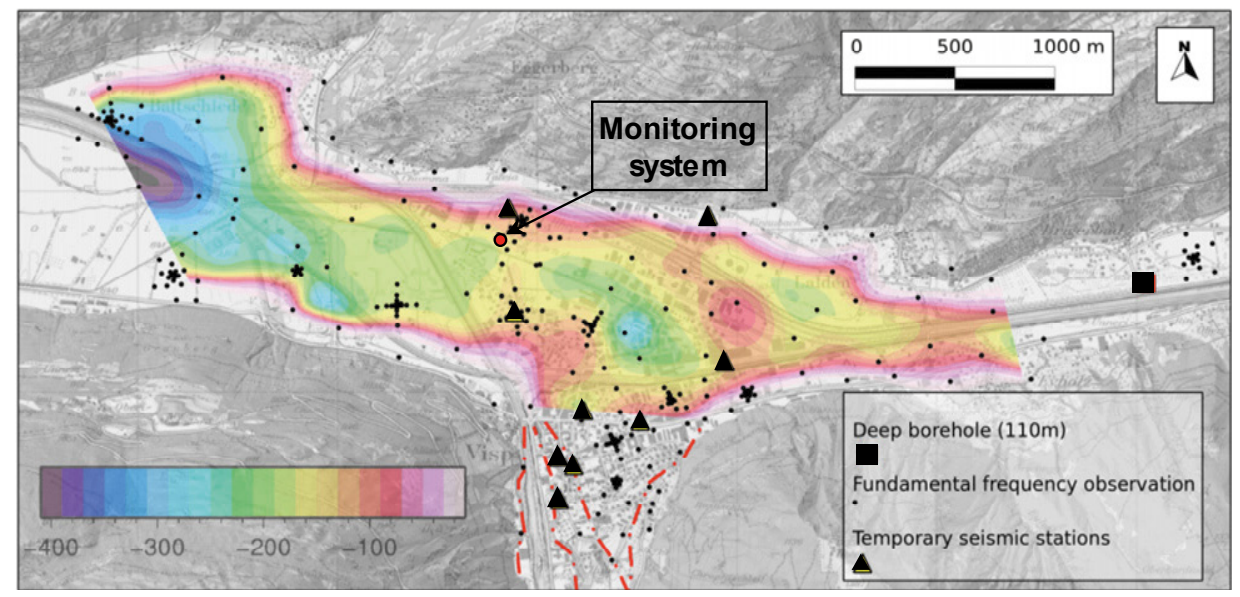

Figure 5.1. Depth of the Rhone Valley in the Visp area (after Burjanek et al., 2011) and location of the monitoring system. 
The five boreholes are arranged in a square shape with a centre hole and each one of them has a different depth and a different designated instrumentation (Table 5.1). The chosen set-up minimises the unwanted interferences between instruments and simplifies the installation of the sensors. An anchored concrete shaft was put in place in the northern corner of the site for the installation of the surface strong-motion sensor (Episensor) (Figure 5.2).

Table 5.1. Boreholes depth and instrumentation at the seismic monitoring site in Visp.

\begin{tabular}{lcl}
\hline Borehole Number & Borehole depth & Borehole instrumentation \\
\hline $\mathrm{BH} 1$ & $15 \mathrm{~m}$ & Strong-motion sensor \\
$\mathrm{BH} 2$ & $25 \mathrm{~m}$ & SAA \\
$\mathrm{BH} 3$ & $25 \mathrm{~m}$ & Multi-level piezometer \\
$\mathrm{BH} 4$ & $58 \mathrm{~m}$ & Strong-motion sensor \\
$\mathrm{BH} 5$ & $102 \mathrm{~m}$ & Strong-motion sensor \\
\hline
\end{tabular}

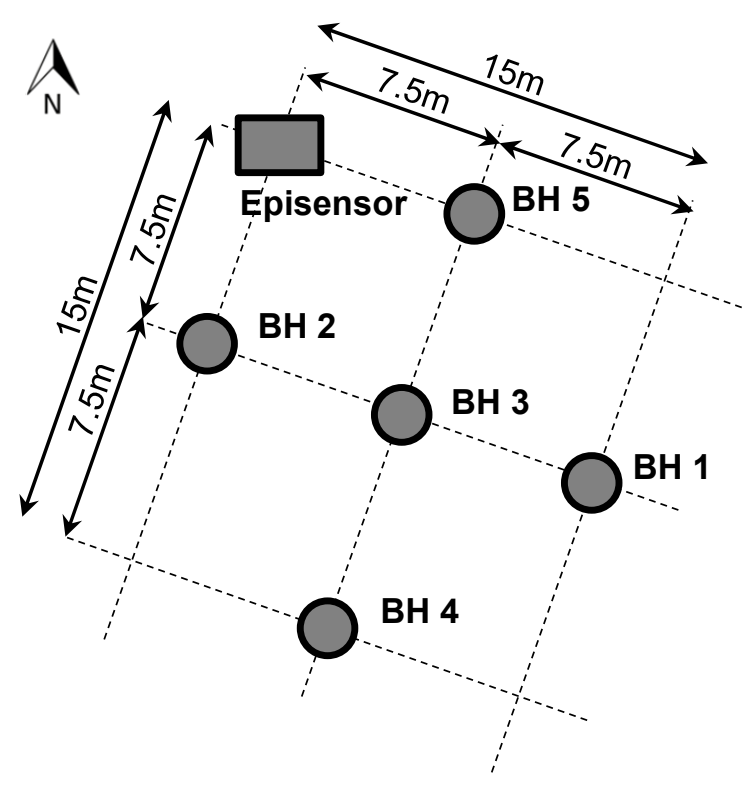

Figure 5.2. Plan view of the seismic monitoring site in Visp.

The valley is filled with alternating alluvial layers of silt and gravel and talus deposits may be found at greater depths. The identification of the soil layers down to $108 \mathrm{~m}$ was achieved by destructive drilling, while more detailed information about the soil layers close to the surface (down to $25 \mathrm{~m}$ ) obtained by cored drilling. The layers of alluvial deposits in Figure 5.3 correlate with profiles determined previously from the analysis of shear waves velocities obtained in the same area (Burjanek et al., 2011). 


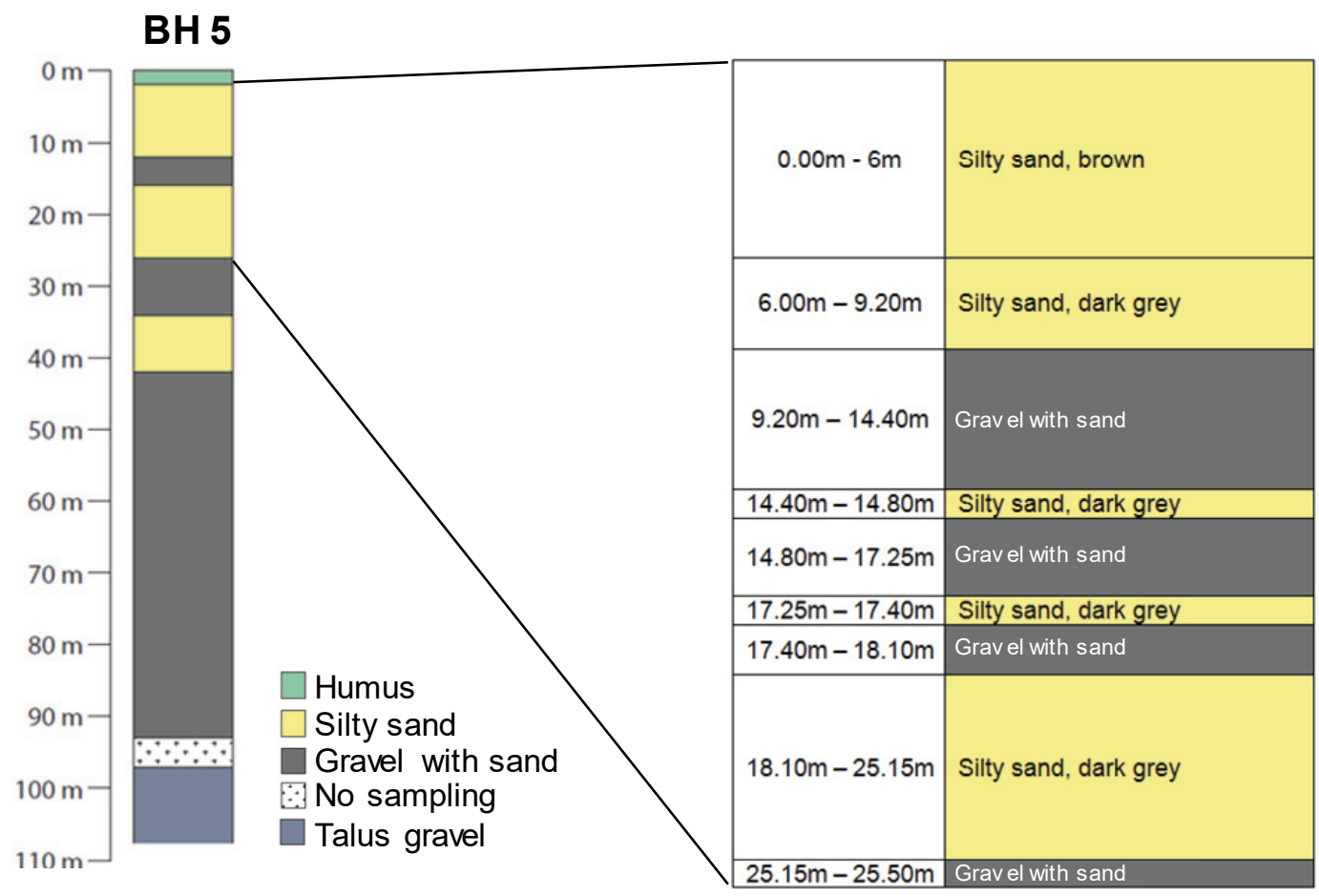

Figure 5.3. Geological profiles at the location of the seismic monitoring site in Visp (left: destructive drilling profile; right: cored drilling profile).

Originally, borehole $\mathrm{BH} 5$ was planned to be $150 \mathrm{~m}$ deep. However, a layer of rough talus deposits was encountered between 90-100 $\mathrm{m}$ and the drilling technique utilised was not effective anymore. In addition, the temperature of the water sampled at $96 \mathrm{~m}$ raised suddenly to $18{ }^{\circ} \mathrm{C}$ indicating the existence of a thermal aquifer. The possible risks associated with drilling through thermal aquifers (artesian conditions) and the difficulties imposed by the new geological conditions (talus deposits) lead to the decision to stop the advancement at $108 \mathrm{~m}$ depth.

\subsection{Components of the monitoring system}

\subsubsection{Shape-Acceleration Array}

The SAA is a monitoring system, which was developed by a team of researchers from Rensselaer Polytechnic Institute (RPI) together with Measurand Inc., based on MEMS technology (micro-electro-mechanical system) (Danisch et al., 2007). The system is able to measure simultaneously 3D deformations and accelerations, based on the tilt from the gravitational direction. The SAA installed in $\mathrm{BH} 2$ is $12 \mathrm{~m}$ long and consists of 24 rigid segments (each $0.5 \mathrm{~m}$ long). These are connected by joints with two degrees of freedom, which do not allow torsion or extension. Each segment has three tri-axial accelerometers, and for each eight segments there is one in-array microprocessor collecting and sending the digital data. As a result, 3D deformations and accelerations can be measured in each of the 25 joints of the SAA segments. 
Some of the technical specifications of the SAA purchased from the manufacturer (Measurand, 2010) can be found in Table 5.2.

Table 5.2. Summarized technical specifications of the SAA.

\begin{tabular}{ll} 
Dynamic measurements & \\
\hline Measurement range & $+/-2 \mathrm{~g}$ \\
Noise floor & $220 \cdot 10^{-6} \mathrm{~g} / \mathrm{root}-\mathrm{Hz}$ \\
Sampling frequency & $100 \mathrm{~Hz}$ \\
Static measurements & \\
Measurement range of software in 3D mode & $+/-60^{\circ}$ from vertical \\
Resolution relative to starting shape & $+/-1.5 \mathrm{~mm}$ for $32 \mathrm{~m}$ of SAA \\
\hline
\end{tabular}

The SAA can be generally installed in any position from horizontal to vertical, as the intended position does not influence the factory fabrication and calibration. For the current monitoring system, the instrument was installed vertically in a PVC protection pipe in the designated borehole. The space between the borehole casing and the protection pipe was filled with fine sand (Perth-sand, Buchheister, 2009) as adopted by Buchli et al. (2013) (Figure 5.4).
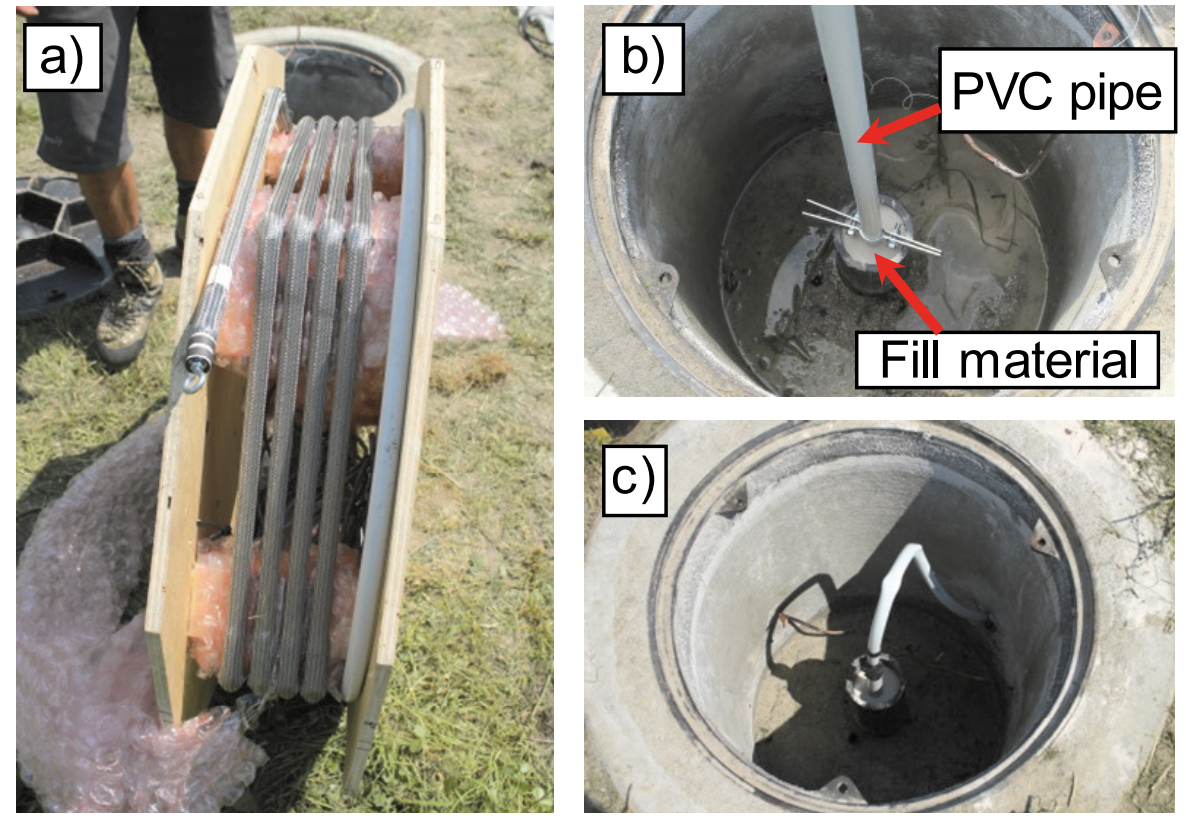

Figure 5.4. Snapshots from the installation of the SAA (August 2015): a) SAA on the delivery reel before installation; b) PVC protection pipe and fill material; c) final position of SAA connection cables at the borehole top. 
After being installed in its final position, the SAA provides 25 measurement points in approximately $12 \mathrm{~m}$ of soil below the surface (Figure 5.5 ). This includes the entire top layer of silty sand $(9.20 \mathrm{~m})$ and $3 \mathrm{~m}$ of the sandy gravel layer. Under these conditions, the identification of seismic wave amplification due to the stiffness contrast between the two different materials is possible. Figure 5.5 shows a schematic representation of the final position of the SAA in borehole $\mathrm{BH} 2$.

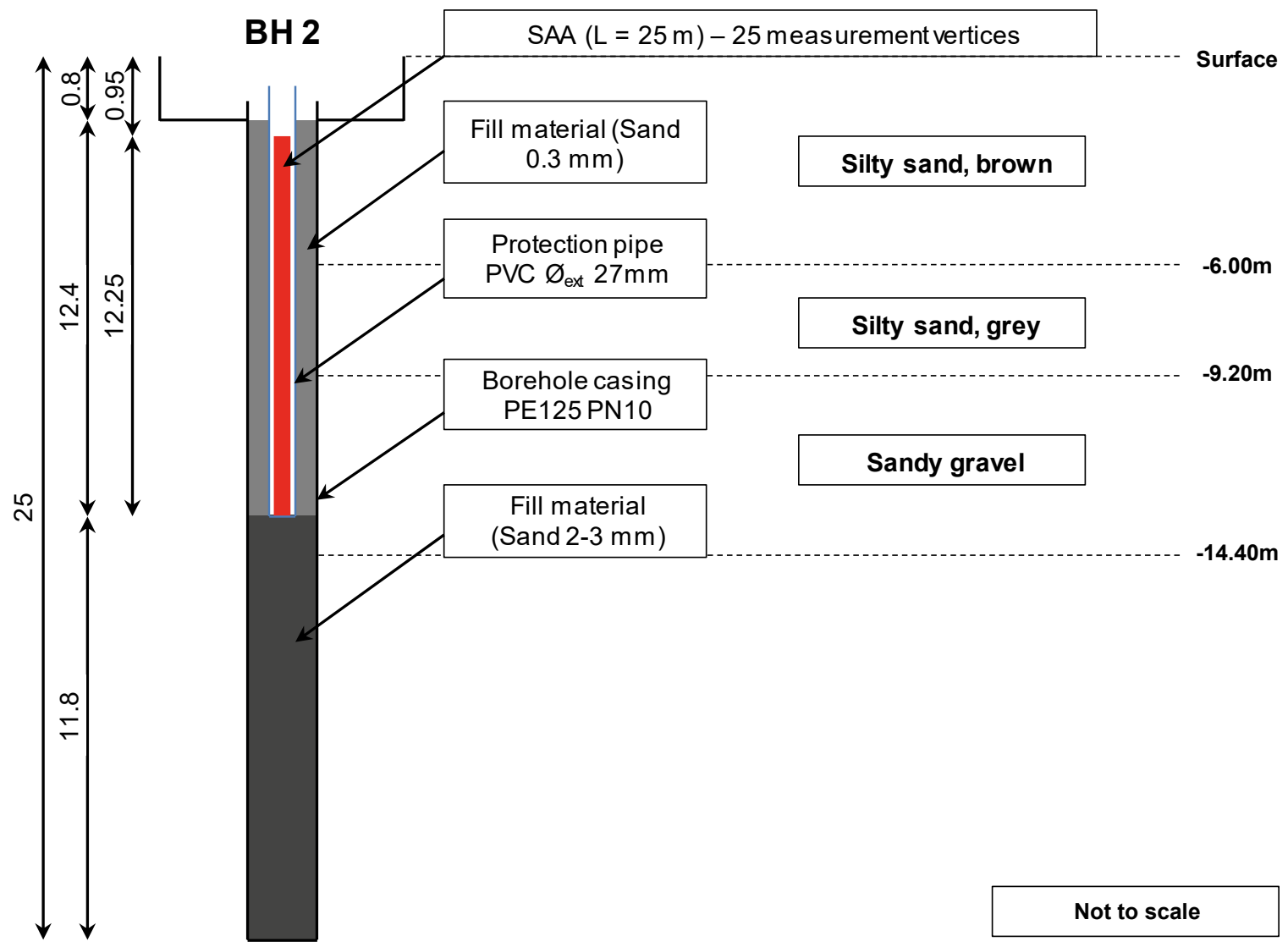

Figure 5.5. Schematic representation of the final position of the SAA at the seismic monitoring site in Visp.

\subsubsection{Multi-level piezometer array}

The multi-level piezometer array consists of six vibrating wire piezometers (Geokon, 2014; 4500 Series) They measure pressure by means of a sensitive steel diaphragm connected to a vibrating wire element. Any change in the pressure on the diaphragm causes a change in the frequency of the vibrating wire element. The pressure applied to the diaphragm can be easily determined, as it is proportional to the square of the vibration frequency. The main technical specifications of the vibrating wire piezometers are given in Table 5.3. 
Table 5.3. Technical specifications of the vibrating wire piezometers.

\begin{tabular}{ll}
\hline Measurement range & $+/-500 \mathrm{kPa}$ \\
Resolution & $0.125 \mathrm{kPa}$ \\
Accuracy & $0.5 \mathrm{kPa}$ \\
Temperature range & $-20 \ldots+80^{\circ} \mathrm{C}$ \\
\hline
\end{tabular}

The piezometers are shielded from each other in borehole $(\mathrm{BH} 3)$ to be able to record the pore pressure independently at different depths. Each piezometer was installed in a permeable collection zone filled with quartz-sand. The layers separating the collection zones were made by injecting an impermeable mix of bentonite and cement. Textile pockets filled with sand ("sand-plugs") were used to prevent the contamination of the collection zones with the fresh impermeable mix. The borehole was stabilised using a screen casing, allowing the pore pressure in the surrounding soil layers to be measured. (Figure 5.6).
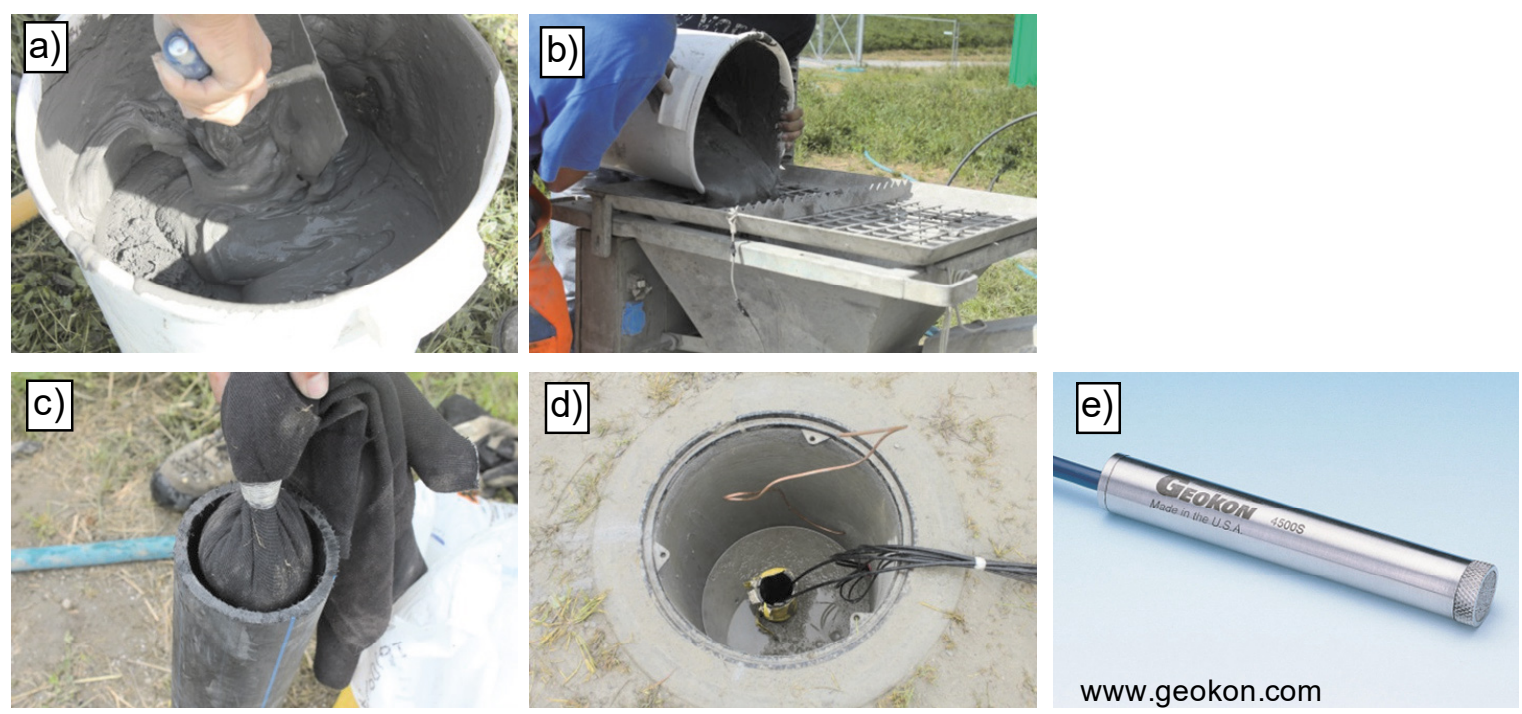

Figure 5.6. Snapshots from the installation of the multi-level piezometer (August 2015): a) impermeable mix preparation; b) impermeable mix injection; c) "sand-plugs" installation; d) piezometer installation in the permeable collection zone; e) vibrating wire piezometer.

During the installation of the array, the depth of each piezometer was measured to determine its position with respect to the identified soil layers. In conjunction with the SAA, which also covers the first $12 \mathrm{~m}$ of alluvial deposits, the multi-level piezometer provides important data related to the development of the pore pressure in the different soils: the first two piezometers (P1-P2) from the top are located in silty sand and the third one (P3) is at the boundary between silty sand and gravel; the next two piezometers (P4-P5) are installed in gravel and the deepest one (P6) is located in a thin layer of silty sand. Figure 5.7 depicts a schematic representation of the final position of the multi-level piezometer array in borehole $\mathrm{BH} 3$ and the corresponding soil layers. 


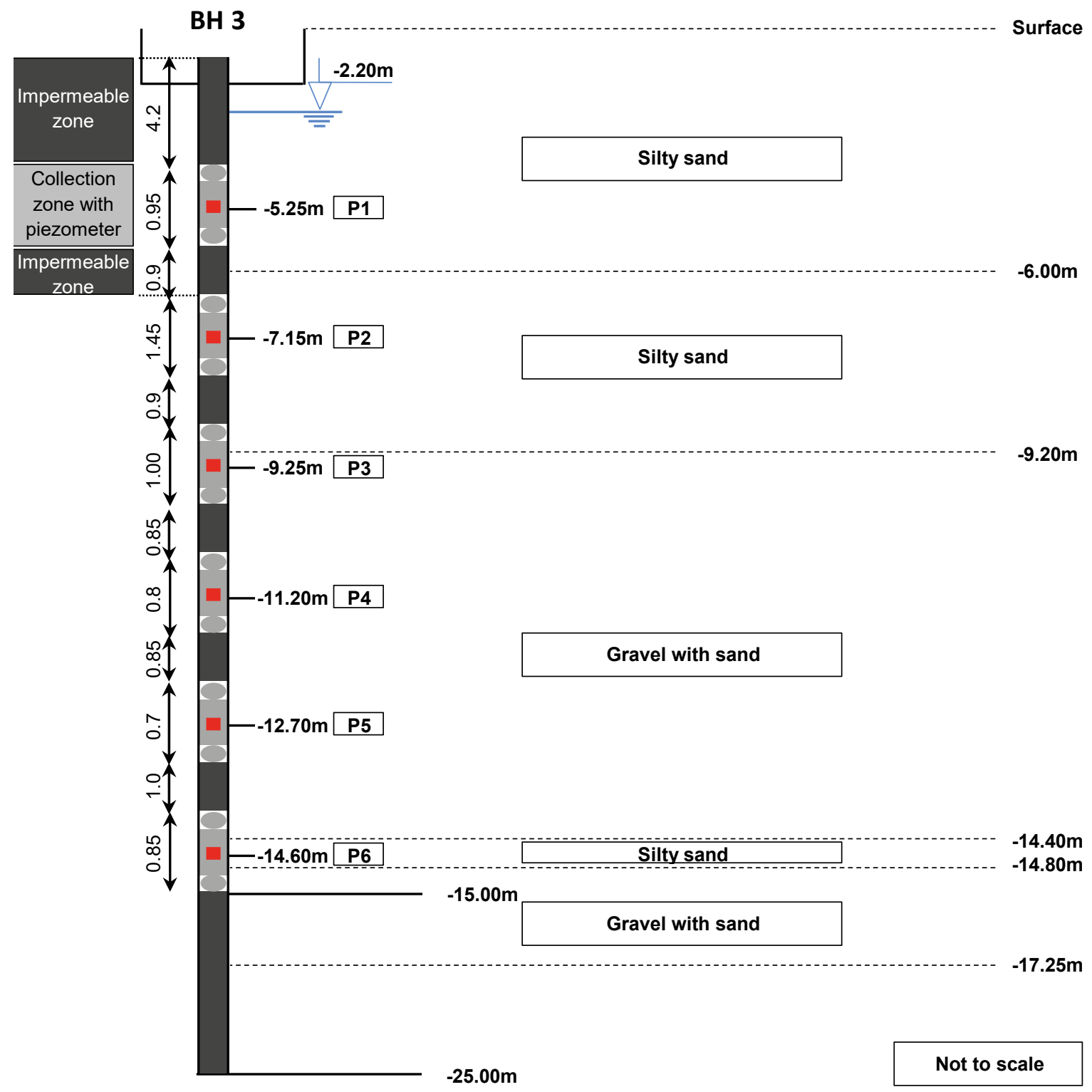

Figure 5.7. Schematic representation of the final position of the multi-level piezometer array at the seismic monitoring site in Visp.

\subsubsection{Strong-motion sensor}

Four strong motion sensors were installed at the monitoring site: three Hyposensors ESDH and one Episensor ES-T (Kinemetrics, 2016) (Figure 5.8). The Hyposensors were installed at the bottom of the boreholes intended for that purpose and the Episensor was installed at the surface to record the free field motion. 


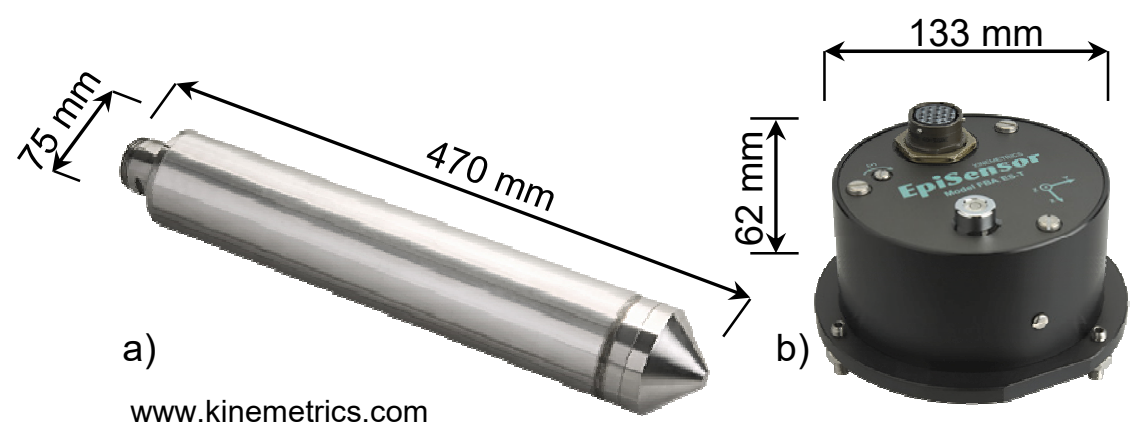

Figure 5.8. Kinemetrics strong motion sensors: a) Hyposensor; b) Episensor.

The sensors consist of three orthogonally mounted force balance accelerometers, based on the principle that the acceleration of a mass is proportional to the force required to accelerate it. More specifically, the force required to keep the mass located inside the accelerometers in balance is measured during the seismic event and then used to determine the acceleration acting on the mass. Some technical details of the sensors can be found in Table 5.4.

Table 5.4. Technical specifications of the strong-motion sensors.

\begin{tabular}{ll}
\hline Dynamic range & $155 \mathrm{~dB}$ \\
Bandwidth & $\mathrm{DC}$ to $200 \mathrm{~Hz}$ \\
Full scale range & User-selectable at: $\pm 0.25 \mathrm{~g}, \pm 0.5 \mathrm{~g}, \pm 1 \mathrm{~g}, \pm 2 \mathrm{~g}$ or $\pm 4 \mathrm{~g}$ \\
Hysteresis & $0.1 \%$ of full scale \\
Linearity & $<1 \cdot 10^{-3} \mathrm{~g} / \mathrm{g}^{2}$ \\
Zero point thermal drift & $<2 \%$ of full scale, between $-20 \ldots+70{ }^{\circ} \mathrm{C}$ \\
Operating temperature & $-20 \ldots+70^{\circ} \mathrm{C}$ \\
\hline
\end{tabular}

\subsection{Data handling}

The instruments installed are constantly monitoring the seismic activity and the pore pressures at the site. The archiving of the measurements is made separately, due to the different volumes of data generated by the sensors. The data from the strong-motion sensors and the multi-level piezometer array is transmitted in real-time to the archive of the Swiss Seismological Service (SED) and can be accessed at any time through the SED public web page http://arclink.ethz.ch. The data from the SAA is saved locally at the monitoring site in Visp and can be downloaded manually via remote desktop. These measurements are available upon request at the Institute for Geotechnical Engineering (IGT). 


\subsection{First static and dynamic measurements}

\subsubsection{Static measurements}

The first measurements after the installation of the monitoring system were made using the multi-level piezometer array and the distribution of pore pressure was compared with the ideal hydrostatic distribution to validate the data. The measurements were performed during seven months (August 2015 - February 2016) and they showed values below the hydrostatic level. The negative offset from the hydrostatic level was caused by the seasonal decrease of the ground water table. This initiated a downward flow within the permeable deposits, which reduced the static component of the pressure measured by the piezometers. The reduced pore pressure $(u)$ measured by the piezometers can be expressed as:

$\mathrm{u}=(1-\mathrm{i}) \cdot \gamma_{\mathrm{w}} \cdot \mathrm{z}$

where $\mathrm{i}$ - hydraulic gradient due to the downward water flow [-]

$\gamma_{w}$ - unit weight of water $10 \mathrm{kN} / \mathrm{m}^{3}$
$\mathrm{z}$ - depth of pore pressure measurement [m].

The value of the hydraulic gradient (i) can be determined using the pore pressure $(u)$ :

$\mathrm{i}=1-\frac{\mathrm{u}}{\gamma_{\mathrm{w}} \cdot \mathrm{z}}$

Figure 5.9a shows the first measurement performed in August 2015 and Figure 5.9b the summary of the hydraulic gradient values from August 2015 to February 2016 determined using (5.2).
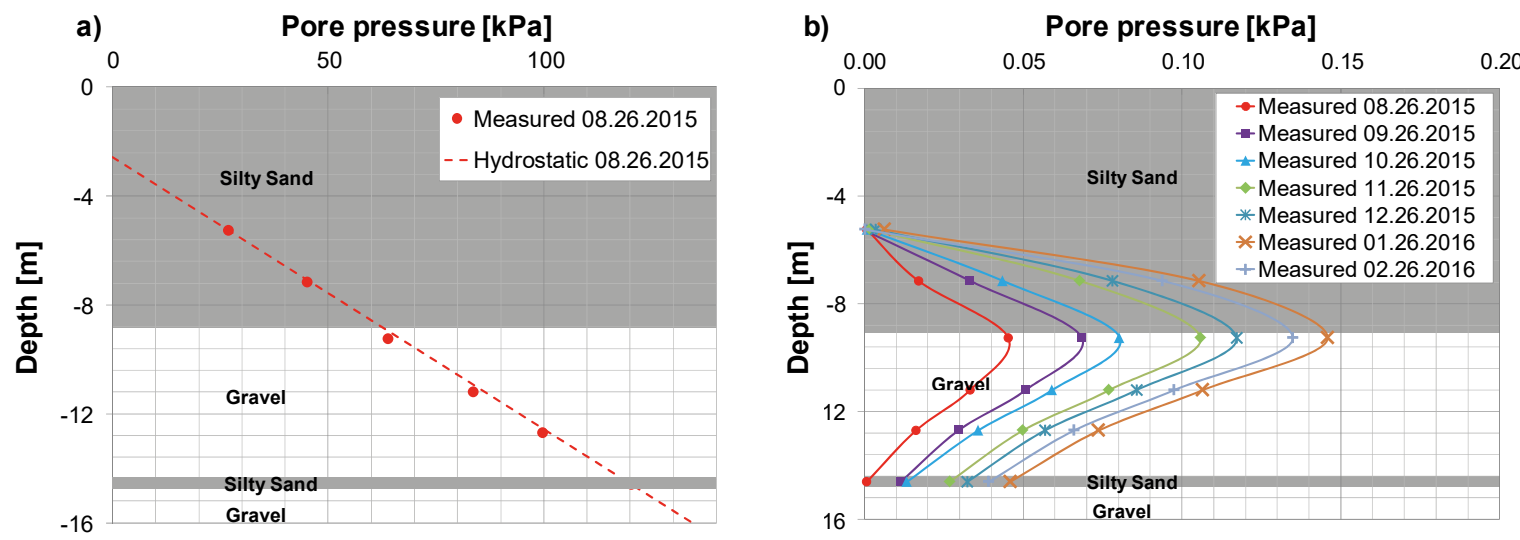

Figure 5.9. Sample data from the multi-level piezometer from the seismic monitoring site in Visp.

The data measured by the multi-level piezometer array is validated by these plots. The hydraulic gradient caused by the seasonal variation of the ground water level fits in the local hydro-geological context. The values of the gradient are increasing in the lower part of the top layer of silty sand and in gravel, and decrease again when approaching the second layer of silty sand, which acts like a barrier in the vertical water flow. The values of 
the gradients increase from August 2015 to February 2016, as the vertical downward flow increases due to the seasonal reduction of the ground water level.

\subsubsection{Dynamic measurements}

The first dynamic measurements were possible soon after the installation of the monitoring system. The town of Visp is located in the most seismically active region in Switzerland, where low magnitude seismic events occur frequently. A magnitude $M=3.1$ event occurred in Sierre, $28 \mathrm{~km}$ west of Visp, on the $14^{\text {th }}$ of October 2015 at 00.13 .44 (UTC). The maximum local accelerations at the surface recorded by the monitoring system were in the range of $0.02-0.05 \mathrm{~m} / \mathrm{s}^{2}$. Although this was a small magnitude event, the strong-motion sensors and the multi-level piezometer array were able to detect it. However, the values of the maximum accelerations did not exceed the noise limit of the SAA $\left(0.02-0.04 \mathrm{~m} / \mathrm{s}^{2}\right)$ and no consistent seismic signal could be identified with this instrument. It is important to mention that the SAA raw data processing was performed using proprietary software from the manufacturer. This can lead to serious challenges when interpreting data if no additional validation is possible, as shown by Buchli et al (2016). In this sense the data obtained from the strong-motion sensors can be used to verify the validity of the SAA measurements, when these are available.

Figures 5.10 and 5.11 show the three components of acceleration recorded by the surface strong-motion sensor and the data measured by the multi-level piezometer array.

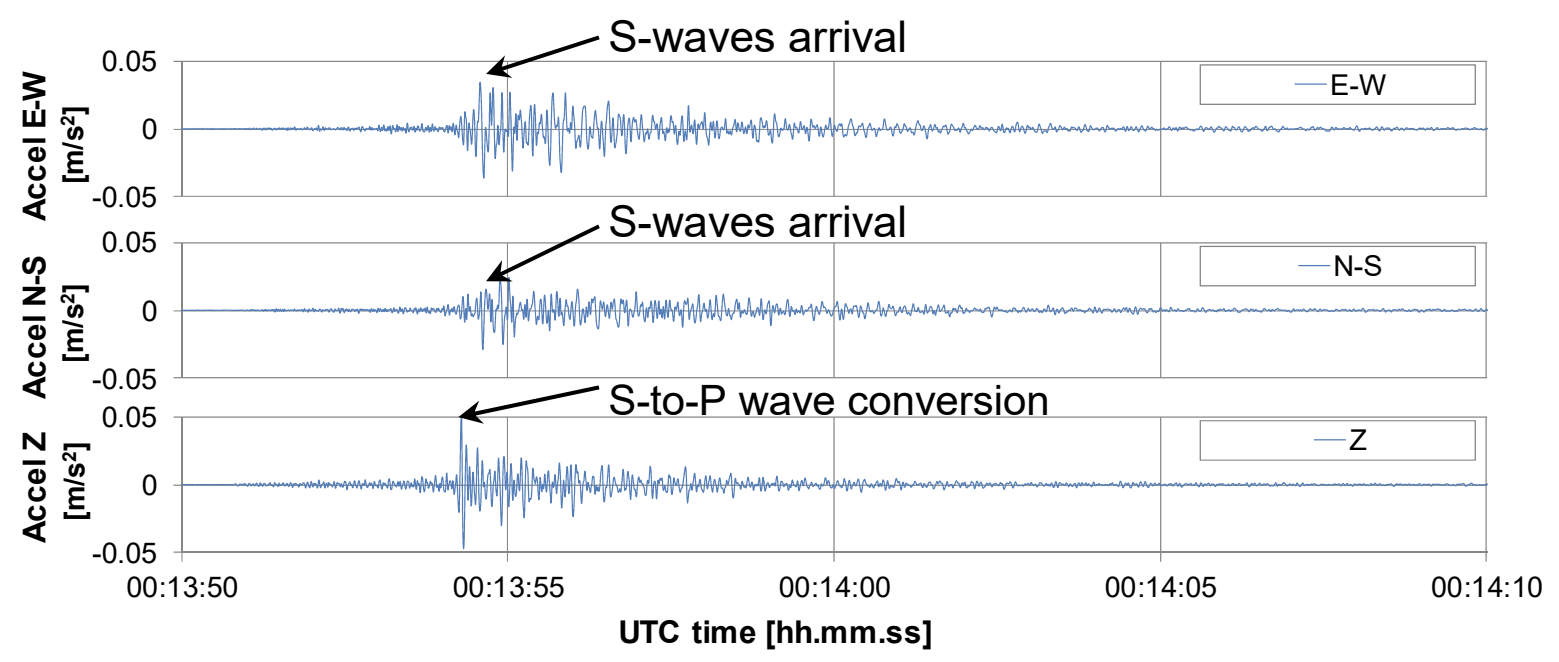

Figure 5.10. Local accelerograms from the Episensor at the seismic monitoring site in Visp during the Sierre event on $14^{\text {th }}$ October 2015. 


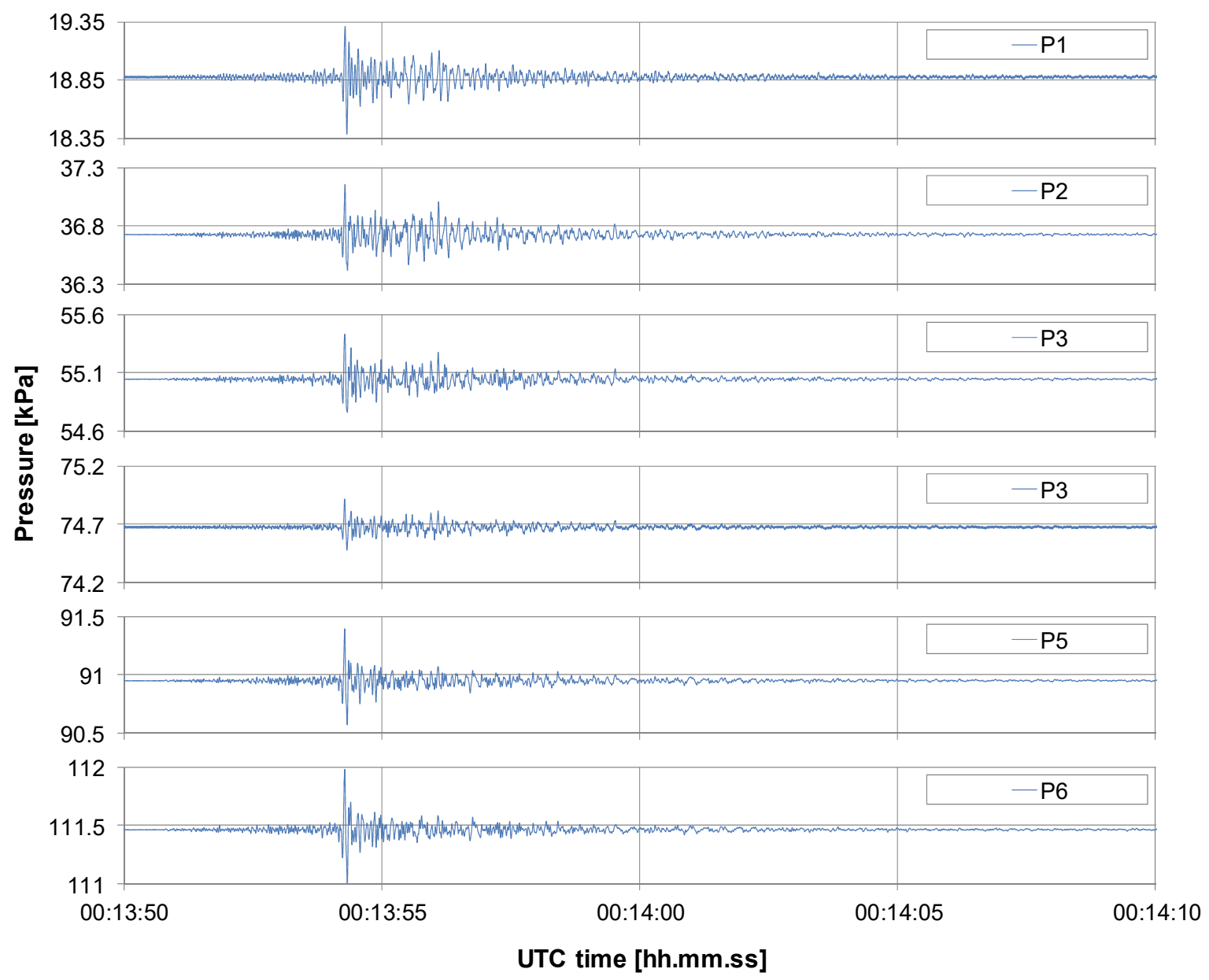

Figure 5.11. Pore pressure variation in borehole BH 3 at the seismic monitoring site in Visp during the Sierre event on $14^{\text {th }}$ October 2015.

A clear relationship between the acceleration data and the pore pressure measurements can be observed. Love and S-waves do not induce pressure variations and therefore the peak recordings of piezometers are caused by Rayleigh and P-waves. These are generated by the S-to-P wave conversion occurring at the deep interface between bedrock and alluvial sediments. Figure 5.11 shows that peak values of the pore pressure occur simultaneously with the arrival of $\mathrm{P}$-waves $(00: 13: 54.3)$ best seen on the vertical component Accel $Z$ from Figure 5.10.

The influence of the soil type on the amplitude of the pore pressure variation can be identified by plotting the maximum amplitudes recorded by each piezometer on the existing soil profile. As expected, the piezometers installed in the silty layers, or in their close vicinity, show the highest pore pressure increase $(0.4-0.5 \mathrm{kPa})$ and those in the gravel layer record lower values $(0.25 \mathrm{kPa})$ (Figure 5.12$)$. Although the values of the pore pressure increase are very low, due to the reduced magnitude of the seismic event, these measurements support the possibility of capturing effects related to non-linear soil behaviour using the monitoring system installed. They also confirm the initial hypothesis related to the liquefaction susceptibility of the soils in the area investigated. 


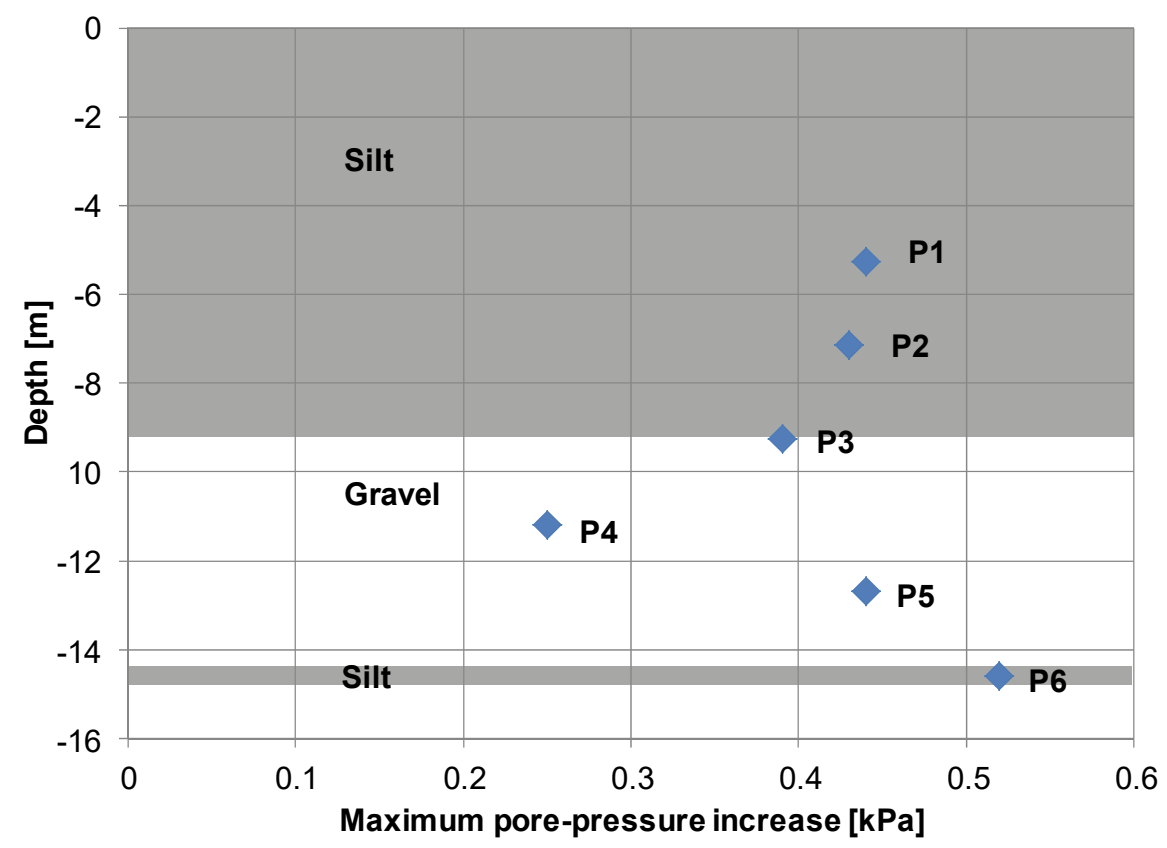

Figure 5.12. Maximum pore pressure increase recorded by the multi-level piezometer array at the seismic monitoring site in Visp during the Sierre event on $14^{\text {th }}$ October 2015.

\subsection{Conclusions}

One focus of the interdisciplinary project COGEAR was the investigation of the hazard chain related to earthquakes, based on a clear understanding of the seismic soil response. This can open the way for identifying and quantifying the effects caused by nonlinear soil behaviour. The monitoring system installed at the site in Visp contributes to better understanding of the soil response to seismic events.

The site can be considered as representative for situations of deep alpine valleys that are both filled with sediments prone to liquefaction and exposed to moderate seismic activity. The location and geology of the instrumented site are optimal for the planned purpose.

The sensor combination of this monitoring system enables a seismic event to be investigated from different perspectives. The data provided by the strong motion sensors installed at different depths $(102 \mathrm{~m}, 58 \mathrm{~m}$, and $15 \mathrm{~m})$ and at the surface allows the evaluation of the wave propagation at large scale. The SAA can provide similar data for the first $12 \mathrm{~m}$ of soil profile, with better spatial resolution. In addition to this, the multi-level piezometer array can measure the pore pressure development in the same depth range in which the SAA measures deformations during seismic events.

The first measurements showed that the monitoring system functions effectively in both static and dynamic regimes. The static measurements made using the multi-level piezometer array contribute to a better understanding of the response of local aquifers, by quantifying the effect of seasonal variation of the ground water table in terms of vertical water flow. The dynamic measurements during the small earthquake from Sierre $(M=3.1$, $R_{\text {epi }}=28 \mathrm{~km}$ ) confirmed the potential non-linear soil behaviour due to pore pressure increase. They show the sensitivity to the seismic action of the local saturated silty de- 
posits, in terms of pore pressure variation. This also points to the liquefaction susceptibility of the silty layers in the Rhone Valley, should the shaking be of sufficient magnitude and duration.

The recording of seismic events starting from the range of low magnitudes and the measurement of the associated deformations and pore pressures in the $12 \mathrm{~m}$ of alluvial deposits below the surface was made possible with this seismic monitoring system. As the first measurements show, essential data for the understanding of wave propagation and non-linear soil behaviour in alpine valleys can be obtained.

\subsection{Acknowledgements}

The long-term seismic monitoring system presented in this paper is part of Module 3 of the COGEAR project, funded by the Competence Centre for the Environment and Sustainability (CCES) and by the Federal Office for the Environment (FOEN). The interdisciplinary context created by COGEAR enabled the cooperation between the SED and IGT at ETH Zurich and made possible the combined set-up of strong-motion (SED) and geotechnical sensors (IGT). The authors thank all who contributed to the success of this project. Special thanks are due to the colleagues from IGT who had previous experience with the SAA and kindly provided pieces of advice that contributed to the accomplishment of the field installation.

\subsection{References}

Abdoun, T., Bennett, R., Dobry, R., Thevanayagam, S. \& Danisch, L. (2008) Full-scale laboratory tests using a Shape-Acceleration Array system. In: Proceedings of the $4^{\text {th }}$ Decennial Geotechnical Earthquake Engineering and Soil Dynamics Conference. pp. 1-9. Sacramento, California.

Buchheister, J. (2009) Verflüssigungspotential von reinem und siltigem Sand unter multiaxialer Belastung. Dissertation No. 18312. ETH Zurich.

Buchli, T., Merz, K., Zhou, X., Kinzelbach, W. \& Springman, S.M. (2013) Characterization and Monitoring of the Furggwanghorn Rock Glacier, Turtmann Valley, Switzerland: Results from 2010 to 2012. Vadose Zone Journal 12(1). DOI: 10.2136/vzj2012.0067.

Buchli, T., Laue, J. \& Springman, S.M. (2016) Amendments to Interpretations of SAAF Inclinometer Data from the Furggwanghorn Rock Glacier, Turtmann Valley, Switzerland: Results from 2010 to 2012. Vadose Zone Journal. DOI:10.2136/vzj2015.09.0132.

Burjanek, J., Gassner-Stamm, G., Poggi, V. \& Fäh, D. (2011) Estimation of local site effects in the Upper Valais (Switzerland). In: 4th IASPEI/IAEE International Symposium: Effects of surface geology on seismic motion. University of California, Santa- Barbara, USA.

Clinton, J., Cauzzi, C., Fäh, D., Michel, C., Zweifel, P., Olivieri, M., Cua, G., Haslinger, F. \& Giardini, D. (2011) The current state of strong motion monitoring in Switzerland. In: 
Earthquake Data in Engineering Seismology, S. Akkar, P. Gülkan, and T. van Eck (eds.), Vol. 14, Springer, Dordrecht, The Netherlands, 219-233.

Danisch, L.A., Lowery-Simpson, M.S., \& Abdoun, T. (2007) Shape-acceleration measurement device and method, US Patent US7296363 B2.

Fäh, D., Moore, J.R., Burjanek, J., losifescu, I., Dalguer, L., Dupray, F., Michel, C., J. Woessner, J., Villiger, A., Laue, Marschall, I., Gischig, V., Loew, S., Marin, A., Gassner, G., Alvarez, S., Balderer, W., Kästli, P., Giardini, D., Iosifescu, C., Hurni, L., Lestuzzi, P., Karbassi, A., Baumann, C., Geiger, A., Ferrari, A., Laloui, L., Clinton, J. \& Deichmann, N. (2011) Coupled seismogenic geohazards in Alpine regions. Bollettino di Geofisica Teorica ed Applicata, 53(4). pp. 485-508.

Fritsche, S., Fäh, D., Gisler, M. \& Giardini, D. (2006) Reconstructing the damage field of the 1855 earthquake in Switzerland: historical investigations on a well-documented event. Geophysical Journal International, 166. pp. 719-731.

Geokon (2014) Instruction manual - Model 4500 series. Vibrating wire piezometers. Geokon, USA.

Kinemetrics (2015) Technical specification sheets. Kinemetrics Inc. USA.

Marin, A., Habegger, R. \& Laue, J. (2016) One and two-dimensional site characterisation in the Rhone Valley. Bulletin of Earthquake Engineering, under review.

Measurand (2010) ShapAccelArray (SAA) Specifications. Measurand Inc. Fredericton, Canada.

Mercado, V.M., Zeghal, M., \& Abdoun, T. (2011) Advanced Site Monitoring and Characterization of Site Dynamic Properties. Geo-Frontiers 2011, pp. 1774-1784.

Michel, C., Edwards, B., Poggi, V., Burjanek, J., Roten, D., Cauzzi, C. \& Fäh, D. (2014) Assessment of $2 \mathrm{D}$ and $3 \mathrm{D}$ site effects in alpine regions through systematic site characterization. Bulletin of the Seismological Society of America, 104(6). pp. 2809-2826.

Roten, D., Fäh, D., Olsen, K.B. \& Giardini, D. (2008) A comparison of observed and simulated site response in the Rhône valley. Geophysical Journal International 173. pp. 958-978.

Roten, D., Fäh, D., Bonilla, L.F., Alvarez-Rubio, S., Weber, T.M. \& Laue, J. (2009) Estimation of non-linear site response in a deep Alpine valley. Geophysical Journal International, 178(3). pp. 1597-1613.

Zeghal, M., Abdoun, T. \& Oskay, C. (2004) A novel shape-acceleration-array and local identification of geotechnical systems. In: Proceedings of the International Workshop for Site Selection, Installation, and Operation of Geotechnical Strong-Motion Arrays, Workshop 1. pp. 221-230. 



\title{
6. Displacement-Based Seismic Analysis of Slopes, Dams, and Embankments
}

\author{
Alexandru Marin \\ ETH Zürich, Institute for Geotechnical Engineering, \\ Stefano-Franscini-Platz 5, 8093 Zürich, Switzerland \\ E-mail address: amarin@ethz.ch \\ Jan Laue ${ }^{1}$ \\ ETH Zürich, Institute for Geotechnical Engineering, \\ Stefano-Franscini-Platz 5, 8093 Zürich, Switzerland \\ E-mail address: jan.laue@ltu.se
}

Submitted to the Journal of Earthquake and Tsunami

Status: published on the $6^{\text {th }}$ of January 2016

This chapter represents a revised version of the original article.

\footnotetext{
${ }^{1}$ Appointment of Luleå University of Technology since August 2015 Department of Civil, Environmental and Natural Resources Engineering Mining and Geotechnical Engineering SE-971 87 Luleå, Sweden
} 


\begin{abstract}
The seismic design of slopes, dams or embankments is usually based on limit equilibrium calculations, which include the seismic action by means of an equivalent static force acting on the failure mechanism. This approach is limited, especially in situations in which existing steep structures or natural slopes have to be analysed. An alternative approach, which overcomes the limitations of the classical limit equilibrium calculations, is available with displacement-based methods. The displacement-based analysis offers the possibility of evaluating the seismic behaviour in terms of displacements, in contrast to the limit-equilibrium calculations, which only provide information about the ratio between the stabilising and destabilising forces acting on the structure. The displacement-based approach allows the analysis of the seismic behaviour and, based on the resulting deformations, the corresponding risk evaluation. In addition to that, the optimised seismic design of new geotechnical structures is possible by ensuring the compliance of the seismic behaviour with given requirements. This paper presents a displacement-based procedure to be incorporated in the Swiss design codes for the seismic analysis of slopes, dams and embankments.
\end{abstract}

Keywords: displacement-based design, seismic deformations, slope stability, dams, embankments. 


\subsection{Introduction}

The cornerstone of the displacement-based geotechnical seismic design is the slidingblock method published by Newmark (1965). This method is based on the assumption that the displacement of a geotechnical structure can be associated with the sliding of a solid block on an inclined plane. The friction between the solid block and the inclined plane consists of all stabilising factors acting in the failure mechanism of a geotechnical structure such as a slope. The stabilising factors in the soil include the effective angle of internal friction, any cementation, suctions, and effects of vegetation roots or anchors. When the global factor of safety $\mathrm{FS}_{g}$ reaches values smaller than one due to seismic forces acting in the ground, the conditions are created for sliding to occur and the driving forces generate displacements.

The critical acceleration $a_{\text {crit }}$, representing the acceleration at which $\mathrm{FS}_{g}=1$ is obtained from the limit-equilibrium calculations, is the most important factor in Newmark's method. For accelerations higher than $a_{\text {crit, }}$ the stability is lost, the driving forces are larger than the friction forces, and displacements are generated as long as the relative velocity of the sliding block, obtained from the integration of the accelerations, is larger than 0 . The sum of the displacements obtained from the integration of the relative velocity represents the expected deformations of the geotechnical structure for the given seismic signal (Figure 6.1)
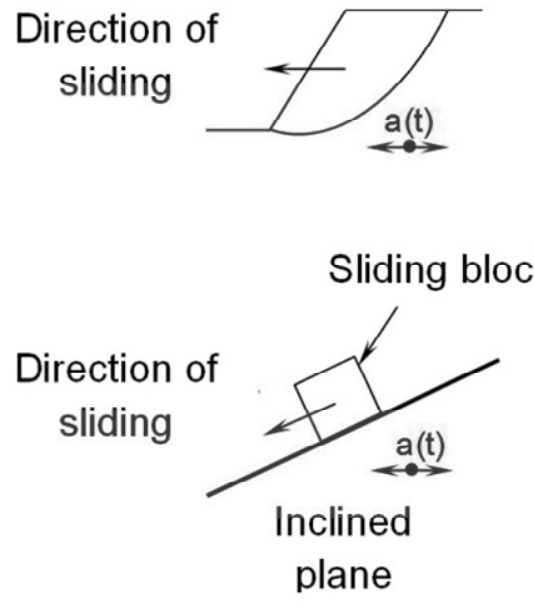

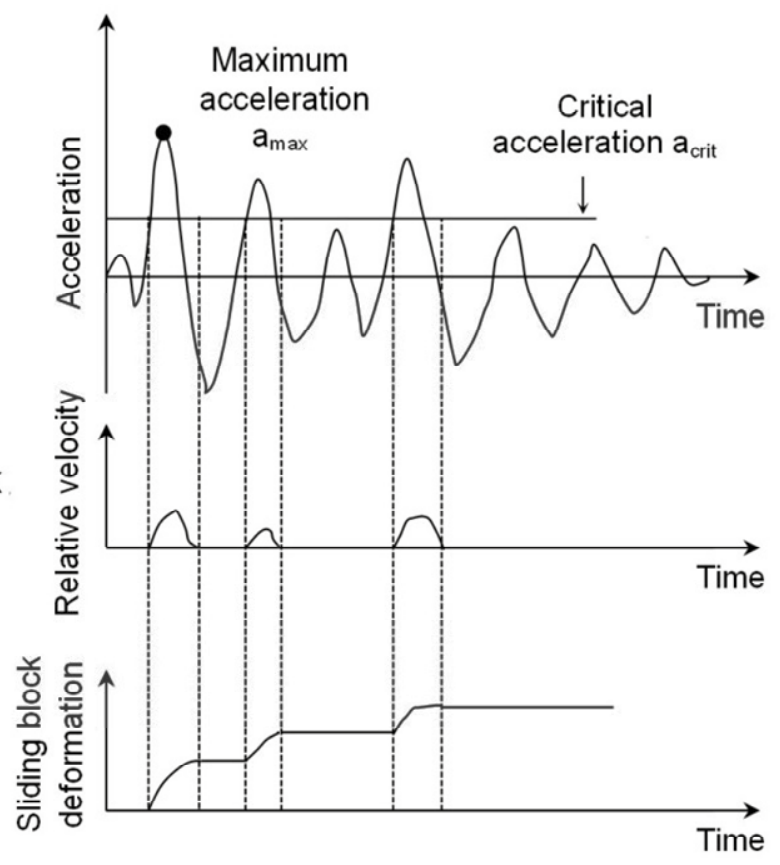

Figure 6.1. The concept of Newmark's sliding-block (after Anderson et al., 2008). 
Early studies explored and evaluated the possibilities of applying the concepts of Newmark's method to improve the approximation of seismic displacements of dams. In this context, Seed and Martin (1966), Ambraseys and Sarma (1967), or Makdisi and Seed (1978) suggested different methods for the evaluation of the seismic coefficients to be used in the limit-equilibrium calculations for the determination of the critical acceleration. Lin and Whitman (1983), Chopra and Zhang (1991), Gazetas and Uddin (1994), Kramer and Smith (1997), Bray and Rathje (1998) investigated the possibility of a more accurate determination of the seismic response of the sliding mass mobilized by the failure mechanism.

Methods of approximation of the seismic-induced displacements for geotechnical structures such as dams, slopes, and retaining structures, were developed based on Newmark's method. The failure mechanisms are compatible with Newmark's concepts for these types of structures. In this context, Richards and Elms (1979), Whitman and Liao (1984), Martin and Qiu (1994), Cai and Bathurst (1996), Bray et al. (1998), SCEC (2002), or Bray and Travasarou (2007) suggested seismic slope displacement procedures based on large sets of selected earthquakes.

Using the results of these studies, Anderson et al. (2008) refined the semi-empirical relationships for the evaluation of the seismic-induced displacements suggested by Martin and Qiu (1994) and adapted them to the seismic conditions in the USA. The displacements calculated depend on the maximum acceleration $a_{\max }$ of the earthquake, the ratio of the critical acceleration of the geotechnical structure to the maximum acceleration of the earthquake $a_{\text {crit }} / a_{\max }$, and the peak ground velocity PGV (Equation 6.1).

$$
\log (\mathrm{d})=\mathrm{b}_{0}+\mathrm{b}_{1} \log \left(\frac{\mathrm{a}_{\text {crit }}}{\mathrm{a}_{\max }}\right)+\mathrm{b}_{2} \log \left(1-\frac{\mathrm{a}_{\text {crit }}}{\mathrm{a}_{\max }}\right)+\mathrm{b}_{3} \log \left(\frac{\mathrm{a}_{\max }}{\mathrm{g}}\right)+\mathrm{b}_{4} \log (\mathrm{PGV})
$$

where $d \quad$ - seismic-induced displacement [cm]

$$
\begin{aligned}
& a_{c r i t} \quad \text { - critical acceleration of the geotechnical structure [g] } \\
& a_{\max } \quad \text { - maximum acceleration of the earthquake }[\mathrm{g}] \\
& P G V \text { - peak ground velocity [in/s] } \\
& b_{1} \ldots b_{4} \text { - regression coefficients. }
\end{aligned}
$$

A displacement estimation method was developed for the moderate seismicity of the alpine environment in Switzerland, based on the international methods mainly proposed for areas of high seismicity. Even though the maximum magnitude of a seismic event in the Swiss alpine region is not expected to exceed $M=6.5$ (475 years return period), the demand for displacement-based analysis is high, especially for natural slopes, but also for man-made structures. 


\subsection{Calculation of seismic displacements}

The estimation of the seismic displacements was performed using a total of 1'114 representative earthquake signals selected by the Swiss Seismological Service (SED) from different earthquake databases:

- 224 signals from the Italian earthquake database (Luzi et al., 2008; Pacor et al., 2011)

- 810 signals from the Japanese seismic network (http://www.kyoshin.bosai.go.jp/)

- 80 signals from the European Strong-Motion database (Ambraseys et al., 2002).

The selected earthquakes originate from sources equivalent to the Swiss seismicity. The criteria used in the selection process were defined by considering the fault mechanism, the magnitude, the epicentral distance, and the soil conditions. Therefore, the final set of earthquakes includes events characterised by the strike-slip fault mechanism with a magnitude $M_{w}=4.8-5.6$ for an epicentral distance $R_{e p i}<30 \mathrm{~km}$, and $M_{w}=5.6-7.0$ for $R_{\text {epi }}<50$ $\mathrm{km}$, recorded on sites with various soil conditions (from soft soil to rock).

Figures 6.2 and 6.3 show the distribution of the magnitudes and epicentral distances of the selected earthquakes and display their compatibility with the criteria used to define the Swiss seismicity.

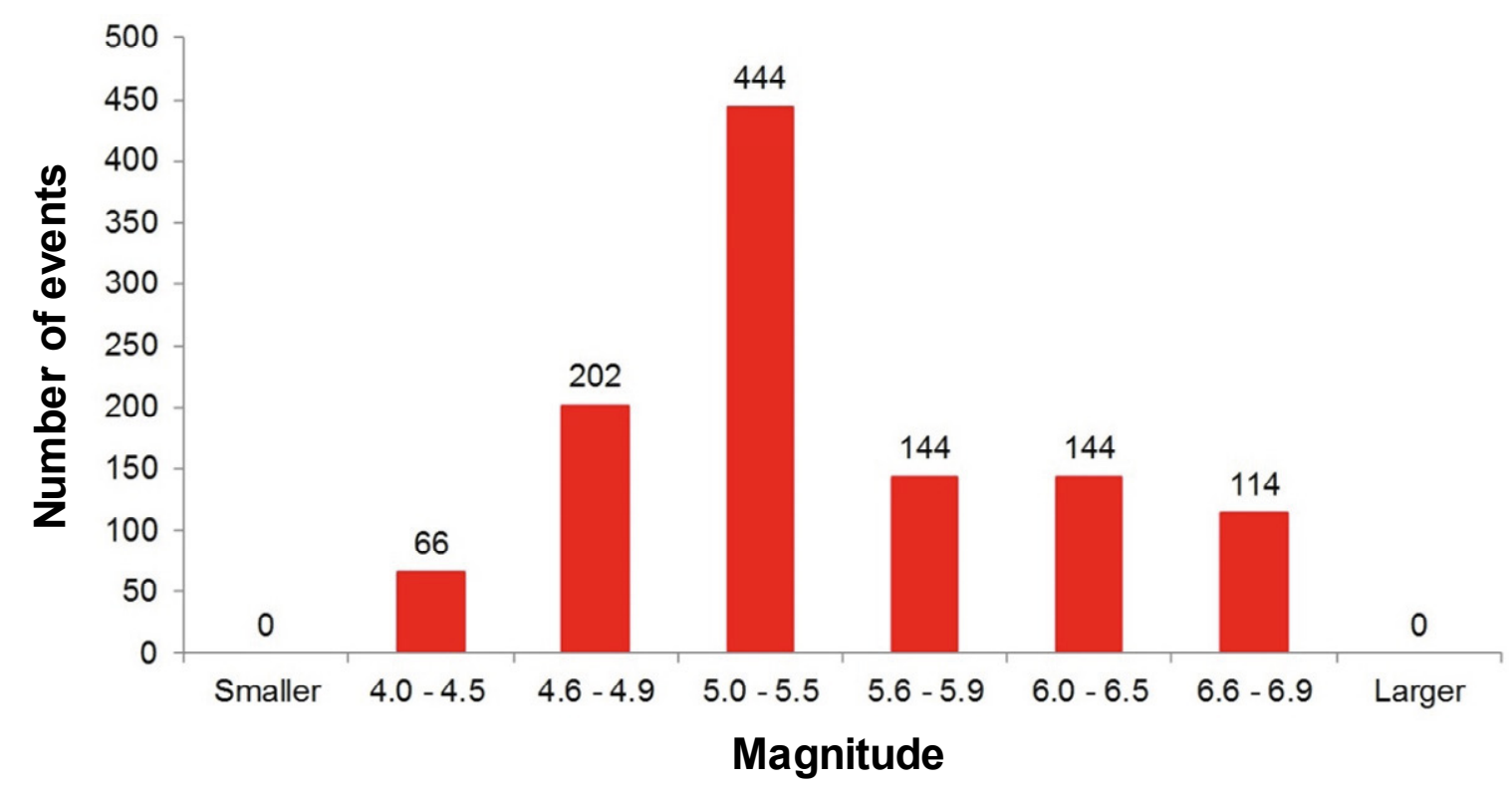

Figure 6.2. Distribution of the magnitudes of the selected set of earthquake signals compatible with the seismicity in Switzerland (1'114 events). 


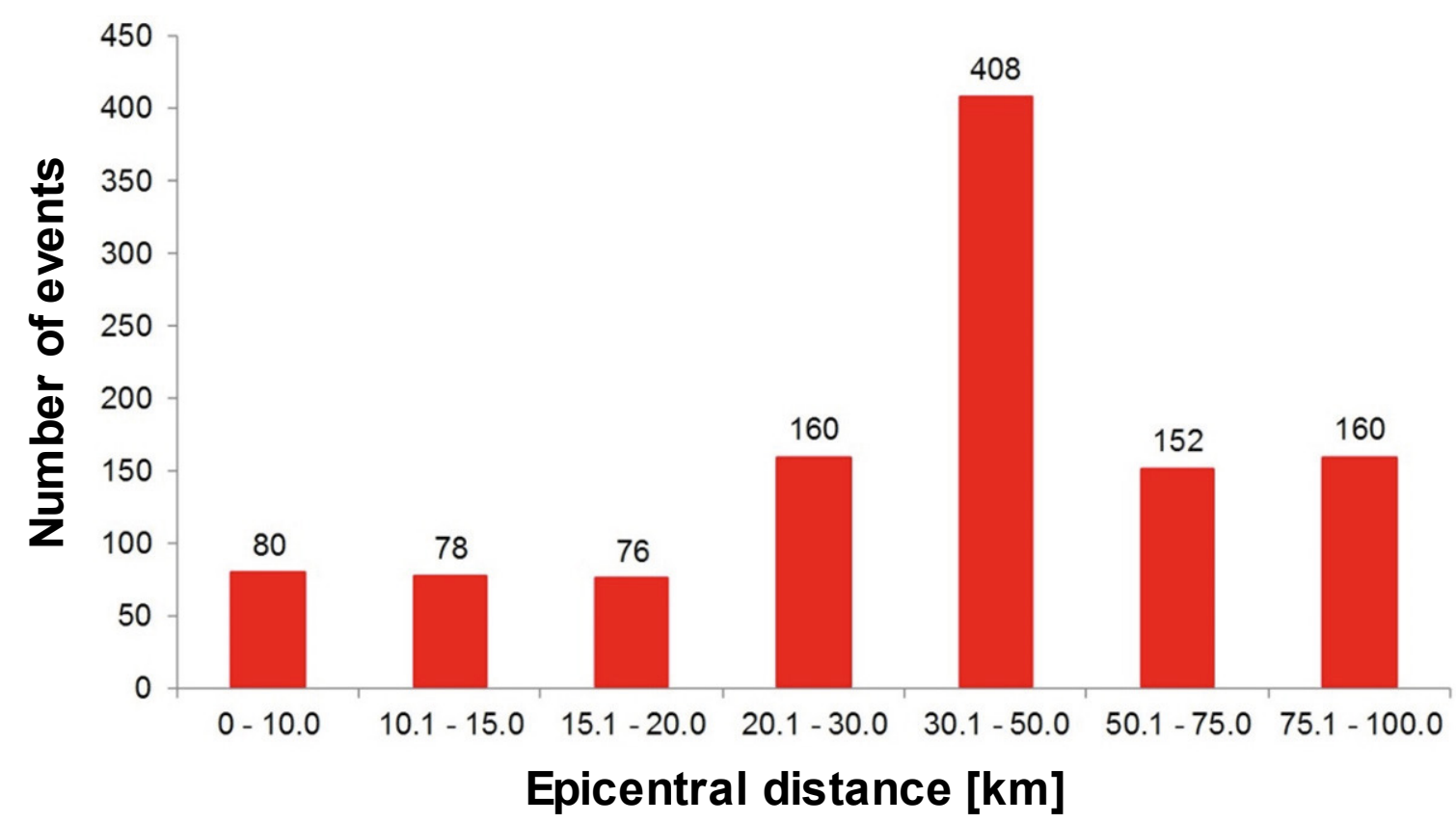

Figure 6.3. Distribution of the epicentral distances of the selected set of earthquake signals compatible with the seismicity in Switzerland (1'114 events).

The set of 50 hypothetical structures analysed covers a wide range of slopes, dams, and embankments with critical accelerations $a_{\text {crit }}$ ranging from $0.01-0.50 \mathrm{~g}$, with an incremental step of $0.01 \mathrm{~g}$. The information related to the type and geometry of each hypothetical structure is incorporated in the assumed value of the critical acceleration $a_{\text {crit. }}$. The seismic displacements of these structures were calculated based on Newmark's method for both the negative and positive direction of the 1'114 earthquakes (a total of 2'228 different earthquake scenarios). As a result, a total of 111'400 Newmark analyses were systematically performed to evaluate the expected deformations of geotechnical structures for earthquakes likely to occur in Switzerland.

More than $97 \%$ of the entire set of the analyses performed (107'699 of 111'400) showed seismic displacements below $1 \mathrm{~cm}$ and more than $99 \%$ of the results (110'579 of $111^{\prime} 400$ ) were below $10 \mathrm{~cm}$. The distributions of the results can be seen in Figures 6.4 and 6.5. 


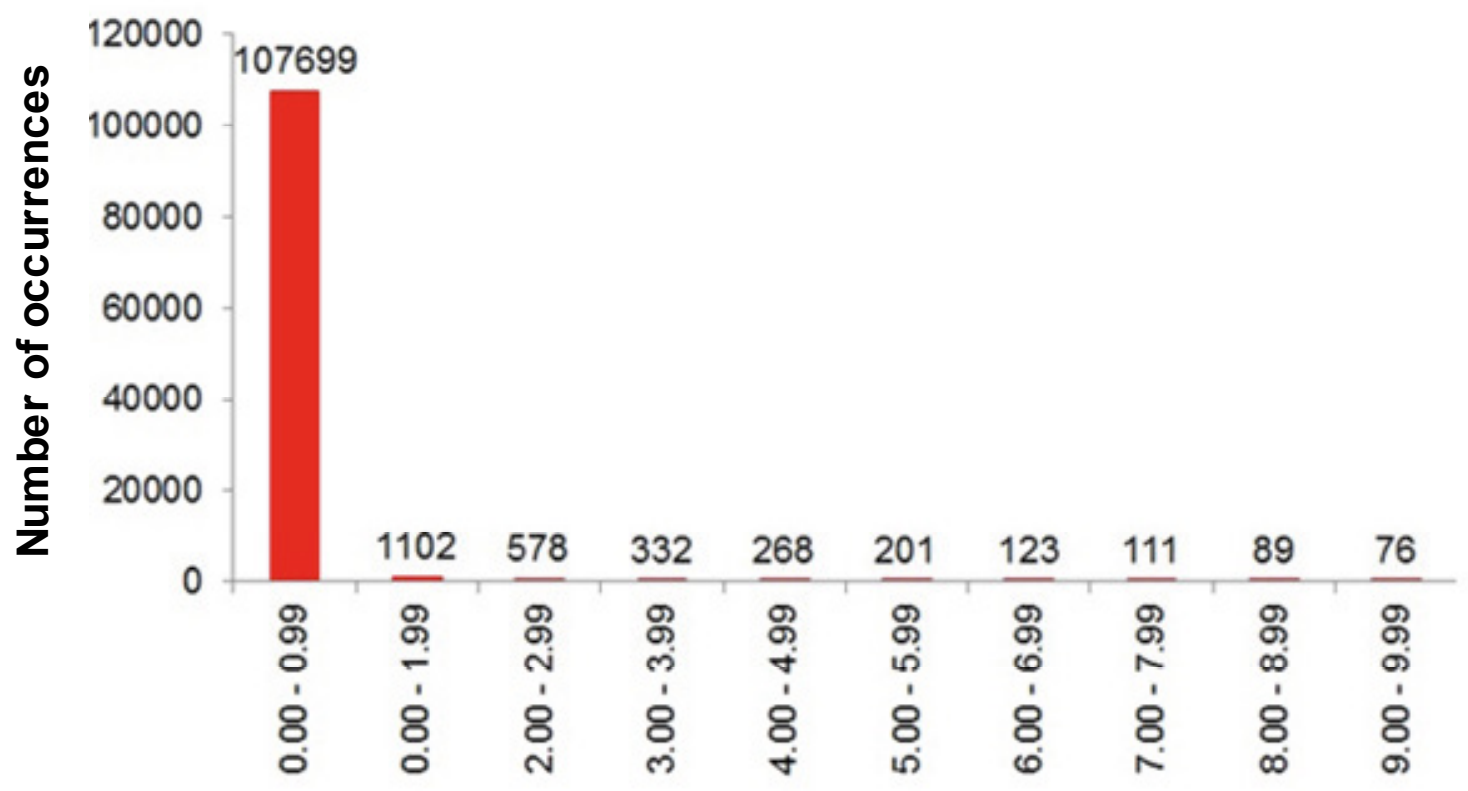

Displacement [cm]

Figure 6.4. Distribution of the calculated displacements from 0-9.99 cm (110'579 displacements).

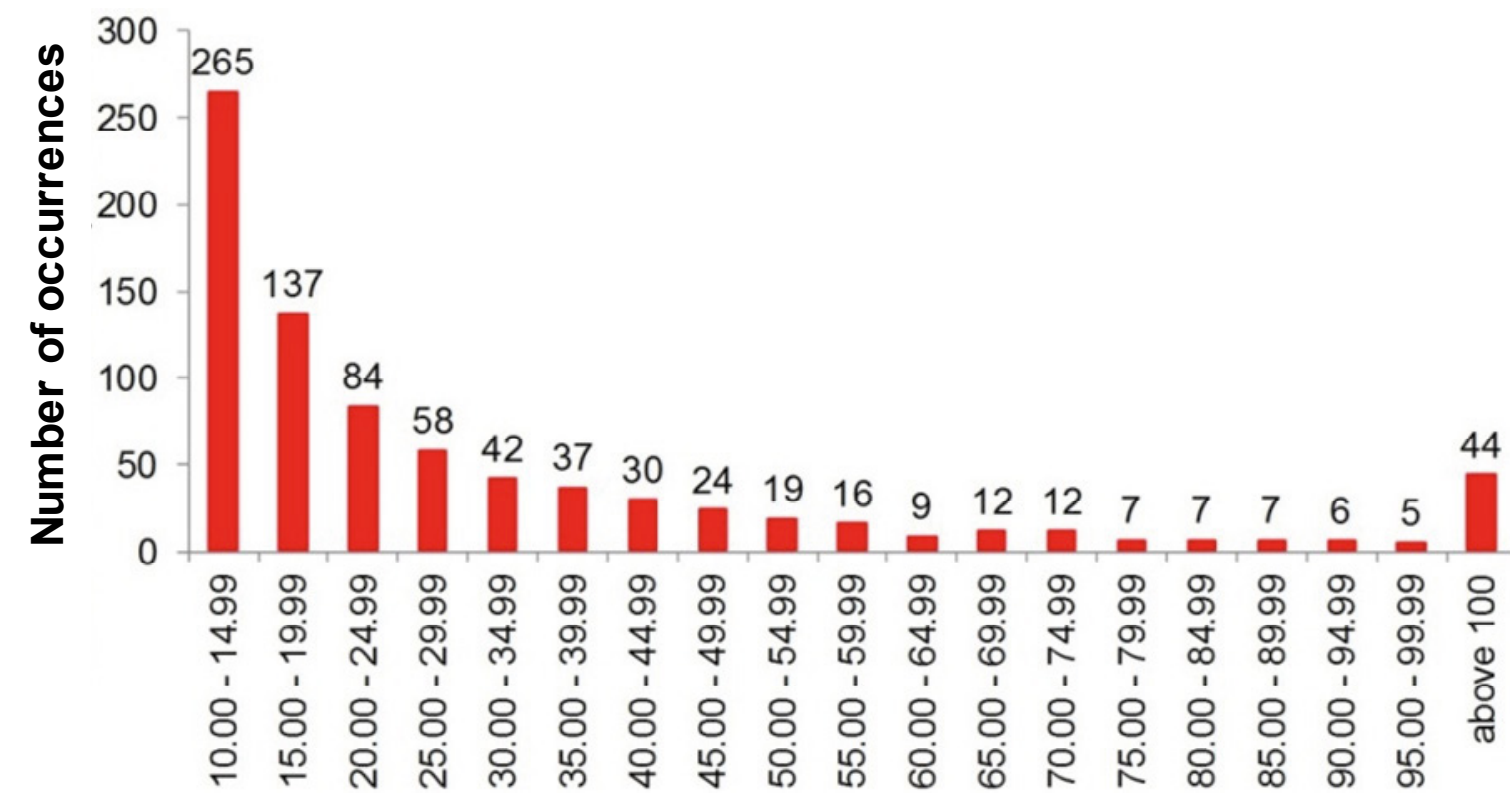

Displacement [cm]

Figure 6.5. Distribution of the calculated displacements from $10-99.99 \mathrm{~cm}$ and above $100 \mathrm{~cm}(821$ displacements).

Due to the different size of the displacement intervals on the horizontal axes (i.e. $1 \mathrm{~cm}$ intervals in Figure 6.4, and $5 \mathrm{~cm}$ intervals in Figure 6.5) a jump in the number of calculated displacements from $76(9.00-9.99 \mathrm{~cm})$ to $265(10.00-14.99 \mathrm{~cm})$ can be 
observed. The two diagrams should be regarded as separate, considering the different scales and interval sizes on their horizontal axes.

Another way of analysing the results is to display the expected displacements for structures with different values of $a_{\text {crit. }}$ In the first step, an overview of the PGA values of the earthquakes used in the Newmark analyses is displayed in Figure 6.6.

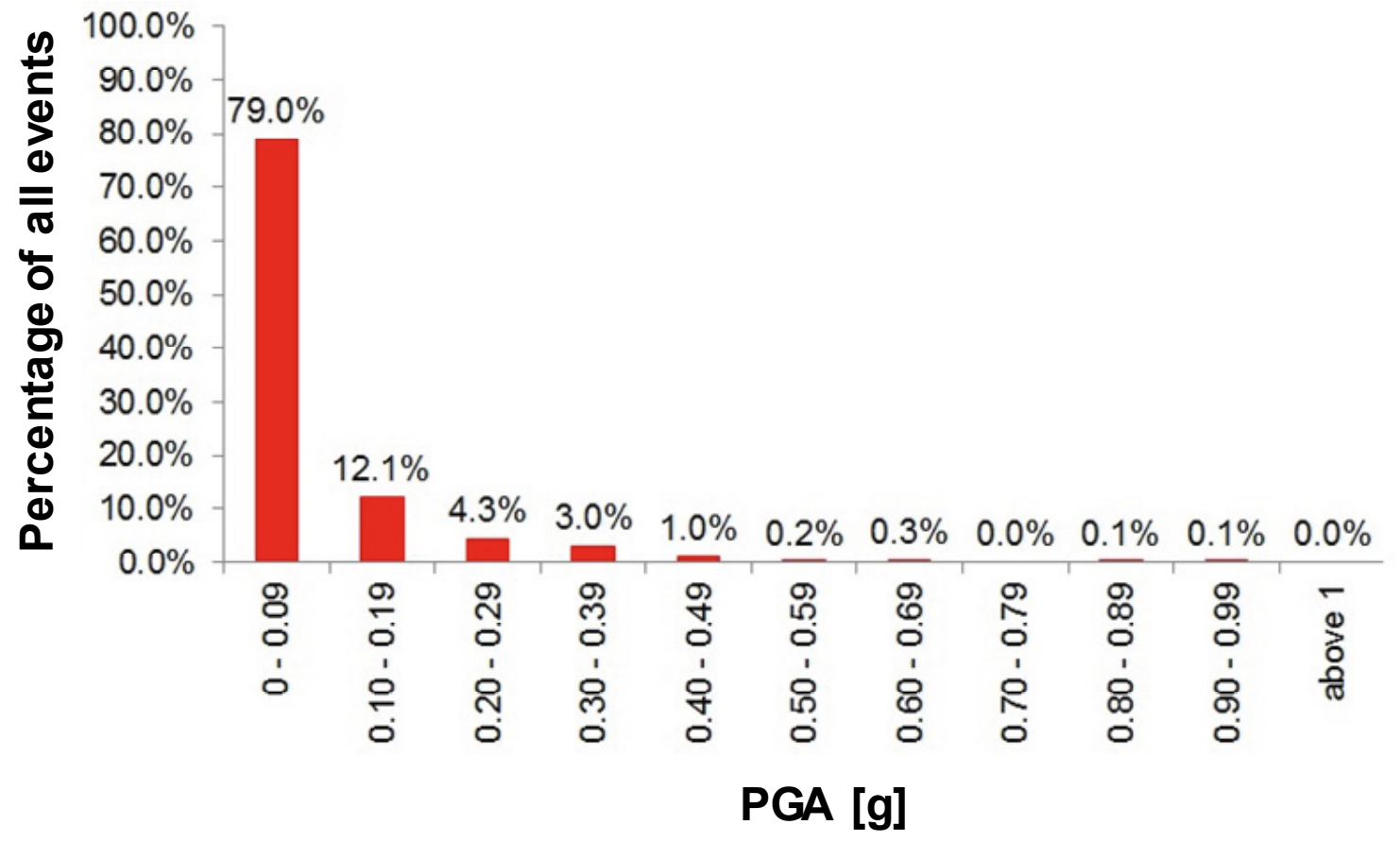

Figure 6.6. Distribution of the PGA values in the set of selected earthquakes (1'114 events).

In the next step, the distribution of displacements was summarised for four groups of hypothetical structures, covering four ranges of critical acceleration values (Table 6.1). The structures in group I $\left(0.01 \mathrm{~g}<a_{\text {crit }}<0.05 \mathrm{~g}\right)$ showed displacements below $1 \mathrm{~cm}$ in $81 \%$ of the cases. This percentage correlates with the signals with PGA values below 0.1 $\mathrm{g}$, representing $79 \%$ of the entire set of earthquakes. Further on, the deformations between $1-10 \mathrm{~cm}$ occurred in $13.5 \%$ of the cases for the same group of structures. This correlates with the signals with PGA values between $0.10-0.19 \mathrm{~g}$, representing $12.1 \%$ of the entire set. Finally, the structures in group I showed displacements above $10 \mathrm{~cm}$ in only $5.5 \%$ of the cases. The signals with PGA values above $0.19 \mathrm{~g}$ can be correlated with these displacements. This is also the highest percentage of displacements above $10 \mathrm{~cm}$, as the other groups of structures with higher values of $\mathrm{a}_{\text {crit }}$ showed lower percentages (i.e. $15 \%$ for group II, $0.5 \%$ for group III, and $0 \%$ for group IV). 
Table 6.1. Distribution of the calculated displacements considering the critical acceleration of the geotechnical structure.

\begin{tabular}{llccc}
\hline $\begin{array}{l}\text { Group of } \\
\text { structures }\end{array}$ & \multicolumn{2}{l}{$\begin{array}{l}\text { Critical acceleration } \mathrm{a}_{\text {crit }} \\
\text { [g] }\end{array}$} & \multicolumn{3}{l}{$\begin{array}{l}\text { Percentage of calculated displacements } \\
\text { below } 1 \mathrm{~cm}\end{array}$} & $1 \mathrm{~cm}-10 \mathrm{~cm}$ & above $10 \mathrm{~cm}$ \\
\hline I & $0.01-0.05$ & $81 \%$ & $13.5 \%$ & $5.5 \%$ \\
II & $0.05-0.10$ & $93 \%$ & $5.5 \%$ & $1.5 \%$ \\
III & $0.10-0.20$ & $97 \%$ & $2.5 \%$ & $0.5 \%$ \\
IV & above $0.20 \mathrm{~g}$ & $99.5 \%$ & $0.5 \%$ & $0 \%$ \\
\hline
\end{tabular}

As shown by Sarma and Bhave (1974), the relationship between the critical acceleration and the global factor of safety is linear (6.2):

$\frac{\mathrm{a}_{\text {crit }}}{\mathrm{g}}=\frac{\left(\mathrm{FS}_{\mathrm{g}}-1\right)}{3.33}$

where $a_{\text {crit }} \quad$ - critical acceleration of the geotechnical structure [g]

$\mathrm{FS}_{\mathrm{g}} \quad$ - global factor of safety, calculated with characteristic soil parameters (no reduction factors for partial safety)

However, the critical acceleration values obtained with this relationship are not reliable for all slope geometries. For flat slopes with very small driving forces, the global factor of safety $\mathrm{FS}_{\mathrm{g}}$ is high, but only very small inertia forces are required to cause slope failure. This effect is not captured by (6.2) and a reliability range in terms of slope inclinations needs to be defined.

Figure 6.7 shows the comparison of the critical accelerations obtained using relationship (6.2) and Bishop's method of slope stability, for slope inclinations ranging from $5^{\circ}-40^{\circ}$. Relationship (6.2) over-estimates the value of the critical acceleration by a factor of 2-4 for flat slopes (below $10^{\circ}$ ), while the value is under-estimated by $20-25 \%$ for slopes steeper than $35^{\circ}(1: 1.4)$. In this context, a possible range where this relationship can be used is between $20^{\circ}-30^{\circ}$. The results include additional conservatism for steeper slopes, since the calculated critical acceleration is lower than the real one. 


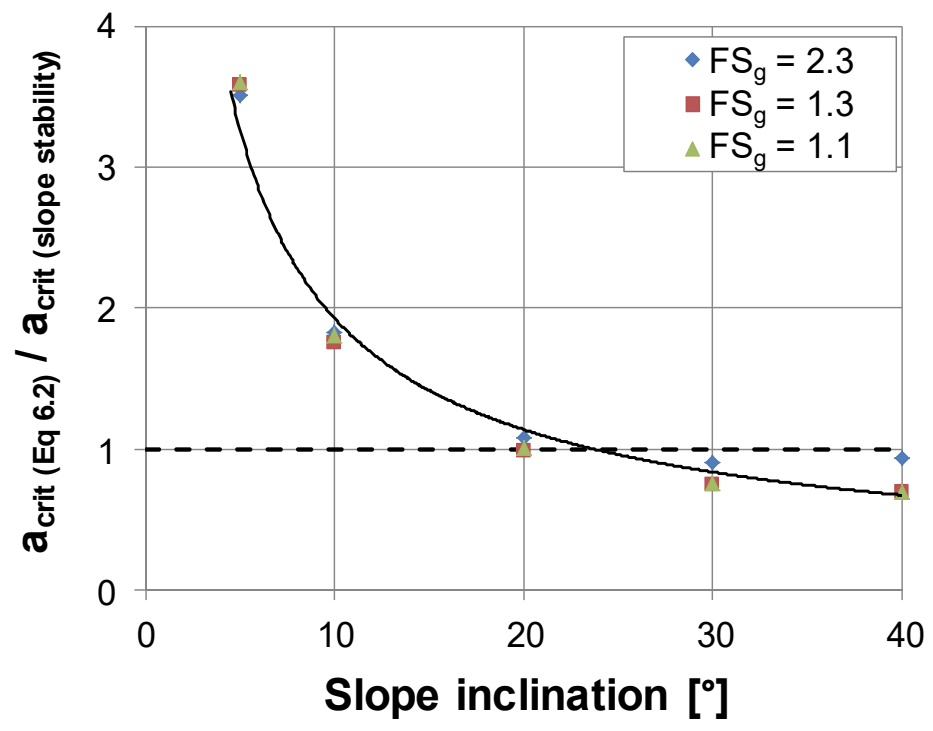

Figure 6.7. Ratio between critical accelerations obtained using Eq. (6.2) and Bishop's method for slope stability analysis for different slope inclinations.

A relationship similar to (6.2) was also observed by Laue et al. (2012) in the results of comparable numerical simulations perfomed on a $34^{\circ}$ inclined slope (Figure 6.8). According to (6.2), geotechnical structures with slope inclinations between $20^{\circ}-30^{\circ}$ and a global factor of safety $\mathrm{FS}_{\mathrm{g}}=1.3$ are characterised by a corresponding critical acceleration $a_{\text {crit }}=0.09 \mathrm{~g}$. These structures are expected to experience deformations smaller than 10 $\mathrm{cm}$ in $98.5 \%$ of the cases, in the context of moderate Swiss seismicity (see Table 6.1).

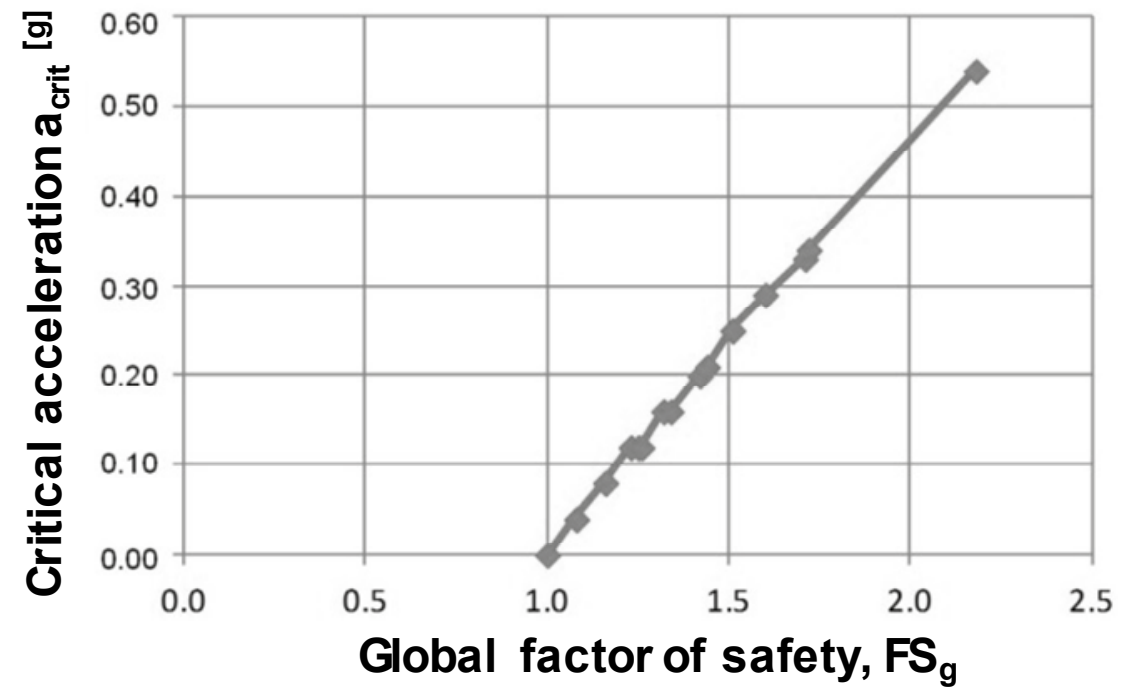

Figure 6.8. Relationship between the critical acceleration and the global factor of safety $\mathrm{FS}_{\mathrm{g}}$ (after Laue et al., 2012).

Since only $5.5 \%$ of the displacements calculated for $a_{\text {crit }} \leq 0.05 \mathrm{~g}$ are above $10 \mathrm{~cm}$, this limiting value of the critical acceleration represents a reasonable threshold for the seismic analysis. The corresponding global factor of safety is $\mathrm{FS}_{g}=1.16$, according to Sarma and Bhave (1974). 
Considering these results, only geotechnical structures with $\mathrm{FS}_{\mathrm{g}}<1.16$ are expected to experience large deformations in the case of an earthquake in Switzerland. These structures are already critical, as the global factor of safety $\mathrm{FS}_{\mathrm{g}}=1.05-1.1$ indicates a state in which stability is assured only by mechanisms usually not accounted for in standard static calculations (e.g. vegetation in natural slopes, suctions and cementation in old dams, etc.). Creep and loss of stability in case of events such as intensive rainfall or earthquake can occur for these structures.

\subsection{Development of the displacement estimation relationship}

All geotechnical structures compatible with Newmark's sliding block assumption can be characterised using the critical acceleration $a_{\text {crit. }}$. This is also the only parameter of the displacement estimation relationship that is affected by factors such as friction angle, cohesion, and pore pressures. If $\mathrm{a}_{\text {crit }}$ was correctly determined, the displacement estimation relationship provides reliable results, by taking into account the effect of these factors. However, the relationship cannot be used in the situations in which the pore pressure and the critical acceleration vary during the earthquake, since Newmark's assumptions are violated in these cases.

The validation of existing displacement estimation methods e.g. (Anderson et al., 2008) and the development of new estimation approaches were possible by plotting the displacements against the ratio $a_{\text {crit }} / a_{\max }$. The plot of the results can be seen in Figure 6.9.

The top most data points marked with dashed lines, representing the upper bound of the scatter, were generated by two earthquakes: Montenegro 1979, $M_{w}=6.9$ and Friuli 1976, $M_{w}=5.9$. These points influenced the further considerations and they were left in the data set for conservative reasons.

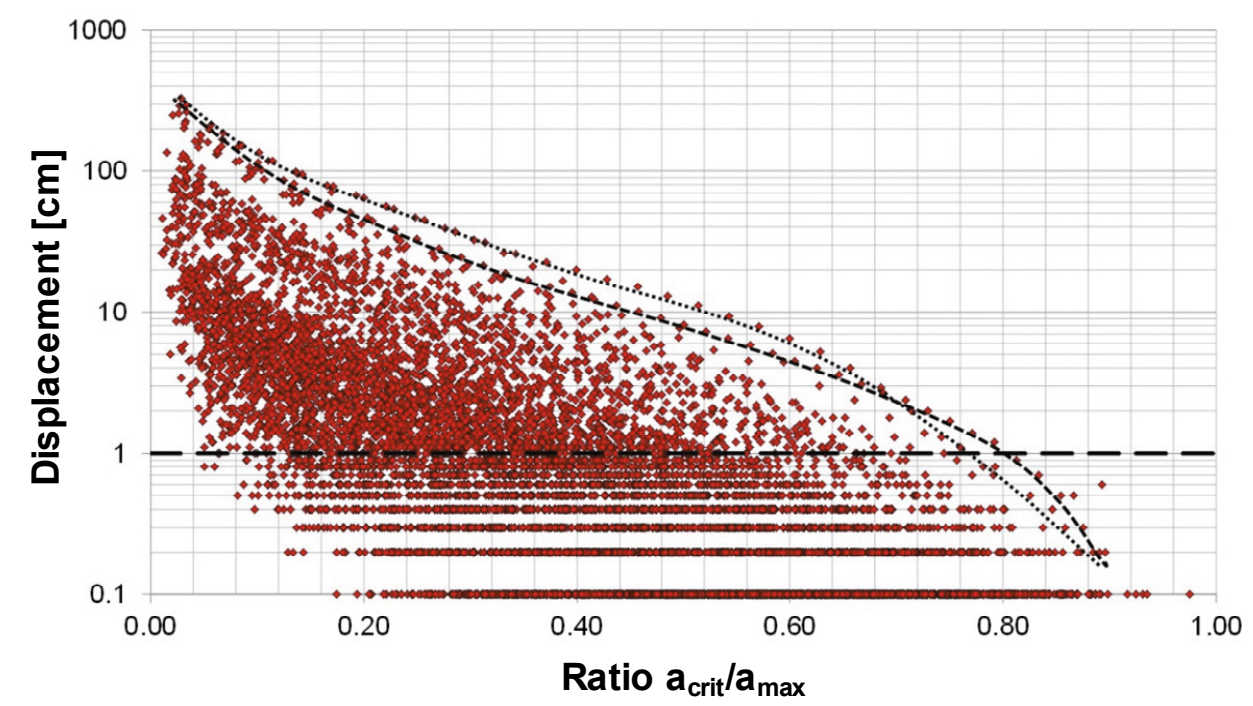

Figure 6.9. Calculated displacements against the corresponding ratios acrit/amax. 
The displacements were estimated with an accuracy of $0.1 \mathrm{~cm}$. This leads to displacement values that seem to be identical for different values of the ratio $a_{\text {crit }} / a_{\max }$, especially below $1 \mathrm{~cm}$. Moreover, Figure 6.9 shows that most of the data points in the scatter are below the limit of $1 \mathrm{~cm}$ (see also Figure 6.4).

The shape of the scatter is very similar to the results presented by Anderson et al. (2008) and this supports the idea of transposing the regression curves given by him to the Swiss context. The following regression relationship suggested by Anderson et al. (2008) was considered in the following steps:

$\mathrm{d}=2 \cdot 2.54 \cdot 10^{\left(-1.51-0.74 \log \left(\frac{\mathrm{a}_{\text {crit }}}{\mathrm{a}_{\max }}\right)+3.27 \log \left(1-\frac{\mathrm{a}_{\text {crit }}}{\mathrm{a}_{\max }}\right)-0.80 \log \left(\frac{\mathrm{a}_{\max }}{\mathrm{g}}\right)+1.59 \log (\mathrm{PGV})\right)}$

Where $d \quad$ - seismic-induced displacement $[\mathrm{cm}]$

$a_{\text {crit }} \quad-$ critical acceleration of the geotechnical structure [g]

$a_{\max } \quad-$ maximum acceleration of the earthquake $[\mathrm{g}]$

$P G V$ - peak ground velocity assumed as $P G V=30 \cdot a_{\max } / \mathrm{g}[\mathrm{in} / \mathrm{s}]$

$g \quad$ - gravitational acceleration.

The factor 2 at the beginning of the relationship indicates that the suggested regression curve represents an $84 \%$ fractile curve in the North American context.

The adaption of the relationships suggested by Anderson et al. (2008) was made separately for every value of $a_{\text {crit, }}$ as shown e.g. in Figure 6.10 for $a_{\text {crit }}=0.01 \mathrm{~g}$ and in Figure 6.11 for $a_{\text {crit }}=0.15 \mathrm{~g}$. The regression curve was plotted together with the scatter of the calculated displacements to check their compatibility.

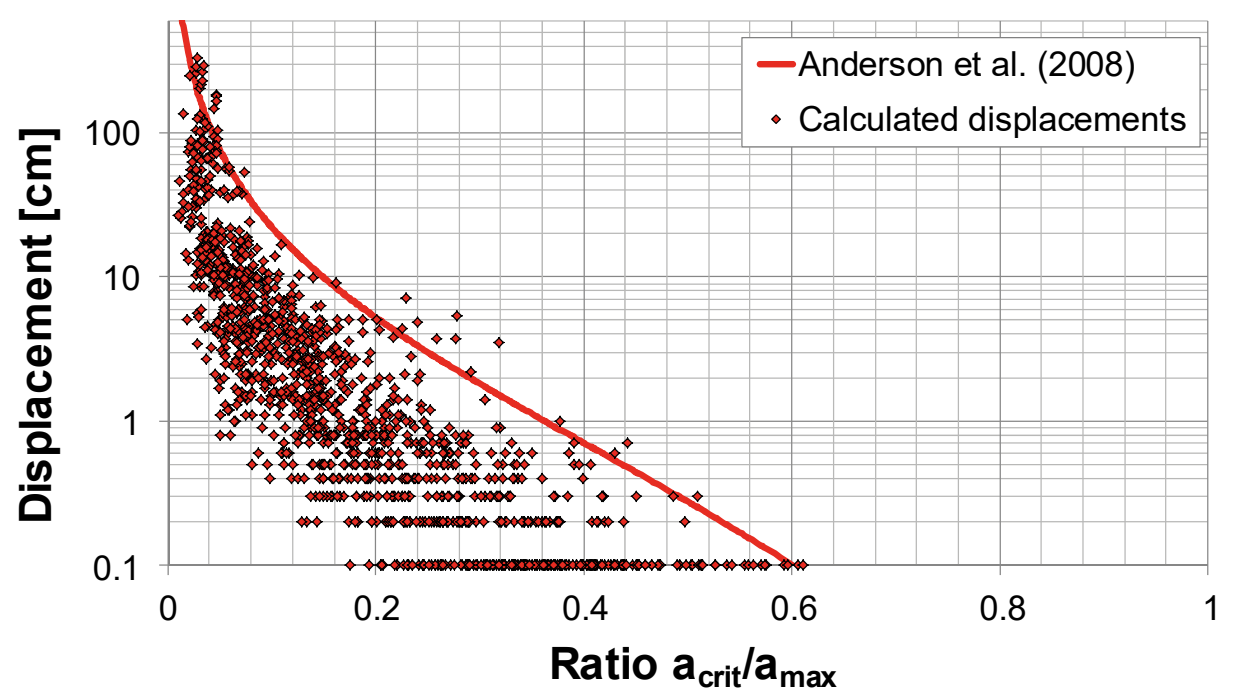

Figure 6.10. Calculated displacements and regression curve (Anderson et al., 2008) for $\mathrm{a}_{\text {crit }}=0.01 \mathrm{~g}$. 


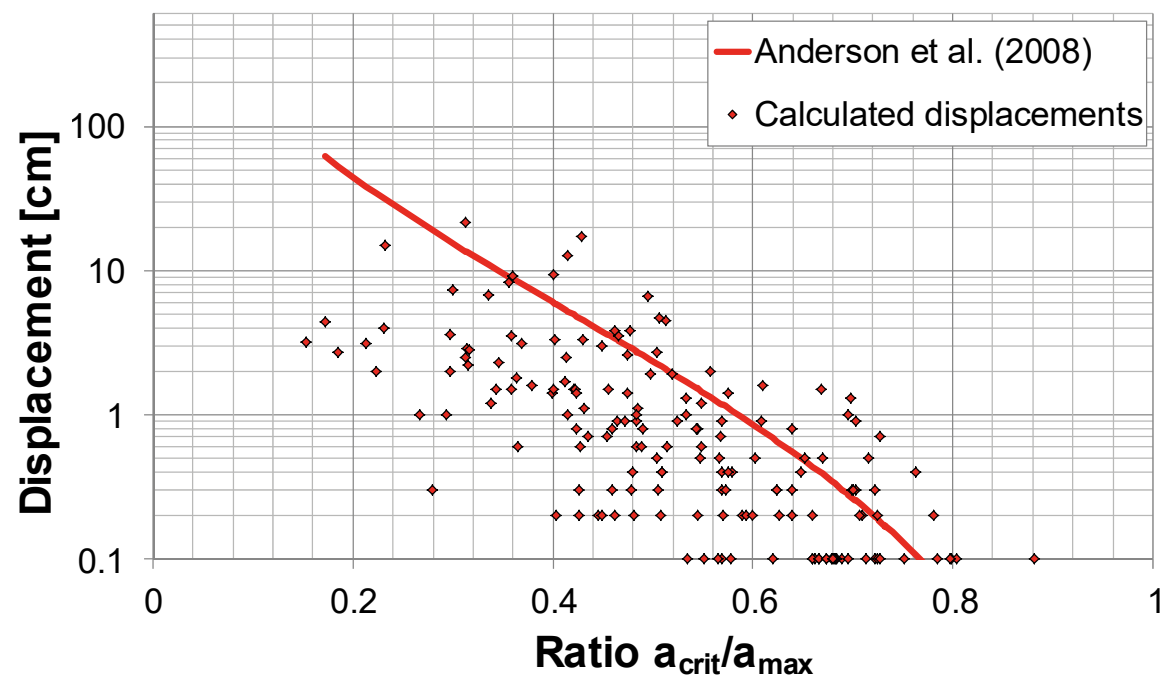

Figure 6.11. Calculated displacements and regression curve (Anderson et al., 2008) for $\mathbf{a}_{\text {crit }}=0.15 \mathrm{~g}$.

The compatibility of the results can be observed by comparing the calculated displacements with the curve presented by Anderson et al. (2008) as the $84 \%$ fractile for the US seismicity. This curve is relevant for the Swiss seismicity context because it incorporates enough conservatism, especially for the structures with low values of $a_{\text {crit }}$ (see Figure 6.10). For higher values of $a_{\text {crit, }}$ the curve is exceeded by some data points. However, high values of $a_{\text {crit }}$ represent geotechnical structures that are expected to experience only small displacements. Only 60 of 2'228 data points shown in Figure 6.11 represent displacements above $1 \mathrm{~cm}$. The exceedance of the curve is more probable for higher values of $\mathrm{a}_{\text {crit, }}$ but most of the corresponding displacements are very small (Table 6.2).

Under these circumstances, the regression curve developed by Anderson et al. (2008) can be transferred to the Swiss context as an estimation of the maximum expected displacements in case of an earthquake. This requires, by all means, scenarios where the sliding-block assumption is compatible with the failure mechanism of the geotechnical structure (e.g. slopes, dams, embankments, etc.).

In a final step, a displacement estimation chart can be developed, for situations when a fast evaluation of the seismic-induced deformations is needed and basic information related to the geotechnical structure (i.e. inclination and soil friction angle) is available.

This is a further development of the concepts presented by Leschinsky and San (1994) relating the soil friction angle and the slope angle in a limit equilibrium state for a given seismic coefficient. Two main assumptions were used: the first one is that the failure mechanism can be represented by an infinite slope with a failure plane parallel to the slope; the second one is related to the soil strength parameters, which can be included in an equivalent maximum friction angle. This equivalent maximum friction angle accounts for all additional stabilising factors such as cementation, dilatancy, suctions, etc. and eliminates the eventual cohesion term from the description of the soil strength. 
Table 6.2. Number of calculated displacements for different values of the critical acceleration.

\begin{tabular}{|c|c|c|c|c|c|c|c|c|c|c|c|c|}
\hline \multirow[b]{3}{*}{$\begin{array}{l}a_{\text {crit }} \text { Direction } \\
\end{array}$} & \multicolumn{8}{|c|}{ Total number of calculated displacements } & \multicolumn{4}{|c|}{ Displacement values $[\mathrm{cm}]$} \\
\hline & \multicolumn{2}{|c|}{$0 \mathrm{~cm} \ldots 1 \mathrm{~cm}$} & \multicolumn{2}{|c|}{$1 \mathrm{~cm} \ldots 10 \mathrm{~cm}$} & \multicolumn{2}{|c|}{$10 \mathrm{~cm} \ldots 100 \mathrm{~cm}$} & \multicolumn{2}{|c|}{$100 \mathrm{~cm} \mathrm{\ldots ..500} \mathrm{cm}$} & \multicolumn{2}{|c|}{ Maximum } & \multicolumn{2}{|c|}{ Average } \\
\hline & Positive & Negative & Positive & Negative & Positive & Negative & Positive & Negative & Positive & Negative & Positive & Negative \\
\hline 0.01 & 769 & 767 & 233 & 236 & 101 & 99 & 11 & 12 & 330.70 & 293.40 & 5.47 & 5.35 \\
\hline 0.02 & 866 & 872 & 186 & 179 & 56 & 59 & 6 & 4 & 215.10 & 198.20 & 3.11 & 3.09 \\
\hline 0.03 & 926 & 931 & 137 & 133 & 48 & 46 & 3 & 4 & 152.50 & 149.60 & 2.09 & 2.09 \\
\hline 0.04 & 961 & 962 & 106 & 110 & 45 & 41 & 2 & 1 & 119.00 & 117.80 & 1.51 & 1.51 \\
\hline 0.05 & 991 & 994 & 92 & 83 & 30 & 37 & 1 & 0 & 101.00 & 95.80 & 1.13 & 1.12 \\
\hline 0.06 & 1015 & 1007 & 71 & 78 & 28 & 29 & 0 & 0 & 85.60 & 79.60 & 0.87 & 0.84 \\
\hline 0.07 & 1026 & 1029 & 70 & 62 & 18 & 23 & 0 & 0 & 71.40 & 66.70 & 0.68 & 0.65 \\
\hline 0.08 & 1038 & 1040 & 61 & 59 & 15 & 15 & 0 & 0 & 58.50 & 56.10 & 0.54 & 0.50 \\
\hline 0.09 & 1046 & 1049 & 57 & 57 & 11 & 8 & 0 & 0 & 50.50 & 47.00 & 0.43 & 0.40 \\
\hline 0.10 & 1054 & 1055 & 51 & 52 & 9 & 7 & 0 & 0 & 43.90 & 39.20 & 0.35 & 0.32 \\
\hline 0.11 & 1058 & 1064 & 48 & 45 & 8 & 5 & 0 & 0 & 38.20 & 32.40 & 0.28 & 0.26 \\
\hline 0.12 & 1061 & 1067 & 49 & 42 & 4 & 5 & 0 & 0 & 33.00 & 26.50 & 0.23 & 0.21 \\
\hline 0.13 & 1069 & 1071 & 41 & 40 & 4 & 3 & 0 & 0 & 28.40 & 21.30 & 0.19 & 0.17 \\
\hline 0.14 & 1073 & 1075 & 37 & 37 & 4 & 2 & 0 & 0 & 24.50 & 16.70 & 0.16 & 0.14 \\
\hline 0.15 & 1082 & 1080 & 30 & 32 & 2 & 2 & 0 & 0 & 21.50 & 14.80 & 0.13 & 0.12 \\
\hline 0.16 & 1087 & 1083 & 25 & 30 & 2 & 1 & 0 & 0 & 19.00 & 13.20 & 0.11 & 0.09 \\
\hline 0.17 & 1091 & 1090 & 21 & 23 & 2 & 1 & 0 & 0 & 17.00 & 11.80 & 0.09 & 0.08 \\
\hline 0.18 & 1097 & 1092 & 15 & 21 & 2 & 1 & 0 & 0 & 15.20 & 10.40 & 0.07 & 0.06 \\
\hline 0.19 & 1098 & 1097 & 15 & 17 & 1 & 0 & 0 & 0 & 13.80 & 9.20 & 0.06 & 0.05 \\
\hline 0.20 & 1099 & 1098 & 14 & 16 & 1 & 0 & 0 & 0 & 12.40 & 8.00 & 0.05 & 0.04 \\
\hline 0.21 & 1101 & 1101 & 12 & 13 & 1 & 0 & 0 & 0 & 11.20 & 7.00 & 0.05 & 0.04 \\
\hline 0.22 & 1103 & 1104 & 10 & 10 & 1 & 0 & 0 & 0 & 10.10 & 6.00 & 0.04 & 0.03 \\
\hline 0.23 & 1104 & 1104 & 10 & 10 & 0 & 0 & 0 & 0 & 9.10 & 5.20 & 0.03 & 0.03 \\
\hline 0.24 & 1105 & 1107 & 9 & 7 & 0 & 0 & 0 & 0 & 8.10 & 4.60 & 0.03 & 0.02 \\
\hline 0.25 & 1106 & 1108 & 8 & 6 & 0 & 0 & 0 & 0 & 7.30 & 4.00 & 0.02 & 0.02 \\
\hline 0.26 & 1108 & 1108 & 6 & 6 & 0 & 0 & 0 & 0 & 6.50 & 3.50 & 0.02 & 0.02 \\
\hline 0.27 & 1110 & 1108 & 4 & 6 & 0 & 0 & 0 & 0 & 5.80 & 3.10 & 0.02 & 0.01 \\
\hline 0.28 & 1110 & 1110 & 4 & 4 & 0 & 0 & 0 & 0 & 5.10 & 2.70 & 0.01 & 0.01 \\
\hline 0.29 & 1110 & 1111 & 4 & 3 & 0 & 0 & 0 & 0 & 4.50 & 2.30 & 0.01 & 0.01 \\
\hline 0.30 & 1110 & 1111 & 4 & 3 & 0 & 0 & 0 & 0 & 4.00 & 2.00 & 0.01 & 0.01 \\
\hline 0.31 & 1110 & 1111 & 4 & 3 & 0 & 0 & 0 & 0 & 3.60 & 1.70 & 0.01 & 0.01 \\
\hline 0.32 & 1110 & 1111 & 4 & 3 & 0 & 0 & 0 & 0 & 3.60 & 1.70 & 0.01 & 0.01 \\
\hline 0.33 & 1112 & 1112 & 2 & 2 & 0 & 0 & 0 & 0 & 2.70 & 1.20 & 0.01 & 0.00 \\
\hline 0.34 & 1112 & 1112 & 2 & 2 & 0 & 0 & 0 & 0 & 2.40 & 1.10 & 0.01 & 0.00 \\
\hline 0.35 & 1112 & 1113 & 2 & 1 & 0 & 0 & 0 & 0 & 2.00 & 1.00 & 0.01 & 0.00 \\
\hline 0.36 & 1112 & 1113 & 2 & 1 & 0 & 0 & 0 & 0 & 1.70 & 1.00 & 0.00 & 0.00 \\
\hline 0.37 & 1112 & 1114 & 2 & 0 & 0 & 0 & 0 & 0 & 1.40 & 0.90 & 0.00 & 0.00 \\
\hline 0.38 & 1112 & 1114 & 2 & 0 & 0 & 0 & 0 & 0 & 1.20 & 0.90 & 0.00 & 0.00 \\
\hline 0.39 & 1113 & 1114 & 1 & 0 & 0 & 0 & 0 & 0 & 1.00 & 0.90 & 0.00 & 0.00 \\
\hline 0.40 & 1114 & 1114 & 0 & 0 & 0 & 0 & 0 & 0 & 0.90 & 0.80 & 0.00 & 0.00 \\
\hline 0.41 & 1114 & 1114 & 0 & 0 & 0 & 0 & 0 & 0 & 0.80 & 0.80 & 0.00 & 0.00 \\
\hline 0.42 & 1114 & 1114 & 0 & 0 & 0 & 0 & 0 & 0 & 0.80 & 0.70 & 0.00 & 0.00 \\
\hline 0.43 & 1114 & 1114 & 0 & 0 & 0 & 0 & 0 & 0 & 0.70 & 0.70 & 0.00 & 0.00 \\
\hline 0.44 & 1114 & 1114 & 0 & 0 & 0 & 0 & 0 & 0 & 0.60 & 0.70 & 0.00 & 0.00 \\
\hline 0.45 & 1114 & 1114 & 0 & 0 & 0 & 0 & 0 & 0 & 0.60 & 0.60 & 0.00 & 0.00 \\
\hline 0.46 & 1114 & 1114 & 0 & 0 & 0 & 0 & 0 & 0 & 0.60 & 0.60 & 0.00 & 0.00 \\
\hline 0.47 & 1114 & 1114 & 0 & 0 & 0 & 0 & 0 & 0 & 0.50 & 0.60 & 0.00 & 0.00 \\
\hline 0.48 & 1114 & 1114 & 0 & 0 & 0 & 0 & 0 & 0 & 0.50 & 0.50 & 0.00 & 0.00 \\
\hline 0.49 & 1114 & 1114 & 0 & 0 & 0 & 0 & 0 & 0 & 0.40 & 0.50 & 0.00 & 0.00 \\
\hline 0.50 & 1114 & 1114 & 0 & 0 & 0 & 0 & 0 & 0 & 0.40 & 0.50 & 0.00 & 0.00 \\
\hline
\end{tabular}

The groundwater table was assumed to be located at the base of the inclined geotechnical structure in all the investigations performed. This is a realistic assumption for the typical engineered slopes and embankments, but it introduces a degree of uncertainty in the results obtained for natural slopes. A more detailed analysis of the conditions related to soil layers and groundwater has to be performed, before proceeding with the actual investigations of the seismic-induced displacements of a natural slope. 
Displacement limit curves were developed using the relationship for the upper bound of the displacements (6.3) under the assumptions presented above. The curves were obtained by iteratively calculating, for a range of slope inclinations $\left(1^{\circ}-35^{\circ}\right)$, the friction angles that lead to the target displacement limit. In other words, by replacing the desired values of the limit displacement and the maximum acceleration $a_{\max }$ in relationship (6.3), the critical acceleration $a_{\text {crit }}$ can be obtained. Using $a_{\text {crit }}$ and the given value of the slope inclination, the corresponding friction angle can be calculated, under the assumption of an infinite slope with a parallel failure plane. This slope inclination corresponds to the target displacement limit.

Diagrams of displacement limit curves were developed for all possible values of $a_{\max }$ given by combinations of seismic zones, ground classes, and importance classes, according to the Swiss code SIA 261 (2014). The displacement estimation chart for the seismic zone $3 \mathrm{~b}$, soil class $\mathrm{D}$ and importance class $\mathrm{I}$, coresponding to a maximum acceleration $\mathrm{a}_{\max }=$ $0.216 \mathrm{~g}$ can be seen in Figure 6.13.

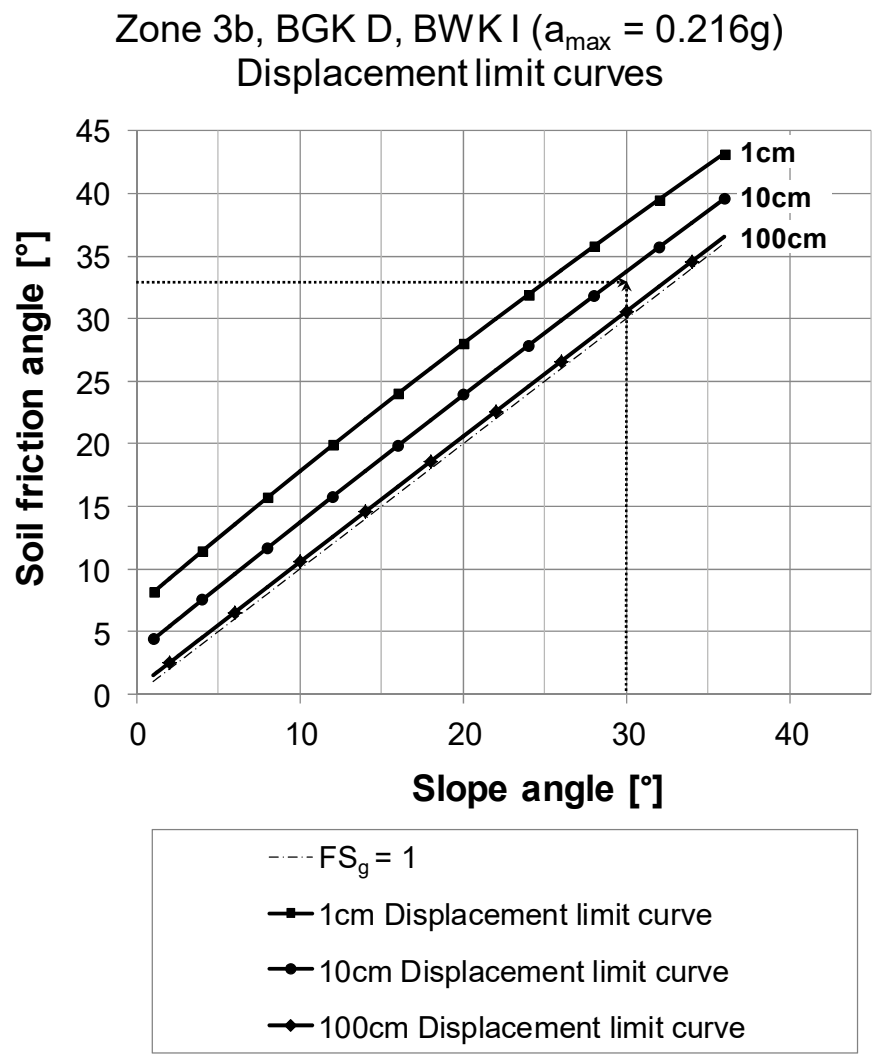

Figure 6.12. Displacement limit curves for seismic zone $3 b$, ground class $D$, importance class I $\left(a_{\max }=\right.$ $0.216 \mathrm{~g}$ ) according to SIA 261 (2014).

If a combination of the slope inclination and soil friction angle leads to a point located on the $1 \mathrm{~cm}$ displacement limit curve, the expected seismic-induced deformations are $1 \mathrm{~cm}$. All points below this curve are characterised by higher deformations, and above the curve by lower ones. Due to the logarithmic character of the regression curves behind this diagram, the space between the different displacements limit curves is highly nonlinear and, 
therefore, the displacements vary accordingly. All the points located above the black dashed line represent structures with a global factor of safety $\mathrm{FS}_{g}>1.0$, under the assumption of an infinite slope with a parallel failure plane. For a global safety factor equal or lower than 1.0, the displacements are expected to be large. In this, case no accurate estimation can be made without further investigations and adjustments of the assumed maximum equivalent angle of friction.

As a practical example, a slope with an inclination angle of $30^{\circ}$ consisting of a soil with a friction angle of $33^{\circ}$ can be identified on the diagram as a point between the $10 \mathrm{~cm}$ and the $100 \mathrm{~cm}$ displacement limit curves (Figure 6.13). The global factor of safety is, in this case, $\mathrm{FS}_{\mathrm{g}}>1.0$ and the expected displacements are between 10 and $100 \mathrm{~cm}$.

\subsection{Discussion}

The method proposed for the evaluation of the seismic-induced displacements is in accordance with international practice. It facilitates displacement-based design and it also meets the increasing demand for the verification of existing structures, roads, railways, and other linear infrastructure.

A first element of the displacement-based method is the regression relationship (6.3) for the estimation of the seismic-induced displacements. The variability of the seismic action, and of the geotechnical structures, was taken into account by the large number of Newmark analyses performed. The suggested relationship can also be used in situations when no specific earthquake recordings are available, for the investigation of the seismic behaviour of a geotechnical structure. The determination of the seismic-induced displacement can be made in these cases using general parameters, such as $a_{\text {crit, }} a_{\max }$, and PGV. These can be either determined from limit equilibrium calculations or using the design codes.

The assumption of the peak ground velocity PGV $[\mathrm{in} / \mathrm{s}]=30 \cdot \mathrm{a}_{\max } / \mathrm{g}$, also analysed by Anderson et al. (2008), allows the displacements to be determined using the suggested relationship as a function of $\mathrm{a}_{\max }$ and $\mathrm{a}_{\text {crit }}$ only. As the results showed, this formulation can be adopted for relatively weak seismic events, which would be compatible with the values given in the Swiss codes. However, the simplifying assumption proposed removes a significant parameter from the problem: the dominant period of the seismic motion, equivalent to the ratio PGV / $a_{\max }$. The importance of this parameter was already shown by Newmark (1965) in his original formulation for the upper bound to the computed values of displacements. Franklin and Chang (1977) and Yegian et al. (1991) also presented the importance of this factor. Gazetas et al. (2009) showed that, for a given maximum acceleration and nature of loading pulses, the sliding displacement is directly proportional to the squared dominant ("characteristic") period of excitation. Under these circumstances, the suggested regression relationship (6.3) with the simplifying assumption PGV $=30$. $a_{\max } / \mathrm{g}$ has considerable limitations in the determination of the seismic-induced displacements in areas with strong seismicity ( $M>6.5$ for return periods of 475 years) or e.g. in situations of near-fault ground shaking, influenced by forward-directivity or fling- 
step effects (Garini et al., 2010). A more detailed analysis, considering the specific effects should be performed in these situations.

The displacement estimation charts are a second element of the suggested displacementbased method. This graphical method of displacement evaluation, based on the regression relationship, can be used for the fast estimation of the expected displacements. Moreover, it can be also applied in the screening and prioritisation of large number of objects to be analysed. The approximation of the seismic-induced displacements is made solely by means of slope geometry and soil friction angle. The groundwater table was assumed to be at the base of the slope and, therefore, the displacement-based method proposed should be used with caution when partially saturated slopes are analysed. Detailed investigations have to be performed in such cases, to quantify the influence of the soil layers and the water content on the general stability and, hence, on the critical acceleration of the slope. The effect of pore water pressure increase in the slope caused by the cyclic loading during seismic events was disregarded in the current analysis, considering its complexity and the ongoing debates related to the best method to approach this problem. Recommendations related to the liquefaction potential of saturated soils in slopes (e.g. Youd et al., 2001; Idriss and Boulanger, 2008), the residual shear strength of soils (e.g. Seed and Harder, 1990; Stark and Mesri, 1992; Idriss and Boulanger, 2008) and the influence of groundwater on the slope stability (e.g. Loáiciga, 2015) should be considered in such cases.

The results of the method proposed provide information related to the order of magnitude of the displacements, since the underlying assumptions have a strong simplifying character. The purpose of fast evaluation, prioritisation, and screening is, however, perfectly served for a wide range of structures. In particular, structures with $\mathrm{FS}_{\mathrm{g}}<1.00$ have to undergo a more detailed analysis in any case.

Furthermore, the two elements presented above can also be used in the process of displacement- or performance-based design of new structures. The displacement charts can be used to determine the required slope angle for a given order of magnitude of the allowed deformations. They can also help in defining design measures for increasing the maximum mobilised shear strength. The regression curve can provide information about the required global factor of safety by means of $a_{\text {crit, }}$ given that the design seismic action $a_{\max }$ is known.

The stabilising factors mentioned in the beginning of the article (i.e. effective angle of internal friction, cementation and suctions, and effects of vegetation roots or anchors) can be taken into account by means of an increased mobilised friction angle. This influences the value of the critical acceleration, which is one of the key parameters in the displacement-based procedure. A correctly determined critical acceleration, considering the influence and mechanical compatibility of the stabilizing factors, leads to reliable estimations of the expected displacements. Therefore, the procedure accounts for the effect of the additional stabilising factors, as long as the input parameter $a_{\text {crit }}$ incorporates their influence in a suitable way. 
The most important step in the displacement-based approach is the verification of the compatibility of the estimated displacements with the mechanics of soil behaviour. For example, if the presence of suctions in a slope is expected and accounted for in the displacement-based analysis by means of an increased maximum mobilized friction angle, the compatibility of the displacements obtained must be checked with the strain range where the soil behaviour is dilatant and the effect of suctions is available. The same concept is valid for any other stabilising factors such as cementation, dilatancy, or vegetation roots.

Finally, the question arises of whether the proposed displacement-based procedure is superior to the limit equilibrium approach. This question can be answered using the case study of an existing river dam, with a slope inclination of $32^{\circ}$, consisting of a silty sand with a characteristic value of the friction angle of $31^{\circ}$ (Mayor, 2013; Marin, 2014).

The static factor of safety of the dam according to the SIA 267 (2013) is FS $=1.03$, taking into account the corresponding partial safety factors. The extraordinary seismic action is represented by the maximum horizontal acceleration $a_{\max }=0.259 \mathrm{~g}$, as defined by SIA 261 (2014) for the seismic zone 3b, soil class D, and importance class II. The dynamic factor of safety drops to $\mathrm{FS}_{\mathrm{dyn}}=0.8$, when considering this action. Under these conditions, the results of the limit equilibrium calculations indicate the river dam would fail under the seismic action, and would need to be replaced or retrofitted. The main issue of the limit equilibrium approach is the hidden conservatism of the characteristic value of the friction angle. Firstly, this is a critical state value, which already incorporates a safety margin. Moreover, the dam is an old compacted structure with relative density values of $70-90 \%$. However, SIA 267 (2013) requires a reduction of the already conservative value of the friction angle, which leads to a low factor of safety.

On the other hand, using the suggested displacement-based procedure, the critical aceleration of the dam can be determined as $a_{\text {crit }}=0.09 \mathrm{~g}$ and the ratio $a_{\text {crit }} / a_{\max }=0.34$. The expected displacements in the case of an earthquake are in the range of $7 \mathrm{~cm}$ according to equation (6.3). These displacements pose no threat to the structure as a flood protection measure, and the dam can be considered as safe with no additional remedial actions required. This simple example shows the clear advantage of the displacementbased procedure over the classic limit equilibrium approach, which was unable to give any information about the seismic behaviour of the dam, besides a sub-unitary factor of safety.

\subsection{Conclusions}

The increasing demand for displacement-based seismic design and verification of slopes, dams, and embankments was met by means of displacement estimation tools. These are based on Newmark's method (1965) and are supported by similar studies performed internationally.

The $84 \%$ fractile curve presented by Anderson et al. (2008) can be used as an upper bound of the displacements for moderate Swiss seismicity. Conservative estimations of the expected deformations can be made for geotechnical structures ranging from steep 
natural slopes with low values of $\mathrm{a}_{\text {crit }}$ to regular engineered inclined geotechnical structures. No large deformations are expected in the context of moderate Swiss seismicity for stable structures with a global factor of safety $\mathrm{FS}_{\mathrm{g}}>1.1$. These estimations are compliant with the assumptions related to the failure mechanism and soil behaviour.

Deformation charts were also developed based on the regression suggested, under the assumption of a drained infinite slope (i.e low groundwater table located well below the slope), and an equivalent angle of friction, which includes all stabilising factors such as cementation, dilatancy, suction etc. These charts can be used as a fast method for approximating the order of magnitude of seismic-induced displacements.

\subsection{Acknowledgements}

This paper represents a partial summary of the work performed at the Institute for Geotechnical Engineering at ETH Zurich within the project "Earthquake and Geotechnics" initiated and financed by the Federal Office for the Environment (FOEN), the Swiss Federal Railways (SBB), and the Federal Roads Office (FEDRO).

\subsection{References}

Ambraseys, N. N. \& Sarma, A. K. (1967) The response of earth dams to strong earthquakes. Géotechnique., 17. pp. 181-213.

Ambraseys, N., Smit, P., Sigbjornsson, R., Suhadolc, P. \& Margaris, B. (2002) InternetSite for European Strong-Motion Data, European Commission, Research-Directorate General, Environment and Climate Programme.

Anderson, D.G., Geoffrey, R.M., Ignatius, L. \& Wang, J.N. (2008) Seismic Analysis and Design of Retaining Walls, Buried Structures, Slopes, and Embankments. National Cooperative Highway Research Program, NCHRP Report 611. Transportation Research Board, Washington, D.C.

Bray, J.D. \& Rathje, E.M. (1998) Earthquake-induced displacements of solid-waste landfills. Journal of Geotechnical and Geoenvironmental Engineering, 124(3). pp. 241253.

Bray J.D., Rathje, E.M., Augello, A.J. \& Merry, S.M. (1998) Simplified seismic design procedures for geosynthetic-lined solid waste landfills. Geosynthetics International 5(1-2). pp. 203-235.

Bray, J.D. \& Travasarou, T. (2007) Simplified procedure for estimating earthquakeinduced deviatoric slope displacements. Journal of Geotechnical and Geoenvironmental Engineering, ASCE, 133(4). pp. 381-392.

Cai, Z. \& Bathurst, R.J. (1996) Seismic-induced permanent displacement of geosyntheticreinforced segmental retaining walls. Canadian Geotechnical Journal, 33. pp. 937-955. 
Chopra, A.K. \& Zhang, L. (1991) Base sliding response of concrete gravity dams to earthquakes. Rep. No. UCB/EERC-9//05, Earthquake Engrg. Res. Ctr., Univ. of California, Berkeley, California.

Franklin, A.G. \& Chang, F.K. (1977) Permanent displacements of earth embankments by Newmark sliding block analysis. Report 5. Miscellaneous paper S-71-17. US Army Corps of engineers Waterways Experiment Station, Vicksburg, Mississippi.

Garini, E., Gazetas, G. \& Anastasopoulos, I. (2011) Asymmetric 'Newmark' sliding caused by motions containing severe 'directivity' and 'fling' pulses. Géotechnique 61(9). pp. 733756.

Gazetas, G. \& Uddin, N. (1994) Permanent deformation on pre-existing sliding surfaces in dams. Journal of Geotechnical Engineering ASCE 120(11). pp. 2041-2061.

Gazetas, G., Garini, E., Anastasopoulos, I. \& Georgarakos, T. (2009) Effects of Near-Fault Ground Shaking on Sliding Systems. Journal of Geotechnical and Geoenvironmental Engineering 135(12). pp. 1906-1921.

Idriss, I.M. \& Boulanger, R.W. (2008) Soil Liquefaction During Earthquakes. Earthquake Engineering Research Institute MNO-12, Oakland California.

Kramer, S.L. \& Smith, M.W. (1997) Modified Newmark model for seismic slope displacement of compliant slopes. Journal of Geotechnical and Geoenvironmental Engineering ASCE, 123(7). pp. 635-644.

Laue, J., Weber, T. \& Marin, A. (2012) Berücksichtigung von Erdbeben bei der Berechnung von Hängen und Böschungen. Bundesamt für Strassen ASTRA. (in German)

Leschinsky, D. \& San, K.-C. (1994) Pseudostatic seismic stability of slopes: design charts. Journal of Geotechnical Engineering ASCE, 120(9). pp. 1514-1532.

Lin, J.S. \& Whitman, R.V. (1983) Decoupling approximation in the evaluation of earthquake-induced plastic slip in earth dams. Earthquake Engineering and Structural Dynamics, 11. pp. 667-678.

Loáiciga, H.A. (2015) Groundwater and earthquakes: Screening analysis for slope stability. Engineering Geology 193. pp. 276-287.

Luzi, L., Hailemikael, S., Bindi D., Pacor, F., Mele, F. \& Sabetta, F. (2008) ITACA - ITalian ACcelerometric Archive: A Web Portal for the Dissemination of Italian Strong-motion Data. Seismological Research Letters, 79(5). pp. 716-722.

Makdisi, F.I. \& Seed, H.B. (1978) Simplified procedure for estimating dam and embankment earthquake-induced deformations. Journal of the Geotechnical Engineering Division ASCE, 104(GT7). pp. 849-867. 
Marin, A. (2014) Sicherungsmassnahmen der Rhone Dämme. Mitteilungen der Geotechnik Schweiz 168. pp. 87-101. In German.

Martin, G.R. \& Qiu, P. (1994) Effects of Liquefaction on Vulnerability Assessment. NCEER Highway Project on Seismic Vulnerability of New and Existing Highway Construction, Year One Research Tasks, Technical Research Papers.

Mayor, P.A (2013) Verhalten eines Flussdammes unter wiederholter Hochwasserbelastung. DSc Thesis No. 21367, ETH Zurich.

Newmark, N.M. (1965) Effects of earthquakes on dams and embankments. Géotechnique, 15 (2). pp. 139-160.

Pacor, F., Paolucci, R., Luzi, L., Sabetta, F., Spinelli, A., Gorini, A., Nicoletti, M., Marcucci, S., Filippi, L., \& Dolce, M. (2011) Overview of the Italian strong motion database ITACA 1.0. Bulletin of Earthquake Engineering, 9(6). pp. 1723-1739.

Richards Jr., R. \& Elms, D. (1979) Seismic Behavior of Gravity Retaining Walls, Journal of Geotechnical Engineering Division ASCE, 105(GT4). pp. 449-464.

Sarma, S.K. \& Bhave, M.V. (1974) Critical acceleration versus static factor of safety in stability analysis of earth dams and embankments. Géotechnique, 24(4). pp. 661-665.

SCEC. (2002) Recommended Procedures for Implementation of DMG Special Publication 117: Guidelines for Analyzing and Mitigating Landslide Hazards in California, Southern California Earthquake Center, Los Angeles, California.

Seed, R.B. \& Harder, L.F. (1990) SPT-based analysis of cyclic pore pressure generation and undrained residual strength. In: Duncan, J.M. (ed.), Proceedings, H. Bolton Seed Memorial Symposium vol. 2. University of California, Berkeley, California. pp. 351-376.

Seed, H.B. \& Martin, G.R. (1966) The seismic coefficient in earth dam design. Journal of Soil Mechanics and Foundations Division ASCE, 92 (SM3). pp. 25-58.

SIA 261 (2014) Actions on Structures. Swiss Society of Engineers and Architects. Zurich.

SIA 267 (2013) Geotechnical Design. Swiss Society of Engineers and Architects. Zurich.

Stark, T.D. \& Mesri, G. (1992) Undrained shear strength of sands for stability analysis. Journal of Geotechnical Engineering 118 (11). pp. 1727-1747.

Whitman R.V. \& Liao S. (1984) Seismic Design of Gravity Retaining Walls. In: Proceedings of the 8th World Conference on Earthquake Engineering San Francisco, California. Volume

Yegian, M.K., Marciano, E.A. \& Ghahraman, V.G. (1991) Earthquake induced permanent deformations: A probabilistic approach. Journal of Geotechnical Engineering 117(1). pp. $35-50$. 
Youd, T.L., Idriss, I.M., Andrus, R.D., Arango, I., Castro, G., Christian, J.T., Dobry, R., Liam Finn, W.D., Harder Jr., R.F., Hynes, M.E., Ishihara, K., Koester, J.P., Liao, S.S.C., Marcuson III, W.F., Martin, G.R., Mitchell, J.K., Moriwaki, Y., Power, M.S., Robertson, P.K., Seed, R.B. \& Stokoe II, K.H. (2001) Liquefaction resistance of soils: summary report from the 1996 NCEER and 1998 NCEER/NSF workshops on evaluation of liquefaction resistance of soils. Journal of Geotechnical and Geoenvironmental Engineering 127(10). pp. 817-833. 


\section{Summarising Conclusions}

The scope of the current research was to investigate the dynamic non-linear soil behaviour and its special aspects in alpine areas and to use the results obtained in mitigating the impact of earthquakes in such regions. The main achievements relate to some elements of the four main challenges of geotechnical earthquake engineering stated in the introductory part of the thesis:

- Identification and quantification of dynamic non-linear soil behaviour and its main influencing factors.

- Identification and calibration of numerical models for seismic analyses.

- Field investigations adapted to capture the specific seismic effects in alpine areas.

- Development of standardised evaluation methodologies for the seismic behaviour of inclined geotechnical structures.

The first three challenges were approached by analysing the dynamic non-linear soil behaviour using laboratory, numerical, and field investigations. The outcome of the investigations was rounded off by the element of outreach to the world of practice, as an answer to the last challenge in the list. This element is a displacement-based method of evaluation of the seismic behaviour of slopes, dams, and embankments in alpine areas under conditions of moderate seismicity. Figure 7.1 summarises the main achievements of the research in relation to the initial goals. Subsequently, the conclusions of the field, laboratory, and numerical investigations are presented in a more detailed manner, with emphasis on their practical significance. 
Goals

\begin{tabular}{|c|c|c|}
\hline 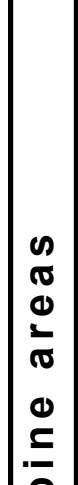 & 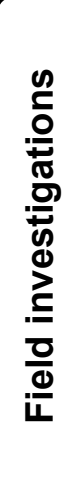 & $\begin{array}{l}\text { - Measurements of seismic site } \\
\text { effects related to wave } \\
\text { propagation alpine areas } \\
\text { - Records of pore pressure } \\
\text { development during cyclic } \\
\text { loading } \\
\text { - Identification of threshold } \\
\text { values for non-linear soil } \\
\text { behaviour }\end{array}$ \\
\hline
\end{tabular}

- Extensive investigation of static and dynamic behaviour of alpine silty sand

- Identification and quantification of the effect of cyclic preloading on subsequent soil response

- Prediction of pore pressure increase during cyclic loading

- Calibration of damping parameters for dynamic analyses

- Derivation of an optimal analyses of large ground models

- Investigation of soil-structure interaction under strong simplifying assumptions

- Identification and quantification of 2D effects of wave propagation in alpine valleys solution for non-linear

Achievements

- Installation of a long-term monitoring system able to record seismic events in terms of accelerations, 3D deformation profiles, pore pressure variation profiles.

- Recording of a weak seismic event $(M=3.1)$ with evidence of potential non-linear soil response

$>$ Clear relation between wave propagation and pore pressure variation

$>$ Differences between piezometers installed in silty and gravely soil

$>$ Confirmation of local liquefaction susceptibility

- Complete set of static and dynamic soil parameters

- Post-cyclic effects identified and quantified:

$>$ Marginal reduction of the maximum friction angle (from $48.2^{\circ}$ to $47.3^{\circ}$ )

$>$ Dilatant behaviour at large strains $\left(\varepsilon_{a}=25 \%\right)$

$>$ More brittle static behaviour (the residual friction angle was reached at $\varepsilon_{\mathrm{a}}=13.8 \%$, compared to $\varepsilon_{\mathrm{a}}=$ $16 \%$ in the static case)

- Parameters calibrated for the prediction of pore pressure development after Egglezos \& Bouckovalas (1999)

\section{- Alternative calibration procedure for} Rayleigh parameters

- Optimised hybrid ground model: non-linear modelling (e.g. HSs) of the surface soil layers prone to non-linear response; linear elastic perfectly plastic modelling (e.g. $\mathrm{MC})$ for the deep soil layers.

- Realistic kinematic effects (e.g. base slab averaging, embedment effects) of soil-structure interaction obtained using a linear elastic perfectly plastic constitutive model (i.e. MC)

- $2 D$ effects identified and quantified:

$>$ Single value of the natural period of the sediment basin, independent on the location

$>$ Stiffer soil response, compared to 1D results

$>$ Non-vertical wave propagation generating Rayleigh waves

$>$ Body wave reflections in the valley, amplifying and extending the ground motion locally

- Mitigation of the impact of earthquakes in alpine areas
- Displacement-based method for the seismic analysis of slopes, dams, and embankments.

Figure 7.1. Main goals and achievements of the field, laboratory, and numerical investigations of dynamic non-linear soil behaviour and practical outreach of the research. 


\subsection{Field Investigations}

The main goals of the field investigations were the quantification of the seismic site effects related to the wave propagation in alpine areas, the measurement of pore-pressure development during earthquakes in soils deposited in alpine valleys, and the identification of threshold values for non-linear soil behaviour.

A novel long-term monitoring system was installed in the area of Visp and one weak seismic event $(M=3.1)$ was recorded on October $14^{\text {th }}, 2015$. The data showed a clear correlation between the variation of the pore pressures and the time history of the vertical accelerations measured at the monitoring site. The highest pore pressure increase was measured by the piezometers installed in the silty soil, and the lowest in the gravelly layer. These measurements confirmed the liquefaction susceptibility of the local silty-sandy soils, which was observed historically (Fritsche et al., 2006) and also investigated more recently in the area of Visp by Résonance (2010). They also indicated the possibility of calibrating non-linear soil models using data recorded during weak seismic events. This is an essential element for areas of moderate seismicity, such as Switzerland, where strong ground motions occur rarely but non-linear soil behaviour cannot be excluded due to local topographic conditions (e.g. deep alpine valleys filled with sediments).

The practical aspects of the measurements are related to numerical applications, such as calibration and validation of soil models that can be used for the prediction of the local ground motion. Moreover, the measurements made with the piezometers under static regime contribute to a better understanding of the response of local aquifers and they can be used to quantify the flow due to seasonal variations of the groundwater table.

\subsection{Laboratory investigations}

The laboratory investigations focused on the dynamic behaviour of alpine silty sand from Visp, the same area where the monitoring system was installed. The effect of cyclic preloading on the subsequent static and dynamic soil behaviour, and the pore pressure increase due to cyclic loading, were thoroughly investigated using simple (i.e. cyclic axial compression) and advanced stress paths (e.g. successive cyclic axial compression stages that would represent consecutive seismic events).

The main outcome of the laboratory tests is an extensive set of static and dynamic soil parameters of the alpine silty sand from Visp. In particular, the results revealed some important aspects related to the post-cyclic soil behaviour, which influence the choice of parameters in subsequent numerical investigations.

A marginal reduction of the post-cyclic maximum friction angle (e.g. from approx. $43^{\circ}$ to $42^{\circ}$ for a soil sample with $D_{D}=79 \%$ ) was observed during soil testing. Different values of the maximum friction angle are expected for soil samples with other relative densities (Bolton, 1986). However, the marginal reduction observed supports the assumption of unaltered maximum friction angle for the alpine silty sand from Visp in case of consecutive seismic events, which is a positive effect of the soil response. 
Another positive effect observed is the post-cyclic dilatant behaviour of the investigated soil samples (relative densities $D_{D}=55-76 \%$ ) at large strains (i.e. $\varepsilon_{a}=25 \%$ ). This reveals the contribution of suctions to the increased shear resistance of the alpine silty sand, assuming that no other subsequent cyclic loading occurs. Therefore, the stabilising effect of suctions is available in natural slopes consisting of similar soils even in situations when large displacements occur. These results also explain the numerous cases of partially eroded dams in the Rhone valley that are still stable (Mayor, 2013).

A less positive effect of the cyclic preloading is the more brittle post-cyclic static soil response, indicated by the lower axial strains at which the residual value of the friction angle was reached (i.e. $\varepsilon_{a}=13.8 \%$, compared to $\varepsilon_{a}=16 \%$ in the case of no cyclic preloading). This effect indicates e.g. the risk of progressive slope failures in case of earthquake aftershocks, which induce strains in the soil causing the mobilised friction angle to plunge earlier to its residual value (i.e. constant volume value).

Another aspect of the laboratory testing was the calibration of a set of parameters to fit the relationships presented by Egglezos and Bouckovalas $(1998 ; 1999)$ with the pore pressure measurements performed on samples subjected to cyclic axial compression loading. The relationships and parameters calibrated are useful in problems related to soil liquefaction or slope stability of partially saturated slopes. They can be used in displacementbased investigations based on Newmark's method with variable critical acceleration that depends on the pore pressure increase during the seismic event (e.g. Biondi et al., 2000). Unfortunately, no validation of these relationships could be performed using field measurements, since no major seismic event was recorded so far with the monitoring system presented in Chapter 5 . However, this represents an important further step to be made as soon as relevant measurements are available.

\subsection{Numerical investigations}

The numerical analyses performed were based on the outcome of the laboratory investigations, which allowed the determination of parameters for both simple (e.g. linear elastic perfectly plastic Mohr-Coulomb, MC) and more advanced constitutive models (e.g. Hardening-soil small strain, HSs). The results obtained are related to the wave propagation in alpine areas and to basic soil-structure interaction effects.

A new calibration method was developed for the Rayleigh parameters (Rayleigh \& Lindsay, 1945) often used in the damping formulation for seismic analyses in the time domain. These parameters are determined iteratively at the convergence between two parallel analyses in the frequency and time domain, in which the seismic-induced strains in the soil are in the elastic range. This method finds its practical application during determination of the soil parameters for any kind of seismic analysis using the Rayleigh parameters to model soil damping.

Another practical contribution to the advance of numerical modelling was the derivation of an optimised solution for large ground models (e.g. entire alpine valleys including the bedrock profile) used in non-linear seismic analyses. The increased calculation times and 
costs, usually associated with such analyses (Roten et al., 2009) were optimised by deriving a hybrid ground model, including both linear and non-linear constitutive models. Particularly, the solution was developed for a section of the Rhone valley in the area of Visp, which was modelled using a non-linear constitutive model (e.g. HSs) for the first 22 $\mathrm{m}$ of soil below the surface, and a linear elastic perfectly plastic one (e.g. MC) for the rest of the soil layers. The concept of a hybrid ground model can be extended to any other situation by identifying the depth of the soil layers expected to experience non-linear behaviour (e.g. $22 \mathrm{~m}$ in the particular case presented). This optimisation allowed the seismic analysis to be performed on a regular PC using widely available software (i.e. PLAXIS 2D - Brinkgreve et al., 2014).

The outcome of the numerical investigations of the kinematic soil-structure interaction indicated clear evidence of such effects, despite simplifying assumptions related to soil behaviour (i.e. linear elastic perfectly plastic constitutive model) and boundary conditions (i.e. absorbent lateral boundaries and rigid base). This recommends the use of appropriate elements to account for the soil-structure interaction (e.g. interface elements between structures and soil) even in the case of simplistic approaches to seismic analyses in alpine areas and elsewhere. The results confirmed that these effects cannot be neglected in any seismic analysis and showed a possible accessible approach to this complex problem.

The investigations related to the identification and quantification of $2 \mathrm{D}$ effects of wave propagation incorporated the calibration method for the Rayleigh parameters and the hybrid model solution presented above. The results of the analyses showed that $1 \mathrm{D}$ analyses of site response in the time or frequency domain, with linear or non-linear soil models, are not able to represent the entire soil response in an alpine valley. Considering this, the future seismic analyses in such areas with rough topography should take into account the 2D conditions that cause an increase of the local ground motion. Existing microzonation spectra obtained under 1D conditions should be used with caution, as they do not take into account the effects observed in the numerical analyses performed under 2D conditions (e.g. lower resonance periods, surface waves generated by non-vertical incident waves, increased duration and amplitude of the ground motion in the valley centre due to body wave reflections).

The selection of input signals for any kind of seismic analyses should be based on a clear understanding of the seismic hazard. The signals selected for the analyses described in Chapters 3 and 4 are rather at the upper boundary of the deaggregation of the seismic hazard for the Visp area and they introduce a high level of conservatism in the final results. Therefore, it is recommended that input signals for seismic analyses should be selected by ensuring the compatibility with the hazard deaggreagation and the uniform hazard spectra for the investigated location.

The most important element of numerical investigations is the verification of the consistency of results. Factors related to FE calculations such as integration time step, mesh size, boundary conditions, interface elements, etc. have a significant effect on the con- 
sistency of the final results, in addition to assumptions of soil behaviour and seismic input. The possible influence of such factors should be clearly identified before proceeding to the interpretation of the results. The consistency of the results can be verified by comparing them with first-order approximations obtained using e.g. linear-equivalent or simple elastic analyses, for which soil properties are readily available. Such analyses (e.g. 1D SHAKEtype of analyses) have been used for many years for the approximation of the soil response and they still dominate practice since their reliability (within certain boundary conditions) was proven in time. Simple comparisons of the numerical results with analytical solutions can also be an effective method to validate the outcome of the investigations performed. The final results of the numerical investigations must include basic information related to FE calculations, soil models, and seismic input, required to assess their consistency and validity.

\subsection{Practical outreach}

The practical outreach of the investigations performed on the dynamic non-linear soil behaviour in alpine areas is represented by the displacement-based method for the seismic analysis of slopes, dams, and embankments. Such geotechnical structures are very numerous in alpine regions and this method can be used in the mitigation of the impact of earthquakes, both in design and verification processes.

The method developed provides a regression relationship for the estimation of seismicinduced displacements based on basic parameters such as the critical acceleration of the geotechnical structure ( $\left.a_{\text {crit }}\right)$, the maximum local horizontal acceleration $\left(a_{\max }\right)$, and the local peak ground velocity (PGV). Simplifying assumptions were adopted for the determination of these parameters and they can be used for relatively weak seismic events, which would be compatible with typical Swiss seismicity.

Another element of the method developed is represented by the displacement estimation charts. These charts were derived based on the regression relationship mentioned above, considering a slope-parallel failure mechanism and a groundwater table located below the slope. The only input parameters are the slope geometry and mobilised soil friction angle and the results obtained can be used when a fast estimation of the order of magnitude of the expected seismic-induced displacements is required (e.g. when large numbers of structures need to be screened and prioritised for analysis).

The structures expected to experience pore pressure increase during seismic events require special investigations. In such cases, modified Newmark analyses with variable critical acceleration due to pore pressure increase (e.g. Biondi et al., 2000) can be used in conjunction with the parameters calibrated in laboratory for analytical relationships presented by Egglezos and Bouckovalas (1998; 1999).

The key element of the displacement-based method for the seismic analysis of slopes, dams, and embankments is the verification of the mechanical compatibility between the displacements and the stabilising factors incorporated in the mobilised soil friction angle (e.g. suctions, dilatancy, cementation, vegetation, etc.). The soil behaviour observed in 
the laboratory can be used to perform this verification. For example, the laboratory investigations of the alpine silty sand from Visp showed a marginal reduction of the postcyclic maximum friction angle and a large-strain compatibility of suctions. Considering this, the displacements predicted using the method proposed are reliable, under the assumption that the maximum mobilised friction angle incorporates only the effect of suctions. 



\section{Outlook}

The outcome of the current research showed the importance of taking the non-linear soil behaviour into account in the earthquake mitigation in the alpine areas. This cannot be excluded since it was observed in the past and confirmed by the results of the analyses performed. Further research is required in the field, laboratory, and numerical investigations to be able to incorporate the effects of non-linear soil behaviour in the earthquake mitigation measures in a more effective way.

\subsection{Field investigations}

Future recordings of seismic events should be used to identify thresholds for non-linear soil behaviour that are very important, especially in areas with moderate seismicity where non-linear soil behaviour cannot be excluded because of the local conditions. They can be used to optimise seismic analyses, e.g. by defining ranges of application for non-linear investigations. The thresholds can be determined by investigating different factors such as: local maximum acceleration and peak ground velocity, energy content (e.g. arias intensity), or duration of the ground motion, in the context of local amplification and pore pressure development.

\subsection{Laboratory investigations}

The laboratory investigations should be extended from the specific case of the silty sand in Visp to silty soils from other locations. The aspects of non-linear soil behaviour and the influencing factors discussed in this work should be the common ground for comparison with the results of investigations on other alluvial deposits found in alpine valleys. Such studies will extend the validity and applicability of the results to a wider range of soils.

The parameters calibrated in the laboratory and the relationships proposed to predict the pore pressure increase should be validated using field measurements obtained from the monitoring site in Visp. A better evaluation of future laboratory investigations and their ability to simulate the conditions in the field will be possible, by quantifying the differences between laboratory and field measurements. Correction and correlation factors can be determined for the more efficient use of laboratory results. This will be possible as soon as stronger seismic events will be recorded by the instruments.

\subsection{Numerical investigations}

The numerical investigations should be generalised by extending them to other valley cross-sections. Additionally, more advanced soil models should be used to represent special aspects of soil behaviour such as strain softening, densification due to permanent volumetric strain, cyclic mobility, liquefaction, etc. 
The validation and calibration of the numerical investigations performed should be carried out using future field measurements of wave propagation. In this way, the conservatism of the microzonation spectra available (e.g. Résonance et al., 2005) can be analysed and more accurate spectra can be developed, by incorporating the 2D effects.

A further step should be made by investigating under what conditions simple 1D investigations of soil response are sufficient and can replace $2 \mathrm{D}$ analyses. Criteria related to the geometry of the valley, as proposed e.g. by Bard \& Bouchon (1985), should be reconsidered in the context of local Swiss seismicity.

\subsection{Displacement-based method for the evaluation of the seismic behaviour of slopes, dams, and embankments}

The displacement-based method proposed should be refined by including the influence of the predominant period of the earthquake in the formulation of the seismic displacements. This can be made by a more accurate evaluation of the peak ground velocity, using recordings from the strong-motion network in Switzerland.

A further refining step can also be made by advanced physical modelling. The displacements provided by the analytical method should be compared with seismic simulations with standard prototype models in the geotechnical centrifuge. Parallel numerical simulations can provide more detailed information related to the stress states and failure mechanisms of such structures. 


\section{References}

Bard, P.-Y. \& Bouchon, M. (1985) The two-dimensional resonance of sediment filled valleys. Bulletin of the Seismological Society of America 75(2). pp. 519-541.

Biondi, G., Cascone, E., Maugeri, M. \& Motta, E. (2000) Sesimic response of saturated cohesionless slopes. Soil Dynamics and Earthquake Engineering 20. pp. 209-2015.

Bolton, M.D. (1986) The strength and dilatancy of sands. Géotechnique 36(1). pp. 65-78.

Brinkgreve, R.B.J., Engin, E. \& Swolfs, W.M. (2014) PLAXIS 2D Anniversary Edition 2014. Delft University of Technology \& PLAXIS bv. The Netherlands.

Egglezos, D. N. \& Bouckovalas, G. D. (1998) Analytical relationships for earthquake induced pore pressure in sand, clay and silt. In: 11th European Conference on Earthquake Engineering, Paris. pp. 167. (full article on CD-ROM).

Egglezos, D. N. \& Bouckovalas, G. D. (1999) Permanent strain and pore pressure relations for cyclic loading of sand. In: Seco e Pinto (ed.), Proceedings of the 2nd International Conference on Earthquake Geotechnical Engineering, Lisbon. Balkema, Rotterdam. pp. 131-136.

Fritsche, S., Fäh, D., Gisler, M. \& Giardini, D. (2006) Reconstructing the damage field of the 1855 earthquake in Switzerland: historical investigations on a well-documented event. Geophysical Journal International, 166. pp. 719-731.

Mayor, P.A (2013) Verhalten eines Flussdammes unter wiederholter Hochwasserbelastung. DSc Thesis No. 21367, ETH Zurich.

Rayleigh, J.W.S. \& Lindsay, R.B. (1945) The Theory of Sound. Dover Publications, New York.

Résonance S.A., Rovina-Partner A.G. \& Tissières S.A. (2005) Spektrale seismische Mikrozonierung der Region Brig-Visp. Technischer Bericht No. 220.4. Kanton Wallis. Dienststelle für Raumplanung.

Résonance S.A. (2010) Reévaluation du danger de liquéfaction du sol sur le site de Lonza à Viège. Rapport no. RT 226.26. Carrouge, Suisse.

Roten, D., Fäh, D., Bonilla, L.F., Alvarez-Rubio, S., Weber, T.M. \& Laue, J. (2009) Estimation of non-linear site response in a deep Alpine valley. Geophysical Journal International, 178(3). pp. 1597-1613. 



\section{Appendix I. Evaluation of the Seismic Behaviour of a Natural Steep Slope}

\subsection{Introduction}

The analysis of slope stability and seismic behaviour represents the main concept in the design of new geotechnical structures as well as in the evaluation of existing structures. Currently this problem is approached by means different methods, which can be divided into two main groups, having as fundamental requirement the realistic assumption of the failure mechanism. The first group are the pseudo-static methods (Terzaghi, 1950; Seed \& Martin, 1966; Seed, 1979; Marcuson, 1981; Dakoulas \& Gazetas, 1986), which approximate the seismic action using a pseudo-static horizontal inertial force acting on the failure mechanism. The second group are the displacement-based methods (Sarma, 1975; Franklin \& Chang, 1977; Makdisi \& Seed 1978; Ambraseys \& Menu, 1988), which evaluate the expected deformations of slopes using Newmark's (1965) sliding-block theory.

The main challenges appear in the case when the widely used pseudo-static methods have to be applied to evaluate the seismic stability and behaviour of steep geotechnical structures (e.g. old railway dams which are still in service) and natural slopes. In these situations the equivalent force methods tend to render the analysed structures unstable without offering more information about the deformation behaviour and the serviceability after a seismic event.

In this context, an evaluation procedure using displacement-based concepts (Marin \& Laue, 2016) was developed to investigate situations of steep geotechnical structures (e.g. old railway dams which are still in service, natural slopes, etc.). This procedure offers the possibility of evaluating the seismic behaviour by comparing the expected seismic deformations with pre-defined allowable deformations. In this way, more accurate information about the behaviour of the geotechnical structures beyond the equilibrium point can be made available and used for design purposes as well as for risk evaluation and mitigation plans.

\subsection{Description of the situation}

The analysed hypothetical slope is located in the seismic zone Z3b of Switzerland (SIA $261,2014)$, characterised by a design value of the ground acceleration $a_{g d}=1.6 \mathrm{~m} / \mathrm{s}^{2}$ for a return period of 475 years. A local road $(7 \mathrm{~m}$ wide) is located at the top of the slope, which has to be accessible in case of an earthquake at least on one lane. In order to fulfil this requirement, a maximum differential settlement of $d_{\max }=30 \mathrm{~cm}$ can be allowed. During intensive rain the slope creeps and experiences displacements. 
The slope geology is uniform and consists of naturally deposited scree material with a friction angle $\varphi_{\mathrm{cv}}=37^{\circ}$ and a unit weight $\gamma=18 \mathrm{kN} / \mathrm{m}^{3}$. The slope surface as well as the underlying rock and are inclined with the same angle $\alpha=36.8^{\circ}$, which is close to the internal friction angle of the slope soil. The rock is considered to be a partially weathered molasse with a shear wave velocity of $v_{s}=800 \mathrm{~m} / \mathrm{s}$. A schematic representation of the considered situation is shown in Figure 10.1.

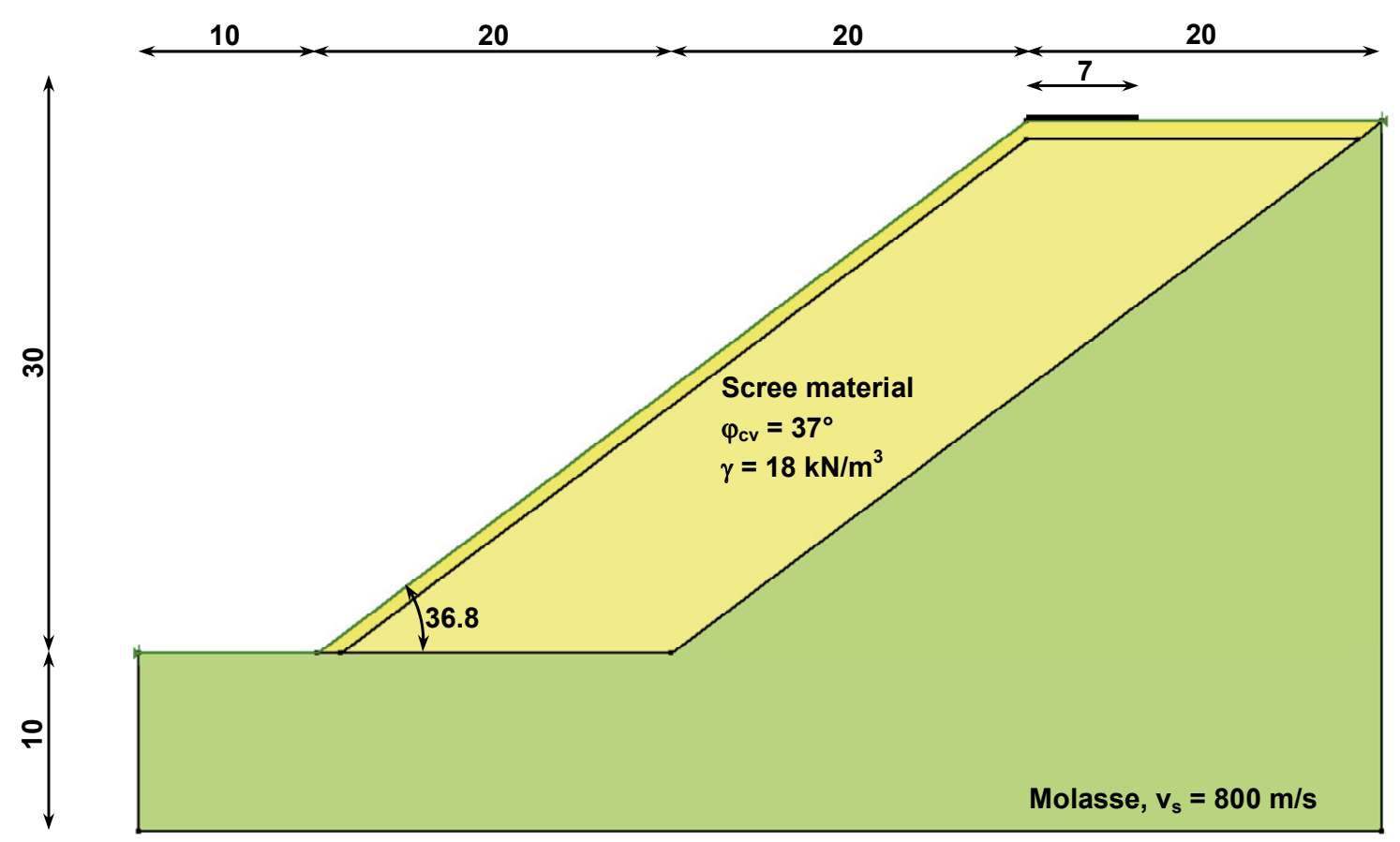

Figure 10.1. Schematic representation of the analysed slope.

\subsection{General assessment of the slope stability under static conditions}

The first step of the procedure is the general assessment of the slope stability. The comparison of the soil friction angle $\varphi_{c v}^{\prime}=37^{\circ}$ with the slope inclination $\alpha=36.8^{\circ}$ indicates the unstable state of the geotechnical structure. Eventual safety calculations under these boundary conditions are not relevant because the failure mechanisms will develop only at surface. On the other hand, there are also other factors which contribute to the slope stability, considering the obvious fact that the slope is stable under its own weight. These additional factors such as particle interlocking (dilatancy), suctions or vegetation can be accounted for using an increased mobilized friction angle. A global factor of safety $\mathrm{FS}_{\mathrm{g}}=$ 1.05 can be assumed to determine the mobilized friction angle, due to the fact that the slope creeps during events such as heavy rain. For steep slopes which are visibly stable $\mathrm{FS}_{\mathrm{g}}=1.1$ can be assumed. The back-calculation of the mobilized friction angle can be conducted under the assumption of an infinite slope:

$\mathrm{FS}_{\mathrm{g}}=\frac{\tan \left(\varphi_{\mathrm{cv}, \mathrm{mob}}^{\prime}\right)}{\tan (\alpha)}=\mathbf{1 . 0 5} \rightarrow \varphi_{\text {mob }}^{\prime}=\arctan (\mathbf{1 . 0 5} \cdot \tan (\alpha)) \approx \mathbf{3 9}^{\circ}$ 
For the given slope inclination $\alpha=36.8^{\circ}$, the mobilized friction angle corresponding to a global safety factor $\mathrm{FS}_{\mathrm{g}}=1.05$ is $\varphi_{\text {mob }}^{\prime} \approx 39^{\circ}$. The action of additional stabilising factors can often be guaranteed only in the surface layers and therefore the increased value of the friction angle was used in the calculations only for the first meter of scree material. The critical failure mechanism affects $2 \mathrm{~m}$ of the width of the road and the associated global factor of safety is $\mathrm{FS}_{\mathrm{g}}=1.07$ (Figure 10.2).

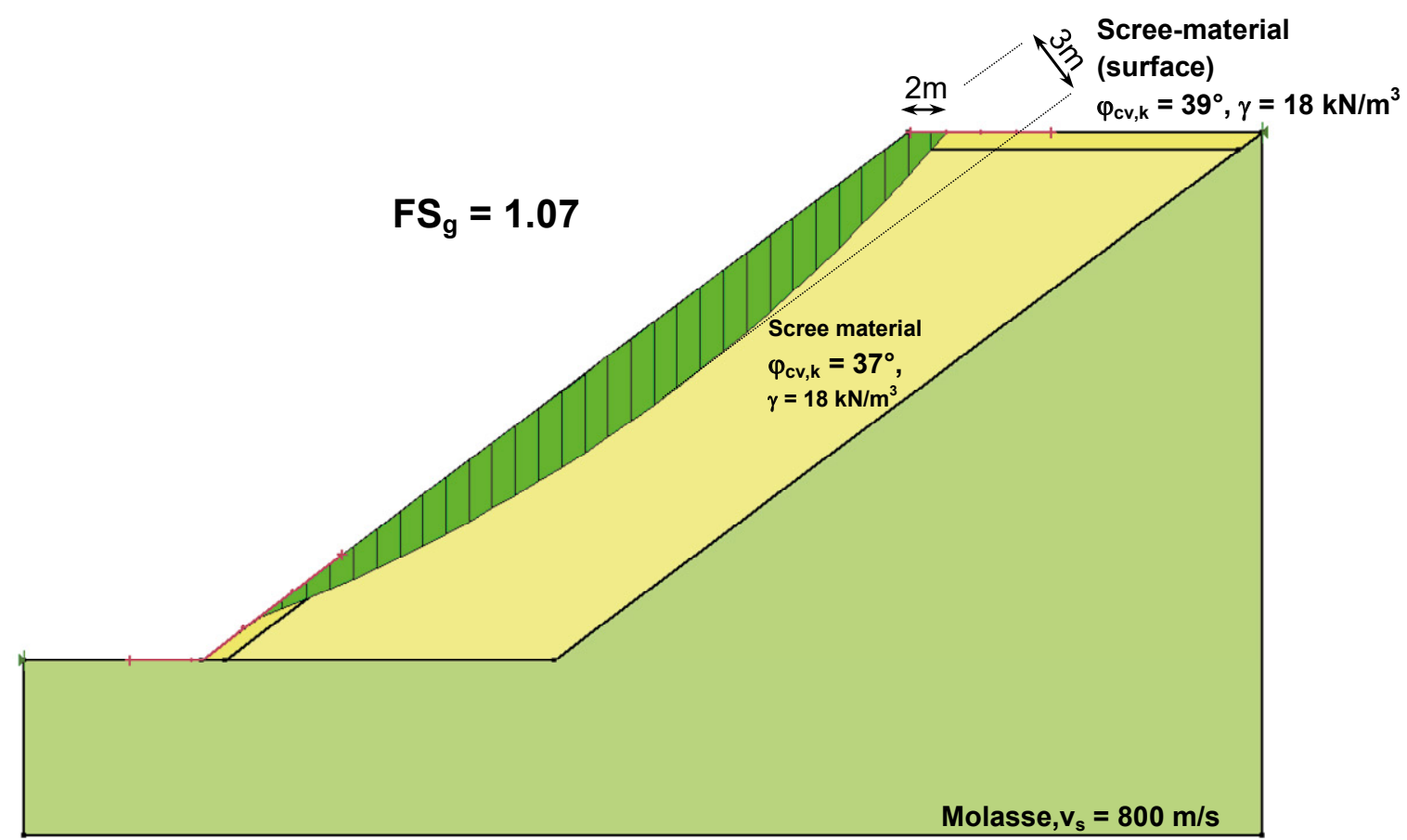

Figure 10.2. Critical failure mechanism and the corresponding global factor of safety of the analysed slope - GeoStudio (Krahn, 2012).

The plausibility of the identified critical failure mechanism can be verified with a $\mathrm{FE}$ analysis (Figure 10.3) by determining the global factor of safety using the phi-c reduction method (Brinkgreve et al., 2012). The FE analysis was stable only under the condition of an increased friction angle $\varphi_{\mathrm{mob}}^{\prime}=39^{\circ}$ in the entire soil mass in the slope. The convergence criterion of the phi-c reduction method is represented by the failure of the soil mass, marked by the development of large displacements for small reductions of the strength parameters. The safety determinations using this method are therefore questionable and the results should be critically interpreted, considering the initially unstable state of the slope. Nevertheless, the developed failure mechanism is almost identical with the one previously identified and the value of the global factor of safety $\mathrm{FS}_{\mathrm{g}}=$ 1.01 is in the same range with the value determined by the classical method of slices. These results confirm the employed assumptions as well as the concept of an increased mobilized friction angle. 


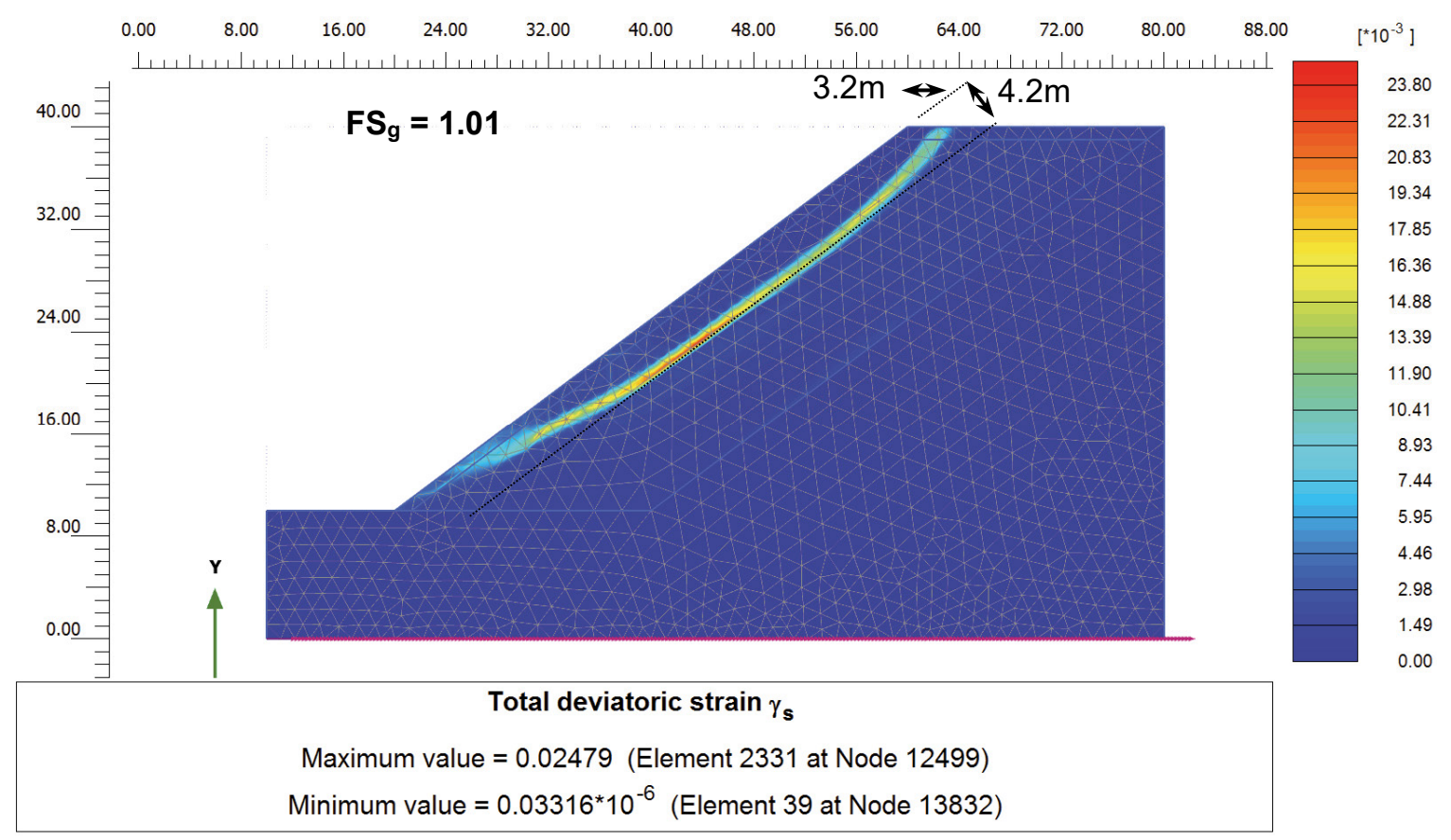

Figure 10.3. Failure mechanism and global factor of safety determined by the phi-c reduction method in PLAXIS 2012 (Brinkgreve et al., 2012).

The first step of general assessment of the static slope stability is summarized in Table 10.1.

Table 10.1. Summary of the general assessment of the slope stability under static conditions.

\begin{tabular}{lll}
\hline Method of assessment & FS $_{\mathbf{g}}$ & Observations \\
\hline Method of slices (GeoStudio 2012) & 1.07 & Increased $\varphi^{\prime}$ mob $=39^{\circ}$ in the surface layer $(1 \mathrm{~m})$ \\
Finite-element method & 1.01 & Increased $\varphi^{\prime}{ }_{\mathrm{mob}}=39^{\circ}$ in the entire slope \\
\hline
\end{tabular}

\subsection{Evaluation of the seismic global factor of safety}

The evaluation of the seismic global factor of safety using the seismic action from the design code SIA 261 (2014) is the second step of the procedure. The slope soil corresponds to the ground class BGK $C$, which has an amplification factor $S=1.15$. Considering the infrastructure function of the road at the top of the slope, an importance factor $\gamma_{\mathrm{f}}=1.2$ can be assumed for the determination of the maximal horizontal ground acceleration at the slope site:

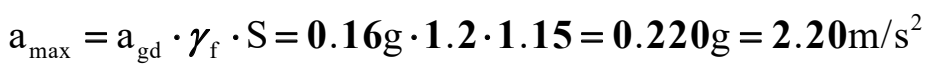


where $a_{\max } \quad$ - maximum horizontal ground acceleration at the slope site [g]

$\gamma_{f} \quad-$ importance factor of the construction work class [-]

$S \quad-$ amplification factor of the ground class [-].

The seismic global factor of safety of the investigated slope according to SIA 267 (2013) is $\mathrm{FS}_{\mathrm{d}}=0.85$ (Figure 10.4). Although this value is below 1.0, it doesn't necessarily imply the failure of the slope (Gazetas et al., 2014) but rather the development of seismic-induced displacements.

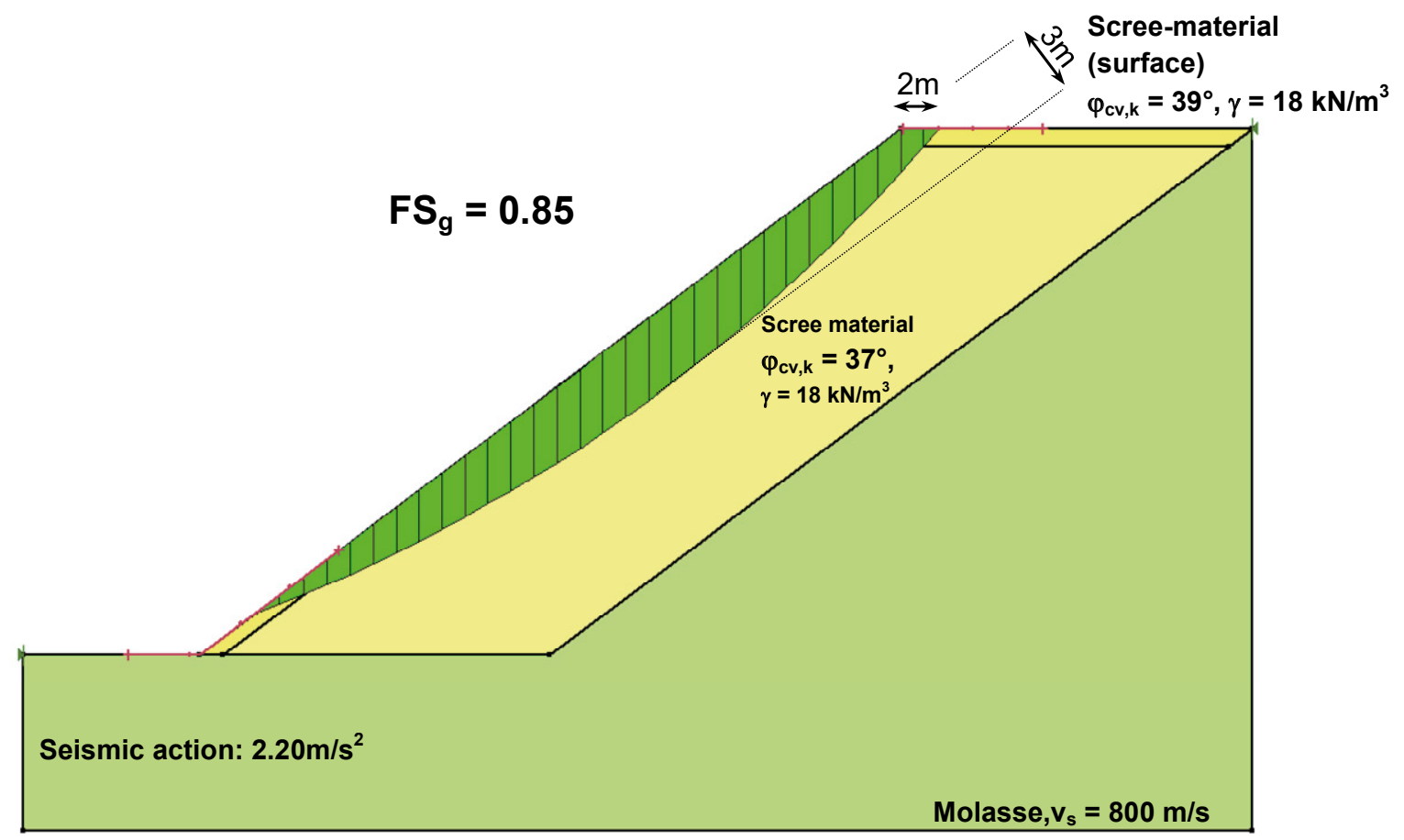

Figure 10.4. Critical failure mechanism and the corresponding global factor of safety under seismic action - GeoStudio (Krahn, 2012).

\subsection{Evaluation of the seismic displacements}

A further step in the evaluation of the seismic behaviour was made using the graphical tool for displacement estimation presented in Chapter 6. The input parameters are the slope inclination $\alpha=36.8^{\circ}$ and the soil friction angle $\varphi_{\text {mob }}^{\prime}=39^{\circ}$. For the maximal horizontal acceleration $a_{\max }=2.20 \mathrm{~m} / \mathrm{s}^{2}$ the expected earthquake induced displacement is between 10-100 cm (Figure 10.5). 
Zone 3b, BGK D, BWKI $\left(a_{\max }=2.20 \mathrm{~m} / \mathrm{s}^{2}\right)$

Displacement limit curves

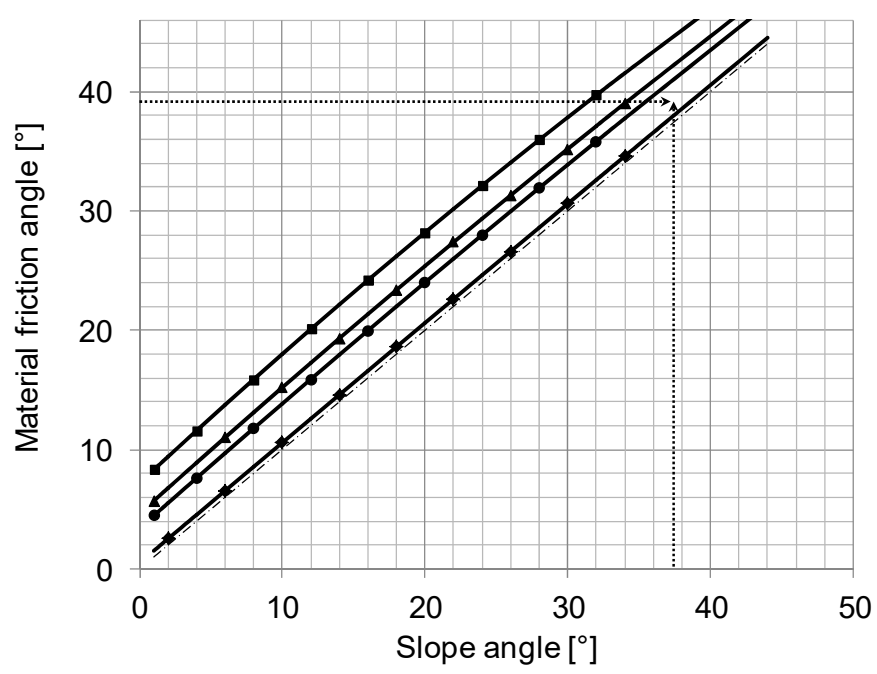

$-\cdots \mathrm{FS}=1$

$\rightarrow 1 \mathrm{~cm}$ Displacement limit curve

$\leftarrow 5 \mathrm{~cm}$ Displacement limit curve

$\rightarrow 10 \mathrm{~cm}$ Displacement limit curve

$\rightarrow 100 \mathrm{~cm}$ Displacement limit curve

Figure 10.5. Graphical displacement estimation for the investigated slope.

As the maximum allowed displacement is $30 \mathrm{~cm}$ and the variation of deformations with the different positions in Figure 10.5 is not linear, a more accurate approach on the expected deformations of the slope in case of an earthquake is required.

A more accurate evaluation of the seismic displacement of the slope can be made in the next step using the regression relationship suggested in Chapter 6 as an upper bound of the earthquake induced displacements.

$\mathrm{d}=2 \cdot 2.54 \cdot 10^{\left(-1.51-0.74 \log \left(\frac{\mathrm{a}_{\text {crit }}}{\mathrm{a}_{\text {max }}}\right)+3.27 \log \left(1-\frac{\mathrm{a}_{\text {crit }}}{\mathrm{a}_{\max }}\right)-0.80 \log \left(\frac{\mathrm{a}_{\max }}{\mathrm{g}}\right)+1.59 \log (\mathrm{PGV})\right)}$

The critical acceleration of the slope, namely the acceleration at which irreversible deformations start to occur, corresponds to a global seismic factor of safety $\mathrm{FS}_{\mathrm{g}}=1.0$ and is $a_{\text {crit }}=0.3 \mathrm{~m} / \mathrm{s}^{2}$. Using this value and the assumption that $P G V=30 \cdot a_{\max } / \mathrm{g}$, the expected seismic displacement of the slope can be determined: $d=28.65 \mathrm{~cm}$. As in the previous case the accuracy of this result is dependent on the compatibility of the failure mechanism with the sliding-block assumption introduced by Newmark (1965). If no additional partial safety factors are considered, the seismic displacements $d=28.65 \mathrm{~cm}$ are smaller than the maximum allowed deformations of $d_{\max }=30 \mathrm{~cm}$. However, $a$ separate dynamic FE analysis will be conducted to verify the plausibility of the performed calculations. 


\subsection{Detailed numerical analysis of the seismic behaviour of the slope}

The last step in the procedure of evaluation of the seismic behaviour is a dynamic FEanalysis using e.g. the software package PLAXIS 2D (Brinkgreve et al., 2012). The results of this analysis offer a more accurate overview of the seismic deformations and their distribution in the slope, which is a very important factor in the behaviour and risk evaluation.

\subsubsection{Numerical FE model}

The numerical model of the slope corresponds to the geometry and geology presented in the previous section. The generated FE mesh and the boundary conditions can be seen in Figure 10.6. An average element size of $1.05 \mathrm{~m}$ provides compliance with the accuracy criterion for finite element analyses introduced by Kuhlemeyer \& Lysmer (1973). The boundary conditions at the sides of the model are free-field elements and at the bottom, a compliant base was introduced (Brinkgreve et al., 2012). The seismic action was applied as a prescribed displacement at the compliant base of the model.

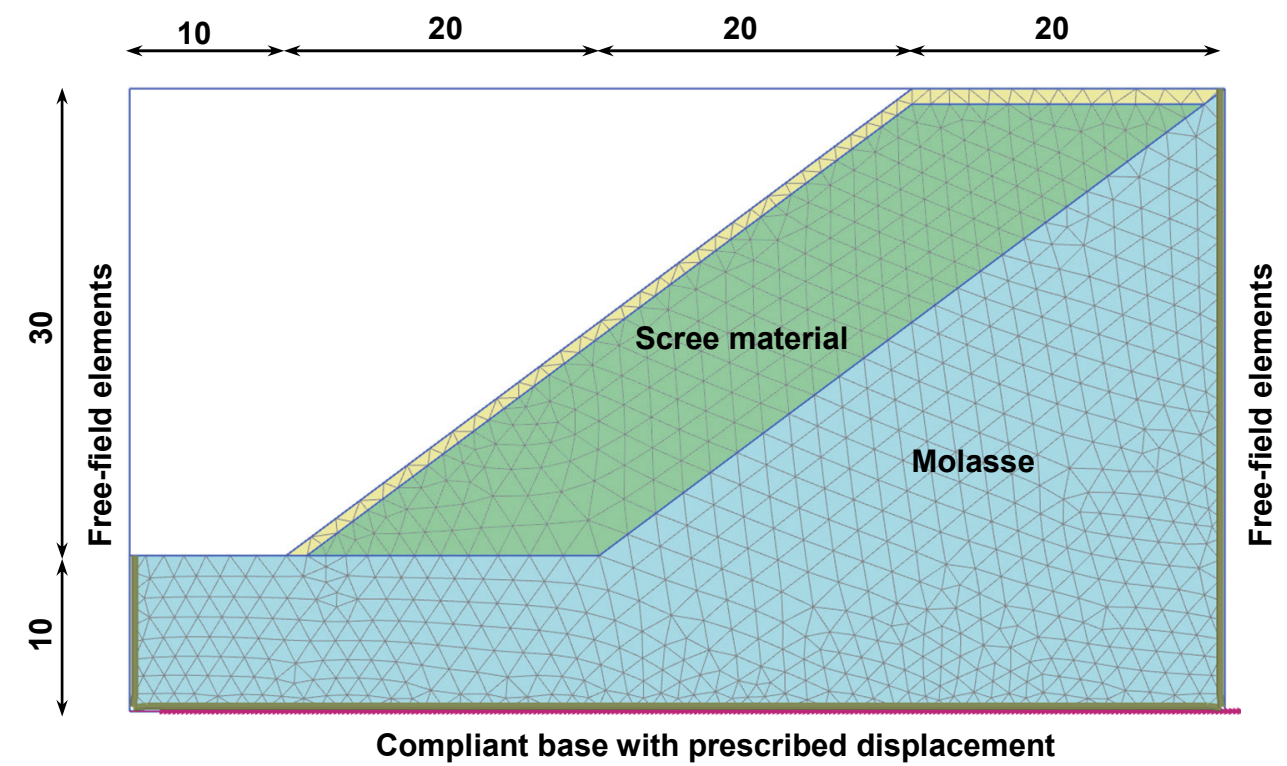

Figure 10.6. Generated FE mesh and applied boundary conditions.

\subsubsection{Constitutive models}

The constitutive model used in the analysis was Hardening Soil-Small Strain (HS-Small) (Brinkgreve et al., 2012). This model takes into account the small strain stiffness available in the range of very low strains and the stiffness decay with the increase of the shear strain. The increase of the stiffness with the effective stresses is also implicitly modelled without any additional input. A frequency dependent material damping of $5 \%$ was introduced in the system using Rayleigh parameters (Rayleigh \& Lindsay, 1945), in addition to the hysteretic damping modelled by HS-Small. 
The rock mass was modelled using a linear elastic constitutive model, considering the fact that its stiffness is relatively high $\left(v_{s}=800 \mathrm{~m} / \mathrm{s}\right)$. Rayleigh parameters corresponding to a damping of $0.5 \%$ were introduced for this soil as well, because the linear elastic model does not account for any kind of damping.

A summary of the soil parameters can be found in Tables 10.2 and 10.3.

Table 10.2. Soil parameters for the scree material.

Unsaturated unit weight $\gamma_{\text {unsat }}$

$18 \mathrm{kN} / \mathrm{m}^{3}$

Saturated unit weight $\gamma_{\text {sat }}$

$18 \mathrm{kN} / \mathrm{m}^{3}$

Power coefficient for the stress level dependency of the stiffness $m \quad 0.5$

Secant stiffness in the standard drained triaxial test $E_{50}$ ref

$50 \mathrm{MPa}$

Tangent stiffness for primary oedometer loading $E_{o e d}{ }^{r e f}$

$50 \mathrm{MPa}$

Unloading / reloading stiffness $E_{u r}$ ref

$226 \mathrm{MPa}$

Poisson's ratio for unloading/reloading $U_{u r}$

0.2

Reference shear modulus at very small strains $G_{0}$ ref

$94.21 \mathrm{MPa}$

Shear strain for a $30 \%$ reduction of the shear modulus $\gamma_{0.7}$

0.007

Cohesion $c^{\text {ref }}$

$1 \mathrm{kN} / \mathrm{m}^{2}$

Effective friction angle $\varphi^{6}$

$39^{\circ}$

Dilatancy $\psi$

$0^{\circ}$

Rayleigh coefficient $\alpha_{R}$

Rayleigh coefficient $\beta_{R}$

$2.091 \cdot 10^{-3}$

Table 10.3. Material parameters for the rock (molasse)

Unsaturated unit weight $\gamma_{u n s a t}$

Saturated unit weight $\gamma_{\text {sat }}$

Axial stiffness $E$

Shear stiffness $G$

Poisson's ratio $v$

Shear wave velocity $v_{s}$

Rayleigh-Beiwert $\alpha_{R}$

Rayleigh-Beiwert $\beta_{R}$
$23 \mathrm{kN} / \mathrm{m}^{3}$

$23 \mathrm{kN} / \mathrm{m}^{3}$

$3.605 \mathrm{GPa}$

$1.502 \mathrm{GPa}$

0.2

$800 \mathrm{~m} / \mathrm{s}$

2.945

$6.366 \cdot 10^{-6}$ 


\subsubsection{Seismic action}

A set of seven different earthquake signals (BGK_C_1 through BGK_C_7) was prepared to meet the code specifications related to the earthquake hazard (SIA 261, 2014). Thus, in a first step, a frequency modulation was performed to match the response spectrum of each earthquake signal with the elastic spectrum of soil class BGK C, according to SIA 261 (2014) Subsequently the amplitude of each earthquake signal was reduced to $50 \%$. After this processing stage, the obtained earthquake signals were applied at the compliant base of the model, generating seven sets of results. These results were at the end summarized and the average values were analysed.

\subsubsection{Verification of the modelled seismic action}

The output of the seven different FE analyses was verified and its plausibility was checked before proceeding to the interpretation and comparison of the results. For this purpose different points were defined across the model and the average output response spectra in these points were compared with $90 \%$ of the corresponding elastic response spectrum according to SIA 261 (2014). The location of the control points can be seen in Figure 10.7.

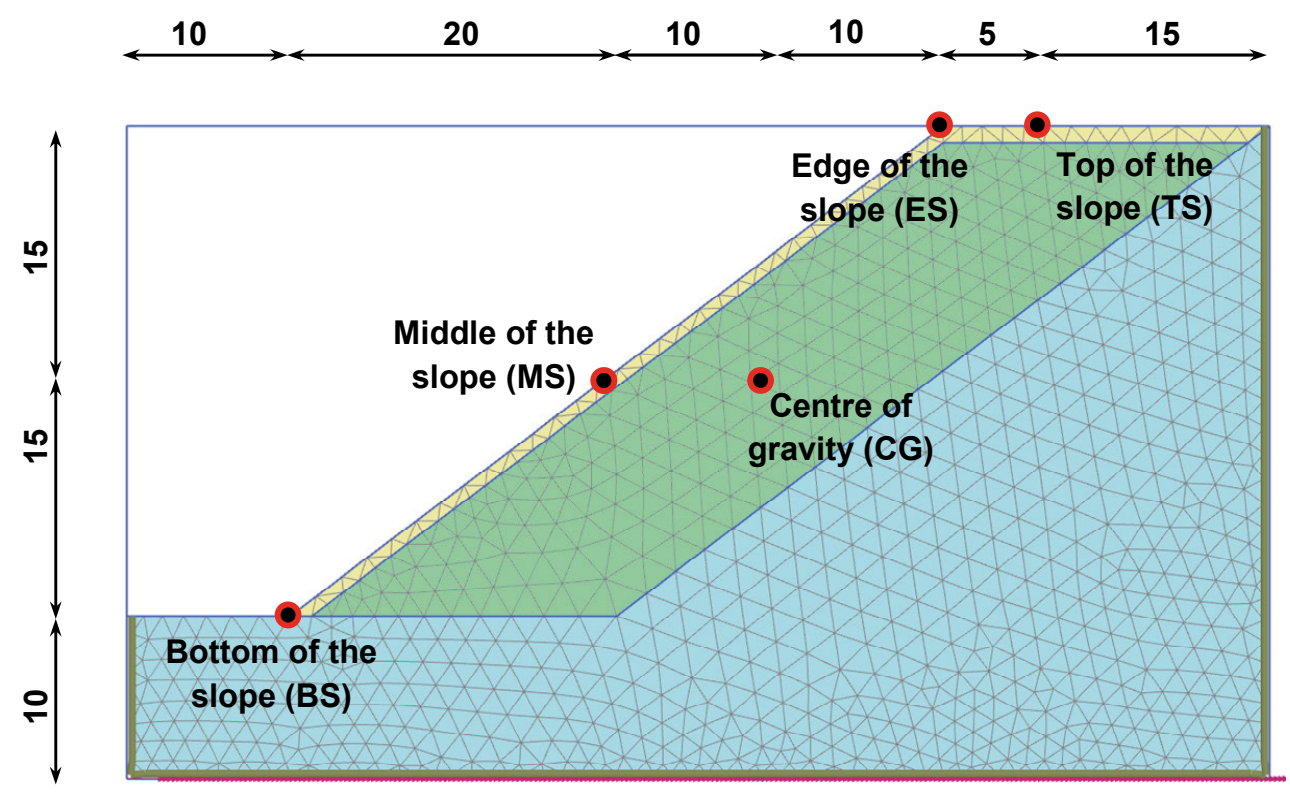

Figure 10.7. Control points for the verification of the results of the analysis.

The seismic signal at the bottom of the slope (BS) is the first to be compared with the corresponding elastic response spectrum according to SIA 261 (2014). The reference response spectrum for this point located on the rock outcrop, is the one for the ground class A (rock), seismic zone Z3b and importance class BGK II. The very good match between the two spectra can be observed in Figure 10.8. The modelled seismic action at the bottom of the slope tends to be conservative for the longer periods $\mathrm{T}>0.4 \mathrm{~s}$. 


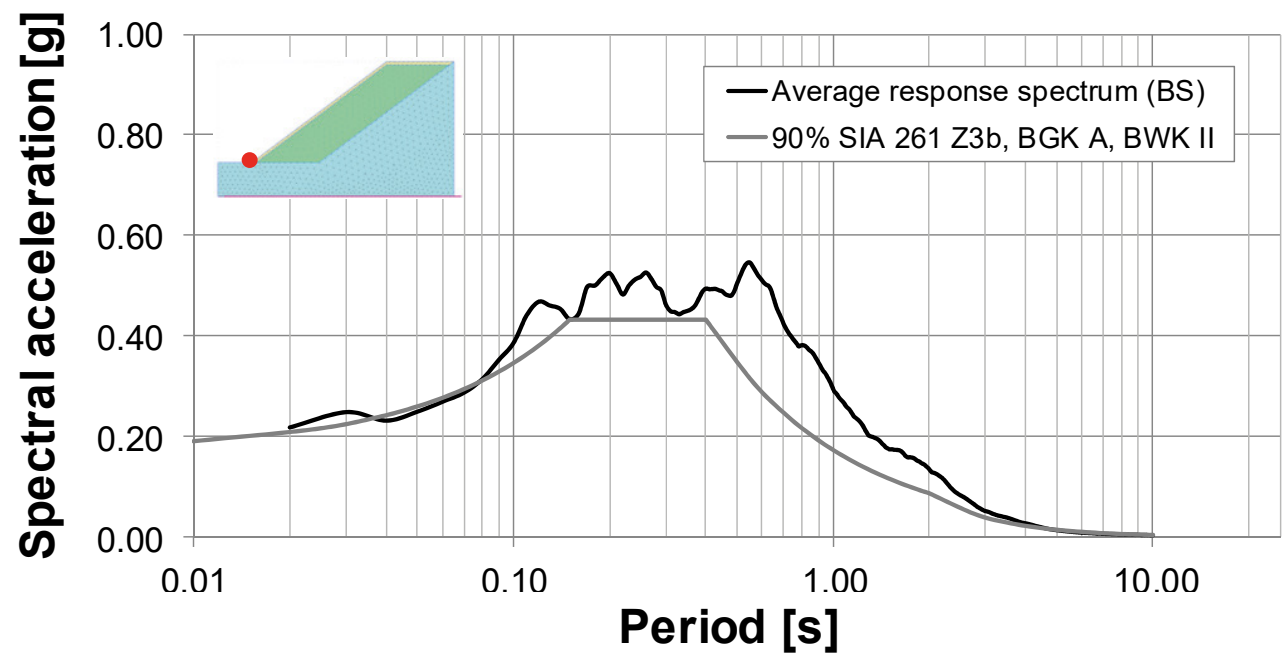

Figure 10.8. Average response spectrum at the bottom of the slope (BS) and $90 \%$ of the elastic response spectrum for seismic zone Z3b, BGK A, BWK II according to SIA 261 (2014).

The following point to be analysed is in the centre of gravity of the slope (CG). The reference spectrum will be the one for the ground class $C$, taking into account the geological conditions in the slope mass. A very good agreement between the modelled seismic action and the one defined by the design code can be observed for this point for almost the entire range of periods (Figure 10.9).

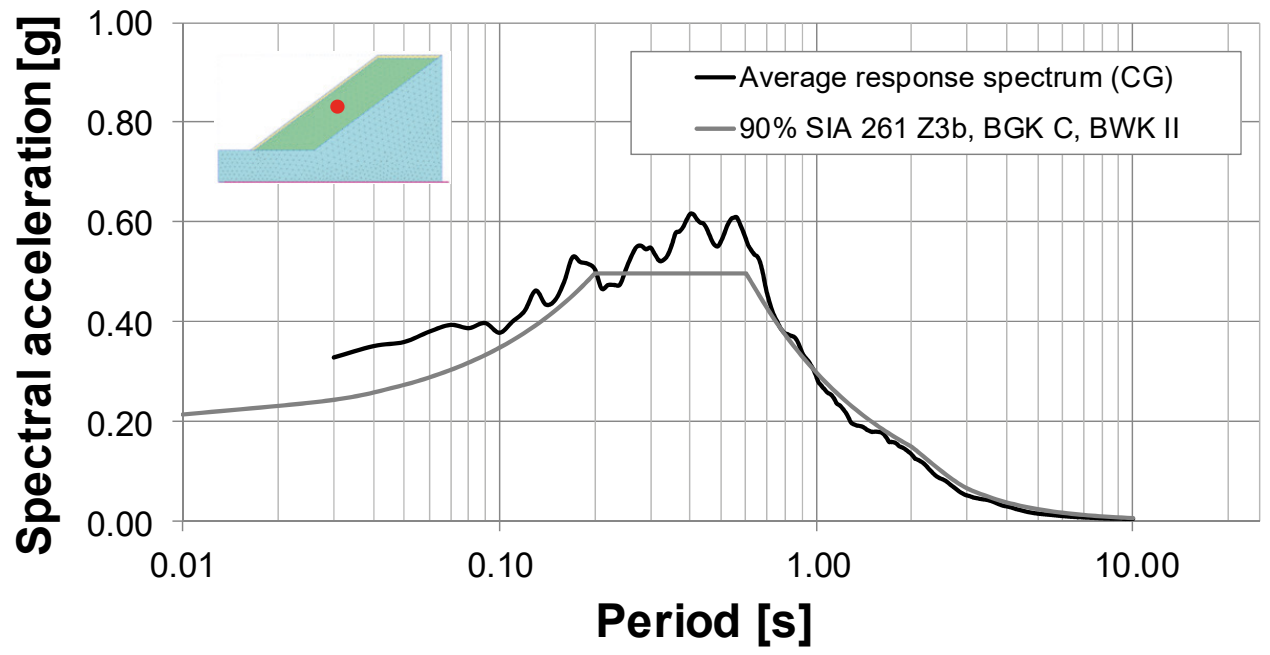

Figure 10.9. Average response spectrum in the centre of gravity of the slope (CG) and $90 \%$ of the elastic response spectrum for seismic zone Z3b, BGK A, BWK II according to SIA 261 (2014).

A further control point is at the surface, in the middle of the slope (MS). The modelled accelerations in this point are significantly higher than the reference spectrum for periods $\mathrm{T}<0.2 \mathrm{~s}$ (Figure 10.10). The same effect can be observed for the top of the slope (TS) where the modelled accelerations exceed the reference spectrum up to a period of $0.7 \mathrm{~s}$ (Figure 10.11). These effects are not surprising and they can be explained by a com- 
bination of topographic effects (e.g. Aki, 1988; Pedersen et al., 1994) confirming the plausibility of the numerical model and its underlying assumptions.

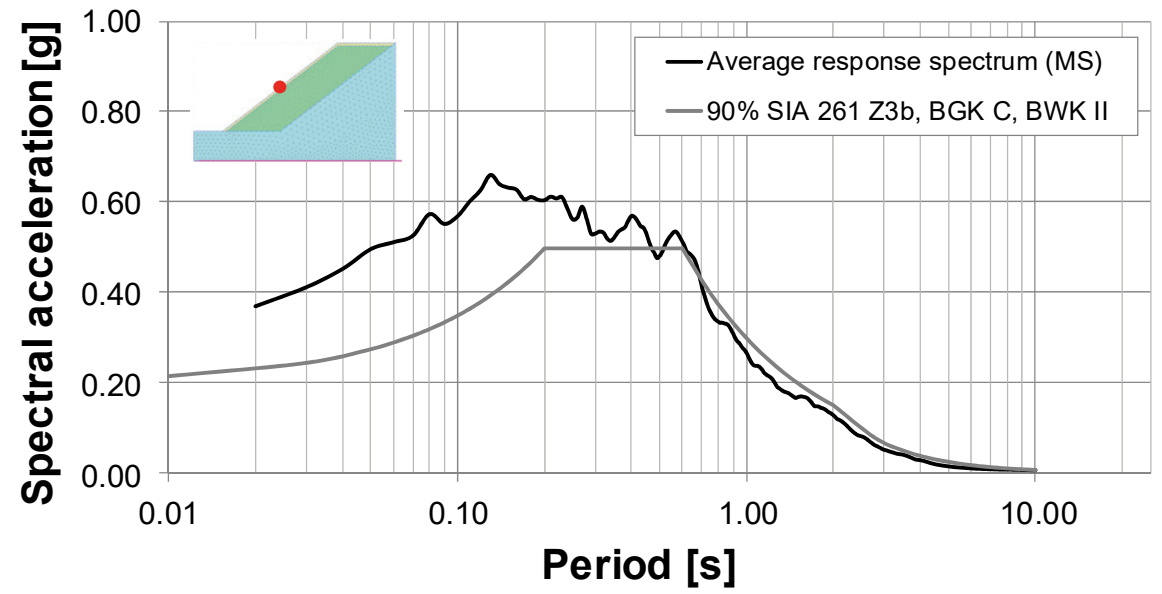

Figure 10.10. Average response spectrum in the middle of the slope (MS) and $90 \%$ of the elastic response spectrum for seismic zone Z3b, BGK A, BWK II according to SIA 261 (2014).

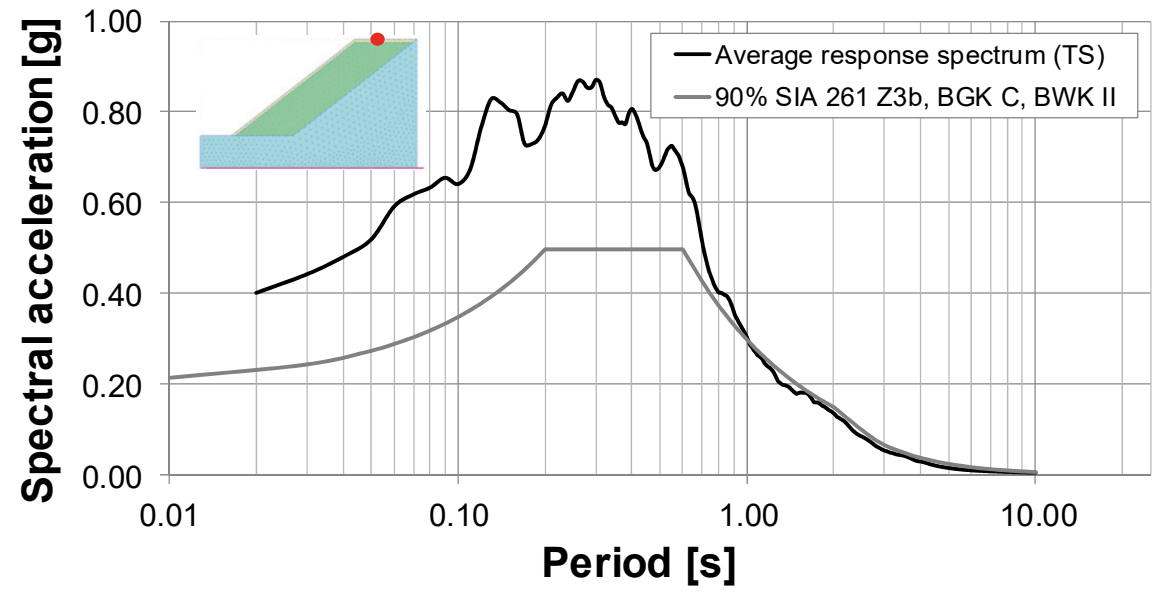

Figure 10.11. Average response spectrum on the top of the slope (TS) and $90 \%$ of the elastic response spectrum for seismic zone Z3b, BGK A, BWK II according to SIA 261 (2014).

The results of the numerical simulations can be considered plausible, as the modelled spectral accelerations at the bottom of the slope (BS) and in the centre of gravity (CG) fit the corresponding reference spectra according to SIA 261 (2014). The modelled displacements can be compared with the results of the analytical approaches presented in the previous section, based on the compliance of the modelled seismic actions with the code specifications. 


\subsubsection{Results of the numerical simulations}

The interpretation of the results from the numerical investigations will be made based on the average displacements obtained with the seven input signals. However, the specific diagrams such as shear strain and displacement distributions are illustrated only for the input signal BGK_C_1 (Figure 10.12).

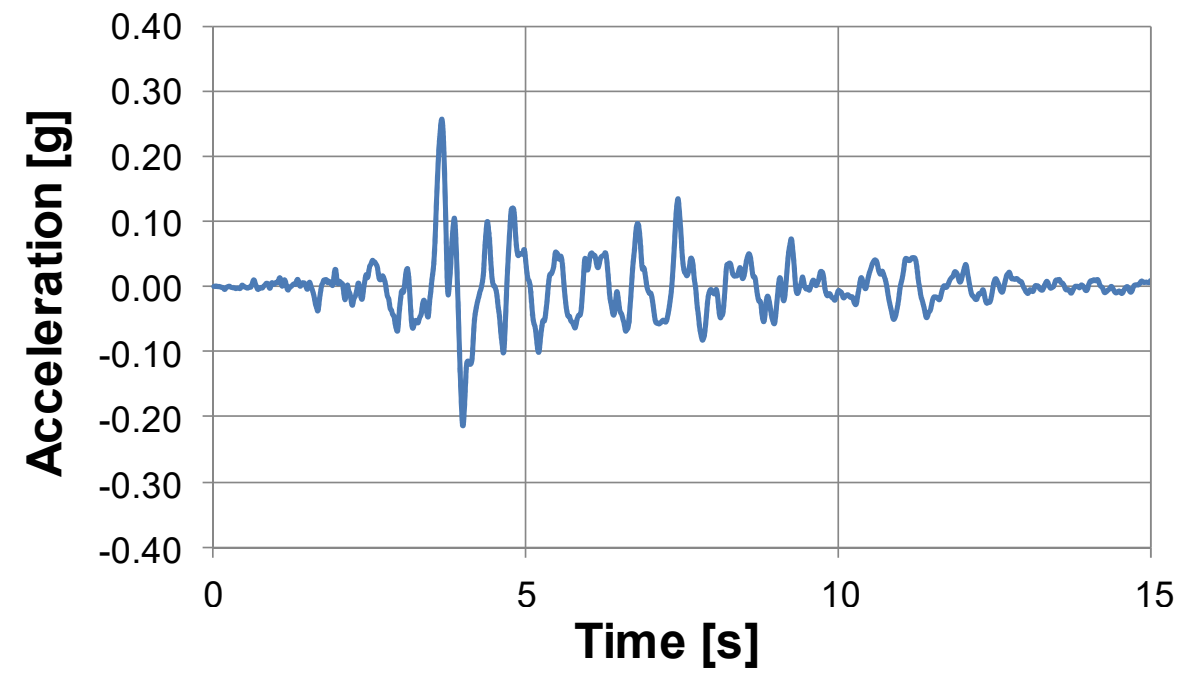

Figure 10.12. Input signal BGK_C_1 used for the seismic analysis.

The shear strains developed in the slope due to the seismic action are concentrated along the critical failure surface identified in the previous sections (Figure 10.3). A plot of the residual strains for the input signal BGK_C_1 can be seen in Figure 10.13. The strains developed in the range of $12 \%$ and they point to the unstable state of the slope.

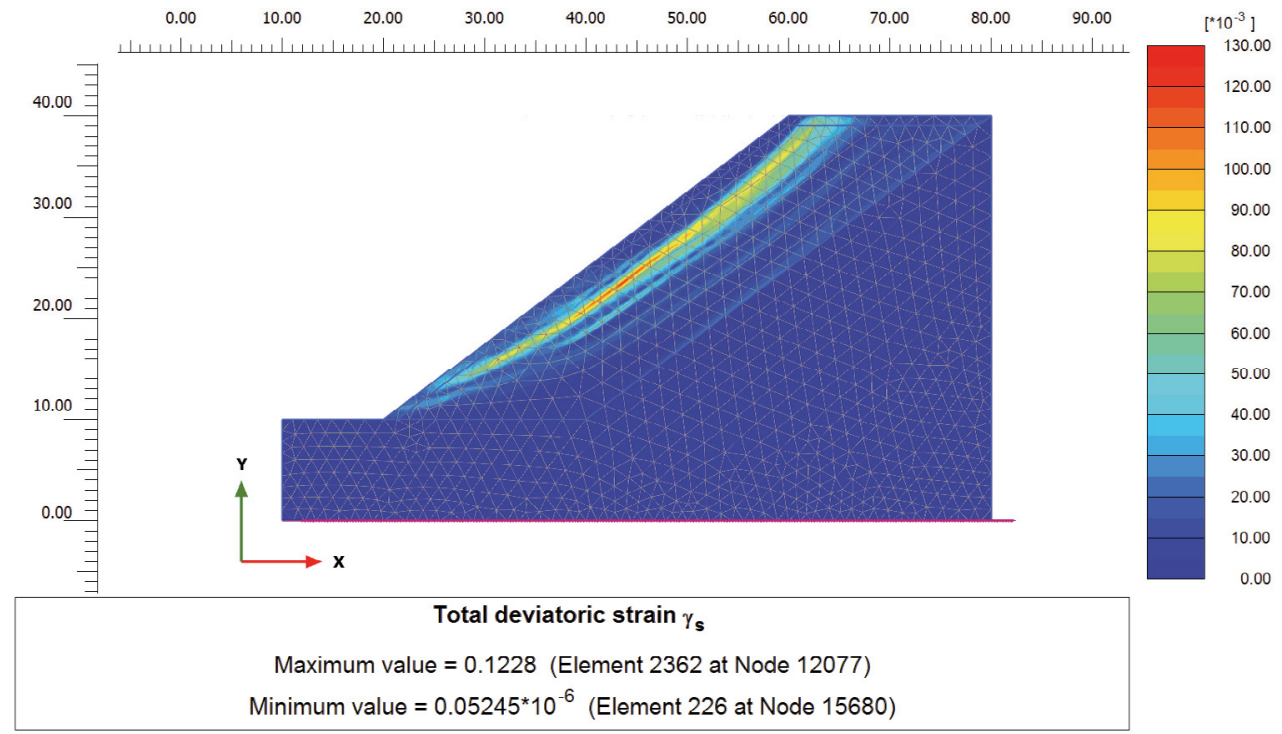

Figure 10.13. Residual shear strains for the input signal BGK_C_1. 
The plot of the total displacements and their distribution at the top of the slope are a good indicator of the seismic behaviour of the investigated geotechnical structure. Figure 10.14 shows the total displacements (the vector sum of the horizontal and vertical displacements) in the slope. The modelled deformations at the base of the slope are negligible and they pose no threat to other infrastructure objects located in that area.

The distribution of the deformations at the top of the slope is gradual without any concentrated offsets and has a maximum absolute value of approx. $48 \mathrm{~cm}$ (Figure 10.15). The maximum differential settlement of the overlying road is approx. $34.2-10.6 \approx 24 \mathrm{~cm}$. This value is smaller than the maximum allowed values of $d_{\max }=30 \mathrm{~cm}$ and it confirms the previously estimated seismic deformation of the slope of $d=28.65 \mathrm{~cm}$ (see Chapter 10.5).

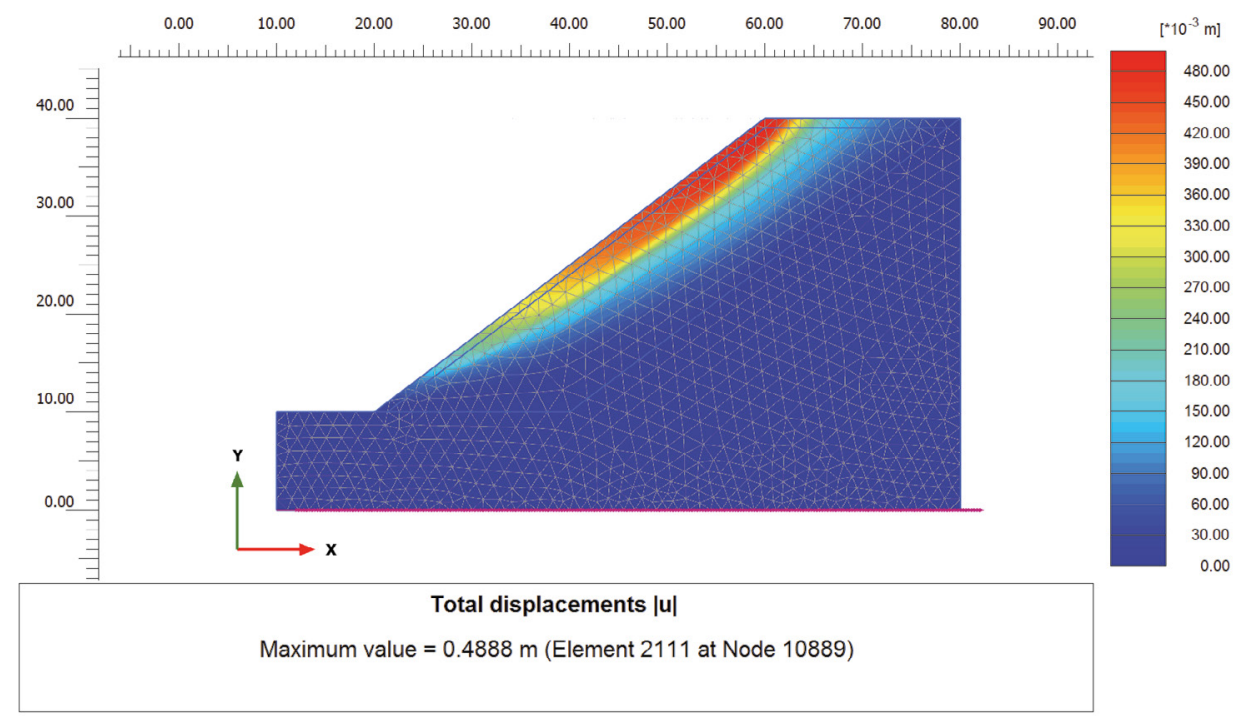

Figure 10.14. Residual total displacements of the slope for the input signal BGK_C_1.

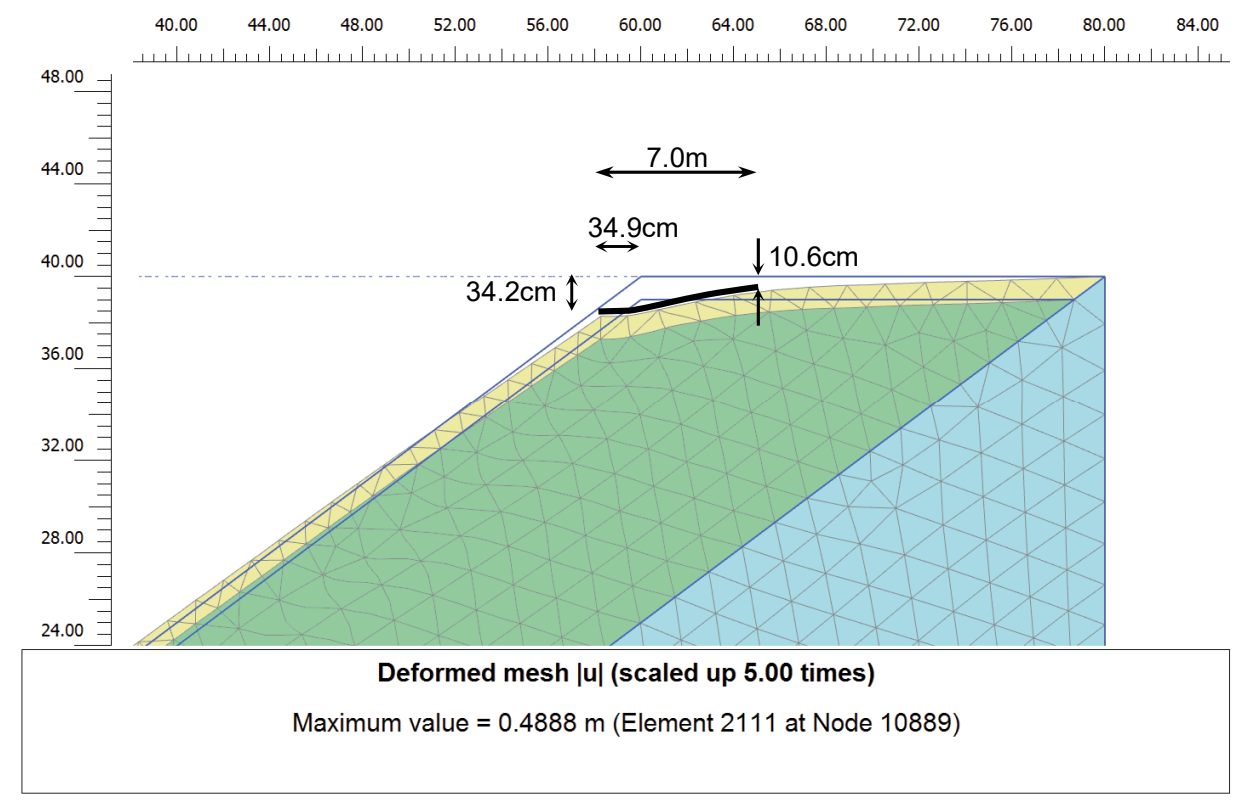

Figure 10.15. Distribution of the total displacements at the top of the slope for the input signal BGK_C_1. 
A statistical approach with an average value of the differential settlements for the seven input signals finalised the analysis (Table 10.4). The average value of the differential settlement at the top of the slope is $28.1 \mathrm{~cm}$ which is smaller than the maximum allowed differential settlement $d_{\max }=30 \mathrm{~cm}$. These values are in the same range with the previously estimated seismic deformations and they confirm the reliability of the suggested methodology. In comparison with the previous steps, the numerical analysis provides more accurate results and more specific information, such as the distribution of the displacements complementing, when necessary and if required, the graphical and analytical steps presented in previous sections.

Table 10.4. Statistical evaluation of the differential settlements at the top of the slope.

\begin{tabular}{|c|c|c|}
\hline Input signal & & Differential settlement [cm] \\
\hline BGK_C_1 & & 23.6 \\
\hline BGK_C_2 & & 30.9 \\
\hline BGK_C_3 & & 22.9 \\
\hline BGK_C_4 & & 40.9 \\
\hline BGK_C_5 & & 25.5 \\
\hline BGK_C_6 & & 22.0 \\
\hline BGK_C_7 & & 31.2 \\
\hline & Average value & 28.1 \\
\hline
\end{tabular}

\subsection{Conclusion and discussion}

The presented procedure approaches the problem of steep slopes using simple concepts based on the compatibility of the developing failure mechanisms with Newmark's slidingblock assumption. This assumption is well suited for the large majority of earthquake-triggered landslides, as indicated by Keefer $(1984 ; 2002)$ in his analyses of data from worldwide earthquakes.

The complexity of the evaluation steps increases from a graphical tool of displacement estimation, to a regression relationship for the upper bound of displacements, and a FE analysis. The accuracy of the results also increases with the complexity of each step (Table 10.5). The validity of the graphical and analytical results can be verified using FE investigations with seismic input signals compliant with design code specifications.

Table 10.5. Summary the evaluation of the seismic behaviour of the slope.

\begin{tabular}{|c|c|c|}
\hline Procedure step & Outcome & Observations \\
\hline $\begin{array}{l}\text { Limit equilibrium calculation } \\
\text { according to SIA } 267 \text { (2013) }\end{array}$ & $\mathrm{FS}_{\mathrm{d}}=0.85$ & $\begin{array}{l}\text { The sub-unitary value does not } \\
\text { necessarily imply the failure of the slope. }\end{array}$ \\
\hline $\begin{array}{l}\text { Graphical evaluation of the } \\
\text { displacements }\end{array}$ & $d=10-100 \mathrm{~cm}$ & $\begin{array}{l}\text { Estimation of the order of magnitude of } \\
\text { the seismic-induced displacements. }\end{array}$ \\
\hline $\begin{array}{l}\text { Regression curve for } \\
\text { displacement evaluation }\end{array}$ & $\mathrm{d}=28.6 \mathrm{~cm}$ & $\begin{array}{l}\text { Approximation of the seismic-induced } \\
\text { displacements of the investigated slope. }\end{array}$ \\
\hline FE analysis using PLAXIS 2D & $d_{a v g}=28.1 \mathrm{~cm}$ & $\begin{array}{l}\text { Evaluation of the distribution of } \\
\text { displacements in the slope }\end{array}$ \\
\hline
\end{tabular}


Large sets of infrastructure objects can be rapidly evaluated and priorities for further investigations can be set based on the magnitude of displacements obtained using the graphical tool (Figure 10.5). In situations in which a more accurate evaluation of displacements is required, the regression relationship can be used on the condition that the developing failure mechanism is compatible with the sliding-block assumption. Alternatively, a FE analysis can be performed if the compatibility with the sliding-block assumption is not given or if more detailed information related to the distribution of seismic displacements is required,.

The concept of an increased mobilized friction angle, based on an increased global factor of safety provides reliable results. The main argument for the use of an augmented friction angle is the conservatism incorporated in the characteristic value of this parameter. This is usually determined as a critical state parameter, which already includes a safety margin and, in addition to that, the existence of additional stabilising factors such as dilatancy, suctions, vegetation, etc. cannot be neglected.

However, the reliability of the calculated displacements under the assumption of an augmented friction angle is given only after the verification of the mechanical compatibility of the obtained seismic-induced displacements with the additional stabilizing factors (See Chapter 6.4). For example, if suctions due to unsaturated soil conditions are the additional stabilising factors in the slope, their mechanical compatibility with the seismic-induced displacements has to be verified. This can be performed using laboratory investigations as showed in Chapter 2.

The procedure presented above using the calculation example confirms once more the concepts related to the sub-unitary seismic factors of safety. As stated by Gazetas et al. (2014), "the consequence of $F_{E}<1$ is a finite inelastic (permanent) deformation of the system: rotation, horizontal, vertical displacement of foundations, slippage of retaining walls and slope wedges". The limitations of the pseudo-static methods in this kind of situations can be totally avoided using displacement-based approaches. Concepts such as maximum displacements, distribution of displacements, etc. become more important and decisive in the design or verification process, giving less relevance to the calculation of safety factors in the classical meaning. This also opens the way for the latest trends in the development of design codes, which advance in the direction of performance-based design, complementing the classical capacity design. As an example, the Swiss code for the basis of structural design (SIA 260, 2003) states that the service criteria agreement, which is the base for the design process of a structure, "shall be formulated on the basis of a dialogue between the owner and the design engineers".

\subsection{Acknowledgements}

This calculation example is a partial summary of the work performed within the project "Earthquake and Geotechnics" initiated and financed by the Federal Office for the Environment (FOEN), the Swiss Federal Railways (SBB) and the Federal Roads Office (FEDRO). 


\subsection{References}

Aki, K. (1988) Local site effects on strong ground motion. In: JL van Thun (ed), Earthquake Engineering and Soil Dynamics II - Recent Advances in Ground Motion Evaluation. pp. 103-155.

Ambraseys, N.N. \& Menu, J.M. (1988) Earthquake-induced ground displacements. Earthquake Engineering and Structural Dynamics, 16. pp. 985-1006.

Anderson, D.G., Geoffrey, R.M., Ignatius, L. \& Wang, J.N. (2008) Seismic Analysis and Design of Retaining Walls, Buried Structures, Slopes, and Embankments. National Cooperative Highway Research Program, NCHRP Report 611. Transportation Research Board, Washington, D.C.

Brinkgreve, R.B.J., Engin, E. \& Swolfs, W.M. (2012) Plaxis 2D 2012 Manual. Delft, Netherlands.

Dakoulas, P. \& Gazetas, G. (1986) Seismic shear strains and seismic coefficients in dams and embankments. Soil Dynamics and Earthquake Engineering, 5(2). pp. 75-83.

Franklin, A.G. \& Chang, F.K. (1977) Permanent displacements of earth embankments by Newmark sliding block analysis. Report 5. Miscellaneous paper S-71-17. US Army Corps of engineers Waterways Experiment Station, Vicksburg, Mississippi.

Gazetas, G., Anastasopoulos, I. \& Garini, E. (2014) Geotechnical design with apparent seismic safety factors well-below 1. Soil Dynamics and Earthquake Engineering, 57. pp. $37-45$.

Keefer, D.K. (1984) Landslides caused by earthquakes. Geological Society of America Bulletin, 95. pp. 406-421.

Keefer, D.K. (2002) Investigating landslide caused by earthquakes - a historical review. Surveys in Geophysics, 23. pp. 473-510.

Krahn, J. (2012) Geo-Studio user manuals. GEO-SLOPE International, Ltd. (Pub), Calgary, CA.

Makdisi, F.I. \& Seed, H.B. (1978) Simplified procedure for estimating dam and embankment earthquake-induced deformations. Journal of the Geotechnical Engineering Division ASCE, 104(GT7). pp. 849-867.

Marcuson, W.F., III. (1981) Moderator's report for session on "Earth dams and stability of slopes under dynamic loads". In: Proceedings of the International conference on recent advances in geotechnical earthquake engineering and soil dynamics. St. Louis, Missouri. Vol. 3. pp. 1175. 
Marin, A. \& Laue, J. (2016) Displacement-Based Seismic Analysis of Slopes, Dams and Embankments. Journal of Earthquake and Tsunami 10 (1). DOI: 10.1142/ S1793431116500056.

Newmark, N.M. (1965) Effects of earthquakes on dams and embankments. Géotechnique, 15 (2). pp. 139-160.

Pedersen, H., Le Brun, B., Hatzfeld, D., Campillo, M. \& Bard, P.-Y. (1994) Ground motion amplitude across ridges. Bulletin of the Seismological Society of America 84(6). pp. 17861800.

Rayleigh, J.W.S. \& Lindsay, R.B. (1945) The Theory of Sound. Dover Publications, New York.

Sarma, S.K. (1975) Seismic stability of earth dams and embankments. Géotechnique, 25. pp. 743-761.

Seed, H.B. (1979) Considerations in the earthquake-resistant design of earth and rockfill dams. Géotechnique 29(3). pp. 215-263.

Seed, H.B. \& Martin, G.R. (1966) The seismic coefficient in earth dam design. Journal of Soil Mechanics and Foundations Division ASCE, 92 (SM3). pp. 25-58.

SIA 260 (2003) Basis of structural design. Swiss Society of Engineers and Architects. Zurich.

SIA 267 (2013) Geotechnical Design. Swiss Society of Engineers and Architects. Zurich.

SIA 261 (2014) Actions on Structures. Swiss Society of Engineers and Architects. Zurich.

Terzaghi, K. (1950) Mechanisms of landslides. Application of Geology to Engineering Practice, Berkeley Volume. Geological Society of America. pp. 83-123. 



\title{
11. Appendix II. Sicherungsmassnahmen der Rhone-Dämme
}

\author{
Alexandru Marin \\ ETH Zürich, Institute for Geotechnical Engineering, \\ Stefano-Franscini-Platz 5, 8093 Zürich, Switzerland \\ E-mail address: amarin@ethz.ch
}

Submitted to the Swiss Geotechnical Association (Geotechnik Schweiz)

Status: published on the $16^{\text {th }}$ of May 2014 


\section{Abstract}

There is an increasing need of evaluating the seismic behaviour of flood protection measures (e.g. Rhone dams) in the context of fast development of buildings and infrastructure in alpine areas. The identification of critical points in already existing systems and the design of new protection measures are of great importance. In addition to that, the evaluation of the seismic behaviour of retrofitted systems is decisive for general risk assessment and further development of the infrastructure. For the specific case of the Rhone dams two alternative retrofitting measures are planned: sheet-piles and mixed-inplace (MIP) walls. These measures aim to improve the flood protection capacity of the existing dams according to the latest dam safety regulations. The current study investigates the seismic behaviour of Rhone dams both with and without the planned retrofitting measures. The results show the main advantages and disadvantages in each situation, facilitating a future decision about the most appropriate retrofitting measure.

Keywords: seismic analysis, non-linear behaviour, soil-structure interaction, river dams 


\subsection{Einleitung}

Im Zusammenhang mit der starken Siedlungs- und Infrastrukturentwicklung in den alpinen Tälern, die durch Hochwasserschutzbauten wie z.B. die Rhonekorrektion ermöglicht wurden, steigt das Bedürfnis nach einer besseren Beurteilung des seismischen Verhaltens der Hochwasserschutzsysteme. Auf der einen Seite sind die Identifizierung der kritischen Stellen für bestehende Bauwerke und der Entwurf eventueller Sicherungsmassnahmen von besonderer Bedeutung. Auf der anderen Seite ist die Beurteilung des seismischen Verhaltens der nachgerüsteten Hochwasserschutzbauten für die allgemeinen Risikoabschätzungen entscheidend für die weiteren Entwicklungsmöglichkeiten der Infrastruktur und der Besiedlungen.

Um den Hochwasserschutz zu verbessern und bestehende Dämme der dritten Rhonekorrektion den neuesten Sicherheitsanforderungen anzupassen, haben sich zwei unterschiedliche Sicherungsmassnahmen als funktionsfähige Nachrüstungen des Dammkörpers ergeben: eine eingerammte Stahlspundwand und eine „Mixed-In-Place“ (MIP)Dichtwand. Diese Studie befasst sich mit der Beurteilung des seismischen Verhaltens der Dämme mit und ohne Nachrüstungsmassnahmen.

\subsection{Methodik}

\subsubsection{Bestimmung der kritischen Geometrie des Dammprofils}

Die Beurteilung des seismischen Verhaltens der Dämme und der Nachrüstungsmassnahmen wurde durch numerische Modellierungen mit finiten Elementen (Plaxis 2012 Brinkgreve et al., 2012) untersucht. In einem ersten Schritt wurden Feldmessungen durchgeführt und repräsentative Querschnitte für die Zusammenstellung eines numerischen Modells ermittelt. Die Feldmessungen haben sich auf die Rhone-Dämme zwischen Visp und Baltschieder konzentriert und die Repräsentativität der ermittelten Querschnitte wurde durch den Vergleich mit vorhandenen Informationen über die 3. Rhonekorrektion (Mayor \& Springman, 2011; Kanton Wallis, 2008; Springman et al., 2013) bestätigt.

Eine Übersichtskarte der ausgemessenen Standorte ist im Bild 11.1 gegeben. 


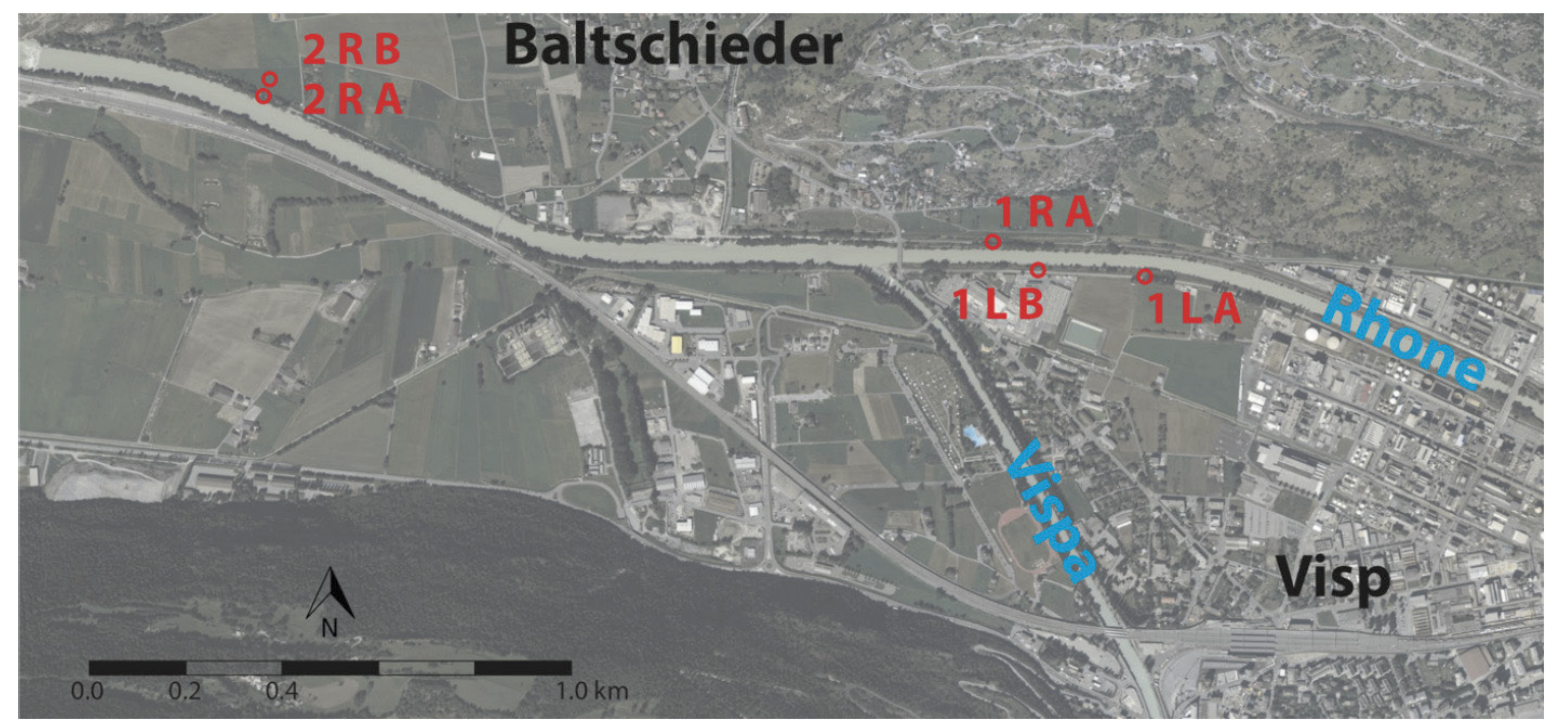

Bild 11.1. Übersichtskarte der ausgemessenen Standorte (Geiser, 2013).

Die aus den Feldmessungen entstandenen und für die numerischen Untersuchungen vorgeschlagenen Profile auf der linken Seite (1LA; 1LB) der Rhone sind in den Bildern 11.2-11.3 ersichtlich.
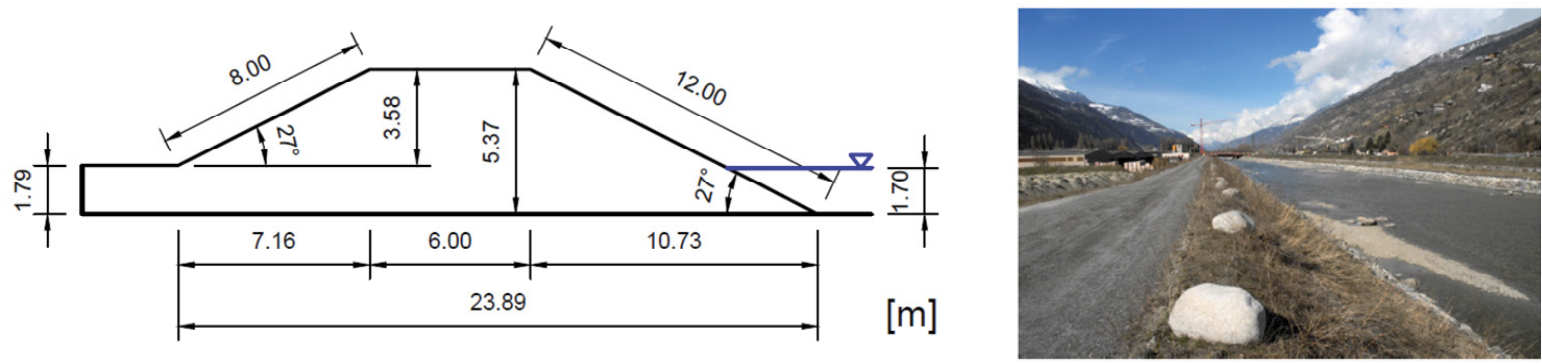

Bild 11.2. Dammprofil am Standort 1LA (vgl. Bild 1) (Geiser, 2013).

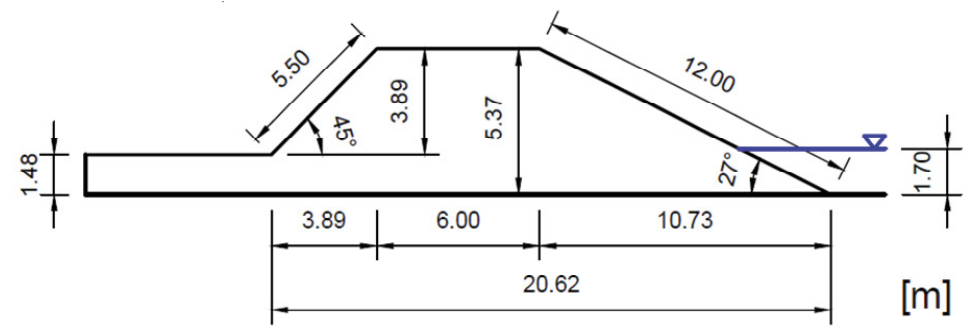

Bild 11.3. Dammprofil am Standort 1LB (vgl. Bild 1) (Geiser, 2013).

Ein Segment besonderer Geometrie wurde am Standort 1LB identifiziert. Durch ein genutztes Gelände, das sehr nahe an der luftseitigen Böschung des Dammes liegt, wurde eine Böschungsneigung von ungefähr $45^{\circ}$ bei der Dammkonstruktion verursacht. 
Auf der rechten Seite der Rhone wurden die folgenden Profile ermittelt (Bild 11.4 - Bild 11.5).
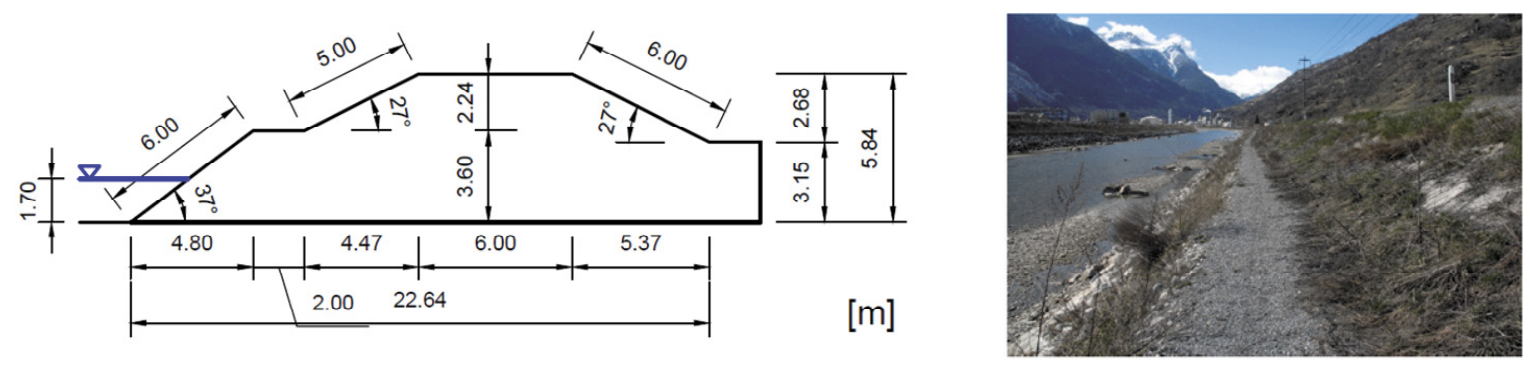

Bild 11.4. Dammprofil am Standort 1RA (vgl. Bild 1) (Geiser, 2013).
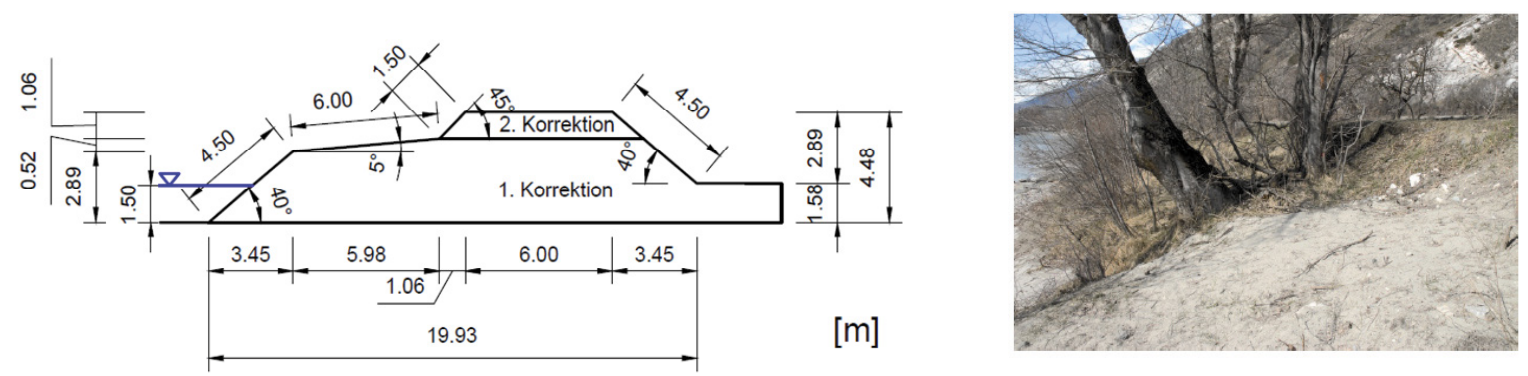

Bild 11.5. Dammprofil am Standort 2RA (vgl. Bild 1) (Geiser, 2013).

Die vorhandene Dammsektion am Standort 2RB (Bild 11.6) gehört zur 3. Rhonekorrektion und ist ein Beispiel für die neuen Dammsegmente mit optimierten Profilen. Die Dammsektion ist noch nicht in Betrieb, aber sie wird in Zukunft das am Standort 2RA vorhandene Segment ersetzen. Dieses Segment wird trotzdem weiter betrachtet, da auch solche Segmente der 2. Rhonekorrektion weiter verwendet werden.
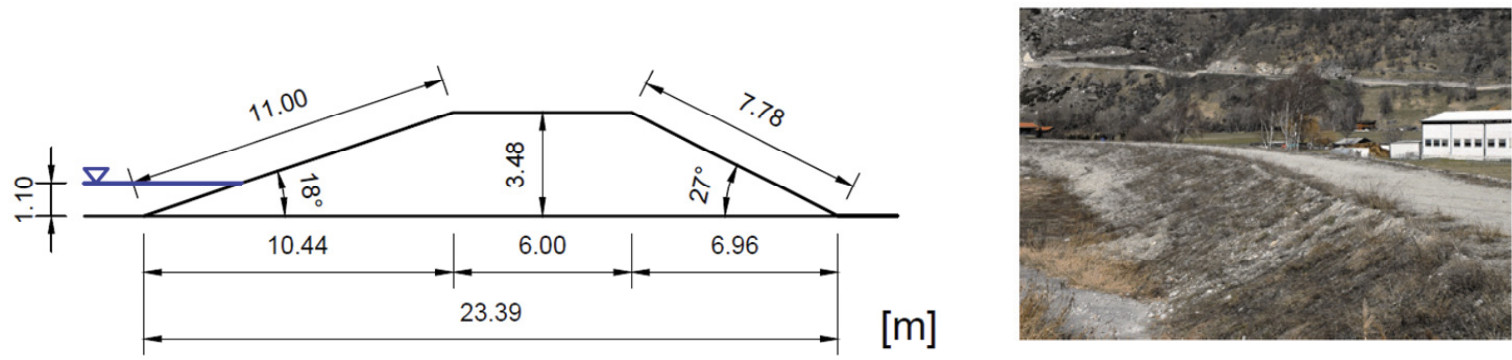

Bild 11.6. Dammprofil am Standort 2RB (vgl. Bild 1) (Geiser, 2013).

Durch die Auswertung der unterschiedlich ausgemessenen Dammprofile hat sich das Profil 2RA als kritisch und repräsentativ für den jetzigen Zustand der Rhone-Dämme ergeben. Obwohl das Profil 1LA eine grössere Neigung auf der Luftseite aufweist, ist dieser Fall eine Ausnahme, die punktuell untersucht werden soll und damit nicht als repräsentativ betrachtet werden kann. Die weiteren Berechnungen werden sich auf die Geometrie des Profils 2RA (vgl. Bild 11.5) beziehen. 


\subsubsection{Bestimmung des Baugrundmodells}

Die Bestimmung und Idealisierung des geologischen Modells basiert auf bereits durchgeführten Untersuchungen in der Umgebung Visp im Rhonetal (e.g. Weber et al., 2007; Burjanek, 2011; Mezger, 2011).

Von besonderer Bedeutung in einer dynamischen Analyse ist die Bestimmung der Lage des Felshorizontes. Anhand von Ambient-Noise-Messungen und Scherwellengeschwindigkeitsprofilen konnte die Tiefe des Felshorizontes am Standort des Dammes mit $100 \mathrm{~m}$ abgeschätzt werden (Bild 11.7).

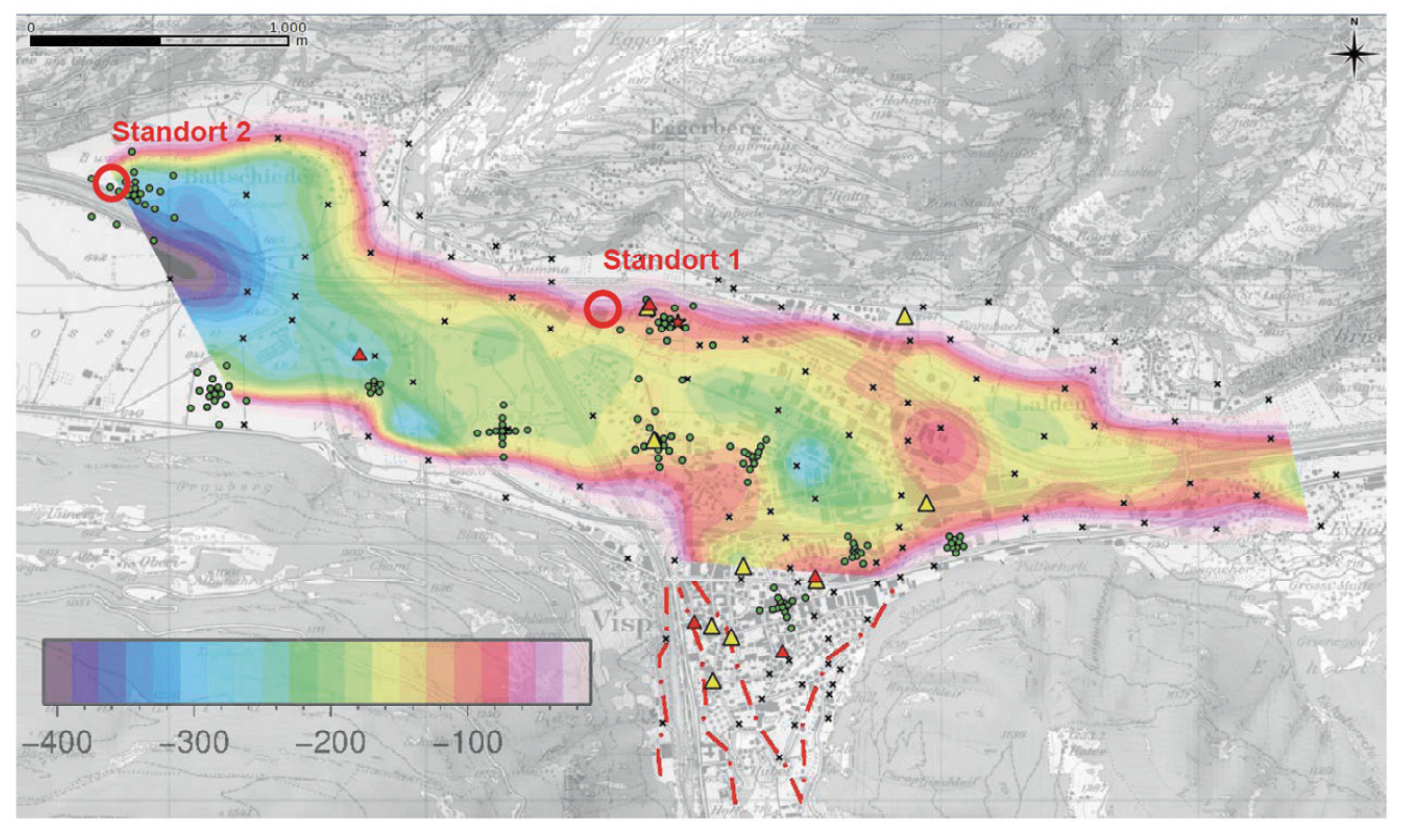

Bild 11.7. Tiefe des Felshorizontes im Rhonetal bei Visp (Burjanek, 2011).

Die Idealisierung des Baugrundmodells erfolgt mithilfe von geologischen Informationen, die den Bohrungen entlang der Autobahn A9 (OSPER, 2014) und den Untersuchungen am Bahnhof Visp (Weber et al., 2007) entnommen wurden. Das idealisierte Baugrundmodell ist im Bild 11.8 dargestellt.

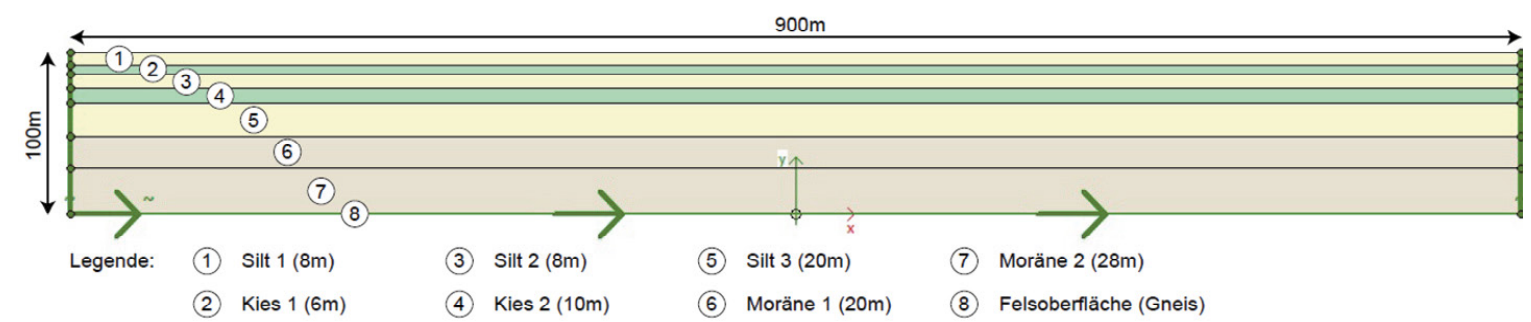

Bild 11.8. Initiales idealisiertes Baugrundmodell mit Angabe der Mächtigkeit der Schichten bis zum Felshorizont (Geiser, 2013).

Um den Berechnungsaufwand zu reduzieren, wurde die Tiefe des modellierten Untergrundbereichs mit Vergleichsberechnungen am grossen Modell (Bild 11.9) optimiert. Statische Untersuchungen der Verformungen mit einem allgemeinen symmetrischen 
Dammprofil haben gezeigt, dass die volumetrischen Dehnungen infolge der Dammerrichtung ab einer Tiefe von $22 \mathrm{~m}$ vernachlässigbar sind.

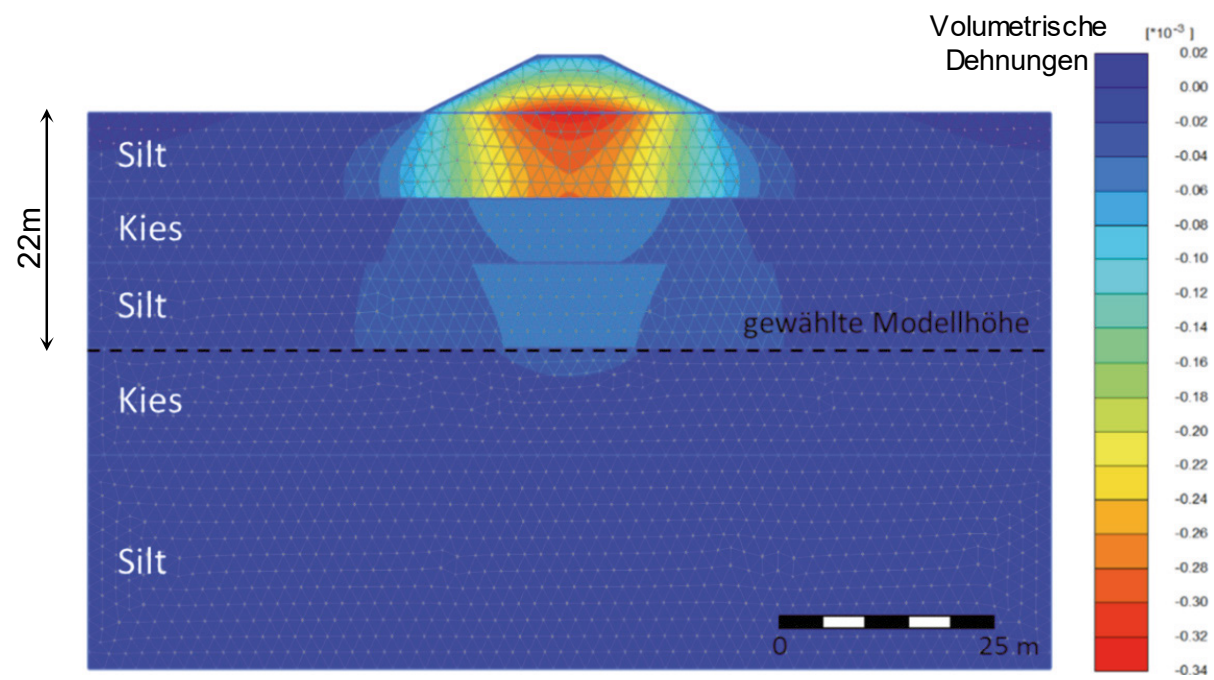

Bild 11.9. Verteilung der volumetrischen Dehnungen infolge der Dammerrichtung.

Für die dynamische Modellierung ist gemäss Marin et al. (2012) die Breite des Modells so gewählt, dass ungewünschte Randeffekte minimiert werden können.

Da die Entwicklung der Porenwasserüberdrucke während der seismischen Anregung durch die Begrenzungen des verwendeten FE-Programms nicht modelliert werden kann und von einem drainierten Verhalten ausgegangen wird, wird der Wasserspiegel in den folgenden Berechnungen vernachlässigt. Das Material im Dammkörper wird als uniform angenommen und besteht aus dem an der Oberfläche vorhandenen siltigen Sand. Die durch den Bewuchs entstandenen Haftkräfte an der Oberfläche der Dammböschungen werden mit einer leicht erhöhten Kohäsion berücksichtigt.

\subsubsection{Stoffgesetze, Bodenkennwerte und FE-Netz}

Für die Modellierung des statischen und dynamischen Verhaltens des Dammes wurde das in Plaxis implementierte Stoffgesetz Hardening-Soil-Small-Strains (HSSmall) verwendet. Dieses Stoffgesetz erlaubt die Modellierung der nicht linearen Abnahme des Schubmoduls mit den Scherdehnungen und den Einsatz der maximalen Schersteifigkeit $\mathrm{G}_{0}$ im Bereich kleiner Dehnungen (Bild 11.10). 

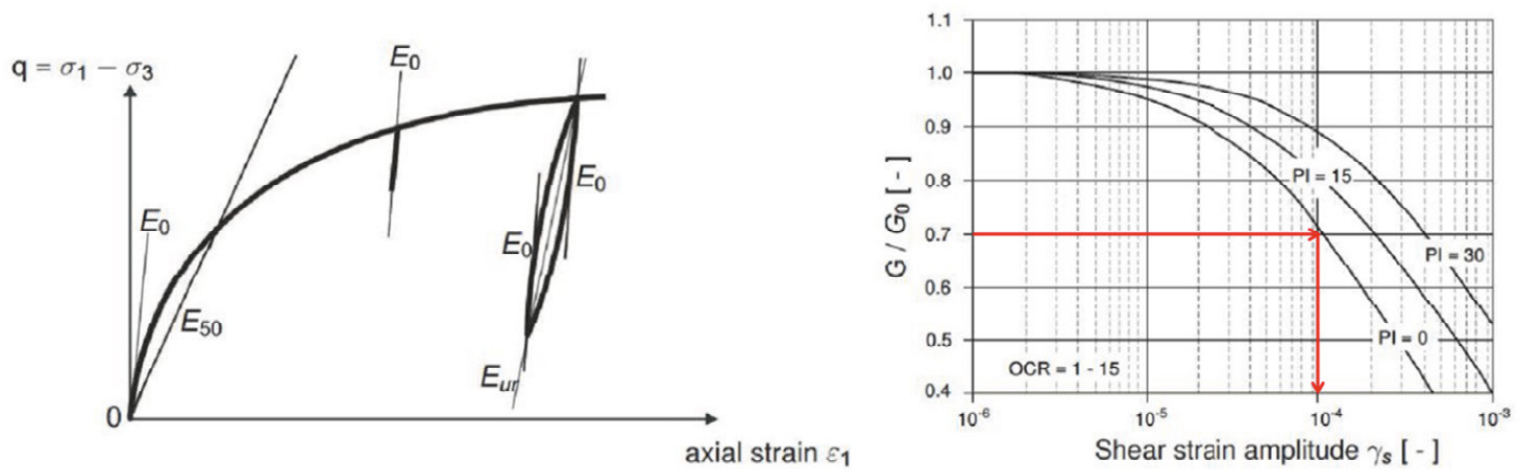

Bild 11.10. Allgemeine Darstellung des Stoffgesetzes HSSmall: links - Spannungs-DehnungsBeziehung; rechts - Verlauf des Schubmoduls mit den Scherdehnungen (nach Brinkgreve et al., 2012).

Die verwendeten Bodenkennwerte basieren auf Laboruntersuchungen sowie auf Erfahrungswerten aus der Literatur (Weber et al., 2007; Mezger, 2011; Geiser, 2013; Scheiwiller, 2013) und sind in der Tabelle 11.1 zusammengefasst. Die erhöhten Werte des Reibungswinkels im Dammkörper und an der Dammoberfläche wurden durch eine Rückrechnung unter Ansatz einer minimalen globalen Sicherheit des Dammes von FS = 1.1 ermittelt. Sie berücksichtigen die im Dammmaterial bestehenden Haftkräfte (z.B. Saugspannungen, Zementierung, Dilatanz, etc.). Die Wandreibung wurde bei 2/3 $\varphi^{\prime}$ des Materials, in dem die MIP- oder Stahlspundwand eingebaut wird, angenommen.

Tabelle 11.1. Kennwerte der unterschiedlichen Materialien.

\begin{tabular}{|c|c|c|c|c|c|c|c|c|c|c|c|}
\hline $\begin{array}{l}\mathrm{Nr} . \\
{[-]}\end{array}$ & $\begin{array}{c}\text { Material } \\
{[-]}\end{array}$ & $\begin{array}{c}\text { Mittlere Tiefe } z \\
{[\mathrm{~m}]}\end{array}$ & $\begin{array}{c}\gamma \\
{\left[\mathrm{kN} / \mathrm{m}^{3}\right]}\end{array}$ & $\begin{array}{l}\varphi^{\prime} \\
{\left[^{\circ}\right]}\end{array}$ & $\begin{array}{c}\mathrm{c}^{\prime} \\
{[\mathrm{kPa}]}\end{array}$ & $\begin{array}{c}\mathrm{E}_{\circ} \\
{[\mathrm{Mpa}]}\end{array}$ & $\begin{array}{c}\mathrm{G}_{0} \\
{[\mathrm{Mpa}]}\end{array}$ & $\begin{array}{c}E_{\text {oed }} \\
{[\mathrm{Mpa}]}\end{array}$ & $\begin{array}{c}v \\
{[-]}\end{array}$ & $\begin{array}{c}\mathrm{v}_{\mathrm{s}} \\
{[\mathrm{m} / \mathrm{s}]}\end{array}$ & $\begin{array}{c}v_{p} \\
{[\mathrm{~m} / \mathrm{s}]}\end{array}$ \\
\hline D1 & Silt Dammkörper & -1.75 & 20.0 & 42.7 & 0.0 & 174 & 67 & 234 & 0.3 & 181 & 339 \\
\hline D2 & Silt Dammoberfläche & -1.75 & 20.0 & 42.7 & 5.0 & 174 & 67 & 234 & 0.3 & 181 & 339 \\
\hline 1 & Silt 1 & 4 & 20.0 & 34.0 & 1.0 & 200 & 77 & 269 & 0.3 & 194 & 363 \\
\hline 2 & Kies 1 & 11 & 21.0 & 35.0 & 1.0 & 800 & 307 & 1077 & 0.3 & 379 & 709 \\
\hline 3 & Silt 2 & 18 & 20.0 & 34.0 & 1.0 & 700 & 269 & 942 & 0.3 & 363 & 680 \\
\hline
\end{tabular}

Für die Bestimmung der Materialdämpfung wurde unter Anwendung des Programms EERA (Bardet et al., 2000) eine Kalibrierung (Marin et al., 2012) der Zeitbereichsanalyse (PLAXIS) mit einer linear äquivalenten Analyse im Frequenzbereich durchgeführt. Die Resultate dieses Kalibrierungsverfahrens sind in der Tabelle 11.2 ersichtlich.

Tabelle 11.2. Rayleigh-Beiwerte für die Modellierung der Materialdämpfung.

\begin{tabular}{|c|r|r|r|r|r|r|r|}
\hline Layer & \multicolumn{1}{|c|}{ 01 Silt } & \multicolumn{1}{c|}{ 02 Kies } & \multicolumn{1}{c|}{ 03 Silt } & \multicolumn{1}{c|}{ 04 Kies } & \multicolumn{1}{c|}{ 05 Silt } & \multicolumn{1}{c|}{06 Moräne } & 07 Moräne \\
\hline$\alpha[-]$ & 0.7530 & 0.0476 & 0.6234 & 0.4858 & 0.5490 & 0.0317 & 0.2931 \\
\hline$\beta[-]$ & 0.000841 & 0.000532 & 0.000696 & 0.000543 & 0.000613 & 0.000355 & 0.000327 \\
\hline
\end{tabular}

Das verwendete FE-Netz ist im Bild 11.11 dargestellt. Die Feinheit des generierten FENetzes wurde optimiert, um die Genauigkeit der Resultate im Bereich des Dammkörpers zu gewährleisten. Die gröberen Elemente ausserhalb dieses Bereiches reduzieren den Berechnungsaufwand. 


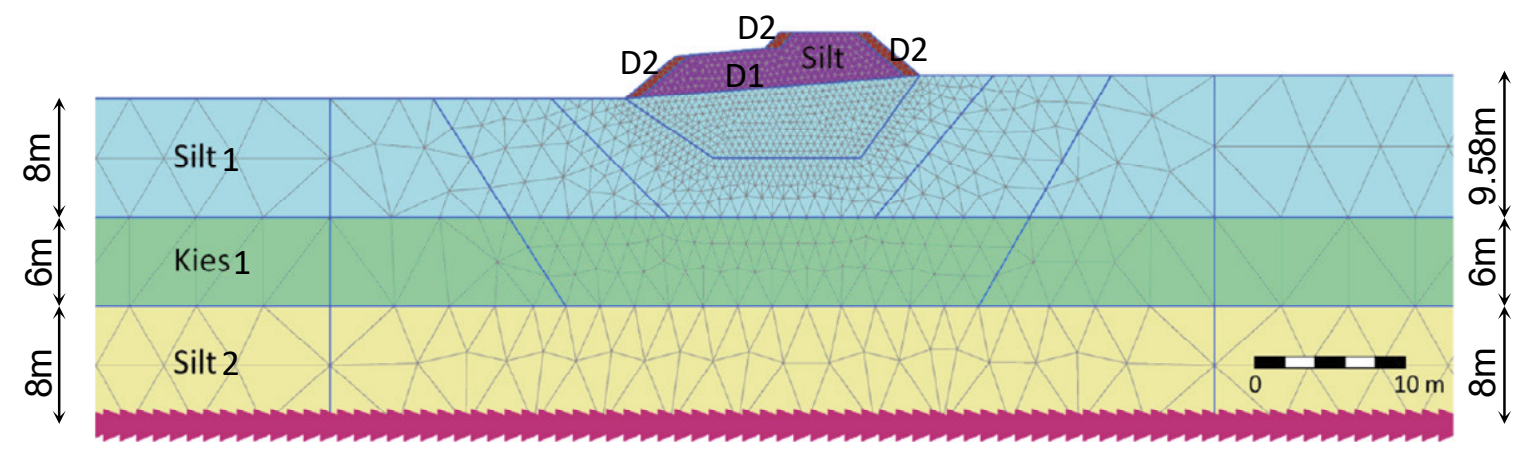

Bild 11.11. Optimiertes FE-Model. Identifizierung der modellierten Materialien.

\subsubsection{Stoffgesetze und Kennwerte der Dichtwände}

\section{Mixed in Place Wand (MIP-Wand)}

Die $0.5 \mathrm{~m}$ breite MIP-Wand wird als Plattenelement mit einem linear elastischen Stoffgesetz modelliert. Die Materialkennwerte sind in der Tabelle 11.3 zusammengefasst.

Tabelle 11.3. Kennwerte der MIP-Wand.

\begin{tabular}{|c|c|c|c|c|c|c|}
\hline $\begin{array}{c}\text { Material } \\
{[-]}\end{array}$ & $\begin{array}{c}\text { Material Typ } \\
{[-]}\end{array}$ & $\begin{array}{c}\mathrm{EA} \\
{[\mathrm{kN} / \mathrm{m}]}\end{array}$ & $\begin{array}{c}\mathrm{El} \\
{\left[\mathrm{kNm}^{2} / \mathrm{m}\right]}\end{array}$ & $\begin{array}{c}\mathrm{V} \\
{[-]}\end{array}$ & $\begin{array}{c}\text { äquivalente Dicke d } \\
{[\mathrm{m}]}\end{array}$ & $\begin{array}{c}\mathrm{f}_{\mathrm{ck}} \\
{\left[\mathrm{N} / \mathrm{mm}^{2}\right]}\end{array}$ \\
\hline $\begin{array}{c}\text { Boden und } \\
\text { Bindemittel }\end{array}$ & elastisch & $9^{\prime} 900$ '000 & $2066^{\prime} 000$ & 0.3 & 0.499 & 3.3 \\
\hline
\end{tabular}

Die mittlere Zugfestigkeit des Materials kann nach DIN 1045-1 (2008) bestimmt werden. Anhand der mittleren Zugfestigkeit kann dann der Biegewiderstand des rechteckigen Querschnitts ermittelt werden.

$$
f_{c t m}=0.3 \cdot f_{c k}^{2 / 3}=0.665 \frac{N}{m^{2}}
$$

$M_{R d}=f_{c t m} \cdot \frac{I_{y}}{x_{\max }}=f_{c t m} \cdot \frac{b \cdot h^{3}}{12 \cdot x_{\max }}=0.665 \frac{\mathrm{N}}{\mathrm{mm}^{2}} \cdot \frac{1 \mathrm{~m}^{\prime} \cdot(500 \mathrm{~mm})^{3}}{12 \cdot 250 \mathrm{~mm}}=27.7 \frac{\mathrm{kNm}}{\mathrm{m}^{\prime}}$

mit: $\quad f_{c t m}\left[N / m^{2}\right] \quad$ mittlere Zugfestigkeit

$\mathrm{f}_{\mathrm{ck}}\left[\mathrm{N} / \mathrm{mm}^{2}\right] \quad$ charakteristischer Wert der Zylinderdruckfestigkeit

$M_{R d}\left[\mathrm{kNm} / \mathrm{m}^{\prime}\right]$ elastischer Bemessungswert des Biegewiderstands pro Laufmeter

$\mathrm{I}_{\mathrm{y}}\left[\mathrm{mm}^{4}\right] \quad$ Flächenträgheitsmoment

$\mathrm{x}_{\max }[\mathrm{mm}] \quad$ elastisches Widerstandsmoment 


\section{Stahlspundwand}

Das Spundwandprofil Larsen 600, S235 (Hoesch, 2013) wird ähnlich wie die MIP-Wand durch ein Plattenelement mit einem linear elastischen Stoffgesetz modelliert. Die Materialkennwerte sind in der Tabelle 11.4 aufgelistet.

Tabelle 11.4. Materialkennwerte für die Stahlspundwand mit dem Profil Larssen 600, S235.

\begin{tabular}{|c|c|c|c|c|c|c|c|}
\hline $\begin{array}{c}\text { Material } \\
{[-]}\end{array}$ & $\begin{array}{c}\text { Material Typ } \\
{[-]}\end{array}$ & $\begin{array}{c}\text { EA } \\
{[\mathrm{kN} / \mathrm{m}]}\end{array}$ & $\begin{array}{c}\text { El } \\
{\left[\mathrm{kNm} \mathbf{m}^{2} / \mathrm{m}\right]}\end{array}$ & $\begin{array}{c}\mathrm{V} \\
{[-]}\end{array}$ & $\begin{array}{c}\text { äquivalente Dicke d } \\
{[\mathrm{m}]}\end{array}$ & $\begin{array}{c}\mathrm{W}_{\text {y,el }} \\
{\left[\mathrm{cm}^{3}\right]}\end{array}$ & $\begin{array}{c}\mathrm{f}_{\mathrm{y}} \\
{\left[\mathrm{N} / \mathrm{mm}^{2}\right]}\end{array}$ \\
\hline Stahl & elastisch & $2^{\prime} 513^{\prime} 700$ & $8^{\prime} 033$ & 0.3 & 0.196 & 510 & 235 \\
\hline
\end{tabular}

Das aufnehmbare Biegemoment wird gemäss SIA 263 (2003) bestimmt.

$$
M_{R d}=\frac{f_{y} \cdot W_{y}}{\gamma_{M 1}}=\frac{235 \frac{\mathrm{N}}{\mathrm{mm}^{2}} \cdot 510^{\prime} 00 \mathrm{~mm}^{3}}{1.05}=114.1 \frac{\mathrm{kNm}}{\mathrm{m}^{\prime}}
$$

mit: $\quad M_{R d}\left[\mathrm{kNm} / \mathrm{m}^{\prime}\right]$ elastischer Bemessungswert des Biegewiderstands pro Laufmeter

$\mathrm{f}_{\mathrm{y}}\left[\mathrm{N} / \mathrm{mm}^{2}\right] \quad$ Fliessgrenze Stahl S235

$\mathrm{W}_{\mathrm{y}}\left[\mathrm{N} / \mathrm{mm}^{2}\right] \quad$ elastisches Widerstandsmoment

$\mathrm{Y}_{\mathrm{M1}}[-] \quad$ Widerstandsbeiwert

\subsubsection{Seismische Einwirkung}

Im ersten Schritt wird eine Amplifikationsanalyse am Standort durchgeführt. Dazu wurde der Beschleunigungszeitverlauf des Erdbebens Northridge 1994 mit einer Magnitude $\mathrm{M}_{\mathrm{w}}=$ 6.7 und einer maximalen Mercalli-Intensität IX (Ambraseys et al., 2002) verwendet. Für die relevante Untersuchung wurde das Originalsignal auf das SIA-Niveau der Erdbebenzone $3 b$ für die Baugrundklasse $A(P G A=0.16 \mathrm{~g}$ ) skaliert (Bild 11.12). Die dynamische Anregung wurde in der Tiefe von $100 \mathrm{~m}$ des initialen idealisierten Modells (vgl. Bild 11.8) angesetzt und durch die Amplifikationsanalyse des Beschleunigungszeitverlaufs in einer Tiefe von $22 \mathrm{~m}$ von der Oberfläche ermittelt, der als Eingangssignal für die Berechnungen verwendet wird (Bild 11.13). 


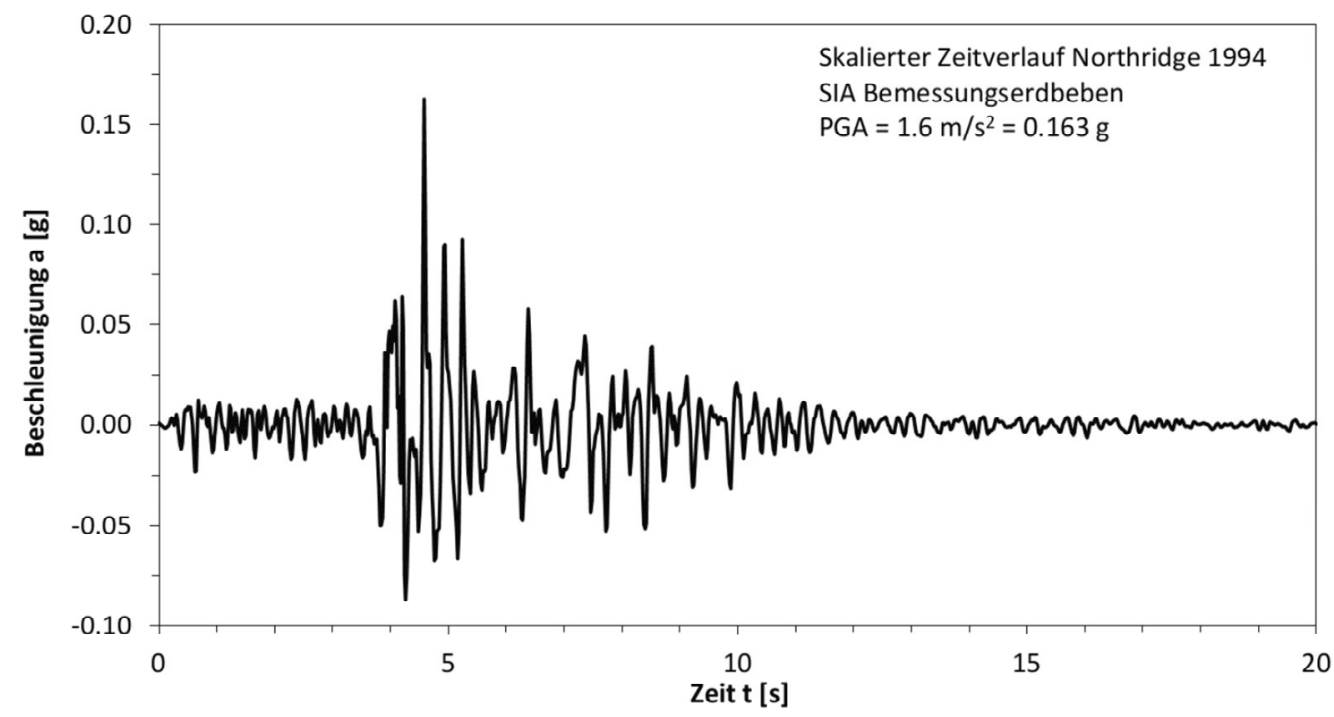

Bild 11.12. Skalierter Zeitverlauf des Erdbebens Northridge 1994.

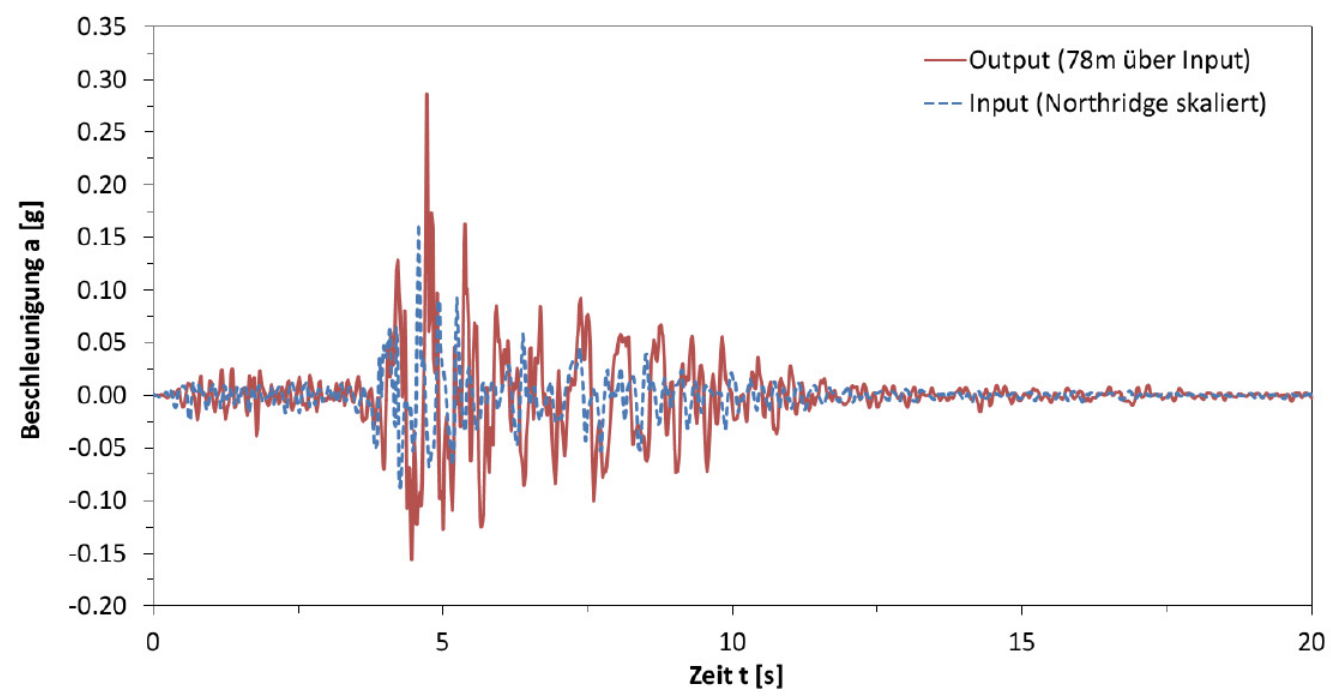

Bild 11.13. Output der Amplifikationsanalyse: Zeitverlauf in einer Tiefe von 22 m von der Oberfläche. Eingangssignal für die weiteren Berechnungen.

\subsection{Resultate der dynamischen Untersuchungen}

Im Folgenden werden die Resultate vergleichend zwischen einem Damm ohne und einem Damm mit Nachrüstungsmassnahmen dargestellt.

\subsubsection{Allgemeine Verformungen des Dammes}

In einem ersten Schritt kann man das verformte FE-Netz des Dammes nach der seismischen Anregung betrachten (Bilder 11.14 - 11.15). Bei der Betrachtung der allgemeinen Verformungen lassen sich keine markanten Unterschiede zwischen dem allgemeinen Verhalten des Dammes in den zwei Situationen feststellen: ohne Nachrüstungsmassnahme oder mit einer MIP- oder Stahlspundwand. Die verformten FE-Netzte sehen 
gleich aus und die maximalen modellierten Deformationen weisen eine minimale Abweichung im Millimeterbereich auf.

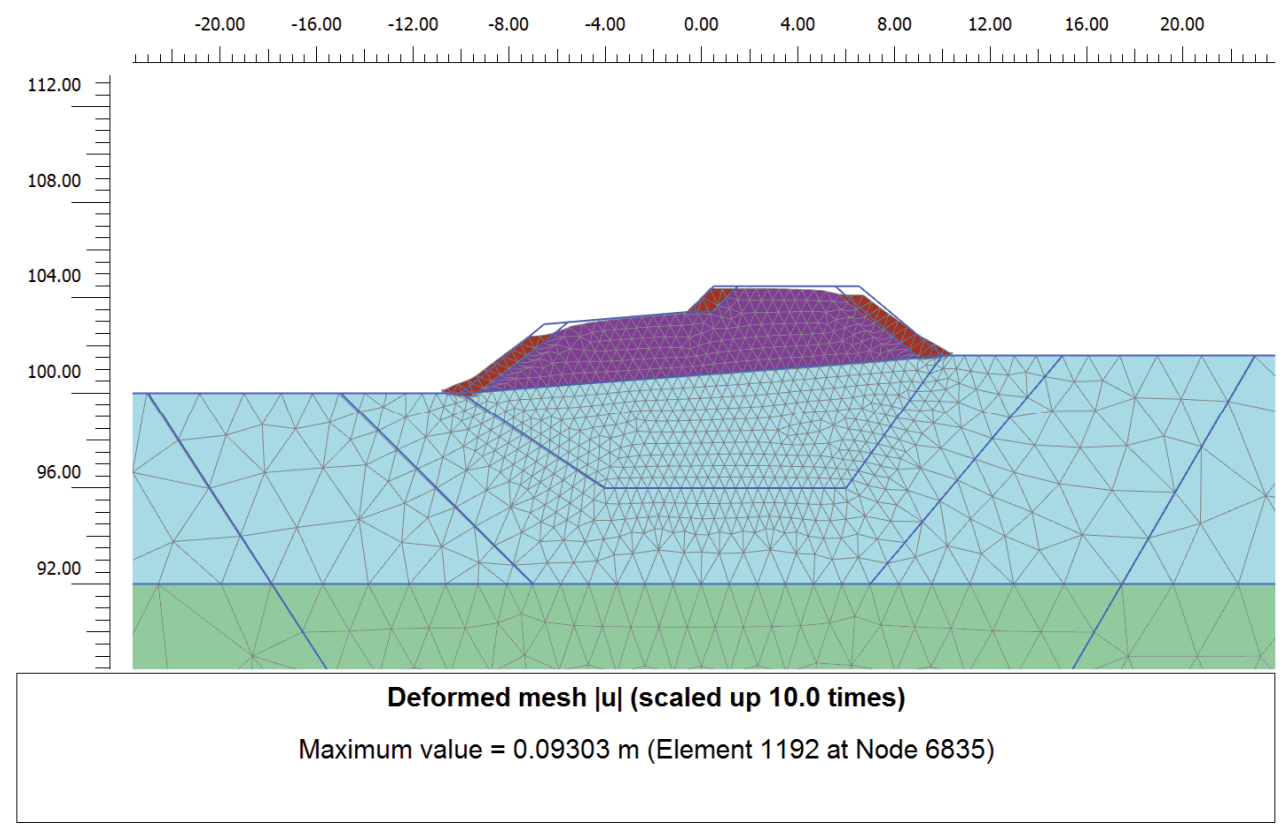

Bild 11.14. Verformtes FE-Netz nach der seismischen Anregung (ohne Nachrüstungsmassnahme).

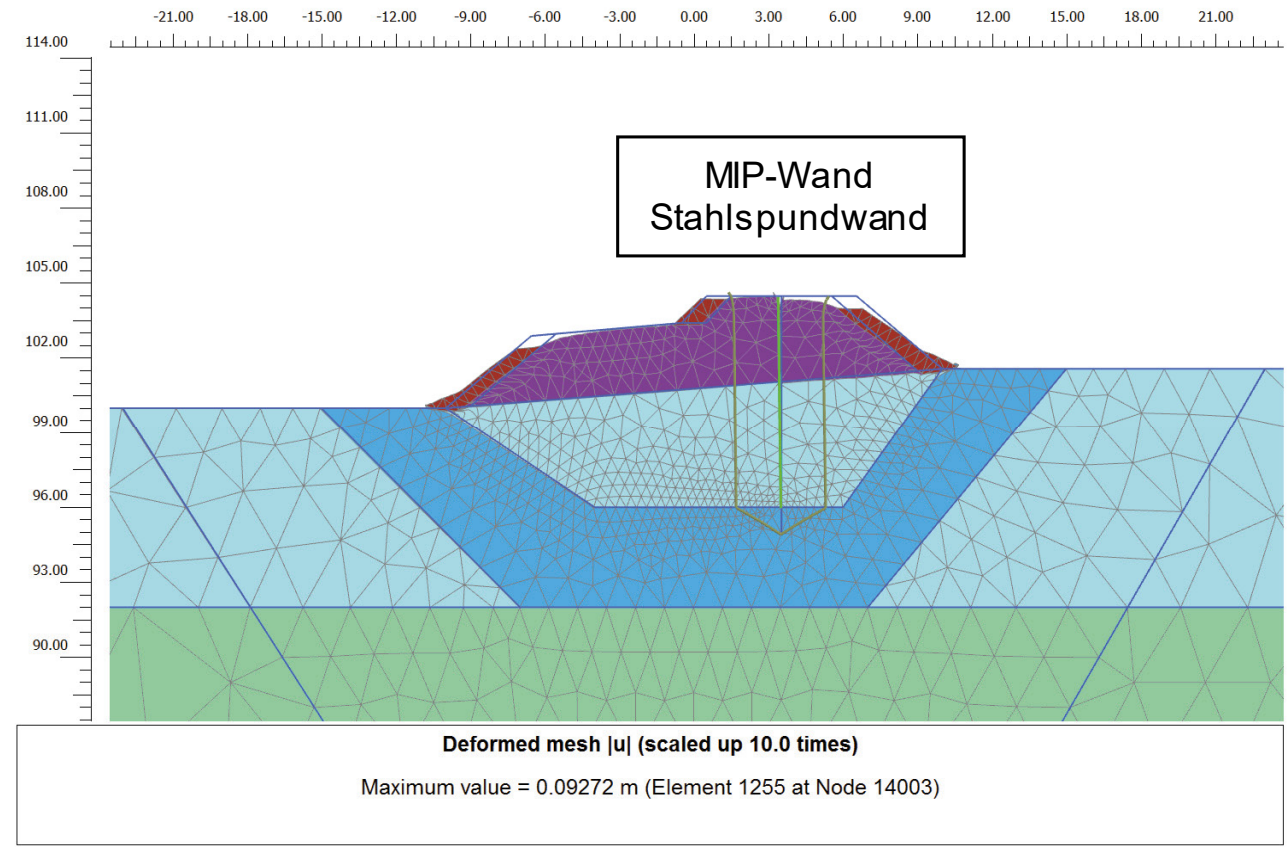

Bild 11.15. Verformtes FE-Netz nach der seismischen Anregung (Damm mit Nachrüstungsmassnahme). 


\subsubsection{Entwicklung des Verformungsmechanismus}

Der Verformungsmechanismus und seine Entwicklung über die Zeit können durch die sich am Ende der seismischen Anregung eingestellten Scherdehnungen dargestellt und untersucht werden (Bilder 11.16-11.17). Auch in diesem Fall sind nur minimale Unterschiede in der Entwicklung der Verformungsmechanismen festzustellen. Die Auswertung der Resultate zeigt, dass die maximalen Scherdehnungen am Ende der seismischen Einwirkung in allen untersuchten Situationen im Bereich von 51-57\% lagen. Die sich einstellenden Verformungsmechanismen sind ähnlich und weisen darauf hin, dass eine Nachrüstungsmassnahme mit einer undurchlässigen Wand im Dammkörper minimale Einflüsse auf das allgemeine seismische Verhalten des Dammes hat.

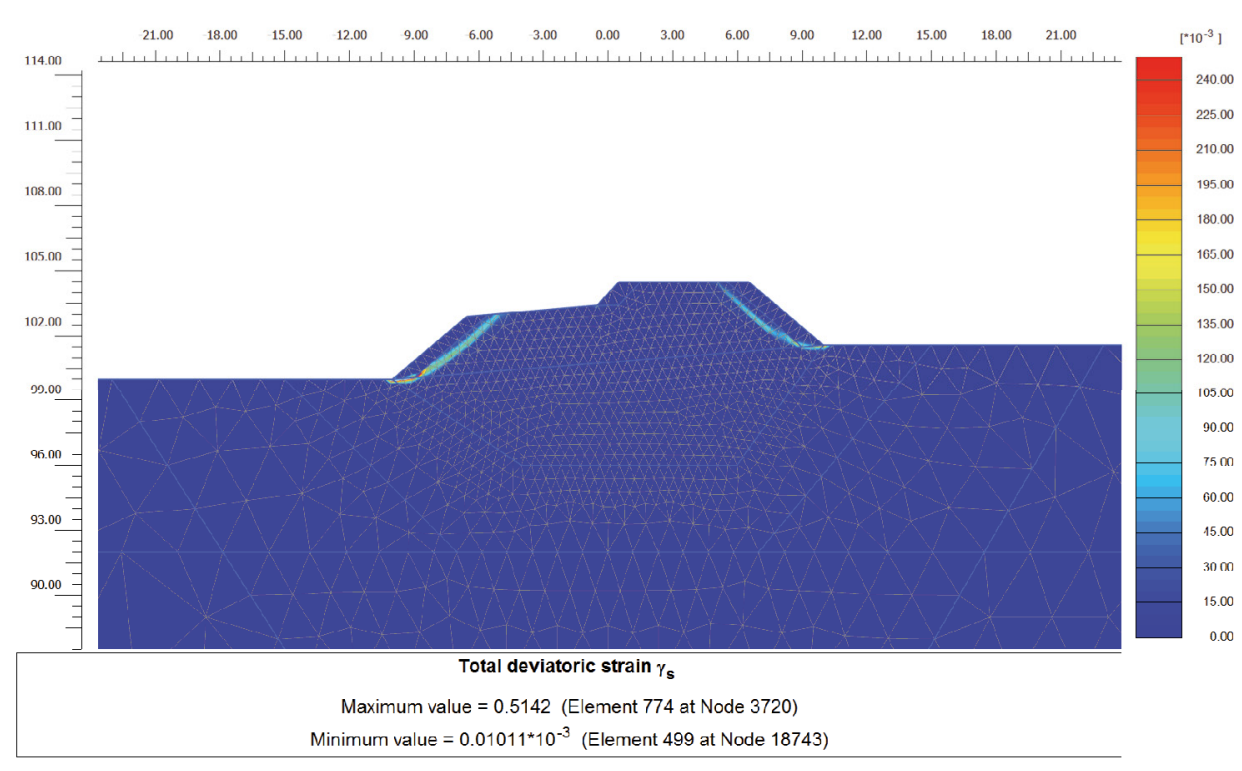

Bild 11.16. Scherdehnungen nach der seismischen Anregung (Damm ohne Nachrüstungsmassnahme).

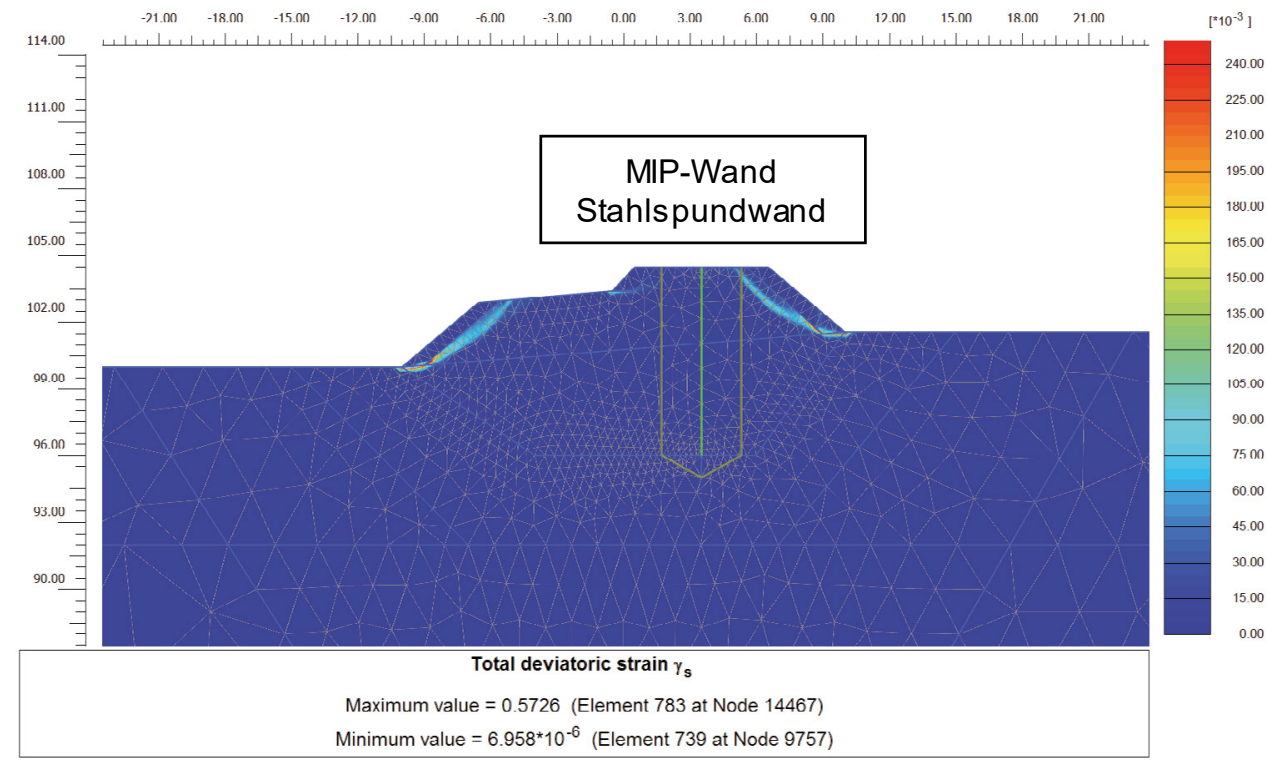

Bild 11.17. Scherdehnungen nach der seismischen Anregung (Damm mit Nachrüstungsmassnahme). 


\subsubsection{Setzungen infolge der seismischen Anregung}

Von besonderer Bedeutung bei der Auswertung des seismischen Verhaltens und der Auswirkungen der dynamischen Anregung auf die Funktionstauglichkeit des Dammes sind die residualen vertikalen Verformungen. Wie schon angedeutet, ist das Verhalten des Dammes in allen Fällen sehr ähnlich und damit sind auch die sich eingestellten vertikalen Verformungen am Ende der seismischen Anregung gleich (Bilder 11.18-11.19). Die maximalen Setzungen betragen $5 \mathrm{~cm}$ und stellen keine Gefahr für die Funktionstauglichkeit des Bauwerks dar. Ein leichter Unterschied ist auf der rechten Seite (Luftseite) des Dammes zu vermerken: Obwohl der Maximalwert gleich ist, sind die vertikalen Verformungen der Luftseite allgemein grösser im Fall einer Nachrüstungsmassnahme (MIPoder Stahlspundwand).

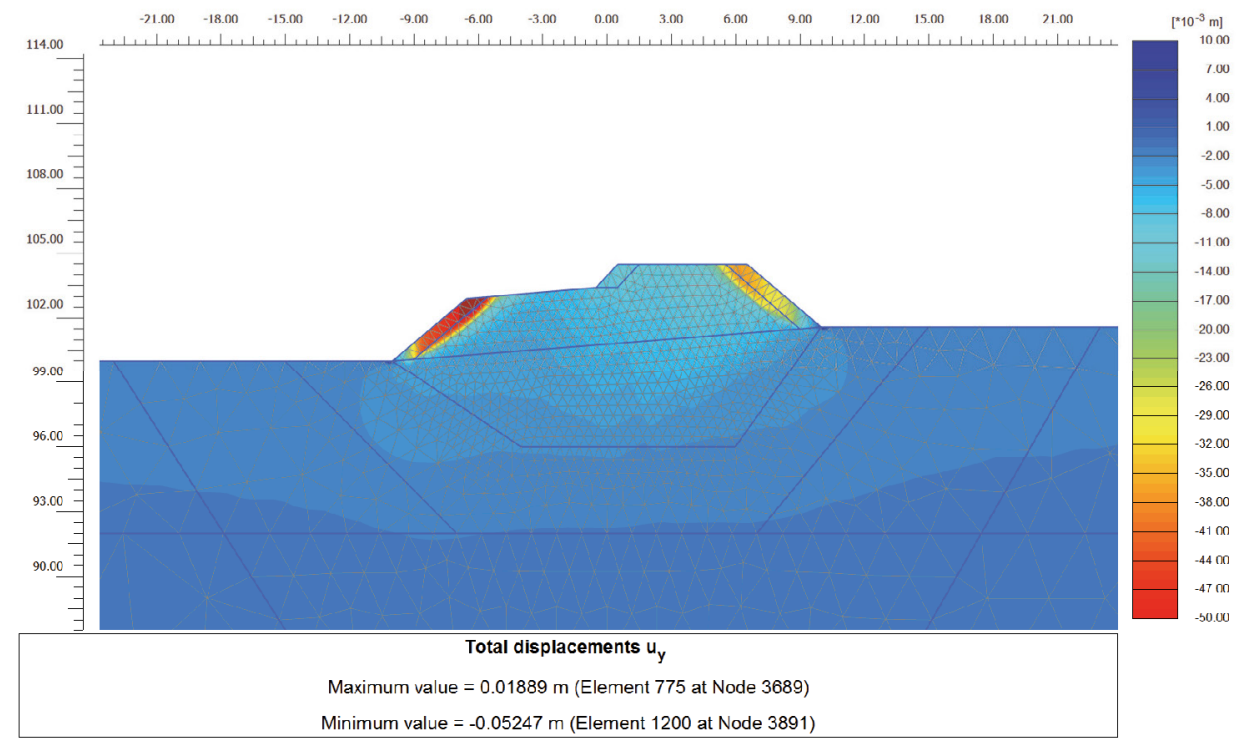

Bild 11.18. Vertikale Verformungen des Dammes nach der seismischen Anregung (ohne Nachrüstungsmassnahme).

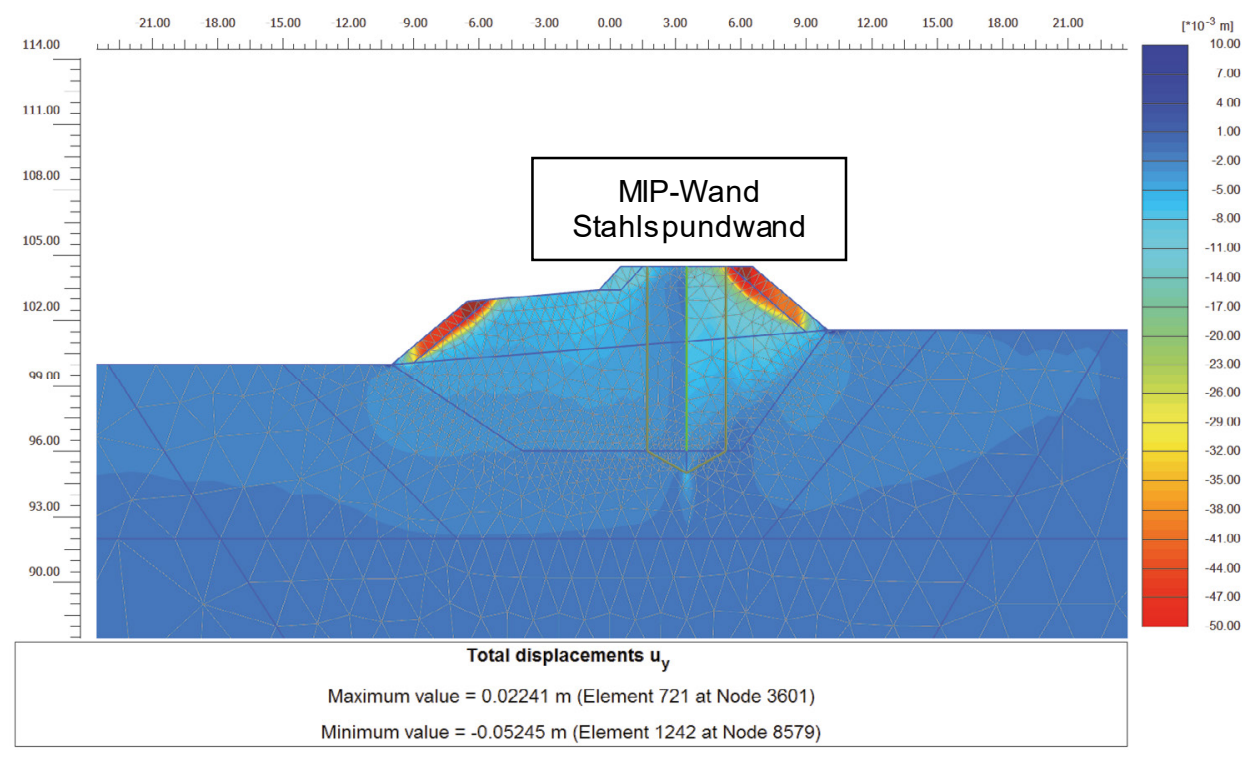

Bild 11.19. Vertikale Verformungen des Dammes nach der seismischen Anregung (mit MIP-Wand). 


\subsubsection{Seismisches Verhalten der Nachrüstungsmassnahmen}

Die Nachrüstungsmassnahmen werden die Hochwasserschutzleistung der bestehenden Dämme ohne weitere Arbeiten am Dammprofil verbessern; sie beeinflussen das allgemeine seismische Verhalten des Dammes nicht. Es bleibt aber sicherzustellen, dass die Funktion der eingebauten Wände (MIP- oder Schmaldichtwand) unter die seismische Einwirkung gewährleistet ist. In einem ersten Schritt wird das umhüllende Diagramm der maximalen Biegemomente in der MIP-Wand dargestellt (Bild 11.20).

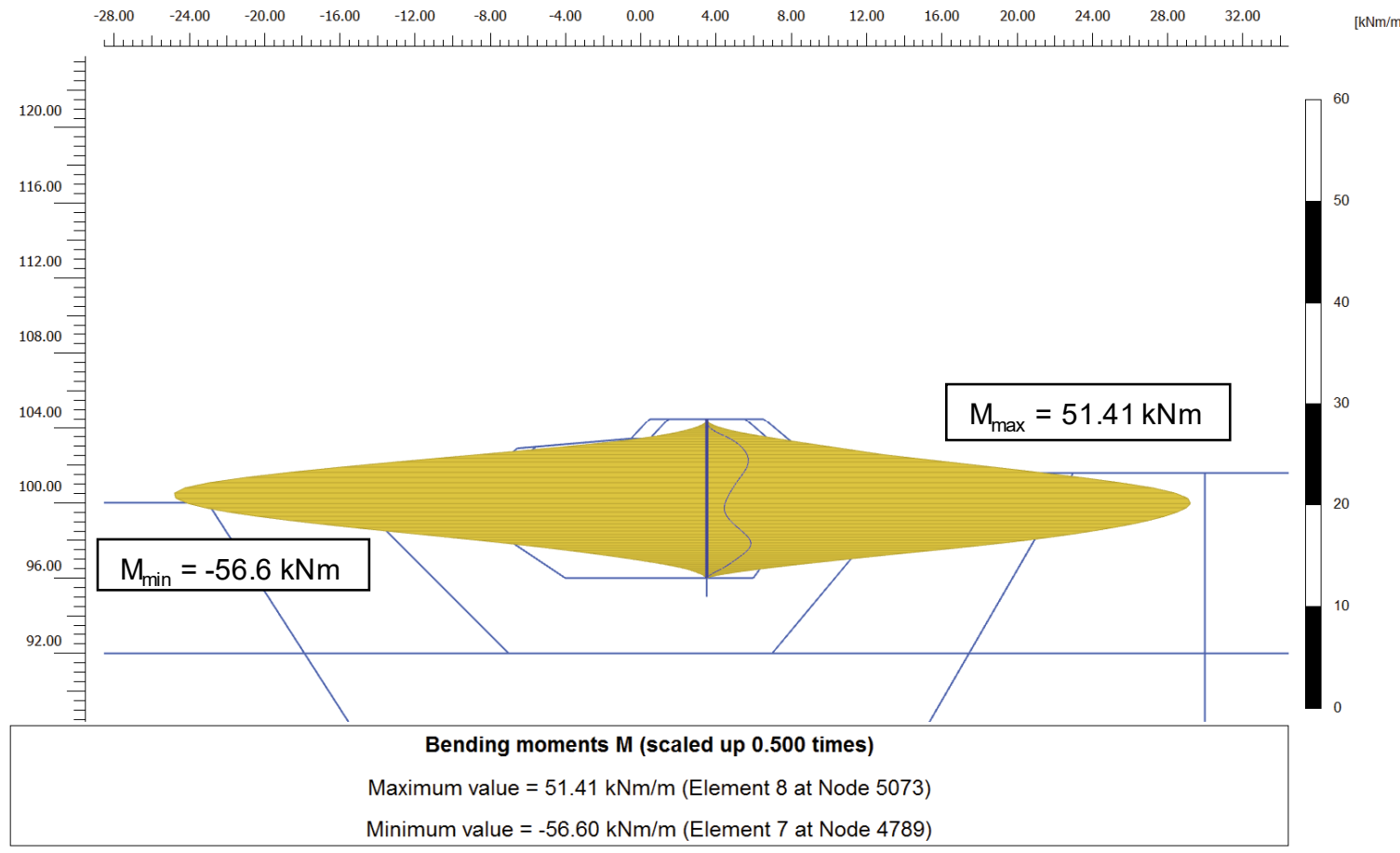

Bild 11.20. Umhüllendes Diagramm der maximalen Biegemomente in der MIP-Wand.

Die maximalen Werte sind auf den beiden Seiten der Wand im ähnlichen Bereich zwischen 50-60 kNm, aber der Extremwert bleibt auf der linken Seite mit $M_{\min }=-56.6 \mathrm{kNm}$ (vgl. Bild 11.21). Dieser Wert ist deutlich höher als das vorher bestimmte aufnehmbare Biegemoment $\mathrm{M}_{\mathrm{rd}}=27.7 \mathrm{kNm}$. Damit ist eine Rissbildung in der Wand zu erwarten, wobei diese Risse sich nicht durchgehend ausbilden werden.

Die zweite Nachrüstungsmassnahme besteht aus der Stahlspundwand (Larssen 600, S. 235); die Umhüllende der maximalen Biegemomente ist im Bild 11.21 ersichtlich. 


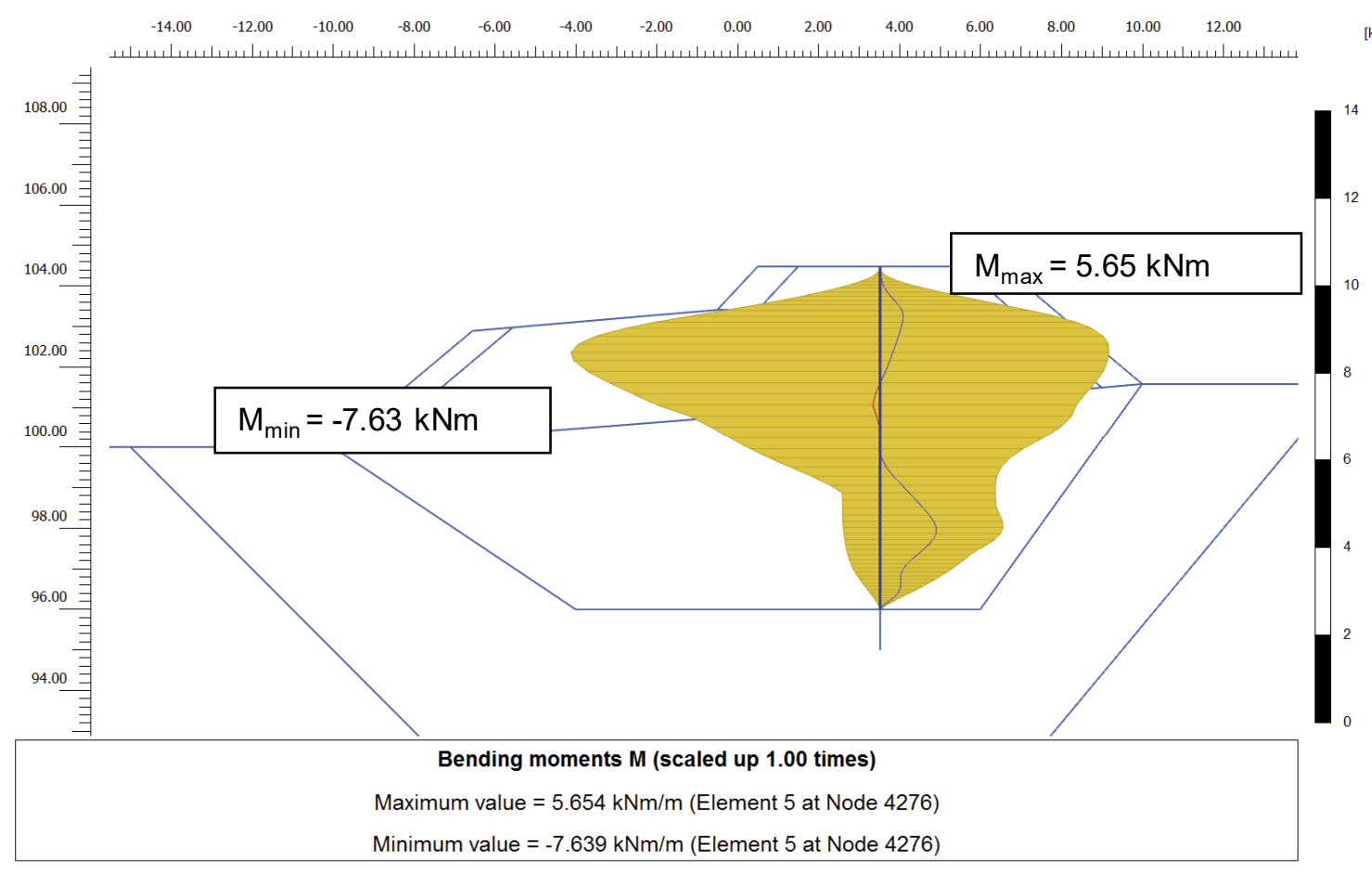

Bild 11.21. Umhüllendes Diagramm der maximalen Biegemomente in der Stahlspundwand.

Durch die erheblich kleinere vorhandene Biegesteifigkeit der Spundwand sind auch die erzeugten Momente viel kleiner und liegen mit dem Extremwert $M_{\min }=-7.63 \mathrm{kNm}$ weit unterhalb der ermittelten Biegekapazität $\mathrm{M}_{\mathrm{rd}}=114.1 \mathrm{kNm}$.

\subsection{Fazit}

Die dynamischen Untersuchungen haben gezeigt, dass das allgemeine Verformungsverhalten des Dammes von der Art der Nachrüstungsmassnahme unabhängig ist. In den beiden Situationen mit und ohne Dichtwand haben sich im Bereich der Dammböschungen und des Dammkörpers residuale Verformungen gleicher Magnitude eingestellt. Totale Verformungen (vertikal und horizontal) von $9 \mathrm{~cm}$ (vgl. Bilder 11.14-11.15) und Setzungen von $5 \mathrm{~cm}$ (vgl. Bilder 11.18-11.19) stellen keine Gefahr für die Funktionstauglichkeit des Dammes dar, selbst wenn dieser die Funktion eines Verkehrsträgers erfüllen müsste.

Die Entscheidung über die geeignete Nachrüstungsmassnahme stellt ein komplexeres Verfahren als lediglich eine kraftbasierte Auswertung der Sicherheit dar. Die Problematik der Rissentwicklung für die MIP-Wand sollte durch eine erweiterte Analyse, die die Umverteilung der Momente im Querschnitt der Wand berücksichtigt, betrachtet werden. Nicht zu vernachlässigen sind die Kosten jeder Massnahme, die eine wichtige Rolle in diesem Entscheidungsverfahren spielen. Auf eine definitive Aussage über die Angemessenheit einer Nachrüstungsmassnahme wird in diesem Beitrag verzichtet, da das Ziel der Studie lediglich die Beurteilung des seismischen Verhaltens des Dammes und der Nachrüstungsmassnahmen sowie der Wechselwirkung zwischen den beiden ist. 
Aus Kapazitätsgründen des verwendeten numerischen Programms sind Stoffgesetze, die eine Erhöhung der Porenwasserdrucke durch die dynamische Belastung berücksichtigen (z.B. lai et al., 1990), nicht in diesem implementiert. Da eine solche Berechnung nur unter unverhältnismässig grossem Aufwand durchgeführt werden könnte (e.g. Roten et al., 2011), wurde eine Erhöhung der Porenwasserdrucke in der numerischen Berechnung nicht berücksichtigt. Eine solche Untersuchung soll für den Fall eines verflüssigungsgefährdeten Bodens als Erweiterung der vorgestellten Studie durchgeführt werden.

\subsection{Referenzen}

Ambraseys, N., Smit, P., Sigbjornsson, R., Suhadolc, P. \& Margaris, B. (2002) InternetSite for European Strong-Motion Data, European Commission, Research-Directorate General, Environment and Climate Programme.

Bardet, J.P., Ichii, K. \& Lin, C.H. (2000) EERA. A computer program for equivalent-linear earthquake site response analyses of layered soil deposits. University of Southern California. Department of Civil Engineering.

Brinkgreve, R.B.J., Engin, E. \& Swolfs, W.M. (2012) Plaxis 2D 2012 Manual. Delft, Netherlands.

Burjanek, J. (2011) Development of 3D Velocity Model for Visp area. Presentation at the Third Annual Meeting of COGEAR, January 2011. Visp.

DIN 1045-1 (2008) Tragwerke aus Beton, Stahlbeton und Spannbeton - Teil 1: Bemessung und Konstruktion. Deutsches Institut für Normierung e.V. Beuth Verlag $\mathrm{GmbH}$. Berlin.

Geiser, S. (2013) Seismisches Verhalten von Hochwasserschutzbauten. Ertüchtigungsmassnahmen. Master Thesis at the Institute for Geotechnical Engineering, ETH Zurich. (in German).

Hoesch Spundwand und Profil GmbH (2013) Lieferprogramm Spundwandprofile. Dortmund.

lai, S., Matsunaga, Y. \& Kameoka, T. (1990) Parameter identification of a cyclic mobility model. Report of The Port and Habour Research Institute, 29(4). pp. 57-83. Nagase, Yokosuka, Japan.

Kanton Wallis. (2008) Dritte Rhonekorrektion - Sicherheit für die Zukunft. Synthesebericht des Generellen Projekts. Dempartement für Verkehr, Bau und Umwelt, Dienststelle für Strassen- und Flussbau, Sion. 
Marin, A., Laue, J. \& Mezger, F. (2012) Modelling of soil-structure interaction in Alpine regions. In: Maugeri \& Soccodato (eds) Second International Conference on PerformanceBased Design in Earthquake Geotechnical Engineering, Taormina (Italy). Patron editore, Bologna. pp. 1426-1439.

Mayor, P.A. \& Springman, S.M. (2011) Aspects géotechniques de la protection contre les crues à l'exemple des digues du Rhône. Présantation, Journée de printemps, Hochschule Luzern.

Mezger, F. (2011) Dynamische Analyse des Lonza Areals in Visp. Masterarbeit, Institut für Geotechnik, ETH Zürich.

OSPER (2014) www.geodata.ethz.ch. Open Support Platform for Environmental Research. Abgerufen am 1. April 2014.

Roten, D., Fäh, D. \& Laue, J. (2011) Application of a neighborhood algorithm for parameter identification in a cyclic mobility model. In the 4th IASPEI/IAEE International Symposium: Effects of Surface Geology on Seismic Ground Motion, University of Santa Barabara. USA.

Scheiwiller, A. (2013) Seismisches Verhalten von Hochwasserschutzbauten. Dauerhaftigkeit. Master Thesis at the Institute for Geotechnical Engineering, ETH Zurich.

SIA 261 (2003) Actions on structures. Swiss Society of Engineers and Architects. Zurich

SIA 263 (2003) Stahlbau. Eingetragene Norm der Schweizerischen Normen-Vereinigung SNV. Zürich.

Springman, S.M., Laue, J., Mayor, P.A. \& Marin, A. (2013) Nachprüfung der Erdbebensicherheit für die Nachrüstungsmassnahmen der Dämme bei Illarsaz und Port-Valais. IGT - Bericht Nr. 4791 unveröffentlicht. ETH Zürich.

Weber, T. M., Laue, J. \& Springman, S. M. (2007) Geotechnical laboratory tests for identification of soil parameters for the cyclic mobility model of sandy soil from Visp (VS). Project report - „SHAKE - VAL 2“, IGT Report No. 4698, ETH Zürich. 


\section{Veröffentlichungen des Instituts für Geotechnik (IGT) der ETH Zürich}

Band 218: Lukas Arenson: Unstable Alpine Permafrost: A Potentially Important Natural Hazard - Variations of Geotechnical Behavior with Time and Temperature ETH-Dissertation Nr. 14801, 2003, 308 Seiten, broschiert, ISBN 978-3-7281-2883-6

Band 219: $\quad$ Alex Schneider: Sicherheit gegen Niederbruch im Untertagbau

ETH-Dissertation Nr. 14556, 2002, 240 Seiten, broschiert, ISBN 978-3-7281-2872-0

Band 220: $\quad$ Georg Anagnostou, Kalman Kovári: The Stability of Tunnels in Grouted Fault Zones 2003, 168 Seiten, broschiert, ISBN 978-3-7281-2874-4

Band 221: Carlo Scapozza: Entwicklung eines dichte- und temperaturabhängigen Stoffgesetzes zur Beschreibung des visko-elastischen Verhaltens von Schnee

2004, 264 Seiten, broschiert, ISBN 978-3-7281-2931-4

Band 222: $\quad$ Sven Köhler: Auswahl und Einsatz von eisenhaltigen Füllmaterialien für Permeable Reaktive Barrieren (PRB) zur in situ Grundwassersanierung am Beispiel eines Chromatschadenfalls 2004, 244 Seiten, broschiert, ISBN 978-3-7281-2953-6

Band 223: Jolanda Luisa Trausch-Giudici: Stress-strain Characterisation of Seebodenlehm 2005, 250 Seiten, broschiert, ISBN 978-3-7281-3003-7

Band 224:

Sarah M. Springman, Rita Hermanns Stengele, Rolf Katzenbach, Lisa Martinenghi,

Stephan Semprich, Arno Thut, Markus von Moos: Festkolloquium zur Verabschiedung von Prof. Dr. Peter Amann: Aktuelle Probleme der Geotechnik 2006, 96 Seiten, broschiert, ISBN 978-3-7281-3072-3

Band 225: $\quad$ Sophie Messerklinger: Non-linearity and small strain behaviour in lacustrine clay 2006, 478 Seiten, broschiert, ISBN 978-3-7281-3083-9

Band 226: Philippe Nater: Belastungs- und Verformungsverhalten von geschichteten Bodensystemen unter starren Kreisfundationen

2007, 330 Seiten, broschiert, ISBN 978-3-7281-3138-6

Band 227: Ravikiran Chikatamarla: Optimisation of cushion materials for rockfall protection galleries 2007, Band 1: 278 Seiten, Band 2: 200 Seiten, broschiert, ISBN 978-3-7281-3164-5

Band 228: $\quad$ Philipp Teysseire: Geotechnische Eigenschaften von Moränen 2007, 330 Seiten, broschiert, ISBN 978-3-7281-3138-6

Band 229: $\quad$ Anja Heinz: Modifizierte Bentonitsuspensionen für geotechnische Bauverfahren in Böden hoher Durchlässigkeit

2007, 160 Seiten, broschiert, ISBN 978-3-7281-3112-6

Band 230: Martin Vogelhuber: Modifizierte Bentonitsuspensionen für geotechnische Bauverfahren in Böden hoher Durchlässigkeit

2007, 326 Seiten, broschiert, ISBN 978-3-7281-3177-5

Band 231: Andrea Thielen: Einfluss der Bodensättigung auf die Stabilität von Hängen 2008, 348 Seiten, broschiert, ISBN 978-3-7281-3165-2

Band 232: $\quad$ Thomas Weber: Modellierung der Baugrundverbesserung mit Schottersäulen 2008, 296 Seiten, broschiert, ISBN 978-3-7281-3167-9

Band 233: $\quad$ Erich Saurer: Shear Band Propagation in Soils and Dynamics of Tsunamigenic Landslides 2010, 190 Seiten, broschiert, ISBN 978-3-7281-3317-5

Band 234: Anton Sres: Theoretische und experimentelle Untersuchungen zur künstlichen Bodenvereisung im strömenden Grundwasser

2010, 168 Seiten, broschiert, ISBN 978-3-7281-3307-6 


\section{Veröffentlichungen des Instituts für Geotechnik (IGT) der ETH Zürich}

Band 235:

Band 236:

Band 237:

Band 238:

Band 239:

Band 240:

Band 241:

Band 242:

Band 243:

Band 244

Band 245:

Band 246:

Band 247:

Band 248:

Band 249:

Band 250:

Band 251:

Band 252:

Stefan Bergamin: Die Stabilität der Felsfundamente von Staumauern

2010, 270 Seiten, broschiert, ISBN 978-3-7281-3306-9

Marco Ramoni: On the feasibility of TBM drives in squeezing ground and the risk of shield jamming 2010, 216 Seiten, broschiert, ISBN 978-3-7281-3363-2

Carlo Rabaiotti: Analysis in Road Geotechnics

2011, 244 Seiten, broschiert, ISBN 978-3-7281-3274-1

Linard Cantieni: Spatial Effects in Tunnelling Through Sqeezing Ground

2011, 188 Seiten, broschiert, ISBN 978-3-7281-3438-7

Michael Iten: Novel Applications of Distributed Fiber-optic Sensing in Geotechnical Engineering 2012, 282 Seiten, broschiert, ISBN 978-3-7281-3454-7

Juliane A. Buchheister: Verflüssigungspotenzial von reinem und siltigem Sand unter multiaxialer Belastung

2012, 334 Seiten, broschiert, ISBN 978-3-7281-3305-2

Bernd Imre: Micromechanical Analyses of Sturzstroms (Rock Avalanches) on Earth and Mars 2012, 172 Seiten, broschiert, ISBN 978-3-7281-3331-1

André Arnold: Tragverhalten von nicht starren Flachfundationen unter Berücksichtigung der lokalen Steifigkeitsverhältnisse

2012, 332 Seiten, broschiert, ISBN 978-3-7281-3400-4

Yuko Yamamoto: Instabilities in alpine permafrost: strength and stiffness in a warming regime 2014, 514 Seiten, broschiert, ISBN 978-3-7281-3640-4

Konstantinos Serafeimidis: On the dissolution, precipitation and transport processes in sulphatic swelling rocks

2014, 248 Seiten, broschiert, ISBN 978-3-7281-3646-6

Pierre André Mayor: Verhalten eines Flussdammes unter wiederholter Hochwasserbelastung 2014, 244 Seiten, broschiert, ISBN 978-3-7281-3648-0

Emma Jane Pooley: Centrifuge modelling of ground improvement for double porosity clay 2015, 268 Seiten, broschiert, ISBN 978-3-7281-3651-0

Wilmer Ferney Morales Peñuela: River dyke failure modeling under transient water conditions 2015, 434 Seiten, broschiert, ISBN 978-3-7281-3630-5

Amin Askarinejad: Failure mechanisms in unsaturated silty sand slopes triggered by rainfall 2015, 364 Seiten, broschiert, ISBN 978-3-7281-3676-3

Sara Zingg: Static effects and aspects of feasibility and design of drainages in tunnelling 2017, 228 Seiten, broschiert, ISBN 978-3-7281-3819-4

Weijie Dong: On the role of constitutive behaviour in the response of squeezing ground to tunnelling 2017, 202 Seiten, broschiert, ISBN 978-3-7281-3860-6

Roberto Schuerch: On the delayed failure of geotechnical structures in low permeability ground 2018, 226 Seiten, broschiert, ISBN 978-3-7281-3856-9

Jean Nicolas François-Xavier Gautray: Influence of smear and compaction zones on the performance of stone columns in lacustrine clay

2019, 408 Seiten, broschiert, ISBN 978-3-7281-3797-5 
ISBN: 978-3-7281-3889-7 (Printversion)

ISBN: 978-3-7281-3890-3 (E-Book)

Doi-Nr.: $10.3218 / 3890-3$

www.vdf.ethz.ch 